\title{
Beat-to-beat variability of repolarisation and drug- induced torsades de pointes in the canine heart
}

Citation for published version (APA):

Thomsen, M. (2005). Beat-to-beat variability of repolarisation and drug-induced torsades de pointes in the canine heart. [Doctoral Thesis, Maastricht University]. Maastricht University. https://doi.org/10.26481/dis.20050415mt

Document status and date:

Published: 01/01/2005

DOI:

10.26481/dis.20050415mt

Document Version:

Publisher's PDF, also known as Version of record

\section{Please check the document version of this publication:}

- A submitted manuscript is the version of the article upon submission and before peer-review. There can be important differences between the submitted version and the official published version of record.

People interested in the research are advised to contact the author for the final version of the publication, or visit the DOI to the publisher's website.

- The final author version and the galley proof are versions of the publication after peer review.

- The final published version features the final layout of the paper including the volume, issue and page numbers.

Link to publication

\footnotetext{
General rights rights.

- You may freely distribute the URL identifying the publication in the public portal. please follow below link for the End User Agreement:

www.umlib.nl/taverne-license

Take down policy

If you believe that this document breaches copyright please contact us at:

repository@maastrichtuniversity.nl

providing details and we will investigate your claim.
}

Copyright and moral rights for the publications made accessible in the public portal are retained by the authors and/or other copyright owners and it is a condition of accessing publications that users recognise and abide by the legal requirements associated with these

- Users may download and print one copy of any publication from the public portal for the purpose of private study or research.

- You may not further distribute the material or use it for any profit-making activity or commercial gain

If the publication is distributed under the terms of Article $25 \mathrm{fa}$ of the Dutch Copyright Act, indicated by the "Taverne" license above, 


\section{Beat-To-Beat Variability of Repolarisation and Drug-Induced Torsades de Pointes in the Canine Heart}


(c) Morten Bakgaard Thomsen, Utrecht 2005 ISBN 90-9019221-2

Cover illustration: Painting by the author Layout and print: Febodruk, The Netherlands 


\section{Beat-To-Beat Variability of Repolarisation and Drug-Induced Torsades de Pointes in the Canine Heart}

ter verkrijging van de graad van doctor aan de Universiteit Maastricht, op gezag van de Rector

Magnificus, Prof. Mr. G.P.M.F. Mols, volgens het bes/uit van het College van Decanen, in het openbaar te verdedigen op vrijdag 15 april 2005 om 11.00 uur 
Promotor:

Prof. dr. Marc A. Vos

Co-promotores:

Dr. Paul G.A. Volders

Dr. Jørgen Matz (Denmark)

Beoordelingscommisie:

Prof. dr. Harry A.J. Struijker Boudier (voorzitter)

Prof. dr. Maurits A. Allessie

Prof. dr. Harry 1.G.M. Crijns

Prof. dr. Dan M. Roden (Vanderbilt Inniversity Medical Center, USA)

Prof, dr. Christian Torp-Pedersen (Copenhagen University Hospital, Denmark)

Financial support by the Netherlands Heart Foundation for the publication of this thesis is appreciated.

Additional support was granted by $H$. Lundbeck, Denmark. 


\section{Content}

Chapter 1: General introduction

35

Chapter 2: Electrophysiological Safety of Sertindole in Dogs with Normal and Remodeled Hearts

57

Chapter 3: Increased Short-Term Variability of Repolarization Predicts $d$-Sotalol-Induced Torsades de Pointes in Dogs

75

Chapter 4: Decreasing the Infusion Rate Reduces the Proarrhythmic Risk of NS-7

93

Chapter 5: Sudden Cardiac Death in Dogs with Remodeled Hearts is Associated with Larger Beat-To-Beat Variability of Repolarization

113 Chapter 6: Beat-to-Beat Variability of Repolarization Determines Proarrhythmic Outcome in Dogs Susceptible to Drug-Induced Torsades de Pointes

Chapter 7: General Discussion

English Summary

$157 \quad$ Nederlandse Samenvatting

161 Dansk Resumé

165 Acknowledgements

169 Curriculum vitae

$171 \quad$ Publications 



\section{General Introduction}

\section{Content:}

Drug-induced proarrhythmia

Current state of non-clinical proarrhythmia assessment

Available test systems

Need for additional proarrhythmia parameters

Aim of the thesis

This chapter is the basis of a review in preparation by: Morten B. Thomsen ${ }^{1.2}$, Jørgen Matz ${ }^{3}$, Paul G.A. Volders ${ }^{2}$ and Marc A. Vos"

1. Department of Medical Physiology, Heart Lung Center Utrecht, University Medical Center Utrecht, Utrecht, Netherlands.

2. Department of Cardiology, Cardiovascular Research Institute Maastricht, Maastricht University, Maastricht, Netherlands.

3. Center of Excellence, Cardiovascular Research, H. Lundbeck, Copenhagen, Denmark. 
Chater 


\section{Drug-induced proarrhythmia}

A large number of pharmaceutical compounds have been associated with torsades de pointes arrhythmias. ${ }^{1,2}$ The spectrum of drugs involves antiarrlyythmic drugs, non-antiarrhythmic cardiovascular drugs and non-cardiovascular drugs. ${ }^{3}$ On the electrocardiogram, torsades de pointes appears as a polymorphic tachycardia characterised by a distinctive pattern of undulating peaks of sequential QRS complexes and $T$ waves that twist around the baseline." It is a well-known side-effect of class-III antiarrhythmic drugs that prolong cardiac repolarisation. "5,6 "these drugs mainly reduce outward repolarising potassium currents at the level of the single myocytes. This is the therapeutic action by which refractoriness of the atria and ventricles is prolonged, however reducing repolarisation current in the ventricles is not without risk. If the individual threshold of repolarisation reserve ${ }^{7}$ is surpassed, there is an increased risk of ensuing torsades de pointes arrhythmia.

The SWORD study provides an example where $d$-sotalol, a class-III antiarriythmic drug was administered to reduce arrhythmogenic mortality in patients with myocardial infarction. ${ }^{8}$ Surprisingly, $d$-sotalol caused an increase in mortality, presumably due to proarrhythmia, although very little objective data supports torsades de pointes as the explanation. "The objective of the DIAMOND-CHF trial was to study changes in overall mortality by dofetilide, another class-III antiarrhythmic drug, in patients with congestive heart failure. ${ }^{10}$ The study identified 25 episodes of torsades de pointes in the 762 enrolled patients $(3.3 \%)$, but no change in overall mortality was identified. Similar proarrhythmic actions of other class-III

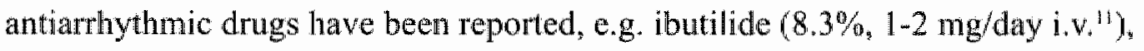
aximilide $\left(0.9 \%, 100-125 \mathrm{mg} / \mathrm{day}\right.$ p.o. $\left.{ }^{12}\right)$, and sotallol $(1.8-4.1 \%, 160-320 \mathrm{mg} / \mathrm{day}$ p.0. $\left.{ }^{13,14}\right)$.

Non-cardiovascular agents have also been implicated in proarthythmic mortality, including psychiatric drugs, antibiotics and antihistamines among others. ${ }^{3}$ The reported incidence of torsades de pointes is rarely larger than a few tens in millions

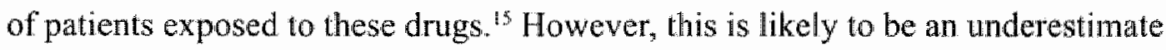
due to the difficulties of recognising torsades de pointes in the general population. Symptoms of torsades de pointes include palpitations, dizziness, syncope and death. Whether an episode of torsades de pointes will be identified and reported to the relevant centres is influenced by many factors, including the underlying disease of the patient and the amount of attention there is on the drug and its potential proarrhythmic properties. 16,17 With such a low incidence of torsades de pointes in 
the patient population treated with such a drug, it is very unlikely that the arrhythmia will be recognised during clinical trials. These trials are generally is not powered to identify such a risk. Nevertheless, it is not acceptable that a number of patients die due to e.g. antihistamine treatment targeting a disease that may not be life threatening.

Of 2194 cases of drug-induced torsades de pointes reported to the American Food and Drug Administration, only $26 \%$ was associated with cardiac agents. ${ }^{5,18}$ of the other drug classes with proarrhythmic side-effects, central nervous compounds comprised $22 \%$, anti-infectives $19 \%$, and antihistamines $12 \%$. Many drugs have been withdrawn from the market and a large number of promising compounds have been stopped during development due to suspected or confirmed proarthythmia. ${ }^{\text {t9 }}$ Since patients are receiving medicine for a non-cardiovascular disease, the majority of the arrhythmia-induced syncopes and deaths occur outside the continuous monitoring environment of the cardiac ward of a hospital. The chance of being resuscitated out-of-hospital and survive to leave hospital after cardiac arrest has been estimated to be only $1 \%^{20,21}$

In 1988 prenylamine, an antianginal drug, was the first non-antiarrhythmic drug to be withdrawn from European markets due to its potential to cause torsades de pointes. ${ }^{5}$ Since then, additional 8 marketed drugs have been withdrawn due to concerns over proarrhythmia (Table 1). That torsades de pointes is a reasonably modern problem is shown by the 2194 cases reported to the Food and Drug Administration: $7 \%$ were reported between 1969 and 1988 in contrast to $93 \%$ between 1989 and 1998 , when the database was analysed. ${ }^{22}$ The surveillance of drugs on the market by regulatory authorities mainly relies on medical personnel voluntarily reporting adverse events and mandatory reporting from the plharnaceutical companies. ${ }^{23}$ In contrast to randomised clinical trials, the postmarketing surveillance is hampered by bias. For example, there are problems of selective reporting of patients exposed to new drugs or the compliance of the patients to take the drugs. Furthermore, certain patient groups, e.g. psychiatric patients, are more prone to sudden cardiac death unrelated to their therapy, ${ }^{24}$ but likely due to their underlying disease. On the other hand, the spontaneous reporting system can detect very rare side-effects, especially when databases are pooled internationally. As such, it is very potent in alerting on potential adverse effects, however the reporting is not sensitive enough to verify the presence of the side-effect. Validation of a potential side-effect includes the disappearance of the side-effect upon withdrawal of the drug as well as reappearance upon rechallenge. 
Authenticating the presence of an adverse effect is helped by elucidation of putative mechanisms and by the demonstration of the side-efect in a susceptible animal model or patient group. For example, the assessment of proarriythmic potential of drugs could be performed in a patient group with congenital long-QT syndrome, which are known to be susceptible. This however is still considered unethical.

Thus, identifying the proarhythmic drug as early as possible is important; however, it took almost ten years after the withdrawal of prenylamine before the preclinical approach to the assessment of proarrhythmic latency of a (potential) drug received intense attention from regulatory authorities.

\begin{tabular}{|c|c|c|}
\hline Drug & Year of withdrawal & Drug indication \\
\hline Prenylamine & 1988 & Angina pectoris ${ }^{12}$ \\
\hline Terodiline & 1991 & Bladder incontinemce ${ }^{1 / 2 \cdot 1 / 4}$ \\
\hline Terfenadine & 1998 & 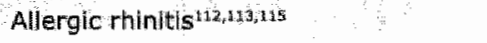 \\
\hline Sertindole* & 1998 & Schizophrenilat12,113,416 \\
\hline Astemizole & 1999 & Allerglo rhinitis ${ }^{1 / 2,143}$ \\
\hline Grepafloxacin & 1999 & Bacterial infections ${ }^{112_{i} 113}$ \\
\hline Cisapride & 2000 & $\begin{array}{l}\text { Mokility-rellated gastrointestinal } \\
\text { disoirdersil }\end{array}$ \\
\hline Droperidol & 2001 & Postoperative nausea and psychosis s.1: $^{118}$ \\
\hline Levacetylmethadol & 2001 & Opiate dependence \\
\hline
\end{tabular}

* Sertindole was reintroduced under restricted use in 2002 .

\section{Current state of non-clinical proarrhythmia assessment}

In 1997 the European Medicinal Agency released a document addressing the testing of compounds to identify repolarisation-prolonging products. ${ }^{2.5}$ It included some recommendations for the test of future non-cardiovascular drugs. At that moment (1997) two types of investigations were suggested before the drug was clinical exposed. It included 1) electrocardiogram (ECG) and blood pressure recordings from conscious dogs and, 2) recordings of action potentials from any appropriate isolated tissue.

Two years later, a survey from 74 laboratories in 54 pharmaceutical industries documented large inconsistencies in the approach to cardiac safety. ${ }^{216}$ The ECG was evaluated from dogs in all laboratories whereas $26 \%$ also collected rat ECG 
data. Both andesthetised and conscious models were employed, and usually a study consisted of three or more doses tested in 3 or 4 animals. In vitro cardiac electrophysiology of non-cardiovascular compounds was done in $56 \%$ of the companies. Usually Purkinje fibres and papillary muscles from dogs, rabbits, guinea pigs or sheep were used for assessing changes in the action potential. Concentrations were based on expected plasma concentrations $(37 \%)$ or they were chosen without knowledge of therapeutic potency $(30 \%)$.

As a consequence of this inconsistent approach, a meeting between researchers, industry and regulatory authorities was organised under the auspices of the European Society of Cardiology, leading to a document in which the inclusion of cell lines expressing cloned channels as well as isolated cells, tissue or heart and whole animals was proposed. ${ }^{3}$ During accumulation of data from the successively higher levels of complexity, risk/benefit assessments should determine the continuation of development.

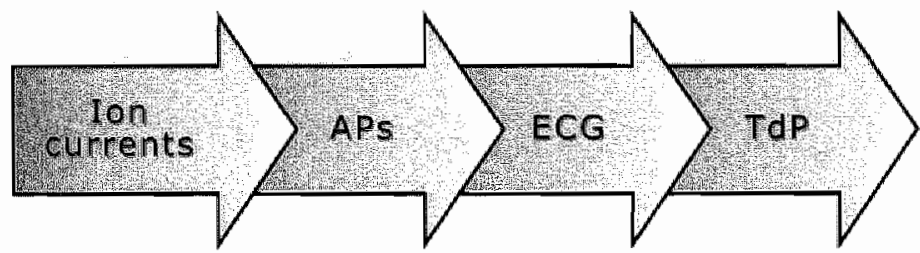

\section{Figure}

Levels of complexity available in the cardiac safety assessment of potential drugs. Specific lion currents can be measured at the level of the single cell, either in freshly isolated ventricular cardiomyocytes or iin non-cardiac cell lines transfected with a human cardiac ion chanmels. Twenty-some different lon currents make up the action potentials (APs), which can differ according to wissue - reglonally within the heart and among species. Action potentials can be acquilined from single myocytes, multicellular preparations or from the beating heart. The various action potentials from different locations in the heart are the basis of the surface electrocandlogram (ECG). Finally, pathological stress can be added to all levels predisposing the materiall to vulnerable stimuli, thereby amplifying the outcome. For example, the ECG of a predisposed animal shows torsades de pointes (TdP) upon proarrhythmic stimuli more often than the naive animal. See text for details.

An important aspect of the aforementioned approach is that decisions should be made only when sufficient data is available and only when several levels of: complexity are addressed. Often decisions are based upon data gathered from too simplistic sources, which at best can give indications and provide directions for studies at other levels. While the Figure is built up of arrows pointing to higher levels of complexity, it should not be perceived as a flowchart for study planning. Similarly, the Figure does not imply that altering an ion current will start a train of 
events culminating in torsades de pointes. Thus, although a potential drug night attenuate or augment any given ion current, it does not necessarilly precipitate into cardiac proarrhythmic death.

Presently, an international guideline is being developed describing studies assessing the potential for delayed ventricular repolarisation by human phamaceuticals (ICH S7B). ${ }^{27}$ According to this guideline substances should be identified for their potentiall to delay ventricular repolarisation in general and to estimate the human risk of drug-induced prolongation of ventricular repolarisation. It proposes four levels of approaches to this evaluation:

- Ionic currents

- Action potential parameters

- ECG parameters

- Proarrhythmic effects

This recommended strategy has some resemblance to the Figure, although the authors of the draft guideline hesitate to recommend proarrhythmia studies. Based on the available information, an integrated risk assessment can be performed, considering potency of test substance, safety margins, predictive value of the assay and knowledge on drug metabolites and interactions. At this point, the guideline does not directly recommend the assessment of proarrlhythmic risk of potential drugs. Although the guideline acknowledges that this is a logical step, the experimental modelling of clinical conditions predisposing the vulnerable patient to arrhythmia is considered to be complicated. ${ }^{27}$

Underlying the development of the guideline is the perception that prolongation of the human QT interval is harmful. At present, there are many experimental reports showing that a delayed repolarisation per se is not necessarily associated with proarthythmia. ${ }^{28-33}$ The role of animal models with increased susceptibility to torsades de pointes is far more important than expressed in the guideline. The various proarrhythmic animal models that are presently avallable ${ }^{34,35}$ will supply valuable additional information to the results generated in the non-predisposed tissue. 


\section{Available test systems}

The battery of preclinical methodologies to evaluate potential drug-induced antagonised repolarisation and proarrhythmia is extensive but still limited in its power. Their aim should be to guide the execution of clinical experiments and to explain mechanisms behind the clinical findings.

\section{Jon-current assays}

Several different ion channels have been found in the human heart, but to date most if not all drugs associated with torsades de pointes have been found to decrease at least one common current, the rapidly activating, delayed rectifying potassium current $\left(I_{\mathrm{KS}}\right)$. Although the proarrhythrnic drugs may affect other cardiac currents, block of $I_{\mathrm{Kr}}$ seems to have a central aspect. $I_{\mathrm{Kr}}$ is an outward potassium current that is important in the repolarisation of the myocyte. ${ }^{36}$ The current is conducted by a pore-shaped protein in the myocyte membrane that changes conformation upon alternations in the membrane voltage. In the human heart, the protein is encoded by HERG ${ }^{37}$ The protein may associate with an additional smaller, regulatory subunit MiRP1 to form native $I_{\mathrm{Kr} r}{ }^{38}$ although this is disputed by others. ${ }^{39,40}$ The current can be studied in isolated myocytes ( $I_{\mathrm{Kr}}$ assays) or reproduced by expressing the protein encoded by HERG in a cell line ( $I_{\text {HERG }}$ assays $) .{ }^{41}$ Other ion currents frequently studied are the L-type calcium current $\left(I_{\mathrm{Ca}, \mathrm{L}}\right)$, the sodium current $\left(I_{\mathrm{Na}}\right)$ and the slowly activating, delayed rectifying potassium current $\left(I_{\mathrm{Ks}}\right)$. The clinical findings that certain congenital long QT syndromes, those involving $I_{\mathrm{Na}}$ and $I_{\mathrm{Ks}}$ demonstrates the possibility that torsades de pointes and sudden cardiac death can occur by mechanisms unrelated to defective $I_{\mathrm{Kr}}$. Thus, these other ion currents should not be overlooked in the assessment of proarrhythmia.

Large varieties of potencies are found among the drugs blocking $I_{\mathrm{kr}}$ (Table 2).

Dofetilide is a very potent blocker with half maximal block $\left(\mathrm{IC}_{50}\right)$ reported at $3.9 \mathrm{nM}$ $\left(\right.$ rabbit $\left.{ }^{42}\right), 32 \mathrm{nM}$ (guinea pig $\left.{ }^{43}\right), 46 \mathrm{nM}\left(\operatorname{dog}^{44}\right)$ and $9.5-47 \mathrm{nM}\left(I_{\text {HERO }}{ }^{45-47}\right)$. A rather weak $I_{\mathrm{Kr}}$ blocker associated with prolongation of the QT interval is the antibiotic, grepafloxacin. ${ }^{45-50}$ Although $\mathrm{IC}_{50}$ values between 27 and $50 \mu \mathrm{M}$ (Table 2) have been reported, the drug was withdrawn from the market in 1999 due to several cases of torsades de pointes and sudden cardiac deaths. ${ }^{49,51}$ Between these extremes are a variety of both proarrlnythmic compounds and drugs not associated with torsades de pointes. For example, the $I_{\mathrm{Ca}, \mathrm{L}}$ blocker verapamil is blocking $I_{\mathrm{HERC}}$ and $I_{\mathrm{Kr}}\left(\mathrm{IC}_{50}=94\right.$ $-1000 \mathrm{nM}^{52,53}$ ) but is not reported to cause arrhythmia. Clearly, studies incorporating 
higher levels of organisation or complexity are needed to elucidate the mechanism behind the differential proarrhythmic properties of these drugs. In essence, there is no relation between the potency of a drug to block $I_{\mathrm{HFR}}$ or $l_{\mathrm{K}}$ and its proarrhythmic potential.

A recent comparison between the $I_{\mathrm{HERG}}$ assay and action potential prolongation in canine Purkinje fibres examined ten drugs with or without clinically associated QT prolongation and torsades de pointes. ${ }^{53}$ The $\mathrm{IC}_{50} \mathrm{~s}$ on $I_{\mathrm{HekG}}$ ranged between $16 \mathrm{nM}$ and $>300 \mu \mathrm{M}$, however only 4 drugs prolonged the action potential in a concentrationdependent manner. For the other drugs there was not correlation between $I_{\text {HER }}$ block and action potential prolongation, which was partly explained by the ability of the drugs to influence multiple channels.

Hence, ion-current assays at best may explain findings found in more integrated systems (e.g. whole animals or clinic). At worst, they cause abandoning of the development of potential unique treatments of hitherto poorly manageable diseases.

\section{Action potential assays}

A result of opening a cardiac ion-channel is that charged ions flow through, causing the voltage gradient across the cell membrane to change. This usually starts a process that leads to closing of the channel and to opening of other ion channels. Alongside the voltage-gated channels are ion pumps and-exchangers that contribute to the movement of ions across the cell membrane. This complicated sequence of events is the basis of the action potential, where the myocyte initially depolarises and later, through repolarisation, returns to a resting potential. Collectively, this cycle is called the action potential which has the sole purpose is to coordinate contraction of the cell and thus of the heart. ${ }^{54,55}$

By altering the properties of one or more ion channels involved in this cycle, the action potential can be changed. For example, treatment with $I_{\mathrm{kr}}$ blockers cause a delay in the repolarisation phase of the action potential and its duration prolongs. Drugs affecting several ion channels will result in more complex changes in action potential shape, usually with concentration-dependent aspects. 


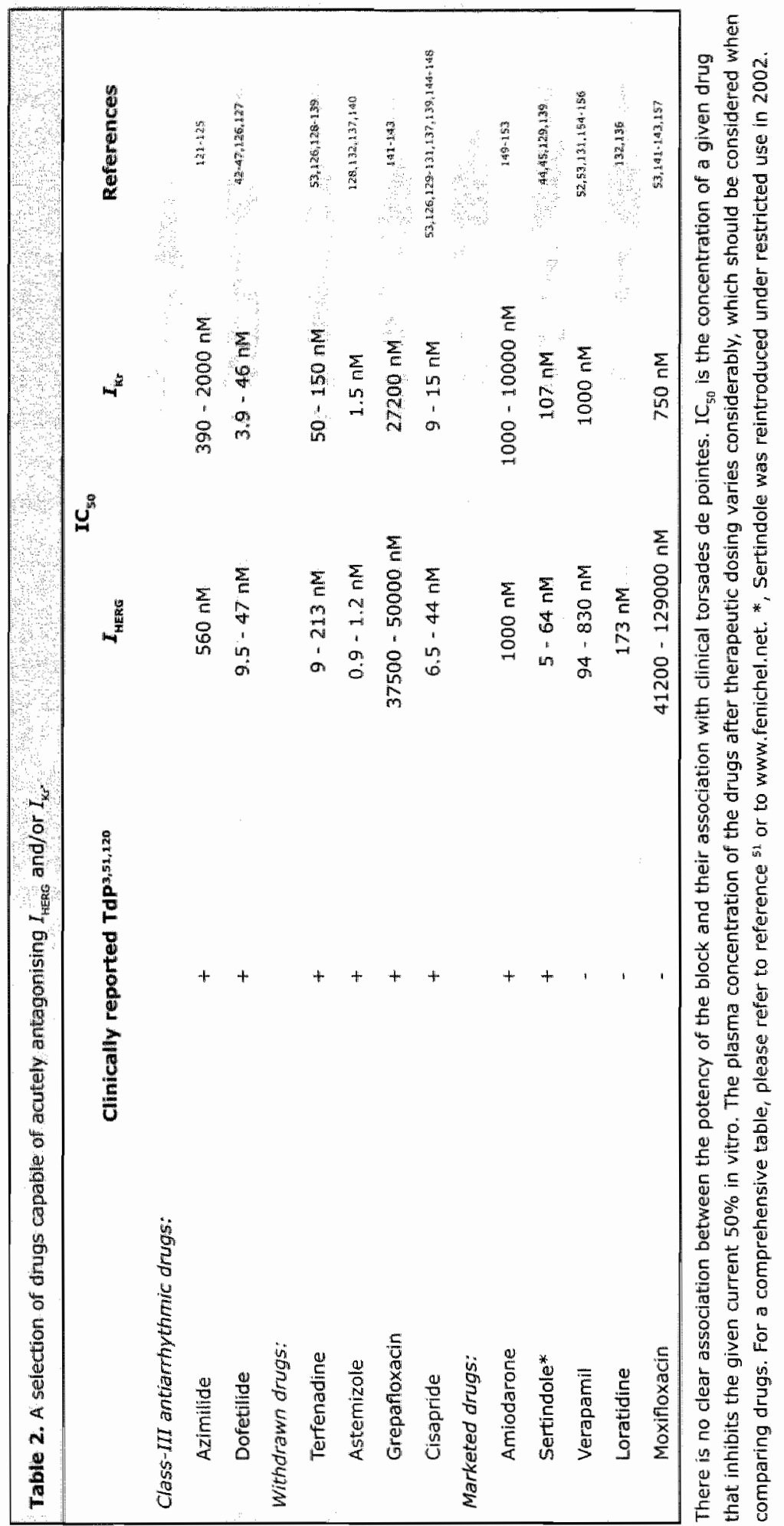


Differences in the ion-channel inventories responsible of the action potentials can result in gender, species and regional differences in action potentials. ${ }^{56-63}$ Action potentials can be assessed from single cells, freshly isolated from various regions of the heart, but also from Purkinje fibres, papillary muscles and ventricular strips or slabs of tissue. In the testing of potential drugs, canine or rabbit Purkinje fibres are most commonly used, whereas the electrophysiology of rats and mice is regarded not to be representative of that of the human.

A comparative study testing 12 drugs for their effects on the action potential of canine Purkinje fibres included 5 of the $l_{k,}$ blockers from Table 1 (terfenadine, sertindole, grepafloxacin, cisapride and moxiffoxacin). ${ }^{\text {at }}$ Later on, the same laboratory reported data on 10 additional $I_{\mathrm{Kr}}$ blockers (including dofetilide and verapamil of Table 1)..$^{53}$ With the exception of verapamil and terfenadine, they all prolonged the action potential in a dose-dependent manner. No relation between the $\mathrm{IC}_{\mathrm{SO}}$ of $I_{\mathrm{HERG}}$ or $I_{\mathrm{Kr}}$ of Table 1 and the action potential prolongation reported is present. Dofetilide at twice the $\mathrm{IC}_{50}(100 \mathrm{nM})$ prolonged the action potentials by up to $180 \mathrm{~ms}$ whereas cisapride at 1000 times $I \mathrm{C}_{50}(10 \mu \mathrm{M})$ prolonged the action potentials by less than $40 \mathrm{~ms} .{ }^{53,64}$ Thus, there are clear discrepancies in how different drugs exert their electrophysiological effects. This will certainly translate into considerably proarrhythmic differences, stressing the importance of assessing electrophysiological and proarrhythmic propenties of drugs at several levels of complexity.

In summary, taking the step to a more complex level of investigation from singlecurrent measurements to analysing the action potential reveals that prolongation of repolarisation is determined by more factors than elucidated in an ion-current assay. Results from one level cannot forecast the results of the other level and more information is available for the risk assessment.

\section{Assessing electrocardiograms:}

The combined signal of cardiac action potentials throughout the lheart can be recorded on the body surface as the ECG. Different species shows different ECG patterns and induced changes in action potential morphology of a significant amount of cardiac tissue will manifest as variations in the $\mathbb{E C G}$. When action potentials are prolonged due to repolarisation delaying drugs (e.g. $L_{\mathrm{Kir}}$ blockers), the time intervall between the start of the Q-wave and the end of the T-wave of the ECG will expand. 
Meaguring this interval - especially the end of the T-wave - is not straightforward. The T-wave usually ends gradually towards the isoelectric line of the ECG, thus no clear ending is defined. It is merely traditionally and not very scientifically grounded, that this critical measurement is defined at complete retum to baseline. For example, the action potentials are often measured to $95 \%$ of full repolarisation to avoid this problem. Manual readings from paper tracings have a repeatability of about $25 \mathrm{~ms}$ in good hands, but even the best readers demonstrate occasional major errors. ${ }^{65}$ Other strategies have been proposed, involving the area of the T-wave, superposition of several ECG leads or pattern recognition, which may prove to be more reproducible.

A number of confounding factors can influence comparisons between QT intervals. Best known is the influence of heart rate, which is inversely related to the QT interval. More than 20 different formulas are available that change a measured QT interval into the interval that would have been present at a heart rate of 60 beats per minute. ${ }^{66}$ None of these formulas are perfect. At present, individual correction formulas seem to be the best choice, although it requires substantial baseline measures to cover a wide range of heart rates. ${ }^{67}$ Even though relations between heart rate and QT interval vary substantially between individuals in a population, the intraindividual relationship is very stable over time. ${ }^{\text {T }}$ The heartrate influence is especially important if the drug tested is causing an altered heart rate and a $\mathrm{QT}$ prolongation. Another way of circunventing this problem is pacing the heart at a constant rate, although this is not always technically convenient. Another factor infuencing the QT interval is the concentrations of electrolytes in the blood. For example thiazide and loop diuretics can cause hypokalemia thereby slowing repolarisation. Vice versa, infusion of potassum reduces drug-induced QT prolongation in healthy subjects. ${ }^{69}$

In the intact animal, blood samples can be gathered to analyse plasma concentrations of administered drugs and possible metabolites. It is often easier to relate this concentration to the expected clinical therapeutic plasna concentration than to relate the in-vitro concentration of a perfusion fluid. The perfusion fluid in an in-vitro setup differs from the in-vivo plasma in many ways, however the most important factor seems to be drug binding to the surface of plasma proteins. This can in some cases result in $>99 \%$ of drug confined to plasma protein with only $<1 \%$ freely dissolved in the plasma. Often disregarded in this context is that the ion channels of the myocytes are not in direct contact with the plasma, but have both vascular endothelium and extracellular matrix of varying distance between. This latter environment can 
possibly accumulate considerable but unknown amounts of the drug. ${ }^{70}$ In the invitro setup, the ion channels are directly exposed to the perfision fuid.

Since, by definition, torsades de pointes is preceded by a prolongation of the QT interval, it makes sense to test a potential drug for QT prolonging effects. However there are examples of drugs that cause significant QT prolongation without being associated with torsades de pointes. Pentobarbital is one drug causing prolongation of the QT interval, but the anaesthetic is not proarrhythmic in dogs or humans. ${ }^{72}$ Another well-known example is chronic amiodarone administration, which inflicts pronounced QT prolongation in animals and in patients. However, wery few reports of torsades de pointes are available. . $4,30,73^{3}$

\section{Proarthythmic animal models}

As indicated, torsades de pointes is a rare phenomenon. Patients with congenital long-QT syndromes can live for decades without experiencing the arrhythmia. The incidence of proarrhythmic side-effects ol drugs is low: in the order of a few tens in millions of treated patients. It is unlikely that the arrhythmia will be registered during the clinical trials of the drugs. To circumvent this problem, several investigators have developed animal models in which torsades de pointes can be induced more easily. Although the regullatory authorities do not acknowledge these models as representative for clinical situations with a high risk of torsades de pointes, the draft guideline ICH S7B encourages scientists to develop and verify these models. At present, reproducible drug-induced torsades-de-pointeslike polymorphic tachycardias have been reported in methoxamine-treated rabbits, in dogs with atrioventricular block, in an isolated perfused rabbit-heart model and in transmural slices of canine ventricle, among others. These models are well established and should, in our believe, receive much higher recognition from regulatory authorities like the American Food and Drug Administration, the European Medicinal Agency and the Japanese Ministry of Health and Welfare.

Retrogradely perfused hearts from rabbits are reasonably devoid of the influence of metabolic, humoral and nervous systems. ${ }^{74}$ The isoltated heart is either left to beat spontaneously or it is paced. Proarhythmic challenges utilised in this model involve bradycardia and hypokalemia. ${ }^{75,76}$ Electrical monitoring is performed through monophasic action potential catheters on the heart and/or from electrocardiographic electrodes surrounding the heart. Administration of various agents affecting $I_{\mathrm{Kr}}$ can show morphological changes in the action potential (e.g. prolongation, triangulation, 
humps resembling early afterdepolarisations), temporal instability of repolarisation duration, ectopic activity and/or arrhythmia morphologically resembling torsades de pointes recorded on the surface ECG of patients. ${ }^{747}$ Furthermore, it seems to be possible to identify many drugs associated with torsades de pointes in humans or in whole-animal models, ${ }^{28,29}$ although comparisons between patient-plasma concentrations and in-vitro perfuision concentrations are difficult. Also, drugs with little association to clinical torsades de pointes have limited effects in this model. ${ }^{28}$

Arterially perfused tissue from the left ventricle of canine hearts has successfully answered a variety of electrophysiological questions. The small transmural slabs of tissue are usually impaled with microelectrodes at the endo-, midmyo- and epicardium, but also action potentials measured by optical mapping techniques have been used. Furthermore, the entire electrical field across the ventricular wall can be recorded and has some resemblances to surface ECG monitoring of the intact heart. Hypokalemia or epicardial extrastimuli in combination with $I_{\mathrm{kr}}$ block can precipitate polymorphic tachyarrhythmia in the tissue slab. ${ }^{78-81}$ The combination of $I_{\mathrm{Kr}}$ and $I_{\mathrm{Ks}}$ block induces early afterdepolarisations on the transmembrane action potentials, triggered beats and occasionally polymorphic tachyarrhythmia. ${ }^{82}$ Also noncardiovascular drugs like cisapride which is associated with QT prolongation and torsades de pointes in patients have been tested in this system and shown to prolong repolarisation, augment heterogeneity of regional repolarisation gradients and induce arrhythmia in the ventricular tissue samples. ${ }^{83}$ Arrhythmia caused by challenging repolarisation with $I_{\mathrm{Kr}}$ block was prevented by pentobarbital despite action potentials were prolonged further. This exemplifies that there are circumstances under which prolongation of action potentials may not be proarrhythmic.

Recently, this multicellular model has been extended to pathological conditions, where the tissues were retrieved from dogs with pacing-induced heart failure ${ }^{84}$ In the absence of any drugs, single extrastimuli could induce polymorphic tachycardia in tissue derived from heart-failure dogs, whereas in control tissue the arrhythmia was not observed. Thus, a pathological predisposition and a subtle proarrhythmic challenge on top is enough to cause serious myocardial events.

Torsades de pointes in a whole animal model, using anaesthetised rabbits sensitised by continuous infusion of the $\alpha_{1}$-adrenergic agonist methoxamine in addition to a class-III drug, was first reported in the early nineties. ${ }^{31,85} \alpha_{1}$-Adrenergic blockers immediately suppress the ventricular tachyarrhythmia seen in the model, indicating the importance of the adrenergic aspect of the model. ${ }^{85}$ It is not clear by what mechanism methoxamine brings the heart into a vulnerable state in which the 
class-III antiarrhythmic drug can exert its proarrhythmic potential. Especially the rabbit seem more susceptible to $\alpha_{1}$-adrenoceptor-induced elevations in intracellular calcium concentrations, an early step towards triggered activity, ${ }^{86}$ which is a candidate explanatory mechanism for the observations in this model. ${ }^{87}$ A substantial battery of agents has been tested in this model, including classical $I_{\mathrm{K}_{r}}$ blockers which all give rise to torsades-de-pointes-like arrhythmia. ${ }^{31.87-91}$ The high reproducibility of arrhythmia has supported the search for novel parameters predicting torsades de pointes. An experimental drug named W-7 prevents torsades in this model without interfering with the $\alpha_{1}$-adrenergic stimulation and without shortening repolarisation. ${ }^{92}$ Using this drug as a tool, a change in relative amplitude of the different notches of the rabbit T-wave was suggested as a precursor of torsades de pointes. ${ }^{93}$

Also dogs seem to be more susceptible to torsades de pointes when the $\alpha$-adrenergic system is stimulated. When anaesthetised dogs with bradycardia due to complete heart block are challenged with $\alpha$-adrenergic agonists and $I_{\mathrm{Kr}}$ blockers, they often show polymorphic ventricular tachycardia resembling torsades de pointes..$^{94,95}$

The canine model of complete atrioventricular block expresses ventricular remodelling occurring as a response to bradycardia-induced volume overload. After ablation of the electrical conduction from atria to ventricles, the slower idioventricular rhythm of the ventricles causes a momentary decrease in cardiac output. This is compensated by an increase in stroke volume accompanied by eccentric hypertrophy of the ventricles and longitudinal growth of the myocytes. ${ }^{96,97}$ Furthermore, the altered ion-channel densities of the myocytes attenuate repolarisation and make the dogs more susceptible to repolarisation-dependent arrhythmia like torsades de pointes. ${ }^{\$ 6.98 .99}$ This ventricular remodelling process takes 2 to 5 weeks. ${ }^{\text {t(tor }}$ In the anaesthetised animals, endocardial biventricular monophasic action potentials and ECG can be recorded whereas a recording in the conscious animal is restricted to ECG recorded on Holter devices or by telemetry. Cardiac. pacing can be performed to stabilise the heart rhythm or to promote arrhythrnia. A number of class-III antiarrhythmic drugs have been administered to the anaesthetised dogs with chronic atrioventricular block to assess mechanisms involved in the precipitation of torsades de pointes. ${ }^{30.97 .101 .1044}$ Also, for considering cardiac adverse effects of various non-cardiovascular drugs, conscious dogs have received drugs orally. ${ }^{105-109}$

Thus, although important information can be gathered from in-vitro assays, data from the intact animal is indispensable for making a qualified risk/benefit analysis of a potential new drug. Since torsades de pointes and not a delayed ventricular 
repolarisation is the culprit adverse effect, a sound cardiac safety assessment of a drug should involve a proarrhythmic assay. Intact predisposed animals or hearts are superior models, merelly because torsades de pointes are absent at lower levels of complexity (Figure).

\section{Need for additionall proarrhythmic parameters}

As illustrated above, $I_{\mathrm{k},}$ block action potential or QT-interval prolongation are not irrevocably connected to proarrhythmic mortality. $3,15,51,110,111$ When assessing the proarrhythmic potential of a drug, multiple strategies are available. However, at present, no single approach is perfect. Since drug-induced torsades de pointes are rare, multiple tactics should be employed to scrutinise early signs of the arrhythmia. Additionally it may be desirable to induce the arrhythmia in an appropriate animal model. Many early markers of proarrhythmia have been proposed. As with the QT prolongation, these other markers are not perfect either.

A number of drugs have been administered to the electrically remodelled dogs with chronic atrioventricular block, to assess mechanisms associated with the arrhythmia. Since only some of the tested drugs cause torsades de pointes, comparisons between proarthythmic indicators can be performed in this model. From published data in Table 3, five class-III antiarrhythmic drugs are listed which all were tested in the model. Alongside the incidence of torsades de pointes are three reasonably established proarrhythmic signs, which in some cases are successful, but in other cases fail to correctly predict the proarrhythmic outcome. A comparable increase in the QT interval ( $>100 \mathrm{~ms}$ ) is seen for all the five drugs in Table 3, although the incidences of torsades de pointes are quite different. Amiodarone and $d$-sotalol show no arrhythmia although they exhibit both physiological and statistical significant prolongation of the QT interval. The absence of arrhythmias may be based on a modest increase in the interventricular dispersion of repolarisation, which does not reach the same levels as with the other three drugs. Also the incidence of extrasystoles tends to be higher in the proarthythmic drugs. Together with Table 2 , this illustrates the advantage of assessing several proarrhythmic signals for any given drug before concluding on its proarrhythmic profile. 


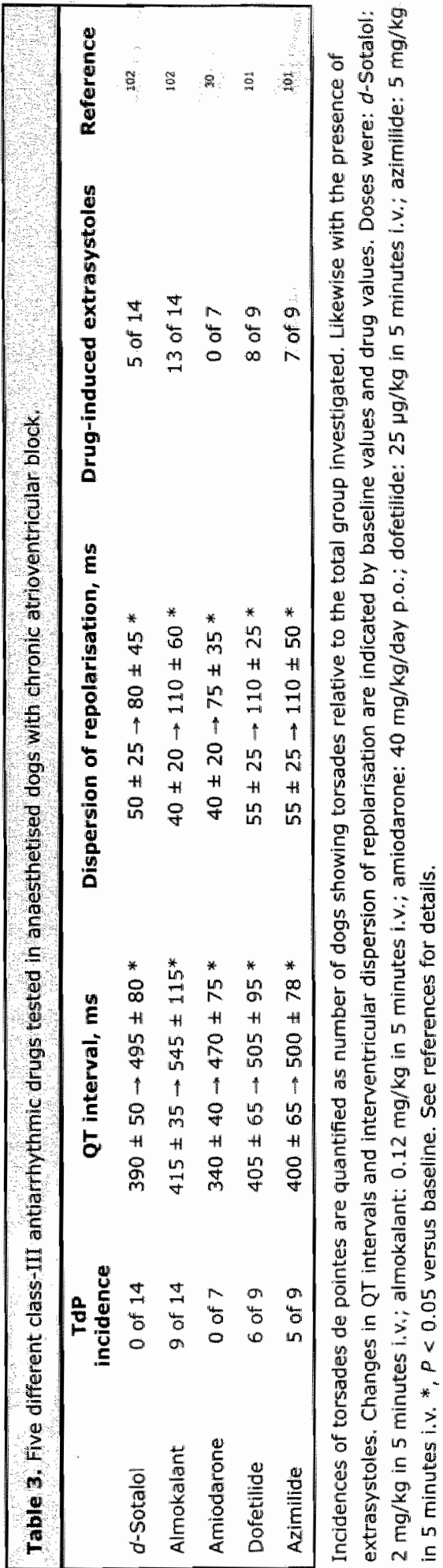


In summary, when assessing the proarnythmic potential of candidate drugs one should involve several lines of investigation. All four levels of complexity (Figure) should be addressed before estimating the electrophysiological and proarrhythmic potential of a drug. Available proarrhythmic models will not only add a level of complexity to the study, but can be used to evaluate predictive signs of proarthythmia.

The present draft of the international guideline (ICH S7B) for the non-clinical evaluation of cardiac side-effects of new drugs covers only recommendations of assessing prolongation of ventricular repolarisation, whereas proarrhythmia and torsades de pointes are the relevant events explaining adverse effects and mortallity in the treated patients. ${ }^{27}$ The guideline fails to recognise the available animal models that provides important information of the proarrhythmic potential of drugs. Furthermore, there is a need for additional surrogate markers for torsades de pointes that could assist the risk assessment of new drugs. Potentially, this could also benefit patients when it is feasible to identify the individual prone to develop proarrhythmia.

\section{Aim of the thesis}

Previous studies from our group have demonstrated a greatly enhanced susceptibility to drug-induced torsades de pointes in dogs with chronic complete atrioventricular block. We used this model to investigate predictive indicators of torsades de pointes. In the first study (chapter 2), we assess several doses of the same proarrhythmic drug. Unexpectedly, the well-known electrophysiological markers for torsades de pointes did not associate well with the proarthythmic outcome. The hypothesis is proposed that novel electrophysiological repolarisation-dependent characteristics could be identufied that have closer relation with the incidence of torsades de pointes. It is the aim of this thesis to propose and investigate these new proarrhythmic markers. 


\section{References}

1. Darpo B. Spectrum of drugs prolonging QT interval and the incidence of torsades de pointes. Eur Heart $J$ Supplements. $2001 ; 3 \times K 70-K 80$.

2. Curtis LH, Ostbye T, Sendersky V, Hutchison S, Allen LaPointe NM. AI-Khatib SM, Usdin Yasuda S, Dans PE, Wright A, Califf RM, Woosley RL, Schulman KA.

Prescription of QT-prolonging drugs in a cohort of about 5 million outpatients. Am I Med. 2003;114:135-41.

3. Haverkamp W, Breithardt G, Camm AJ, Janse MJ, Rosen MR, Antzelevitch C, Escande D, Franz M, Malik M, Moss A, Shah R. The potential for QT prolongation and pro-arrhythmia by non-anti- arrhythmic drugs: clinical and regulatory implications. Report on a Policy Conference of the European Society of Cardiology. Cardiovasc Res. 2000;47:219-33.

4. Dessertenne F. La tachycardie ventriculaire à deux foyers opposés variables. Arch des Mal du Cour. 1966;59:263-272.

5. Sliah RR. Pharmacogenetic aspects of drug-induced torsade de pointes: potential tool for improving clinical drug development and prescribing. Drug Saf. 2004;27:145-72.

6. Elming H, Brendorp B, Pehrson S, Pedersen OD, Kober L, Torp Petersen C. A benefitrisk assessment of class III antiarrhythmic agents. Expert Opin Drug Saf. 2004:3.559-77.

7. Roden DM. Taking the "idio" out of "idiosyncratic": predicting torsades de pointes. Pacing Clin Electrophysiol. 1998;21:1029-1034.

8. Waldo AL, Camm AJ, deRuyter H, Friedman PL, MacNeil DJ, Pauls JF, Pitt B, Pratt CM, Schwartz PJ, Veltri EP. Effect of d-sotalol on mortality in patients with left ventricular dysfunction after recent and remote myocardial infarction. The SWORD Investigators. Survival With Oral d-Sotalol. Lancet. 1996;348:7-12.

9. Pratt CM, Camm AJ, Cooper W, Friedman PL, MacNeil DJ, Moulton KM, Pitt B, Schwartz PJ, Veltri EP, Waldo AL. Mortality in the Survival With ORal D-sotalol (SWORD) trial: why did patients die? Am J Cardiol. 1998;81:869-76.

10. Torp-Pedersen C, Moller M, Bloch-Thomsen PE, Kober L, Sandoe E, Egstrup K, Agner E, Carlsen J, Videbaek J, Marchant B, Camm AJ. Dofetilide in patients with congestive heart failure and left ventricular dysfunction. Danish Investigations of Arrhythmia and Mortality on Dofetilide Study Group. N Engl J Med. 1999;341:857 65.

11. Stambler BS, Wood MA, Ellenbogen KA, Perry KT, Wakefield LK, VanderLugt IT. Efficacy and safety of repeated intravenous doses of ibutilide for rapid conversion of atrial futter or fibrillation. Ibutilide Repeat Dose Study Investigators. Circalation. 1996;94:1613-21.

12. Connolly SJ, Schnell DJ, Page RL, Wilkinson WE, Marcello SR, Pritchett EL. Dose-response relations of azimilide in the management of symptomatic, recurrent, atrial fibrillation. $A m J$ Cardiol. $2001 ; 88: 974-9$.

13. Haverkamp W, Martinez-Rubio A, Hief C, Lammers A, Mullenkamp $S$, Wichter $T$, Breithardt $G$, Borggrefe $M$. Efficacy and safety of $d, 1$-sotalol in patients with ventricular tachycardia and in survivors of cardiac arrest. $J$ Am Coll Cardiol. 1997;30:487-95.

14. Hohnloser SH. Proarrhythmia with class IIJ antiarthythmic drugs: types, risks, and management. Am J Cardiol. 1997;80:82G-89G.

15. Fenichel RR, Malik M, Antzelevitch C, Sanguinetti MC. Roden DM, Priori SG, Ruskin JN, Lipichy RJ, Cantilena LR. Drug-induced tor'sades de pointes and implications for drug development. $J$ Cardiovase Electrophysiol. 2004;15:475-495.

16. De Bruin ML, van Puijenbroek EP, Egberts AC, Hoes AW, Leufkens HG. Non-sedating antihistamine drugs and cardiac arrhythmias -- biased risk estimates from spontaneous reporting systems? BrJ Clin Pharmacol. 2002;53:370-4.

17. Martin RM, Kapoor KV, Witton LV, Mann RD. Underreporting of suspected adverse drug reactions to newly marketed ("black triangle") drugs in general practice: 
obserwational study. Bmj. 1998;317:119-20.

18. Fung MC, Hsiao-luni Wu J, Kwong K. Evaluation of the Profile of Patients with QTo Prolongation in Spontaneous Adwerse Event Reporting over the Past Three Decades [abstract]. Pharmacoepidemial Drug Safery. 2000;9:\$24-25.

19. Roder DM. Drug-induced prolongation of the QT intervall. $N$ Engl I Med. $2004 ; 350: 1013-22$.

20. Bigger Jr. JT. The Predictive Value of RR Variability and Baroreflex Sensitivity in Coronary Heart Disease. Cardiac Electrophysiology Review. 1997;1:198-204.

21. Josephson $\mathrm{M}_{3}$ Wellens HJ. Implantable defibrillators and sudden cardiac death. Circulation. 2004; 109:2685-91.

22. Shah RR. Drug-induced QT interval prollongation: regulatory perspectives and drug development. Ann Med. 2004;36 Suppl 1:47-52.

23. Etminan $M$, Carleton $B$, Rochon PA. Quantifying adverse drug events : are systematic rewlews the answer? Drug Saf. 2004;27:757-61

24. Appleby L, Thomas S, Ferrier $N$, Lewis $G$, Shaw $J$, Amos $T$. Sudden unexplained death in psychiatric in-patients. Br I Psychiarry. 2000;176:405-6.

25. The European Agency for the Evaluation of Medicinal Products: Points to consider: The assessment of the potential for QT interval prolongation by non-cardiovascular medicinal products. In: CPMP/986/96; 1997.

26. Hammond TG, Carlsson L, Dawis AS, Lynch WG, Mackenzie I, Redfern WS, Sullivan AT, Camm AJ. Methods of collecting and evaluating non-clinical cardiac electrophysiology data in the pharmaceutical industry: results of an international survey. Cardiovasc Ress. 2001;49:741-50.

27. International conference on harmonisation of technical requirements for registration of pharmaceuticals for human use: The nonelinical evaluation of the potential for delayed ventricular repolarization (QT interval prolongation) by human pharmaceuticals. S7B. http://www.ich.org. 2004.

28. Hondeghem LM, Carlsson L, Duker G. Instability and triangulation of the action potential predict serious proarrhythmia, but action potential duration prolongation is antiarthythmic. Circulation. 2001;103:2004-13.

29. Hondeghem LM, Dujardin K, De Clerck F. Phase 2 prolongation, in the absence of instability and triangulation, antagonizes class III proarrhythmia. Cardiovasc Res. 2001;50:345-353.

30. van Opsial JM, Schoenmakers M, Verduyn SC, de Groot $\mathrm{SH}_{\text {" }}$ Leunissen JD, Der Hulst FF, Molenschot MM, Wellens HJ, Vos MA. Chronic Amiodarone Evokes No Torsade de Pointes Arrhythmas Despite QT Lengthening in an Animal Model of Acquired LongQT Syndrome. Circulation. 2001; 104:2722-2727.

31. Carlsson L, Abrahamsson C, Andersson B, Duker G, Schiller-Linhardt G. Proarnythmic effects of the class III agent almokalant: importance of infusion rate, QT dispersion, and early afterdepolarisations. Cardiovasc Res. 1993;27:2186-93.

32. Milberg P, Eckardt L, Bruns HJ, Biertz J, Ramtin S, Reinsch N, Fleischer D, Kirchhof P, Fabritz $\mathrm{L}$, Breithardt $\mathrm{G}$, Haverkamp W. Divergent Proarhythmic Potential of Macrolide Antibiotics Despite Similar QT Prolongation: Fast Phase 3 Repolarization Prevents Early Afterdepolarizations and Torsade de Pointes. J Pharmacol Exp Ther. 2002,303:218-22:5.

33. Antzelevitch $\mathrm{C}$. Arrhythmogenic mechanisms of QT prolonging drugs: Is QT prolongation really the problem? J Electrocardiol. 2004;37 Suppl:15-24.

34. Verduyn SC, van Opstal JM, Leunissen JD, Vos MA. Assessment of the pro-arrhythmic potential of anti-arthythmic drugs: an experimental approach. $J$ Cardiovasc Phammacol Ther $2001 ; 6: 89-97$.

35. Janse MJ, Opthof T, Kleber AG. Animal models of cardiac arrhythmias. Cardiovasc Res. 1998;39:165-77. 
36. Sanguinetti MC, Jurkiewicz NK. Two components of cardiac delayed rectifier $\mathrm{K}+$ current. Differential sensitivity to block by class III antianhythmic agents. I Gen Physiol. 1990;96:195-215.

37. Sanguinetti $\mathrm{MC}$, Jiang $\mathrm{C}$, Curran ME, Keating MT. A mechanistic link between an inherited and an acquired cardiac arhythmia: HERG encodes the $\mathrm{KK}$ potassium channel. Cell. 1995;81:299-307.

38. Abbott GW, Sesti F, Splawski I, Buck ME, Lehmann MH, Timothy KW, Keating MT, Goldstein SA. MiRPI forms IKr potassium channels with HERG and is associated with cardiac arrhythmia. Cell. 1999;97:175-87.

39. Tseng GN. I(Kr): the hERG channel. $J$ Mol Cell Cardiol. 2001;33:835-49.

40. Weerapura M, Nattel S, Chartier D, Caballero R, Hebert TE. A comparison of currents carried by HERG, with and without coexpression of MiRPI, and the native rapid delayed rectifier current. Is MiRP1 the missing link? I P/ysiol. 2002;540:15-27.

41. Yang T, Snyders D, Roden DM. Drug block of $\mathrm{i} k \mathrm{kr}$ : model systems and relevance to human arthythmias. J Cardiovase Pharmacol. 2001;38:737-744.

42. Carmeliet E. Voltage- and Time-Dependent Block of the Delayed K Current in Cardiac Myocytes by Dofetilide. J Pharmacol Exp Ther. 1992;262:809-817.

43. Jurkiewicz NK, Sanguinetti MC. Rate-dependent prolongation of cardiac action potentials by a methanesulfonanilide class. III antiarrhythmic agent. Specific block of rapidly activating delayed rectifier $\mathrm{K}+$ current by dofetilide. Circ Res. 1993;72:75-83.

44. Thomsen MB, Volders PG, Stengl M, Spätjens RL, Beekman JD, Bischoff U, Kall MA, Frederiksen K, Matz J, Vos MA. Electrophysiological safety of sertindole in dogs with normal and remodeled hearts. J Pharmacol Exp Ther. 2003;307:776-84.

45. Rampe D, Murawsky MK, Gran $J_{*}$ Lewis EW. The antipsychotic agent sertindole is a high affinity antagonist of the human catdiac potassium channel HERG. $J$ Pharmacol Exp Ther. 1998;286:788-93.

46. Claycomb WC, Lanson NA, Jr., Stallworth BS, EEeland DB, Delcarpio JB, Bahinski $A$, Izzo NJ, Jr. HL-1 cells: a cardiac muscle cell line that contracts and retains phenotypic characteristics of the adult cardiomyocyte. Proc Nat Acad Sci USA. 1998:95:2979-84.

47. Snyders DJ, Chaudhary A. High affinity open channel block by dofetilide of HERG expressed in a human cell line. Mol Pharmacol. 1996;49:949-55.

48. Lipsky BA, Baker CA. Fluoroquinolone toxicity profiles: a review focusing on newer agents. Clin Infect Dis. 1999;28:352-64.

49. Ball P. Quinolone-induced QT interval prolongation: a not-so-unexpected class effect. $j$ Antimicrob Chemother. 2000,45:557-9.

50. Stahmmann R, Schwabe R. Safety profile of grepafloxacin compared with other fluoroquinolones. I Animicrob Chemother. 1997:40 Suppl A:83-92.

51. Redfern WS, Carlsson L, Davis AS, Lynch WG, MacKenzie I, Palethorpe S, Siegl PK, Strang I, Sullivan AT, Wallis R, Camm AJ, Hammond TG. Relationships between preclinical cardiac electrophysiology, climical QT interval prolongation and torsade de pointes for a broad range of drugs: evidence for a provisional safety margin in drug development. Cardiovasc Res. 2003;58:32-45.

52. Zhang $\mathrm{S}$, Zhou Z, Gong Q, Makielski JC, January CT. Mechanism of block and identification of the verapamil binding domain to HERG potassium channels. Circ Res. $1999 ; 84: 989-98$.

53. Martin RL, McDermott JS, Salmen HJ, Palmatier J, Cox BF, Gintant GA. The Utility of hERG and Repolarization Assays in Evaluating Delayed Cardiac Repolarization: Influence of Multi-Channel Block. J Cardionasc Pharmacol. 2004;43:369-379.

54. Roden DM, Balser IR, George AL, Jr., Anderson ME. Cardiec ion channels. Anmu Rev Physiol. 2002;64:431-475.

55. Carmeliet E. Cardiac ionic currents and acute ischemia: from channels to arrhythmias. 
Phystol Rev. 1999;79:917-1017.

56. Pham TV, Sosunov EA, Gaimullin RZ, Danillo P, Jr., Rosen MR. Impact of sex and gonadal steroids on protongation of ventricular repolarization and arhythmias induced by I(K) blocking drugs. Cinctalion. 2001;103:2207-12.

57. Abi-Gerges $N$, Small BG, Lawrence CL, Hammond TG, Valentin JP, Pollard CE. Evidence for gender differences in electrophysiological properties of canine Purkinje fibres. BrJ Phajmacol. 2004.

58. Makkar RR, Fromm BS, Steinman RT, Meissner MD, Lehmann MH. Female gender as a risk factor for torsades de pointes associated with cardiovascular drugs. Jawha. 1993;270:2590-7.

59. Volders PG, Sipido KR, Carmeliet E, Spatjens RL, Wellens HJ, Vos MA. Repolarizing $K+$ currents $I T O 1$ and IKs are larger in right than left canine ventricular midmyocardium. Circullation. 1999:99:206-10.

60. Liu DW, Antzelewitch $C$. Characteristics of the delayed rectifier current ( $\mathrm{K} \mathrm{Kr}$ and $\mathrm{IKs}$ ) in canine ventricular epicardial, midmyocardial, and endocardial myocytes. A weaker IKs contributes to the longer action potential of the M cell. Circ Res. 1995;76:351-65.

61. Zygmunt AC, Eddlestone GT, Thomas GP, Nesterenko VV, Antzelevitch C. Larger late sodium conductance in $M$ cells contributes to electrical heterogeneity in canine ventricle. Am J Physiol Heart Circ Physiol. 2001;281:H689-97.

62. Liu DW, Gintant GA, Antzelevitch C. Ionic bases for electroplyysiological distinctions among epicardial, nidmyocardial, and endocardial myocytes from the free wall of the canine left ventricle. Circ Res. 1993;72:671-87.

63. Lu HR, Marien R, Saels A, De Clerck F. Species plays an important role in drug-induced prolongation of action potential duration and early afterdepolarizations in isolated Purkinje fibers. I Cardiovase Electrophysiol. 2001;12:93-102.

64. Gintant GA, Limberis JT, McDermott JS, Wegner CD, Cox BF. The canine Purkinje fiber: an in vitro model system for acquired long QT syndrome and drug-induced arrhythmogenesis. $J$ Cardiovasc Pharwacol. 2001;37:607-18.

65. Malik M, Bradford A. Human precusion of operating a digitizing board: implications for electrocardiogram measurements. Pacing Clin Electrophysiol. 1998;21:1656-62.

66. Malik M. Problems of heart rate correction in assessment of drug-induced QT interval prolongation. J Cardiovasc Electrophysiol. 2001;12:411-20.

67. Malik M, Hnatkova K, Batchvarow V. Differences Between Study-Specifie and SubjectSpecific Heart Rate Corrections of the QT Interval in Investigations of Drug Induced QTe Prolongation. Pacing Clin Electrophysiol. 2004;27:791-800.

68. Batchwarov VN, Ghuran A, Smetana. P, Hratkova K, Harries M, Dilaveris P, Camm AJ, Malik M. QT-RR relationship in healthy subjects exhibits substantial intersubject variability and high intrasubject stability. Am J Physiol Heart Circ Physiol. 2002;282: H2356-63.

69. Choy AM, Lang CC, Chomsky DM, Rayos GH, Wilson JR, Roden DM. Normalization of acquired QT prolongation in humans by intravenous potassium. Circulation. $1997 ; 96: 2149-54$.

70. Bjorkman S. Reduction and lumping of physiologically based pharmacokinetic models: prediction of the disposition of fentanyl and pethidine in humans by successively simplified models. J Pharmacokinet Pharmacodyn. 2003;30:285-307.

71. Titier K, Canal M, Deridet E, Abouelfath A, Gromb S, Molimard M, Moore N. Determination of myocardium to plasma concentration ratios of five antipsychotic drugs: comparison with their abiitity to induce arrhythmia and sudden death in clinical practice. Toxicol Appl Pharmacol. 2004;199:52-60.

72. Weissenburger $J$, Nesterenko VV, Antzelevitch C. Transmural heterogeneity of ventricular repolarization under baseline and long QT conditions in the canine heart in vivo: torsades de pointes develops with halothane but not pentobarbital anesthesia. 
I Cardiovasc Electrophysiol. 2000;11:290-304.

73. Hohnloser SH, Klingenheben T, Singh BN. Amiodarone-associated proarthythmic effects. A review with special reference to torsade de pointes tachycardia. Aw $\mathrm{Aw}$ wh Med. 1994;121:529-535.

74. D'Alonzo AJ, Zhu JL, Darbenzio RB. Effects of class III antararfythmic agents in an in vitro rabbit model of spontaneous torsades de pointe. Eur J Pharmacol. 1999;369:57-64.

75. Eckardt $L$, Breithardt $G$, Haverkamp W. Electrophysiologic characterization of the antipsychotic drug sertindole in a rabbit heart model of torsade de pointes: low torsadogenic potential despite QT prolongation. J Pharmocol Exp Ther. 2002;300:64-71.

76. Eckardt L, Haverkamp W, Mertens H, Johna R, Clague JR, Borggrefe M, Breithardt G. Drug-related torsades de pointes in the isolated rabbit heart: comparison of clofilium, d,l-sotalol, and erythromycin. $J$ Cardiovase Pharmacol. 1998;32:425-34.

77. Zabel M, Hohnloser SH, Behrens S, Li YG, Woosley RL, Franz MR. Electrophysiologic features of torsades de pointes: insights from a new isolated rabbit heart model. $J$ Cardiovasc Electrophysiol. 1997;8:1148-58.

78. Shimizu W, Antzelevitch C. Sodium channel block with mexiletine is effective in reducing dispersion of repolarization and preventing torsade des pointes in LQT2 and LQT3 madels of the fong-QT syndrome. Circulation. 1997;96:2038 47.

79. Shimiza W, Antzelevitch C. Effects of a $\mathrm{K}(+)$ channel opener to reduce transmural dispersion of repolarization and prevent torsade de pointes in LQT1, LQT2, and LQT3 models of the long-QT syndrome. Cinculation. 2000:102:706-12.

80. Fish JM, Di Diego JM, Nesterenko V, Antzelevitch C. Epicardial Activation of Left Ventricular Wall Prolongs QT Interval and Transmural Dispersion of Repolarization. Implications for Biventricular Pacing. Circulation. 2004.

81. Yan GX, Antzelevitch C. Cellular basis for the normal T wave and the electrocardiographic manifestations of the long-QT syndrome. Circulation. 1998;98:1928-1936.

82. Emori T, Antzelevitch C. Cellular basis for complex. T waves and arthythmic activity following combined I(Kr) and I(Ks) block. J Cardiovasc Electrophysiol. 2001;12:13691378.

83. Di Diego $\mathrm{JM}_{\text {, }}$, Belardinelli $\mathrm{L}$, Antzelevitch $\mathrm{C}$. Cisapricle-induced transmural dispersion of repolarization and torsade de pointes in the canine left ventricular wedge preparation during epicardial stimulation. Cinculation. 2003;108:1027-33.

84. Akar FG, Rosenbaum DS. Transmural Electrophysiological Heterogeneities Underlying Arrhythmogenesis in Heart Failure. Circ Res. 2003.

85. Carlsson L, Almgren O, Duker G. QTU-prolongation and torsades de pointes induced by putative class III antiarrhythmic agents in the rabbit: etiology and interventions. $J$ Candiovasc Pharmocol. 1990;16:276-85.

86. Volders PG, Vos MA, Szabo B, Sipido KR, de Groot SH, Gorgels A.P, Wellens HJ, Lazzara R. Progress in the understanding of cardiac early afterdepolarizations and torsades de pointes: time to revise current concepts. Cardiovasc Res. 2000:46:376-92.

87. Carlsson L, Drews L, Duker G. Rhythm anomallies related to delayed repolarization in vivo: influence of sarcolemmal Cat+4 entry and intracellular $\mathrm{Ca}+t$ overload. $J$ Pharmacol Exp Ther. 1996;279:231-9.

88. Brooks RR, Drexler AP, Maynard AE, Al-Khalidi H, Kostreva DR. Proarthythmia of azimilide and other class III antiarrhythmic agents in the adrenergically stimulated rabbit. Proc Soc Exp Biol Med 2000,223:183-9.

89. Lu HR, Remeysen P, De Clerck F. Nonselective l(Kr)-blockers do not induce torsades de pointes in the anesthetized rabbit during alpha I -adrenoceptor stimulation. $J$ Cardiovasc Pharmacol. 2000;36:728-36.

90. Bril A, Gout B, Bonhomme M, Landais L, Faivre JF, Linee P, Poyser RH, Ruffolo RR, Jr. Combined potassium and calcium channel blocking activities as a basis for 
antiarhythmic efficacy with low proarnythmic risk: experimental profle of BRL32872. J Pharmacel Exp Ther. 1996;276:637-46.

91. Buchanan LV, Kabel $G$, Brunden MN, Gibson JK. Comparative assessment of ibutilide, $D$-sotalol, clofilim, E-4031, and UK-68,798 in a rabbit model of proarrhythmia. J Cardionasc Phamacol. 1993:22:540-9.

92. Mazur A. Roden DM, Anderson ME. Systemic administration of calmodulin antagonist W-7 or protein kinase A inhibitor H-8 prevents torsade de pointes in rabbils. Circulation. $1999 ; 100 ; 2437-42$.

93. Gbadebo TD, Trimble RW, Khoo MS, Tenple J, Roden DM, Anderson ME. Calmodulin inhubutor W-7 unmasks a novel electrocardiographic parameter that predicts initiation of torsade de pointes: Circularion. 2002;105:770-774.

94. Derakhchan K, Cardinall R, Brunet S, Klug D, Pharand C, Kus T, Sasyniuk BI. Polymorphic ventricular tachycardias induced by D-sotalol and phenylephrine in canine preparations of atrioventricular block: initiation in the conduction system followed by spatially unstable re-entry. Cardiowasc Res. 1998;38:617-30.

95. Schram $\mathrm{G}$, Zhang L, Derakhchan $\mathrm{K}$, Ehrlich JR, Belardinelli L, Nattel S. Ranolazine: Ion-channel-blocking actions and in vivo electrophysiological effects. $B r J$ Pharmacol. 2004 .

96. Volders PG, Sipido KR, Vos MA, Kulcsar A, Verduyn SC, Wellens HJ. Cellular basis of biventricular hypertrophy and arrhythmogenesis in dogs with chronic complete atrioventricular black and acquired torsade de pointes. Circklation. 1998;98:1136-47.

97. Vos MA, de Groot SH, Verduyn SC, van der Zande J, Leunissen HD, Cleutjens JP, van Bilsen M, Daemen MJ, Schreuder JJ, Allessie MA, Wellens HJ. Enhanced susceptibility for acquired torsade de pointes arrhythmias in the dog with chronic, complete AV block is related to cardiac hypertrophy and electrical remodeling. Circulation. 1998;98:112535.

98. Volders $P$ G, Sipido KR, Vos MA, Spatjens RL, Leunissen JD, Carmeliet E, Wellens HJ. Downregulation of delayed rectifier $\mathrm{K}(*)$ currents in dogs with chronic complete atrioventricular block and acquired torsades de pointes. Circulation. 1999; 100:2455-61.

99. Sipido KR, Volders PG, de Groot SH, Verdonck F, Van de Werf F, Wellens HJ, Vos MA. Enhanced $\mathrm{Ca}(2+)$ release and $\mathrm{Na} / \mathrm{Ca}$ exchange activity in hypertrophied canine ventricular myocytes: potential link between contractile adaptation and arrhythmogenesis. Circulation. 2000;102:2137-44.

100. Schoenmakers M, Ramakers C, van Opstal JM, Leunissen JD, Londono C, Vos MA Asynchronous development of electrical remodeling and cardiac hypertrophy in the complete AV block dog. Cardiovasc Res. 2003;59:351-9.

101. van Opstal JM, Leunissen JD, Wellens HJ, Vos MA. Azimilide and dofetilide produce similar electrophysiological and proarrlythmic effects in a canine model of Torsade de Pointes arrhythmias. Eur J Phormacol. 2001;412,67-76.

102. Verduyn SC, Vos MA, van der Zande J, Kulcsar A, Wellens HJ. Further observations to elucidate the role of interventricular dispersion of repolarization and early afterdepolarizations in the genesis of acquired torsade de pointes arrhythmias: a comparison between almokalant and d-sotalol using the dog as its own control. $J \mathrm{Am}$ Coll Cardiol 1997;30:1575-84

103. Vos MA, Gorenek B, Verduyn SC, van der Filust FF, Leunissen JD, Dolmen L, Wellens HI. Observations on the onset of torsade de pointes arrhythmias in the acquired long QT syndrome. Candiovase Res. 2000;48:421-9.

1044. Vos MA, Verduyn SC, Gorgels AP, Lipesei GC, Wellens HJ. Reproducible induction of early afterdepolarizations and torsade de pointes arrhythmias by d-sotalol and pacing in dogs with chronic atrioventricular block. Circulation. 1995;91:864-72.

105. Chiba K, Sugiyama A, Satoh $\mathrm{Y}$, Shina $\mathrm{H}$, Hashimoto K. Proarrhythmic effects of fluoroquinolone antibacterial agents: in vivo effects as physiologic substrate for torsades. 
Toxicol Appl Pharmacol. 2000; 169:8-16.

106. Sugiyama A, Satol $\mathrm{Y}$, Shina $\mathrm{H}$, Takeda $\mathrm{S}$, Hashimoto $\mathrm{K}$. Torsadegenic aetion of the antipsychotic drug sulpiride assessed using in vivo canine models. I Cardiowase Pharmacol. 2002;40:235-245.

107. Yoshida H, Sugiyama A, Satoh Y, Ishida Y, Yoneyana M, Kugiyama K., Hashimoto K. Comparison of the in vivo electrophysiological and proarthythimic effects of amiodarone with those of a selective class III drug, sematilide, using a canine chronic atrioventricular block model. Circ J. 2002;66:758-762.

108. Sugiyama A, Ishida $Y$, Satoh $Y$, Aoki S, Hori M, Akie $Y$, Kobayashi $Y$, Hashimoto K. Electrophysiological, anatomical and histological remodeling of the heart to AV block enhances susceptibility to arrhythmogenic effects of QT-prolonging drugs. Jpn $J$ Phamacol. 2002;88:341-350.

109. Chiba K. Sugiyama A, Hagiwara T, Takahashi S-i, Takasuna K, Hashimoto K. In vivo experimental approach for the risk assessment of fluoroquinolone antibacterial agentsinduced long QT syndrome. European Journal of Pharmacology. 2004;486:189-200.

110. Belardinelli L, Antzelevitch C, Vos MA. Assessing predictors of drug-induced torsade de pointes. Trends Pharmacol Sci. 2003;24:619-625.

111. Valentin JP, Hoffmann P, De Clerck F, Hammond TG, Hondeghem L. Review of the predictive value of the Langendorff heart model (Screenit system) in assessing the proarhythmic potential of drugs. J Pharmacol Toxicol Methods. 2004;49:171-81.

112. United Nations Publication: Consolidated list of products whose consumption and/or sale have been banned, withdrawn, severely restricted or not approved by governments. 2003. http:/www.un,org/esa/coordination/ecosoc/Consolidated.List.of.Products, final.pdf

113. De Ponti F, Poluzzi E, Montanaro N. QT-interval prolongation by non-cardiac drugs: lessons to be learned from recent experience. Eu J Clim Pharmacol, 2000;56:1-18.

114. Hartigan-Go K, Bateman DN, Daly AK, Thomas SH. Stereoselective cardiotoxic effects of terodiline. Clin Pharmacol Ther. 1996;60:89-98.

115. The European Agency for the Evaluation of Medicinal Products. EMEA/34168/98.

116. The European Agency for the Evaluation of Medicinal Products. EMEA/CPMP/2852/02.

117. The European Agency for the Evaluation of Medicinal Products. EMEA/24844/02.

118. Cox F. The rise and withdrawal of droperidol. Br J Perioper Nurs. 2002; 12:254-7.

119. The European Agency for the Evaluation of Medicinal Products. EMEA/8776/01.

120. Brendorp B, Pedersen O, Torp-Pedersen C, Sahebzadah N, Kober L. A beneft -risk assessment of class III antiarthythmic agents. Drug Saf. 2002;25:847-65.

121. Fermini B, Jurkiewicz NK, Jow B, Guinosso PJ, Jr., Baskin EP, Lynchi JJ, Jr., Salata JI. Use-dependent effects of the class 11 I antiarthythmic agent NE-10064 (azimilide) on cardiac repolarization: block of delayed rectifier potassium and $\mathrm{L}$-type calcium currents. J Cardiovasc Pharmacol. 1995;26:259-7ll.

122. Gintant GA. Azimilide causes reverse rate-dependent block while reducing both components of delayed-rectifier current in canine ventricular myocytes. J Cardiowasc Pharmacol. 1998;31:945-53.

123. Takacs I, losi N, Lengyel C, Virag L, Nesic M, Varro A, Papp JG. Multiple celluilar electrophysiological effects of azimilide in canine cardiac preparations. Eur $J$ Pharmacol. 2003;470:163-70.

124. Walker BD, Singleton CB, Tie H, Bursill JA, Wyse KR, Valenzuela SM, Breit SN, Campbell TJ. Comparative effects of azimilide and ambasilide on the human ether-a-gogo-related gene (HERG) potassium channel. Cardiovasc Res. 2000;48:44-58.

125. Yao JA, Tseng GN. Azimilide (NE-10064) can prolong or shorten the action potential duration in camine ventricular myocytes: dependence on blockade of $\mathrm{K}, \mathrm{Ca}$, and $\mathrm{Nat}$ channels. I Cardiowasc Electrophysiol. 1997;8:184-98.

126. Rampe D, Roy ML, Dennis A, Brown AM. A mechanism for the proarthythmic effects of cisapride (Propulsid): high affinity blockade of the human cardiac potassium channel 
HERC. FEBS Lett, 1997;417:28-32.

127. Yang T, Snyders DI, Roden DM. Ibutilide, a methanesulfonanilide antiarrhythmic, is a potent blocker of the rapidly activating delayed rectifier $\mathrm{K}+$ current (IKr) in AT-1 cells. Concentration-, time-, voltage-, and use-dependent effects. Circulation. 1995;91:1799806.

128. Salata JJ Jurkiewicz NK, Wallace AA, Stupienski RF, 3rd, Guinosso PJ, Jr, Lynch JJ, Jr. Cardiac electrophysiological actions of the histamine HI-receptor antagonists astemizole and terfenadine compared with chlorpheniramine and pyrilamine. Circ Res. $1995 ; 76: 110-9$.

129. Ekins S, Crumb WJ, Sarazan RD, Wikel JH, Wrighton SA. Three-dimensional quantitative structure-activity relationship for inhibition of human ether-a-go-go-related gene potassium channel. J Pharmacol Exp Ther. 2002;301:427-434.

130. Leisthinan DJ, Helliwell R, Wakerell J, Wallis RM. Effects of E-4031, cisapride, terfenadine and terodiline on cardiac repolarisation in canine Purkinje fibre and HERG channels expressed in HEK293 cells. Br I Pharmacol. 2001;133:130P.

131. Fossa AA, Wisialowski T, Wolfgang E, Wang E, Avery M, Raunig DL, Fermini B. Differential effect of HERG blocking agents on cardiac electrical alternans in the guinea pig. Eur J Pharmacol. 2004;486:209-21.

132. Taglialatela M, Pannaccione A, Castaldo P, Giorgio G, Zhou Z, January CT, Genovese A, Marone $G$, Annunziato L. Molecular basis for the lack of HERG $\mathrm{K}+$ channel blockrelated cardiotoxicity by the $\mathrm{H} 1$ receptor blocker cetirizine compared with other secondgeneration antihistamines. Mol Phamacol. 1998;54:113-21.

133. Carmeliet $\mathrm{E}$. Effects of cetirizine on the delayed $\mathrm{K}+$ currents in cardiac cells: comparison with terfenadine, Br J Pharmacol. 1998;124:663-8.

134. Ko CM, Ducic I, Fan J, Shuba YM, Morad M. Suppression of mammalian K+ channel family by ebastine. J Pharmacol Exp Ther. 1997;28\|:233-44.

135. Roy M, Dumaine R, Brown AM. HERG, a primary human ventricular target of the nonsedating antihistamine terfenadine. Circulation. 1996;94:817-23.

136. Crumb WJ, Jr. Loratadine blockade of $\mathrm{K}(\mathrm{t})$ channels in human heart: comparison with terfenadine under physiological conditions. J Pharmacol Exp Ther. 2000;292:261-4.

137. Wang J, Della Penna K, Wang H, Karczewski J, Connolly TM, Koblan KS, Bennett PB, Salata JJ. Functional and pharmacological properties of canine ERG potassium channels. Am J Physiol Heart Circ Physiol. 2003;284:H256-67.

138. Woosley RL, Chen Y, Freiman JP, Gillis RA. Mechanism of the cardiotoxic actions of terfenadine Jama. 1993;269:1532-6.

139. Lacerda Als, Kramer J, Shen K-Z, Thomas D, Brown AM. Comparison of block among clloned cardiac potassium chamels by non-antiarthythmic drugs. European Heart Jounal Supplements. 2001;3:K23-K30.

140. Zhou $Z$, Vorperian VR, Gong $Q$, Zhang $S$, January CT. Block of HERG potassium channels by the antihistamine astemizole and its metabolites desmethylastemizole and norastemizole. J Cardiovase Electrophysiol. 1999;10:836-43.

141. Anderson ME, Mazur A, Yang T, Roden DM. Potassium current antagonist properties and proarthythmic consequences of quinolone antibiotics. J Pharmacol Exp Ther. 2001;296:806-10.

142. Kang J, Wang L, Chen XL, Triggle DJ, Rampe D. Interactions of a series of fluoroquinolone antibacterial drugs with the human cardiac $\mathrm{K}+$ channel HERG. Mol Pharmacol. 2001:59:122-6.

143. Bischoff U, Schmidt C, Netzer R, Pongs O. Effects of fluoroquinolones on HERG currents. Eur J Pharmacol. 2000;406:341-3.

144. Potet F, Bonyssou T, Escande D, Baro 1. Gastrointestinal prokinetic drugs have different affinuty for the human cardiac human ether-a-gogo $\mathrm{K}(+)$ channel. $J$ Pharmacol Exp Ther. 2001;299:1007-12. 
145. Mohammad S, Zhou Z, Gong Q, January CT. Blockage of the HERG human cardiac K+ channel by the gastrointestinal prokinetic agent cisapride. Am J Phosiol. 1997;273: H2534-8.

146. Walker BD, Singleton CB, Bursill JA, Wyse KR, Valenzuela SM, Qiu MR, Breit SN, Campbell TJ. Inhibition of the human ether-a-go-go-related gene (HERG) potassium. channel by cisapride: affinity for open and inactivated states. $B r J$ Pharmacol. 1999;128:444-50.

147. Carlsson $L$, Amos GJ, Andersson B, Drews L, Duker G, Wadstedt $G$. Electrophysiological characterization of the prokinetic agents cisapride and mostpride in vivo and in vitro: implications for proarrhythmic potential? I Phanmocol Exp Ther. 1997;282:220-7.

148. Drolet B, Khalifa M, Daleau P, Hamelin BA, Turgeon J. Block of the rapid component of the delayed rectifier potassium current by the prokinetic agent cisapride underlies drug-related lengthening of the QT interval. Circulation. 1998:97:204-10.

149. Kamiya K, Nishiyama A, Yasui K, Hojo M, Sanguinetti MC, Kodama 1. Short- and long term effects of amiodarone on the two components of cardiac delayed rectifier $\mathbb{K}(+)$ current. Circulation. 2001;103:1317-24.

150. Kodama I, Kamiya K, Toyama J. Cellular electropharmacology of amiodarone. Cardiovasc Res. 1997;35:13-29.

151. Varro A, Virag L, Papp JG. Comparison of the chronic and acute effects of amiodarone on the calcium and potassium currents in rabbit isolated cardiac myocytes. $\mathrm{Br} J$ Pharmacol. 1996;117:1181-6.

152. Kiehn J, Thomas D, Karle CA, Schols W, Kubler W. Inhibitory effects of the class III antiarrhythmic drug amiodarone on cloned HERG potassium channels. Naunyn Schmiedebergs Arch Pharmacal. 1999;359:212-9.

153. Yang T, Snyders D, Roden DM. Discordance between IKr block and torsades de pointes. Circulation. 1997;96:I-554.

154. Chouabe C, Drici MD, Romey G, Barhanin J, Lazdunski M. HERG and KvLQT 1/IsK. the cardiac $\mathrm{K}+$ channels involved in long QT syndromes, are targets for calcium channel blockers. Mol Pharwacol. 1998;54:695-703.

155. Zhang S, Sawanobori T, Hirano Y, Hiraoka M. Multiple modulations of action potential duration by different calcium channel blocking agents in guinea pig ventricular myocytes. J Cardiovasc Pharmacol. 1997;30:489-96.

156. Waldegger $S$, Niemeyer $G$, Morike K, Wagner CA, Suessbrich $H_{*}$ Busch AE, Lang $F$, Eichelbaum M. Effect of werapamil enantiomers and metabolites on cardiac K+ channels expressed in Xenopus oocytes. Cell Physiol Biochem. 1999;9:81-9.

157. Lacroix P, Crumb WJ, Durando L, Ciottoli GB. Prulifloxacin: in vitro (HERG current) and in vivo (conscious dog) assessment of cardiac risk. Eur I Pharmacol. 2003;477:69. 72. 


\section{Electrophysiological Safety of Sertindole in Dogs with Normal and Remodeled Hearts}

Morten B. Thomsen', Paul G.A.Volders', Milan Stengl', Roel L.H.M.G. Spätjens', Jet D.M. Beekman', Ulrike Bischoff ${ }^{2}$, Morten A. Kall ${ }^{3}$, Kristen Frederiksen ${ }^{3}$, Jørgen Matz ${ }^{3}$ and Marc A. Vos'

1. Department of Cardiology, Cardiovascular Research Institute Maastricht, Academic Hospital Maastricht, Netherlands.

2. GENION, Evotec QAI AG, Hamburg, Germany.

3. H. Lundbeck A/S, Copenhagen, Denmark. 


\section{Abstract}

Inhibition of the potassium current $I_{\mathrm{K}, \mathrm{r}}$ and QT prolongation are associated with drug-induced torsades de pointes arthythmias (TdP) and sudden cardiac death. We investigated the cardiac electrophysiological effects of sertindole, an antipsychotic drug reported to prolong the QT interval in schizophrenic patients. In cell cultures, sertindole appeared a selective blocker of $I_{\mathrm{HERG}}$ over other ion currents. For $I_{\mathrm{HERG}}$

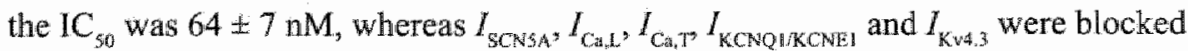
in the micromolar range. In canine ventricular myocytes, the $\mathrm{IC}_{50}$ for $I_{\mathrm{Kr}}$ inhibition by sertindole was $107 \pm 21 \mathrm{mM}$. Action potentials in these cells prolonged in a reverse-rate and concentration-dependent manner at 10 to $300 \mathrm{nM}$ sertindole. In vivo, sertindole was administered to anesthetized dogs at clinically relevant $(0.05$ to $0.20 \mathrm{mg} / \mathrm{kg}$ ) and high doses (1.0 to $2.0 \mathrm{mg} / \mathrm{kg}$ ) i.v. At 0.05 to $0.20 \mathrm{mg} / \mathrm{kg}$ sertindole (plasma concentrations: 30 to $157 \mathrm{nM}$ ), $\mathrm{QT}_{\mathrm{c}}$ was prolonged by 1 to $5 \%$ in normal dogs and by 9 to $20 \%$ in dogs with remodeled hearts due to chronic AV block (CAVB). TdP was not induced at these doses in normal dogs or in CAVB dogs with reproducible induction of $T d P$ by dofetilide in previous experiments. At 1.0 to 2.0 $\mathrm{mg} / \mathrm{kg}$ sertindole (plasma concentrations: 0.5 to $3.1 \mu \mathrm{M}$ ), QT prolonged by 6 to $11 \%$ in normal dogs and by $22 \%$ in dofetilide-sensitive CAVB dogs. TdP occurred in three of five animals in the latter group. Thus, at high i.v. doses sertindole can pose a serious proarthythmic risk when electrical remodeling of the ventricles is present. At clinically relevant doses, however, sertindole does not cause TdP in anesthetized dogs with normal or remodeled hearts. 


\section{Introduction}

An estimated $1 \%$ of the population suffers from various degrees of schizophrenia with a significant burden on the health budget due to long-term hospitalization of these patients. "The average schizophrenic patient has a 10-year shorter duration of life than the rest of the population and suicidal rates are as high as $10 \%$.' Treatment of these patients is not optimal since $30 \%$ respond poorly or not at all to available drugs and non-compliance is high, in part due to neurological side effects. ${ }^{2}$ 5-chloro-1-(4-fluorophenyl)-3-(1-(2-(2-imidazolidinon-1-yl)-ethyl)-4-piperidyl)$1 /$-indole (sertindole) is an antipsychotic compound synthesized in the mid1980s and introduced on the European market in 1996. Clinical phase III trials showed therapeutic effectiveness against both positive and negative symptoms of schizophrenia, ${ }^{3}$ whereas extrapyramidal symptoms were absent. ${ }^{4}$ Sertindole has a high affinity for several serotonin and dopamine receptor subtypes and $\alpha_{1 \mathrm{~A}}$ adrenergic receptors. ${ }^{5-7}$ Furthermore, a high inhibitory effect on the current mediated by the potassium channel encoded by HERG has been shown in vitro. ${ }^{8}$ HERG blocking properties with $\mathrm{IC}_{s 0}$ s ranging from low nanomolar to low micromolar are common for most antipsychotic drugs ${ }^{9-11}$ and may explain the drug-induced QT prolongation caused by some of them. ${ }^{12}$

In 1998, sertindole was withdrawn from the market due to concern about the high ratio of proven or suspected ventricular arrhythmias and sudden deaths in patients. ${ }^{13}$ $\mathrm{QT}_{\mathrm{e}}$ intervals were prolonged in 4 to $5 \%$ of patients receiving sertindole, ${ }^{14}$ and prolongation of action potential duration was confirmed in isolated feline ${ }^{\text {ls }}$ and rabbit hearts. ${ }^{16}$ After reevaluation of the existing data, and based on new preclinical, clinical and epidemiological information, the concern about cardiac risk was outweighed by the therapeutic benefits of sertindole. This led to the reintroduction of sertindole on the European market in 2002 along with a prospective surveillance study of all patients taking the drug. ${ }^{17}$

In the present study we investigated the cardiac electrophysiological effects of sertindole in vitro and in vivo to provide an ionic basis for repolarization prolongation by the drug in relation to possible proarrhythmic actions in intact dogs.

\section{Methods}

Animal handling was in accordance with the 'European Directive for the Protection of Vertebrate Animals Used for Experimental and Other Scientific Purposes (86/609/ EU)'. The 'Committee for Experiments on Animals" of Maastricht University approved all experiments. 
Chinese hamster ovary cells were stably transfected with human cloned HERG

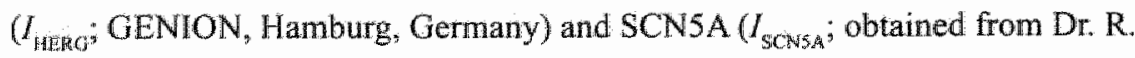
Kallen, University of Pennsylvania, Philadelphia, PA) representing the rapidly actiwating delayed rectifier potassium current and fast inward sodium current, respectively. Maximal outward $I_{\text {Har }}$ and peak $I_{\text {scNs }}$ were measured. KCNQ1 and KCNEI were stably co-transfected in Chinese hamster ovary cells $\left(I_{\text {KCNQIKCNE: }}\right.$; GENION) representing the slowly activating delayed rectifer potassium current. Human embryonic kidney 293 cells transiently expressing Kv4.3 ${ }_{\Delta 2-39}\left(I_{\mathrm{K} v 4.3}\right)$ were used to assess the transient outward potassium current. Calcium-current experiments were performed on a $\mathrm{NG}-108-15$ neuroblastoma-glioma hybrid cell line expressing endogenous L- and T-type calcium channels. Standard voltage-clamp protocols, electrodes, superfusion and internal solutions were used. Ion currents were measured at control and after 5 -minutes incubation of sertindole at various concentrations. Each data point consisted of measurements from three to eight cells. $\mathrm{IC}_{50}$ values were obtained by fitting the data to a two-parameter sigmoidal curve $\left(I=\mathrm{c}^{\mathrm{n}} /\left(\mathrm{c}^{\mathrm{n}}+\right.\right.$ $\left.\left.\mathrm{IC}_{50} \mathrm{n}\right)\right)$.

\section{Experiments in isolated canine ventricular myacytes}

Twelve mongrel dogs (body weight: $29 \pm 5 \mathrm{~kg}, 8$ males) were sacrificed for myocyte isolation. Thoracotomy was performed under anesthesia. Heparin (10.000 IU) was administered $\mathrm{i}$.v. to avoid intracoronary clotting. After quick excision, the heart was placed in cold oxygenated cardioplegic solution and the coronary circulation was cannulated via the aorta. The heart was mounted to a constant-pressure Langendorff-like setup and perfused for 5 minutes using a Tyrode's solution with nominal $\left[\mathrm{Ca}^{2+}\right]$. Collagenase A (Roche Diagnostics, Mannheim, Germany) in $0.5 \mu \mathrm{M}$ $\mathrm{Ca}^{2 *}$ Tyrode with $0.5 \mathrm{mg} / \mathrm{ml}$ bovine serum albumin perfused the heart for 30 to 35 minutes, followed by $0.2 \mathrm{mM} \mathrm{Ca} \mathrm{M}^{2 *}$ Tyrode for 5 minutes to washout the collagenase. Midnyocardial cells were harvested from the free wall of both ventricles, gently minced, filtered, washed and stored in $0.2 \mathrm{mM} \mathrm{Ca}^{2+}$ at room temperature until use within 24 hours after isolation.

Myocytes were selected for experiments if they had sharp striations, clear contours and transparent cytoplasms without granulations or blebs. Further criteria for actionpotential experiments included a stable resting membrane potential below $-70 \mathrm{mV}$ and a 'spike-and-dome' morphology of the action potential.

Whole-cell currents were recorded (AxoPatch 1D; Axon Instruments, Union City, 
CA) using borosilicate glass patch pipettes filled with internal solution (125 $\mathrm{mM}$ $\mathrm{K}$-asp, $20 \mathrm{mM} \mathrm{KCl}, 1.0 \mathrm{mM} \mathrm{MgCl}$, $5 \mathrm{mM} \mathrm{MgATP}, 5 \mathrm{mM}$ HEPES, $10 \mathrm{mM}$ EGTA; $\mathrm{pH}$ adjusted to 7.2 with $\mathrm{KOH}$ ) having a resistance between 1.0 and $3.0 \mathrm{M} \Omega$. Cells were superfused with a standard buffer solution $(145 \mathrm{mM} \mathrm{NaCl}, 5.4 \mathrm{mM} \mathrm{KCl}, 1.0$ $\mathrm{mM} \mathrm{MgCl}, 11 \mathrm{mM}$ glucose, $10 \mathrm{mM}$ HEPES, $1.8 \mathrm{mM} \mathrm{CaCl}, 5 \mu \mathrm{M}$ nifedipine; $\mathrm{pH}$ adjusted to 7.4 with $\mathrm{NaOH}, 37^{\circ} \mathrm{C}$ ). Sertindole was dissolved in dimethyl sulfoxide. The rapidly activating delayed rectifier potassium current $I_{\mathrm{kr}}$ was measured as the tail current fraction fully blocked by $2 \mu \mathrm{M}$ almokalant. ${ }^{18}$

Transmembrane action potentials (TAP) were recorded (AxoClamp 2B; Axon Instruments) using sharp glass microelectrodes filled with $3 \mathrm{M} \mathrm{KCl}$ and with a resistance between 20 and $60 \mathrm{M} \Omega$. Cells were superfused with the same solution as in the whole-cell current experiments except that nifedipine was left out. Addition of $2 \mu \mathrm{M}$ almokalant to the superfusate was used to fully block $I_{\mathrm{K} r}$. Action potentials were recorded at each cycle length (CL) of $300,400,500,1000$ and $2000 \mathrm{~ms}$. Action potential duration at $95 \%$ of repolarization $\left(\mathrm{APD}_{95}\right)$ is presented as the average of five beats $>100$ beats after a change in pacing $\mathrm{CL}$.

\section{In-vivo experiments}

Twenty-four anesthetized dogs (body weight: $29 \pm 4 \mathrm{~kg}, 11$ males) were used for these experiments. In 13 animals complete AV block was induced. ${ }^{19}$ After $4 \pm 1$ weeks of AV block (chronic AV block; CAVB), the dogs were subjected to a TdPsusceptibility test using the $I_{\mathrm{Kr}}$ blocker dofetilide. Only if a dog showed reproducible $\mathrm{TdP}$ upon $25 \mu \mathrm{g} / \mathrm{kg} / 5$ minutes dofetilide, it was selected for the sertindole experiments. Thus, dofetilide was used as the positive reference compound. The average time between two experiments in a dog was $2 \pm 1$ weeks.

Anesthesia ${ }_{\text {, }}$ perioperative care, signal processing, data recording and off-line analysis have been described elsewhere. ${ }^{19}$ Standard and precordial ECGs were recorded. In addition, biventricular endocardial monophasic-action-potential (MAP) recordings were made (EP Technologies, Sunnyvale, CA).

RR and QT intervals in lead II, left- and right-ventricular MAP duration (LV MAPD and RV MAPD, respectively) at 100\% repolarization were measured offline and averaged from five consecutive beats. The interventricular dispersion of repolarization ( $\triangle M A P D$ ) was calculated as the difference between the LV and RV MAPD. QT intervals were corrected for heart rate $\left(\mathrm{QT}_{v}\right)$ according to Van de Water's formula. ${ }^{20}$ The number of ectopic beats, defined as short-coupled beats arising from a new ventricular focus before complete repolarization of the previous beat, was counted during 10 minutes after administration of the drug. Both single and multiple 
Chatger 2

eetopic beats were counted. The latter are considered more proarmythmic. TdP was defined as a polymorphic ventricular tachycardia consisting of tive or more beats twisting around the isoelectric line of the ECG in the setting of a prolonged QT interval.

Sertindole (mol. wt. $44 \mathrm{~g} / \mathrm{mol}$ ) was dissolved in $0.1 \mathrm{M} \mathrm{HCl}$ and diluted in $10 \%$ hydroxypropyl cyclodextrin and $0.05 \mathrm{M}$ phosphatebuffer $(1: 1) . \mathrm{pH}$ was adjusted to 7.4. The solution was filtered through a 22 - $\mathrm{m}$ pore filter prior to use. Sertindole was administered over 5 minutes through a cephalic vein and blood samples were taken from the contralateral cephalic vein to measure plasma concentrations.

\section{Plasma analysis}

Blood samples were obtained 5, 10 and 25 minutes after drug administration and plasma was stored at $-20^{\circ} \mathrm{C}$ until analysis at $\mathrm{H}$. Lundbeck $\mathrm{A} / \mathrm{S}$ (Copenhagen, Denmark). Sertindole plasma samples were extracted by solid mixed phase extraction. The sample extracts were analyzed by a normal phase high-performance liquid chromatography method with a mobile phase consisting of heptane, $2 \%$ piperidine in 2-propanol, and water (100:20:0.45) and quantified by fluorescence detection with excitation/emission wavelengths at 260 and $340 \mathrm{~nm}$, respectively. The method had a mean recovery of $90 \%$ with a quantification limit of $0.5 \mathrm{ng} / \mathrm{ml}$. Total plasma concentrations (free + bound) are reported.

\section{Siatistical analysis}

Electrophysiological parameters were compared with control employing (repeatedmeasures) ANOVA followed by Bonferroni's test. Comparisons between controls were performed with an umpaired Student's $t$ test. Data are reported as mean \pm SEM. $P<0.05$ was considered statistical significant. 


\section{Results}

Serindole is selective for $\mathrm{I}_{\text {BrRG }}$

In Figure 1A the molecular structure of sertindole is shown. Figure IB shows concentration-response curves for the various cardiac ion channels expressed endogenously or by transfection in cell cultures. Sertindole inhibited $I_{\text {HERG }}$ in a concentration-dependent manner over the range of 10 to $1000 \mathrm{nM}$, with $50 \%$ block at $64 \pm 7 \mathrm{nM} . I_{\mathrm{KCNQ1/KCNE}}$ was inhibited by $10 \pm 5 \%$ at $300 \mathrm{nM}$ sertindole $\left(\mathrm{IC}_{50 "}\right.$ $6.9 \pm 2 \mu \mathrm{M})$, whereas other currents $\left(I_{\mathrm{SCN} 5 \mathrm{~A}}, I_{\mathrm{Cal}}, I_{\mathrm{CaT}}, I_{\mathrm{K} \times 4 .}\right)$ were only inhibited at micromolar concentrations. Representative examples of the six currents are shown in Figure 2 .
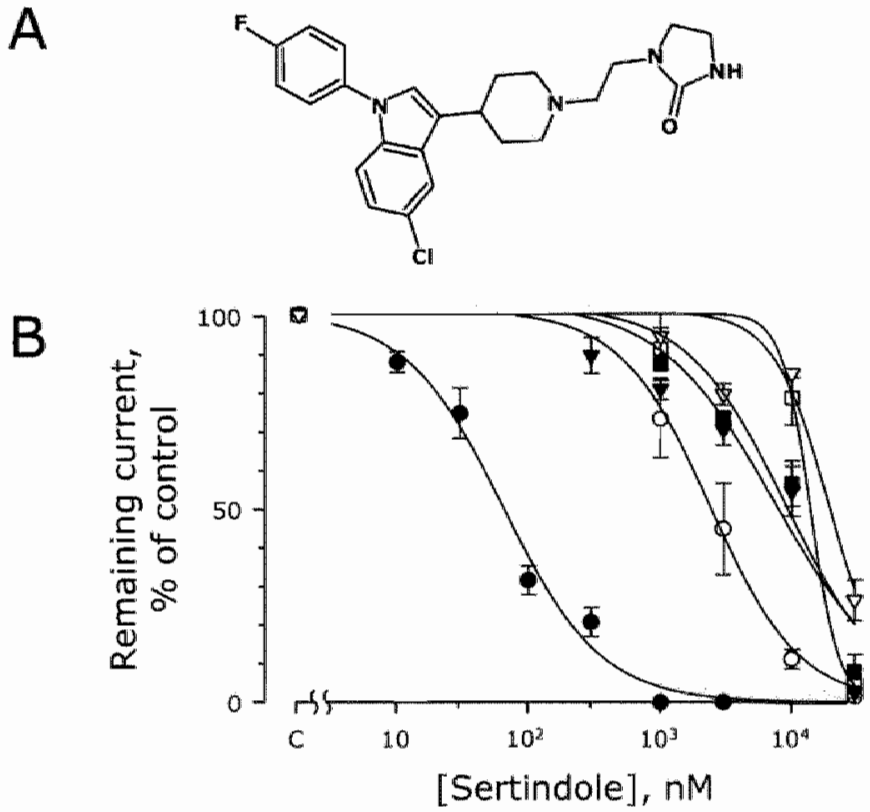

\section{Figure 1}

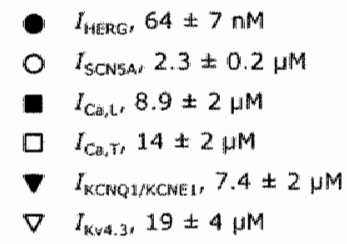

Selective block of $I_{\text {Herg }}$ by sertindole.

A: Chemical structure of sertindole (mol. wt. $441 \mathrm{~g} / \mathrm{mol}$ ).

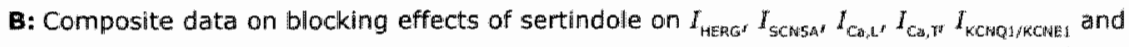
$I_{k \times 4.3}$ in heterologous and endogenous expression systems. Data points represent the means for three to eight cells. Shown are the concentration-response curves, where the remaining current is plotted relative to its control level. $1 \mathrm{C}_{50}$ values for the different currents are giwen

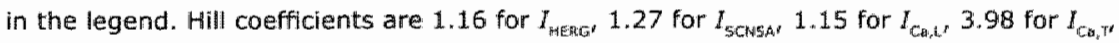

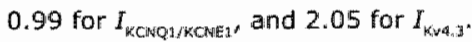



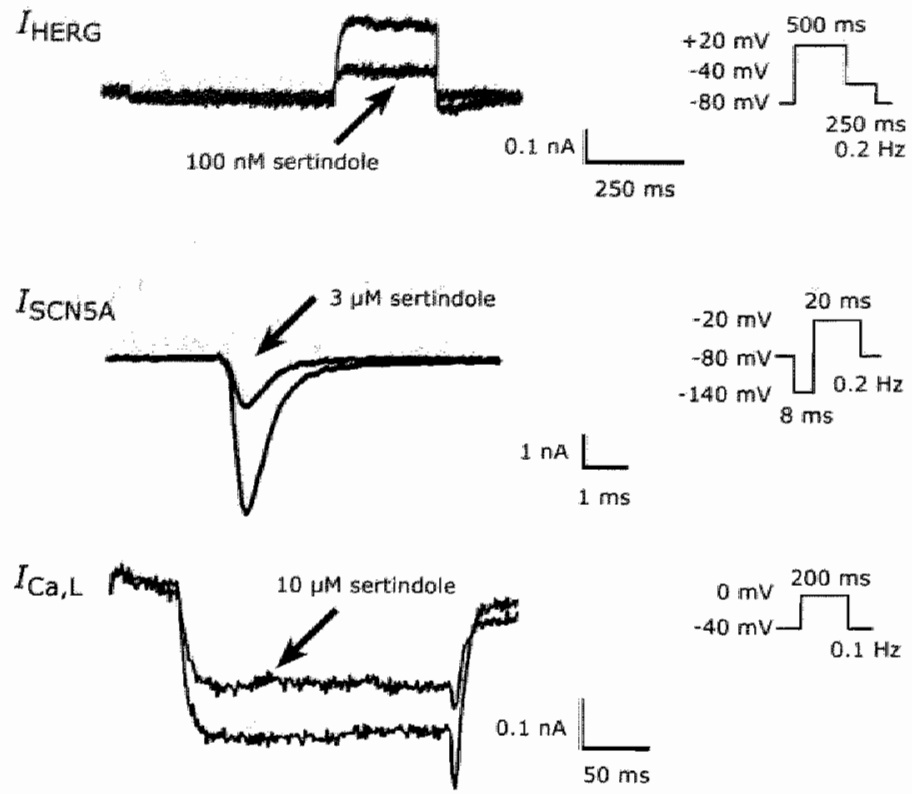

$$
-40 \mathrm{mv}-\prod_{0.1 \mathrm{~Hz}}^{200 \mathrm{~ms}}
$$
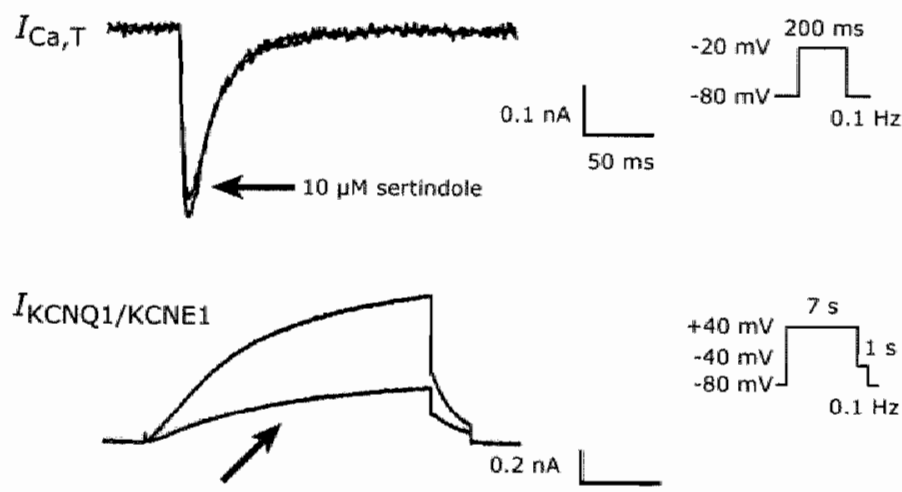

10 . W w stertindole
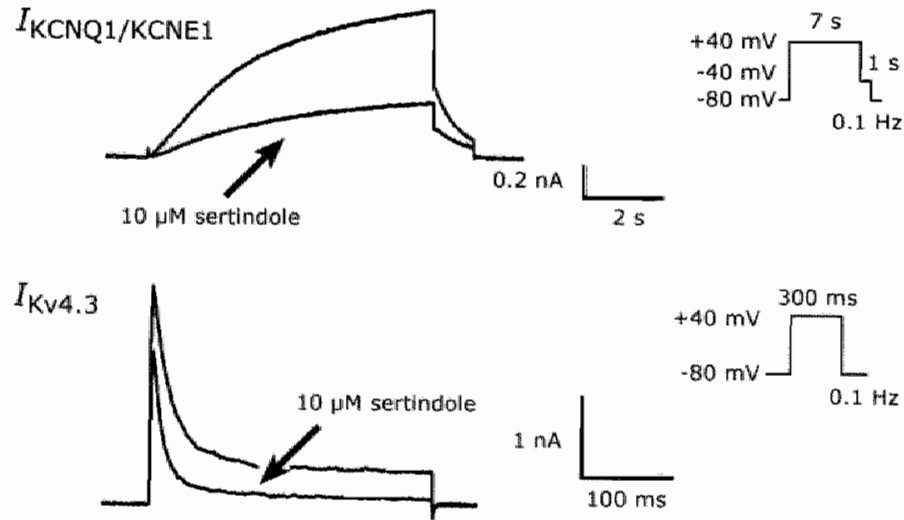

\section{Figure 2}

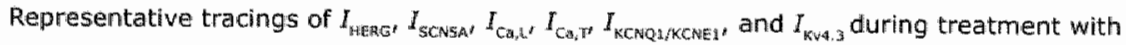
sertindole. Concentrations of sertindole were chosen to indicate selectivity for $I_{\text {HERGS }}$ block. Insets, voltage-clamp protocols. 
Sertindole blocks $I_{k, m}$ in canine venriculat mocytes

Activation of $I_{\mathrm{kg}}$ occurred at depolarizations to higher than $-10 \mathrm{mV}$ and showed saturation at conditioning voltages $\left(V_{\text {cond }}\right) \geq 20 \mathrm{mV}$ (Figure 3B). Maximal $I_{\mathrm{Kr}}$ density at control was $0.14 \pm 0.07 \mathrm{pA} / \mathrm{pF}$. Boltzmann fit to the data revealed a half-maximal activation at $11 \pm 1 \mathrm{mV}$ and a slope factor of $5.9 \pm 0.9 \mathrm{pA} / \mathrm{pF} / \mathrm{mV}$. Hall-time for $I_{\mathrm{K}}$ deactivation upon repolarization to $-50 \mathrm{mV}$ was $294 \pm 23 \mathrm{~ms}$.

An example of $I_{\mathrm{K} r}$ recorded under control conditions and under the influence of 100 nM sertindole is shown in Figure $3 \mathrm{~A}$. Sertindole inhibited $I_{\mathrm{K} .}$ tails in a concentrationdependent and voltage-independent manner. At $300 \mathrm{nM}$, the maximal $I_{\mathrm{Kr}}$ tail density had decreased to $0.08 \pm 0.004 \mathrm{pA} / \mathrm{pF}(57 \pm 4 \% ; P<0.05$; Figure 3B). Boltzmann fit of the remaining $I_{\mathrm{kr}}$ at $300 \mathrm{nM}$ sertindole showed a half-maximal activation at $8 \pm 2 \mathrm{mV}(P=\mathrm{NS}$ versus control) and a slope factor of $4.2 \pm 1.4 \mathrm{pA} / \mathrm{pF} / \mathrm{mV}(P=$ NS versus control). Half-time for deactivation was $273 \pm 48 \mathrm{~ms}$ ( $P=$ NS versus control). Figure $3 \mathrm{C}$ shows an example of the effects of accumulating concentrations of sertindole to illustrate the concentration dependency of the drug on $I_{\mathrm{K}^{*} r^{*}}$ Using multiple voltage protocols to analyze the properties of $I_{\mathrm{K}_{r}}$ under the influence of sertindole, a concentration-response relationship was obtained (Figure 3D). Sertindole inhibited $I_{\mathrm{Kr}}$ in a concentration-dependent manner over the full range of 10 to $1000 \mathrm{nM}$, with $50 \%$ block at $107 \pm 21 \mathrm{nM}\left(\mathrm{n}_{\text {cells }}=10\right)$.

\section{Sertindole prolongs the transmembrane action potential}

TAP in normal canine ventricular myocytes prolonged from $166 \pm 5$ to $278 \pm 13 \mathrm{~ms}$ by increasing pacing CL from 300 to $2000 \mathrm{~ms}\left(\mathrm{n}_{\text {exlls }}=11\right)$. Concentration-dependent prolongation of $\mathrm{APD}_{95}$ was observed for 10 to $300 \mathrm{nM}$ sertindole, reaching statistical significance at $100 \mathrm{nM}$ and higher, and for $\mathrm{CL} \geq 400 \mathrm{~ms}$ (Figure 4). Under the influence of $300 \mathrm{nM}$ sertindole, $\mathrm{APD}_{95}$ was prolonged to $197 \pm 15 \mathrm{~ms}(18 \%)$ and $345 \pm 44 \mathrm{~ms}(24 \%)$ at 300 and $2000 \mathrm{~ms} \mathrm{CL}$, respectively $(P<0.05$ for both CL), showing clear reverse rate dependence. Early afterdepolarizations or abnormal automaticity were not observed. 
A

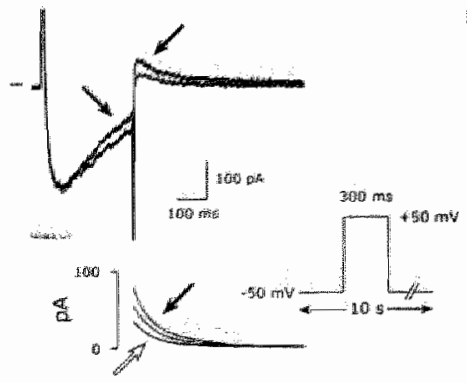

C

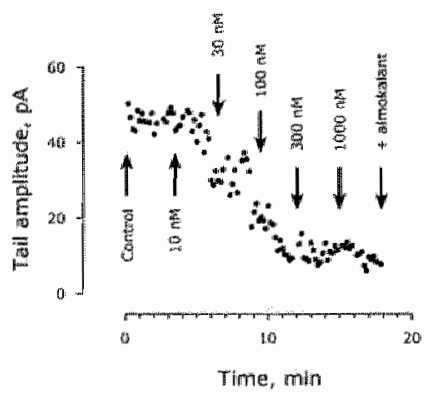

B

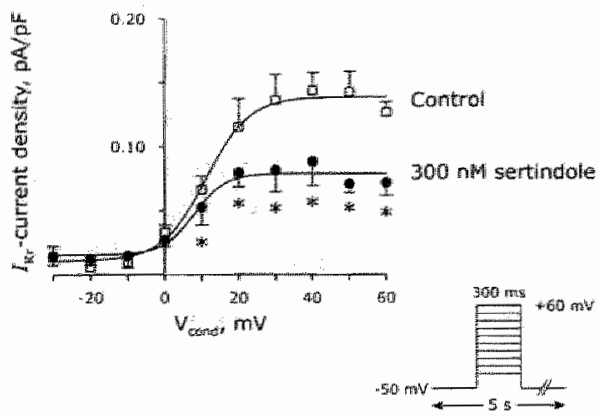

D

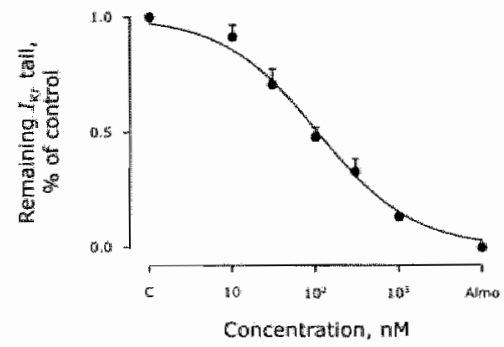

\section{Figure 3}

Effects of sertindale on $I_{k r}$ in normal canine ventricular myocytes.

A: Representative current recordings at control (arrows) and during $100 \mathrm{nM}$ sertindole $\left(C_{m}=\right.$ $207 \mathrm{pF}$ ). Left horizontal bar is at $600 \mathrm{pA}$. Below are illustrated second-order exponential fits of the tail currents at control (black arrow), full $I_{\mathrm{Kr}}$ block (white arrow) and for $100 \mathrm{nM}$ sertindole. Current axis is enlarged, but time axis is identical to current trace in A.

B: $I_{\mathrm{kr}}$ tail densities (difference currents at control and during $300 \mathrm{nM}$ sertindole minus full block by almokalant; $n_{\text {calls }}=6$ ). $*, p<0.05$ versus control. Inset, voltage-clamp protocol.

C: Tall-current amplitudes in a representative cell during increasing concentrations of sertindole $\left(C_{m}=191 \mathrm{pF}\right)$. Almokalant $(2 \mu \mathrm{M})$ provides full $I_{\mathrm{k}, \mathrm{r}}$ block. Voltage-clamp protocol as in A.

D: Concentration-response curve of $I_{\mathrm{kr}}$ inhibition by sertindale. $\mathrm{IC}_{50}$ value is $107 \pm 21 \mathrm{nM}$ (Hill coefficient $=0.76, n_{\text {cidlls }}=10$ ).

Sertindole canses moderate prolongation of repolarization in normal hearts in vivo

Cumulative doses of $0.05,0.10$, and $0.20 \mathrm{mg} / \mathrm{kg}$ sertindole (30-minutes intervals) were administered to five dogs. Plasma concentrations ranged from $33 \pm 1 \mathrm{nM}$ after $0.05 \mathrm{mg} / \mathrm{kg}$ to $157 \pm 18 \mathrm{nM}$ after $0.20 \mathrm{mg} / \mathrm{kg}$. Reported plasma concentrations after human therapeutic dosing are $22 \pm 12$ to $158 \pm 63 \mathrm{nM}$; 21 hence we considered these doses in the dogs to be clinically relevant. Representative examples of the electrophysiological effects are shown in Figure 5. QT interval did not prolong at 
0.05 or $0.10 \mathrm{mg} / \mathrm{kg}$ sertindole. At $0.20 \mathrm{mg} / \mathrm{kg} \mathrm{QT}$ prolonged from $277 \pm 11$ to 292 $\pm 20 \mathrm{~ms}(5 \%, P<0.05$; Figure 6$)$. At this dose, the RR interval increased from 465 \pm 35 to $545 \pm 47 \mathrm{~ms}(17 \% ; P<0.05)$ and the QT interval from $231 \pm 7$ to $252 \pm 12$ ms $(9 \%, P<0.05)$. The LV MAPD prolonged from $191 \pm 8$ to $213 \pm 9 \mathrm{~ms}(10 \% ; P<$ $0.05)$ whereas the RV MAPD remained unchanged ( $181 \pm 9$ to $197 \pm 7 \mathrm{~ms} ; P=\mathrm{NS}$ ), leaving the interventricular dispersion of repolarization unaltered.

Cumulative doses of $0.5,1.0$, and $2.0 \mathrm{mg} / \mathrm{kg}$ sertindole $(30$-minutes interval) were administered to six other dogs. Plasma concentrations ranged from $0.5 \pm$ $0.2 \mu \mathrm{M}$ after $0.5 \mathrm{mg} / \mathrm{kg}$ to $3.1 \pm 0.3 \mu \mathrm{M}$ after $2.0 \mathrm{mg} / \mathrm{kg}$. Twenty-four hours after the high dose-range experiments the mean plasma concentration was $269 \pm 31$ nM. All high doses produced significant $Q T_{\mathrm{c}}$ increases (Figure 6) with a maximal QT prolongation from $294 \pm 8$ to $326 \pm 19 \mathrm{~ms}(11 \% ; P<0.05)$ after $2.0 \mathrm{mg} / \mathrm{kg}$ sertindole. This involved a QT prolongation from $251 \pm 10$ to $289 \pm 24 \mathrm{~ms}$ ( $15 \% ; P$ $<0.05$ ), whereas RR interval remained unchanged. LV MAPD increased from 214 \pm 11 to $264 \pm 28 \mathrm{~ms}(23 \% ; P<0.05)$ and RV MAPD from $208 \pm 11$ to $242 \pm 22 \mathrm{~ms}$ $(16 \% ; P<0.05)$. The interventricular dispersion of repolarization was not changed $(8 \pm 2$ to $20 \pm 12 \mathrm{~ms} ; P=\mathrm{NS})$.

Sertindole induced no changes in the PQ interval or QRS duration. Apart from the QT prolongation, no major changes were seen in the T-wave morphology at low or high doses of administration (Figure 5).

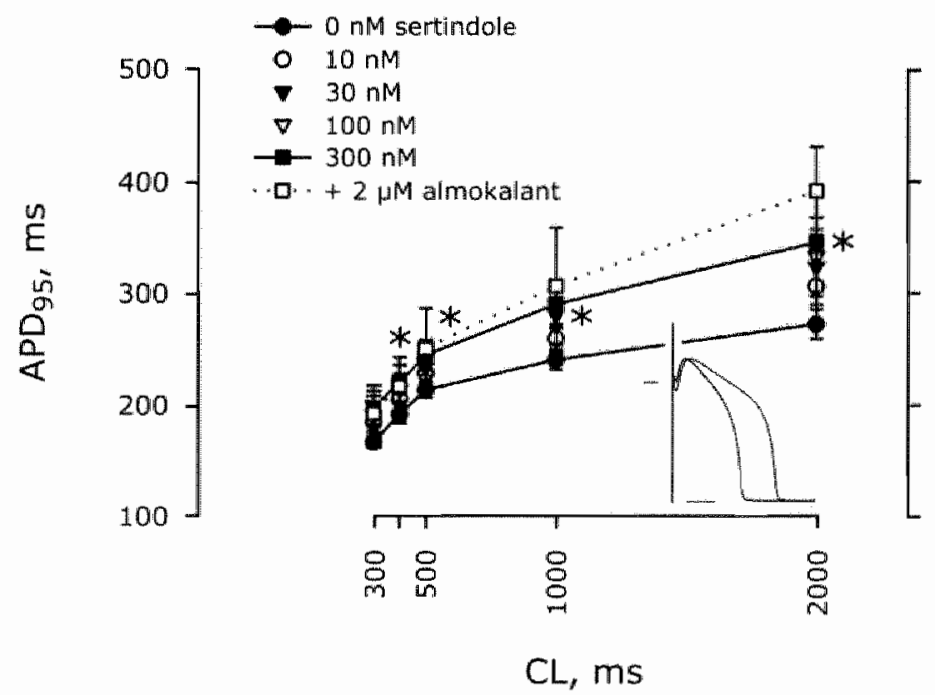

\section{Figure 4}

Transmembrane $\mathrm{APD}_{45}$ during sertindole treatment. Concentrations used were $10,30,100$, and $300 \mathrm{nM}$. Pacing $\mathrm{CL}$ of $300,400,500,1000$, and $2000 \mathrm{~ms}$ were applied. Left and right vertical axes are identical. *, $P<0.05,100$, and $300 \mathrm{nM}$ versus control, $n_{\text {cenls }}=9$. Inset, representative action potentials at control and during $300 \mathrm{nM}$ sertindole, $\mathrm{CL}=2000 \mathrm{~ms}(0 \mathrm{mV}$ level indicated; scale bar, $100 \mathrm{~ms}$ at $-80 \mathrm{mV}$. 


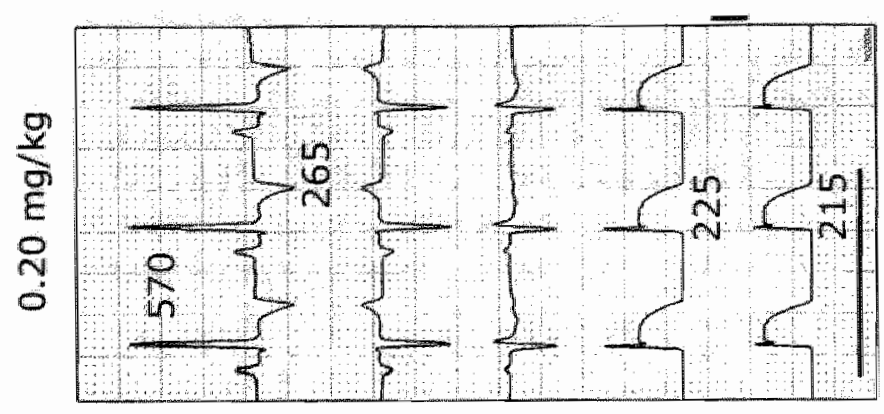

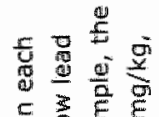

동

동

은

皆

क 50

喜 둥

马ुำ

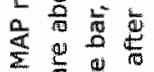

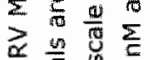

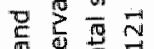

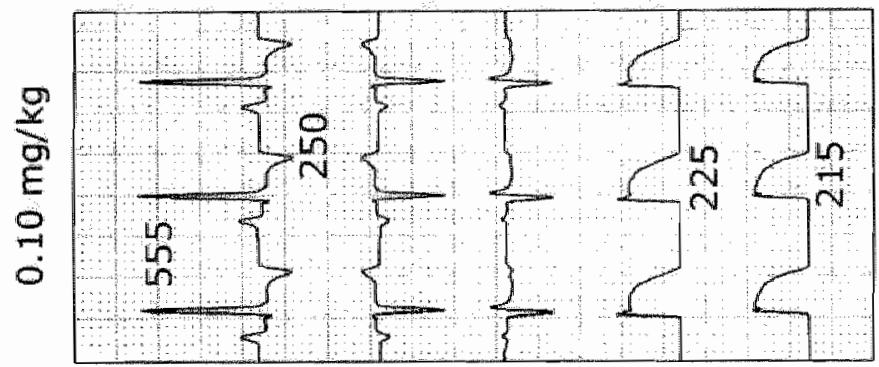

3 돈

in $\frac{\alpha}{\alpha}$ 눙

通的

乌 5 당

4)

造站造

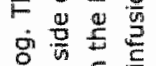

눈

E

E 0

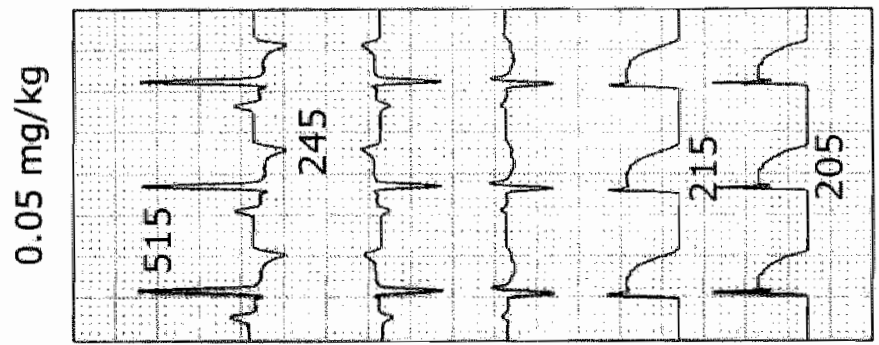

品它点

总要虽

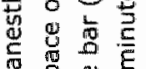

要需

드의

잉

总豆焉

竞㕿

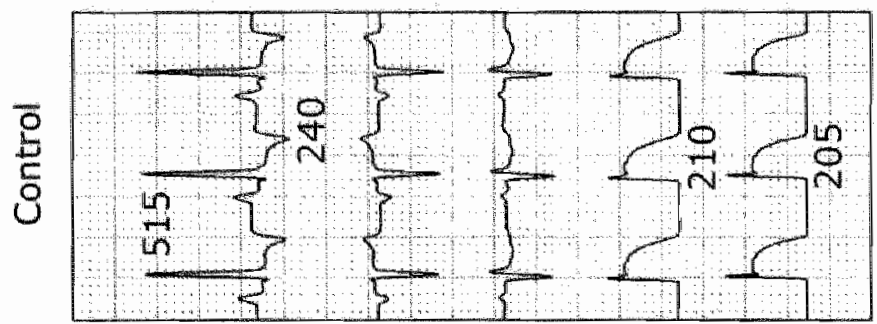

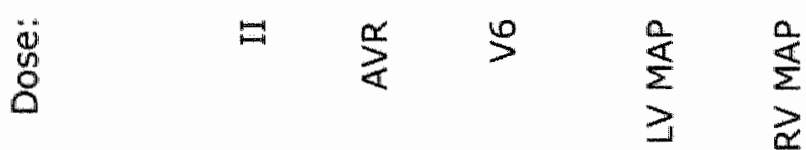

点获

岩 .5

过

热

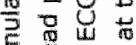

至 $\frac{0}{\mathrm{\sigma}}$

만

4)

(4)

$\frac{11}{8} 0.5$

苟

눈

纱

的立

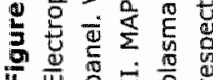




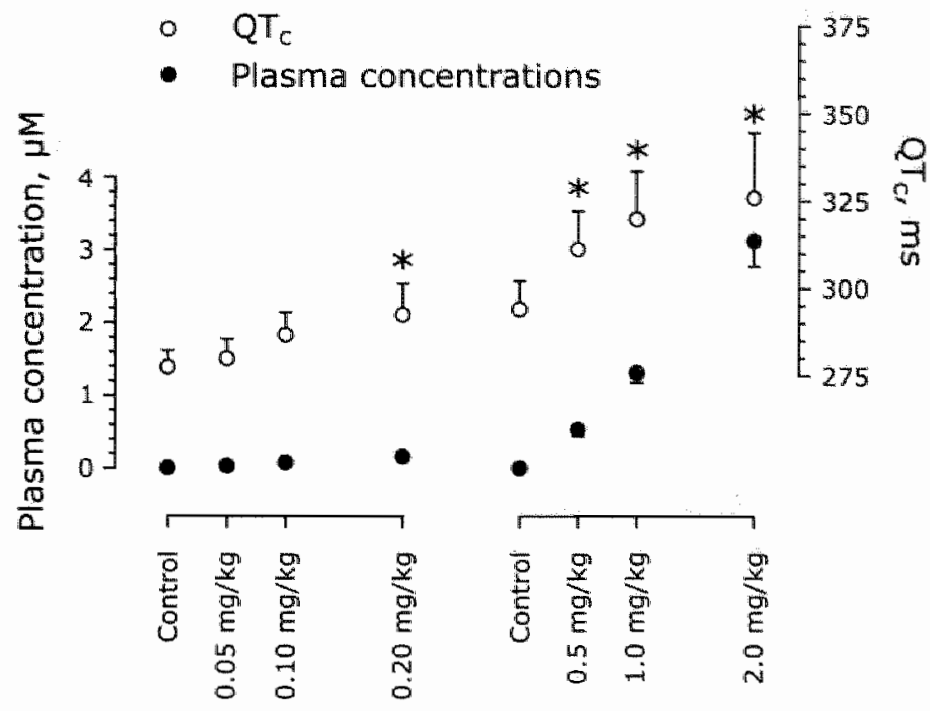

\section{Figure 6}

Relation between $\mathrm{QT}_{c}$ intervals and plasma concentrations of sertindole in anesthetized normal dogs. Curmulative doses of sertindole were administered $i . v$. as indicated $\left(n_{\text {low doses }}=5\right.$ dogs, $n_{\text {high toses }}=6$ dogs). Plasma samples were obtained 10 minutes after start of drug infusion at each dose. *, $P<0.05$ versus respective $Q T_{c}$ at control.

\section{Sertindole carries a proarrhythmic risk in electrically remodeled hearts}

Ten dofetilide-susceptible CAVB dogs received sertindole. In five animals 0.10 $\mathrm{mg} / \mathrm{kg}$ was administered, followed by another $0.20 \mathrm{mg} / \mathrm{kg}$ after 30 minutes. The $\mathrm{QT}_{\mathrm{c}}$ interval prolonged more than in normal dogs (e.g., $20 \%$ after $0.20 \mathrm{mg} / \mathrm{kg}$ in CAVB dogs versus $5 \%$ in normal dogs). Electrophysiological data from these experiments are summarized in Table 1. The five other dogs were tested with 1.0 $\mathrm{mg} / \mathrm{kg}$ sertindole (Table 1). Sertindole prolonged repolarization in a dose-dependent manner, whereas the $C L$ of the idioventricular rhythm only increased at the high dose (Table 1). The high dose of sertindole caused reproducible TdP in three of five dogs (Figure 7). In these three animals, the first TdP was seen on average $7 \mathrm{t}$ 2 minutes after start of the $1.0 \mathrm{mg} / \mathrm{kg}$ sertindole infusion (range 6 to 9 minutes). The two dogs not responding with TdP received another $1.0 \mathrm{mg} / \mathrm{kg}$, which caused $\mathrm{TdP}$ in one dog. During the 1-hour observation period after $1.0 \mathrm{mg} / \mathrm{kg}$ sertindole, a total of $19 \mathrm{TdP}\left(6 \pm 2, \mathrm{n}_{\mathrm{dogs}}=3\right)$ were seen of which four TdP had to be cardioverted electrically. Single ectopic beats (16 \pm 9 ) occurred in all dogs at high dosing, while multiple ectopic beats $(5 \pm 2)$ were seen in four dogs. Interventricular dispersion of repolarization tended to increase, e.g., from $45 \pm 6$ to $79 \pm 19 \mathrm{~ms}$ at $1.0 \mathrm{mg} / \mathrm{kg}(P=$ 0.09). 

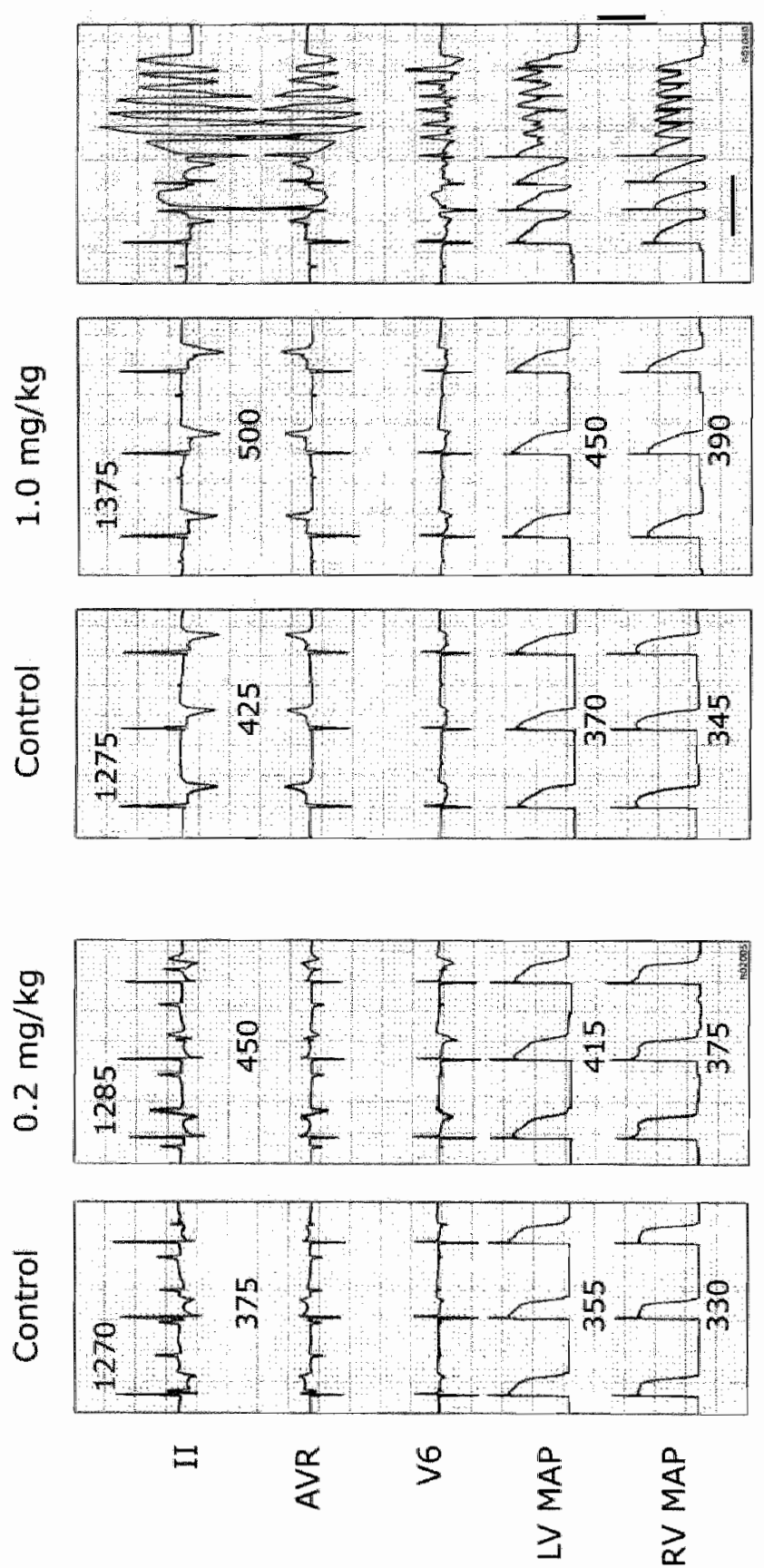

造 $\frac{a}{2}$

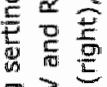

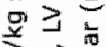

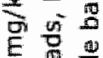

0 응

-i u u

क

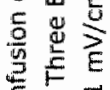

is

8

in

过 焉

亭

屯

荡 $\overline{\bar{\sigma}}$

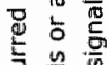

照

岁要

产

t

至

$\pm$

点 部

은

농

g் 豆

क

30

\&

gi

ㄷำ

莸

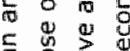

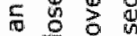

E

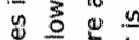

的

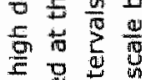

胳是

늠 $\frac{1}{\alpha}$

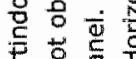

임

古等点

뜨. 요

粞

$n$ 焉要这

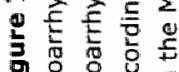

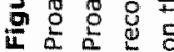


A

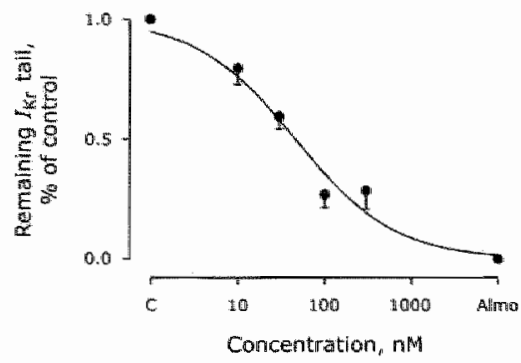

C

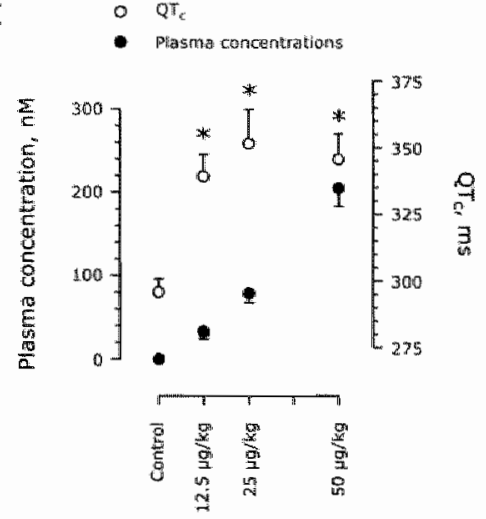

B

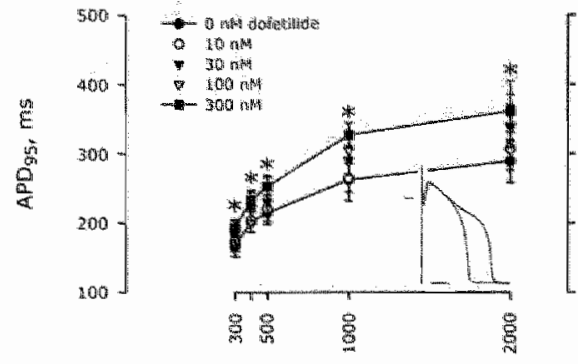

CL, Hits

\begin{tabular}{|c|c|c|c|}
\hline \multicolumn{2}{|r|}{ Contral } & $25 \mathrm{~kg} / \mathrm{kg}$ dofedide & \multirow{2}{*}{$\frac{86}{(15)}$} \\
\hline$R R$ & $1259 \pm 164$ & $1443 \pm 204 *$ & \\
\hline $\mathrm{QT}$ & $414 \pm 41$ & $523 \pm 52^{4}$ & $(26)$ \\
\hline $\mathrm{QT}_{\mathrm{s}}$ & $391 \pm 37$ & 485 is $54^{*}$ & $(24)$ \\
\hline LW & $357 \pm 37$ & $462 \pm 46^{\prime \prime}$ & $(29)$ \\
\hline RV & $306 \pm 37$ & $382 \pm 60^{\circ}$ & $(25)$ \\
\hline$\triangle M A P D$ & 51 业 23 & 60 斗 41 & $(50)$ \\
\hline Singles & & $38 \pm 2$ & \\
\hline Multipless & & 22 生 15 & \\
\hline TdP & & $12 \pm 4$ & \\
\hline Shockes & & $2 \pm 1$ & \\
\hline Time to: & rdp, min & $4 \geq 1$ & \\
\hline Throe to $\mathrm{i}$ & tervention, min & $16 \pm 5$ & \\
\hline
\end{tabular}

\section{Figure 8}

Electrophysiological data on the positive reference compound dofetilide.

A: Concentration-response curve of the inhibition of $I_{\mathrm{Kr}}$ talls by dofetilide in normall canine ventricular myocytes (IC $C_{50}$ value $46 \pm 9$; Hill coefficient, 0.76 ; mean $C_{\mathrm{min}}=180 \pm 11 \mathrm{pF}$; $\mathrm{n}_{\mathrm{cow}}$ $=9$ ). Almokalant (Almo; $2 \mu \mathrm{M}$ ) was used for full block of $I_{\mathrm{Kr}}$

B: Transmembrane $\mathrm{APD}_{95}$ upon increasing concentrations of dofetilide. $*, P<0.05,100$, and $300 \mathrm{nM}$ versus control, $\mathrm{n}_{\text {ceils }}=5$. Vertical axes are identical. Iriset shows two representative action potentials, at control and during $300 \mathrm{nM}$ dofetilide, $\mathrm{CL}=2000 \mathrm{~ms}$ (scale bar, $100 \mathrm{~ms}$ at $-80 \mathrm{mV}, \mathrm{o} \mathrm{mV}$ level indicated).

C: $Q T_{c}$ prolongation by increasing doses of dofetilide $\mathrm{i} v \mathrm{v}$, to six anesthetized normal dogs and corresponding plasma concentrations. *, $P<0.05$ versus control $Q \mathrm{~T}_{\varepsilon}$. For comparison, plasma concentrations after oral administration to humans are 5 to $23 \mathrm{nM}$ (plasma protein binding, $60-70 \%$; volume of distribution, $31 / \mathrm{kg}{ }^{33}$ ).

D: Electrophysiological effects of $25 \mu \mathrm{g} / \mathrm{kg}$ dofetilide i.v. to the 10 anesthetized dogs with CAVB that were TdP-inducible and used for sertindole testing. Values in milliseconds and percentage increases in brackets. ${ }^{*}, P<0.05$ versus control. Singles and multiples, numbers of single and multiple ventricular ectopic beats. TdP and shocks, number of TdP and electrical cardioversions. Times after start of dofetilide infusion. 


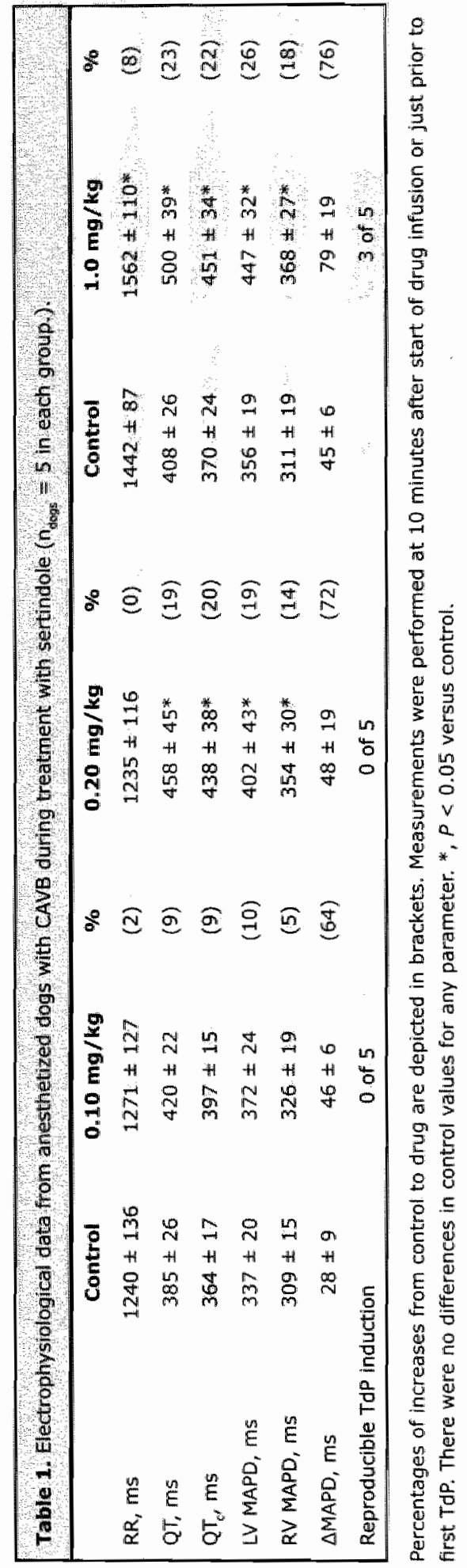


Concentration-response studies of dofetilide on $I_{\mathrm{K}}$ in native ventricular myocytes revealed an $\mathrm{IC}_{39}$ of $46 \pm 9 \mathrm{nM}$ (Figure $8 \mathrm{~A}$ ). Prolongation of TAP in the myocytes was reverse rate-dependent (Figure $8 \mathrm{~B}$ ). In normal anesthetized dogs, i.v. doses of $12.5,25$, and $50 \mu \mathrm{g} / \mathrm{kg}$ dofetilide ${ }^{19}$ caused significant $\mathrm{QT}_{\varepsilon}$ prolongation (19\% to $25 \%$; $P<0.05$ versus control; Figure $8 \mathrm{C}$ ). RR also increased, e.g., by $13 \%$ after $12.5 \mu \mathrm{g} /$ $\mathrm{kg}(P<0.05$ versus control). Plasma concentrations of dofetilide are given in Figure 8 C. Dofetilide $(25 \mu \mathrm{g} / \mathrm{kg})$ induced TdP in 10 of 13 anesthetized CAVB dogs (Figure $8 \mathrm{D}$ for $\mathrm{n}_{\mathrm{dog} s}=10$ used for sertindole testing in vivo).

\section{Discussion}

The present study investigates the electrophysiological properties of sertindole from cloned cardiac ion channels to anesthetized dogs with normal and remodeled hearts. The results can be summarized as follows: 1) Sertindole is a selective blocker of $I_{\text {HERG }}$ over other ion currents expressed in cell cultures. 2) Sertindole causes concentration-dependent block of native $I_{\mathrm{Kr}}$ and this translates into reverserate dependent lengthening of myocyte action potentials. 3) In anesthetized dogs, dose-dependent prolongation of in vivo repolarization by sertindole is observed. 4) Clinically relevant doses of sertindole do not cause $\mathrm{TdP}$ in anesthetized normal dogs or in CAVB animals with reproducible induction of TdP by dofetilide in previous experiments. 5) High doses of sertindole induce multiple ectopic beats and TdP in the majority of these CAVB dogs.

\section{Normal and remodeled hearts}

To elucidate whether a drug is devoid of proarrhythmic properties, a reproducible animal model is essential. Testing drugs in normal hearts is necessary, but is not sufficient for the recognition of proarrhythmic effects in the diseased heart. We used the canine model with $\mathrm{CAVB}$, known to have acquired QT prolongation. Creation of CAVB results in a bradycardia-induced volume overload. Hypertrophy is observed in ventricular myocytes ${ }^{22}$ as well as in the whole heart. ${ }^{23.24}$ Contractile remodeling in vivo restores initially-depressed cardiac output (compensated function), which is associated with an increased cytosolic $\mathrm{Ca}^{2+}$ transient in vitro. ${ }^{25.26}$ Downregulation of $I_{\mathrm{Ks}}$ and $I_{\mathrm{Kr}}{ }^{27,28}$ and upregulation of the sodium-calcium exchanger ${ }^{26}$ contribute to the electrical alterations in remodeled CAVB hearts. This ventricular remodeling 
predisposes to TdP and sudden cardiac death. ${ }^{29}$

Whereas most class III antiarnythmic dnugs cause $\mathrm{TdP}$ in 2 to $5 \%$ of patients, ${ }^{12}$ an incidence in the order of $56-67 \%$ is encountered in anesthetized CAVB dogs, making the model very sensitive. ${ }^{10 \%}$ In the present study, the non-cardiovascular drug sertindole was tested in a number of different ways and using a broad dose regimen. Based on earlier clinical reports of low proarrhythmia of sertindole in patients $\left(0.3 \%\right.$ carduac mortality rate or $\sim 10 \%$ of anti-arrhythmic drugs $\left.{ }^{31}\right)$, we anticipated a low TdP incidence in the CAVB dog. Serial testing in this model has shown reproducible induction of TdP. J Therefore, we chose to increase the sensitivity of the model and to evaluate the proarrhythmia of sertindole only in dogs that showed reproducible TdP after administration of $25 \mu \mathrm{g} / \mathrm{kg}$ dofetilide.

\section{Cardiac safey of sertindole}

This is the first report on sertindole, in which both in vitro and in vivo investigations are combined. Sertindole caused prolongation of repolarization in both normal and CAVB dogs, although at variable degree, e.g., at $0.20 \mathrm{mg} / \mathrm{kg}, \mathrm{QT}$, interval increased by up to $5 \%$ in normal hearts and up to $20 \%$ in CAVB dogs. The plasma concentrations measured in dogs in this study at the low doses were comparable with plasma concentrations from human volunteers ( 4 to $20 \mathrm{mg} /$ day sertindole p.o., range from $22 \pm 12$ to $158 \pm 63 \mathrm{nM}^{21}$ ). These doses did mot cause $\mathrm{TdP}$ in dofetilide-sensitive CAVB dogs. Administration of $25 \mu \mathrm{g} / \mathrm{kg}$ dofetilide led to a plasma concentration of $79 \pm \rrbracket 1 \mathrm{nM}$. Reported plasma concentrations from human volunteers receiving dofetilide ranged from 5 to $23 \mathrm{nM}^{33}$

Eckardt et al. reported a low torsadogenic potential of sertindole in isolated rabbit hearts. "They showed a 15 to $17 \%$ prolongation of the QT interval at a perfusion concentration of $\mathbb{1} .5 \mu \mathrm{M}$ sertindole without induction of TdP. In the present investigation in anesthetized dogs with nomal hearts, $9 \%$ prolongation of the QT interval was observed at $1.3 \pm 0 . \Perp \mu \mathrm{M}$. No TdP was observed, confirming the results from Eckardt et al. ${ }^{16}$ Plasmat protein binding in vivo and unknown levels of accumulation in cardiac tissue complicate comparisons between these models. Relating plasma concentrations to concentrations employed in the in vitro setting can only be done with great caution. Among the factors to be taken into account are plasma protein binding, tissue accumulation and the distance between the plasma protein and the receptor on the cardiomyocyte in situ. Plasma protein binding of sertindole in humans is high $\left(>99 \% \%^{34}\right)$, indicating a free plasma concentration of maximally 1 to $2 \mathrm{nM}$ after therapeutic administration, based on the plasma concentrations in human volunteers." The level of accumulation in cardiac tissue 
is unknown, but a rather large volume of distribution is reported $\left(20-401 / \mathrm{kg}^{\text {tad }}\right)$, indicating accumulation of sertindole in various tissues. In our dogs, maximal QT prolongation was already seen 5 to 10 minutes after the start of infusion of sertindole, suggesting a rapid inhibition of $I_{\mathrm{Kr}}$ once the drug is present in the circulation. The relative $I_{\mathrm{K},}$ block induced by sertindole in vivo or in the clinic could be underestimated when plasma concentrations are compared to in vitro concentrations.

Apart from an inhibition of $\mathrm{K}_{\mathrm{K},}$, sertindole has also been reported to block the human dopamine $\mathrm{D}_{2}$ and the 5-hydroxytryptamine ${ }_{2 \mathrm{~A}}$ receptors. ${ }^{5}$ It does also show $\alpha_{1 . A}$-blocking properties in rat mesenteric arteries. ${ }^{7}$ New studies are required to test possible additional electrophysiological properties of sertindole in the heart under conditions when physiological levels of these agonists are present.

\section{Pharmacological implications}

Previous studies using chronic amiodarone administration have shown that TdP can be absent in CAVB dogs despite prolongation of the $\mathrm{QT}_{\mathrm{c}}$ interval by $21 \%{ }^{3.5}$ The present study indicates again a poor association between the degree of $Q T$. prolongation and the incidence of TdP (Table 1): at a comparable QT after 0.2 and $1.0 \mathrm{mg} / \mathrm{kg}$ sertindole, TdP were only induced after the higher dose. This stresses not only the importance of testing several doses when assessing the proarrhythmic potential of a drug but also the relevance of addressing other proarrhythmic factors like ectopic beats and dispersion.

If our in vitro data from cell cultures and isolated canine myocytes would have determined the future for sertindole, the drug would have likely been abandoned from further development (e.g., based on the recommendations of the Policy Conference of the European Society of Cardiology $y^{12}$ ). The expansion of our study to in vivo testing showed a discrepancy between the in vitro finding of $l_{K, r}$ inhibition and prolonged cellular repolarization and the absence of arrhythmias in normal anesthetized dogs. Our data strongly advocate the use of pathological animal models when testing for proarrhythmic properties of cardiovascular and noncardiovascular drugs.

A recent risk-benefit analysis of the preclinical and clinical data on sertindole by the European Committee for Proprietary Medicinal Products led to the reintroduction of sertindole to the European market in 2002. 


\section{Limitations}

Steady-state plasma concentrations were not obtained in this study, as opposed to previous clinical studies, and the phatmacokinetic difference between acute i.w. and reperated oral dosing should be considered when extrapolating our data to humans. Differences in accumulated tissue concentrations after acute i.v. versus chronic oral administration will likely exist. Furthermore, species differences between dogs and patients should be taken into account.

\section{Conclusions}

In vitro studies clearly show sertindole's selective inhibition of $I_{\text {HERG }}$ over other ion currents. Block of native $I_{\mathrm{Kr}}$ forms the ionic basis for action potential prolongation in canine ventricular myocytes and QT prolongation in vivo. At high i.v. doses, sertindole can pose a serious proarrhythmic risk when electrical remodeling of the ventricles is present, as in dogs with CAVB. At clinically relevant doses, sertindole does not cause TdP in anesthetized dogs with normal or remodeled hearts.

\section{Acknowledgments}

We thank Lone Durup, Pia Maribo Sorensen, and Vivian Lind for technical assistance and skills. Also, the efforts of Anne Reschkewitz, Jens-Jakob Karlsson, and Tina Dige to develop a plasma analysis method and measure sertindole and dofetilide concentrations in dog plasma are greatly appreciated. Dr. Rainer Netzer is acknowledged for providing the HERG and the KCNQ1/KCNE1 cell lines from GENION Forschungsgesellschaft (Hamburg, Germany). Paul G. A. Volders was supported by The Netherlands Organization for Health Research and Development (ZonMw 906-02-068). 


\section{References}

1. WHO. The World Report 2001. Mental Unit: New Understanding, New Hope In; 2001:

2. Oehl M, Hummer M, Fleischhacker WW. Compliance with antipsychotic treatment. Acta Psychiatr Scand Suppl. 2000;102:83-86.

3. Hale AS, Azorin J, Kasper S, Maier W, Syvalahti E, Van Der Burght M, SlothNielsen $M$, Wehnert A. Sertindole improves both the positive and negativa symptoms of schizophrenia: Results of a phase III trial. International Joumal of Psychiaty in Clinical Practice. 2000;4:55-62.

4. Zimbroff DL, Kane JM, Tamminga CA, Daniel DG, Mack RJ, Wozniak PJ, Sebree TB, Wallin BA, Kashikin KB. Controlled, dose-response study of sertindole and haloperidol in the treatment of schizophrenia. Sertindole Study Group. Am J Psychiarry. 1997; 154:782-91.

5. Amt J. Pharmacological differentiation of classical and novel antipsychotics. Int Clin Psychopharmacol. 1998;13 Suppl 3:S7-14.

6. Bigliani V, Mulligan RS, Acton PD, Ohlsen RI, Pike VW, Ell PJ, Gacinovic S, Kerwin RW, Pilowsky LS. Striatal and temporal cortical D2/D3 receptor occupancy by olanzapine and sertindole in vivo: a [123I].]epidepride single photon emission tomography (SPET) study. Psychopharmacology (Berl). 2000;150;132-140.

7. Ipsen $M$, Zhang $Y$, Dragsted N, Han $C$, Mulvany MJ. The antipsychotic drug sertindole is a specific inhibitor of alpha $1 \mathrm{~A}$ - adrenoceptors in rat mesenteric simall arteries. Eut $J$ Pharmacol. 1997;336:29-35.

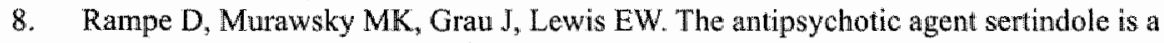
high affinity antagonist of the human cardiac potassium channel HERG. J Pharmacol Exp Ther. 1998;286:788-93.

9. Haverkamp W, Eckardt L, Matz $\mathrm{J}_{3}$ Frederiksen K. Sertindole: cardiac electrophysiological profile. International Jownal of Psychiatry in Clinical Practice. $2002 ; 6: S 11-\mathrm{S} 20$.

10. Kongsamut S, Kang J, Chen X, Roehr J, Rampe D. A comparison of the receptor binding and HERG channel affinities for a series of antipsychotic drugs. Eur $J$ Phammacol. 2002;450:37.

11. Frederiksen $\mathrm{K}$, Adamantidis MM. The atypical neuroleptic compound sertindole does not induce EADs in rabbit Purkinje fibers despite a strong blocking effect of the HERG current (IKr): Comparison to other neuroleptic compounds (abstract). Soc. Neuroscience Abstr: 2000;26:897.

12. Haverkamp W, Breithardt G, Camm AJ, Janse MJ, Rosen MR, Antzelevitch C, Escande D. Franz M, Malik M, Moss A, Shah R. The potential for QT prolongation and proarrhythmia by non-anti arrhythmic drugs: clinical and regulatory implications. Report on a Policy Conference of the European Society of Cardiology. Cardiovasc Res. 2000;47:219-33.

13. Moore $N$. Higher cardiovascular mortality with sertindole in ADROIT: a signal not confirmed. International Joumal of Psychiatry in Clinical Practice. 2002;6:S3-S9.

14. Kasper S, Quiner S, Pezawas L. A review of the benefit:risk profile of sertindole. International Joumal of Psychiatwy in Clinical Practice. 1998;2:59-s64.

15. Drici MD, Wang WX, Liu XK, Woosley RL, Flockhart DA. Prolongation of QT interval in isolated feline hearts by antipsychotic drugs. J CIm Psychopharmacol. $1998 ; 18: 477-81$.

16. Eckardt L, Breithardt $\mathrm{G}$, Haverkamp W. Electrophysiologic characterization of the antipsychotic drug sertindole in a rabbit heart model of torsade de pointes: low torsadogenic potential despite QT prolongation. I Phamacol Exp Ther, 2002;300:64-71

17. Toumi M. Post-marketing surveillance of sertindole. International Journal of Psychiary in Clinical Practice. 2002;6:S33-\$35.

18. Carmeliet E. Use-dependent block and use-dependent unblock of the delayed rectifier $\mathrm{K}+$ current by almokalant in rabbit ventricular myocytes. Circ Res. 1993;73:857-68. 
19. Van Opstal JM, Leunissen JD, Wellens HJ, Vos MA. Azimilide and dofetilide produce similar electrophysiological and proarrhythmic effects in a canine model of Torsade de Pointes arrhythnias. Eur J Phamacol. 2001:412:67-76.

20. Van de Water $A$, Verheyen $J$, Xhonnewx $R$, Reneman $R S$. An improved method to correct the QT interval of the electrocardiogram for changes in heart rate. $J$ Phamacol Methods. 1989;22:207-17.

21. Wong $\mathrm{SL}$, Granneman CR. Modeling of sertindole pharmacokinetic disposition in healthy wolumters in short term dose-escalation sudies. I Pharm Sct. 1998;87:1629. 1631.

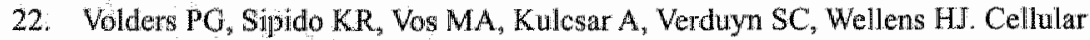
basis of biventricular hypertrophy and arthythmogenesis in dogs with chronic complete atrioveritricular block and acquired torsade de pointes. Circulation. 1998:98:1136-47.

23. Vos $\mathrm{MA}$, de Groot $\mathrm{SH}$, Verduyn $\mathrm{SC}$, van der Zande I, Leunissen $\mathrm{HD}$, Cleutjens $\mathrm{J}$, van Bilsen M, Daemen MJ, Schreuder JJ, Allessie MA, Wellens HJ. Enhanced susceptibility for acquired torade de pointes arrhythmias in the dog with chronic, complete AV block is related to cardiac hypertrophy and electrical remodeling. Circulation. 1998;98:112535 .

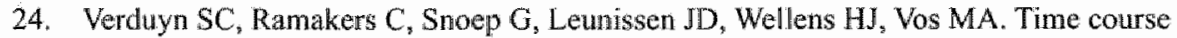
of structural adaptations in chronic AV block dogs: evidence for differentiall ventricular remodeling. Am I Physiol Heart Circ Physiol. 2001;280:H2882-H2890.

25. de Groot SH, Schoenmakers $M$, Molenschot MM, Leunissen JD, Wellens HJ, Vos MA. Contractile adaptations preserving cardiac output predispose the hypertrophied canine heart to delayed afterdepolarization-dependent ventricular arrhythmias. Circulation. 2000;102:2145-2151.

26. Sipido KR, Volders PG, de Groot $S H$, Verdonck F, Van de Werf $F$, Wellens HJ, Vos MA. Enhanced $\mathrm{Ca}(2+)$ release and $\mathrm{Na} / \mathrm{Ca}$ exchange activity in hypertrophied canine ventricular myocytes: potential link between contractile adaptation and arrhythmogenesis. Circulation. 2000;102:2137-44.

27. Volders PG, Sipido KR, Vos MA, Spatjens RL, Leunissen JD, Carmeliet E, Wellens HJ. Downregulation of delayed rectifier $\mathrm{K}(+)$ currents in dogs with chronic complete atrioventricular block and acquired torsades de pointes. Circulation. 1999;100:2455-61.

28. Ramakers C, Vos MA, Doevendans PA, Schoenmakers M, Wu YS, Scicchitano S, lodice A, Thomas GP, Antzelevitch C, Dumaine R. Coordinated down-regulation of $\mathrm{KCNQI}$ and $\mathrm{KCNE} I$ expression contributes to reduction of I(Ks) in canine hypertrophied hearts. Cardiovasc Res, 2003;57:486-496.

29. van Opstal JM, Verduyn SC, Leunissen HDM, de Groot SHM, Wellens HJJ, Vos MA. Fectrophysiological parameters indicative of sudden cardiac death in the dog with chronic complete AV-block. Cardionascular Research 2001;50:354-361.

30. Verduy $\mathrm{SC}$, Vos $\mathrm{MA}$, van der Zande J, Kulcsar $\mathrm{A}$, Wellens HJ. Further observations to elucidate the role of interventricular dispersion of repolarization and early afterdepolarizations in the genesis of acquired torsade de pointes arrhythmias: a comparison between almokalant and d-sotalol using the dog as its own control. $J \mathrm{Am}$ Coll Cardiol. 1997;30:1575-84.

31. Kasper S. Sertindole: safety and tolerability profile. Intermational Joumal of Psychiary in Clinical Practice, 2002;6:S27-S32.

32. Verduyn SC, van Opstal JM, Leunissen JD, Vos MA. Assessment of the pro-arrhythmic potential of anti-arrhythmic drugs: an experimental approach. $J$ Cardiovasc Pharmacol Ther. 2001:6:89-97.

33. Pfizer. Tikosyn (dofetilide) Capsules. In: U.S. Prescribing Information; 1999.

34. Ereshefsky L. Pharmacokinetics and drug interactions: update for new antipsychotics. $J$ Clin Psychiatmy, 1996;57:12-25.

35. Van Opstal IM, Schoenmakers M, Verduyn SC, de Groot SH, Leunissen JD, Der Hulst FF, Molenschot MM, Wellens HJ, vos MA. Chronic Amiodarone Evokes No Torsade de Pointes Arrhythmias Despite QT Lengthening in an Animal Model of Acquired LongQT Syndrome. Cirtulation. 2001;104:2722-2727. 


\section{Increased Short-Term Variability of Repolarization Predicts $d$-Sotalol-Induced Torsades de Pointes in Dogs}

Morten B. Thomsen ${ }^{1,2}$, S. Cora Verduyn', Milan Steng1 ${ }^{1,2}$, Jet D.M. Beekmann ${ }^{1,2}$, Geert de Pater', Jurren wan Opstal', Paul G.A. Volders' and Marc A. Vos ${ }^{1,2}$

1. Department of Cardiology, Cardiovascular Research Institute Maastricht, Academic Hospital Maastricht, Netherlands.

2. Department of Medical Physiology, University Medical Center Utrecht,University of Utrecht, Netherlands. 


\section{Abstract}

Identification of patients at risk for drug-induced torsades de pointes arrhythmia (TdP) is difficult. Increased temporal lability of repolarization has been suggested as valuable to predict proarrhythmia. The predictive value of different repolarization parameters, including beat-to-beat variability of repolarization (BVR), was compared in this serial investigation in dogs with chronic AV block.

In anesthetized dogs with electrically remodeled hearts, the dose-dependent difference in drug-induced TdP ( $d$-sotalol, 2 and $4 \mathrm{mg} / \mathrm{kg}$ i.v. over 5 minutes, $25 \%$ and $75 \% \mathrm{TdP}$, respectively) could not be accounted for by prolongation of $\mathrm{QT}_{\mathrm{c}}(410$ \pm 37 to $475 \pm 60$ versus $415 \pm 47$ to $484 \pm 52 \mathrm{~ms}$, respectively). BVR was quantified by Poincaré plots at baseline and immediately before onset of $d$-sotalol-induced extrasystolic activity. TdP occurrence was associated with an increase in the shortterm variability (STV) of the left ventricular monophasic action potential duration ( $3.5 \pm 1.5$ to $5.5 \pm 1.6$ versus $3.0 \pm 0.7$ to $8.6 \pm 3.8 \mathrm{~ms}$, respectively), which was reversible when TdP was abolished by $I_{K, A T P}$ activation. The absence of TdP despite $\mathrm{QT}_{\mathrm{c}}$ prolongation after chronic amiodarone treatment could also be explained by an unchanged STV. In experiments with isolated ventricular myocytes, STV increased after $I_{\mathrm{Kr}}$ block and was highest in cells, which subsequently showed early afterdepolarizations.

Proarrhythmia is not related to differences in prolongation of repolarization but corresponds to BVR, here quantified as STV of the left ventricle. STV could be a new parameter to predict drug-induced $\mathrm{TdP}$ in patients. 


\section{Introduction}

Torsades de pointes arrhythmias ( $\mathrm{TdP}$ ) are repolarization dependent polymorphic ventricular tachyarrhythmias that can stop spontameously or degenerate into ventricular fibrillation causing sudden death. One of the electrophysiological hallmarks of TdP is the prolonged QT interval often regarded as an unwanted adverse effect of drugs. However, it has been argued that QT time by itself is not a sensitive parameter to predict $\mathrm{TdP}$, because similar, prolonged QT intervals may have distinct arrhythmogenic outcomes. ${ }^{0.7}$ Numerous parameters and ideas have been suggested to be more valuable, ${ }^{1,2.811}$ including the concept of diminished repolarization reserve. ${ }^{12}$ Decreased repolarization force at times of additional demand can explain the higher likelihood for TdP. For the proarrhythmic action of class-III antiarrhythmic drugs, this can be viewed as the final hit in a predisposed heart, which unchallenged functions adequately. Thus, repolarization reserve can be regarded as the ability of a heart to withstand a challenge on repolarization. Creation of chronic AV block (CAVB) in the dog results in a high susceptibility for drug-induced TdP, most likely due to electrical remodeling. ${ }^{13,14}$ In our opinion, this animal model should have a reduced repolarization reserve. In the past, the proarrhythmic potential of several different class III antiarrhythmic drugs was determined showing a comparable and prominent $\mathrm{QT}_{\mathrm{c}}$ prolongation for all drugs but a low TdP incidence after amiodarone ( $(0 \%)$ and $d$-sotalol (0 to $5 \%)$ as compared to 56 to $67 \% \mathrm{TdP}$ for other drugs tested. ${ }^{15}$ This led us to perform the present serial investigation in anesthetized CAVB dogs, where the expected dose-dependent differential TdP occurrence after $d$-sotalol was used to compare the predictive value of different repolarization parameters including beat-to-beat variability of repolarization (BVR).

\section{Methods}

Experiments were performed in eight adult mongrel dogs with CAVB (5 males). In a preliminary operation, the AV node was ablated as described previously..$^{14}$ Experiments reported here were started $>5$ weeks after ablation, which exceeded the completion of ventricular electrical remodeling and proarrhythmia. ${ }^{14}$ Under complete anesthesia (induced by sodium pentobarbital, $20 \mathrm{mg} / \mathrm{kg}$ i.v. and maintained by halothane), two monophasic action potential (MAP) catheters were advanced to the endocardium of left (LV) and right ventricle (RV). $d$-Sotalol was administered in two doses ( 2 and $4 \mathrm{mg} / \mathrm{kg}$ i.v. over 5 minutes) in a serial random crossover design 
$(2+1$ weeks between experiments). The natural sequence of events leading to druginduced TdP in CAVB dogs can be divided into two phases; (1) prolongation of repolarization and (2) occurrence of (multiple) extrasystoles, which are often but not always followed by TdP. ${ }^{3}$ Dogs were considered inducible when 3 or more episodes of TdP occurred after a dose of $d$-sotalol. The $I_{\mathrm{K}_{\mathrm{A}} \mathrm{AT}}$ opener, levcromakalim $(10 \mu \mathrm{g} / \mathrm{kg}$ i.v.) was administered in experiments with $\mathrm{TdP}$ to assess reversibility.

Transmembrane action potentials from enzymatically isolated myocytes from CAVB dogs ${ }^{16}$ were recorded (15 cells, 9 dogs). Microelectrodes $(20$ to $60 \mathrm{M} \Omega$ ) filled with $3 \mathrm{M} \mathrm{KCl}$ and pacing frequencies of $0.5-1 \mathrm{~Hz}$ were used. Action potentials were recorded under conditions of no $I_{\mathrm{K}, \mathrm{b}}$ block versus full $I_{\mathrm{K}, \mathrm{b}}$ block.

\section{Electrophysiological parameters}

Mean RR and QT intervals from lead II and duration of the two MAPs to $100 \%$ repolarization (MAPD) of 30 consecutive beats were determined. Measurements were done before $d$-sotalol administration and in a period during which prolongation of repolarization had reached a plateau but the first drug-induced extrasystole had not yet occurred. Interventricular dispersion ( $\mathrm{MAPD}=\mathrm{LV}$ minus RV MAPD) and heart rate corrected QT interval (QT, van de Water's formula) were calculated. These temporally averaged electrophysiological measurements will be referred to as EP parameters to discern them from parameters of lability.

\section{Lability parameters}

To assess $B V R$, Poincaré plots were drawn by plotting each value against the former value (Figure 1 for LV MAPD ${ }^{2,17.18}$ ). It was performed for RR and QT intervals and for LV and RV MAPD from 30 consecutive beats under stable idioventricullar focus. The areas of the plots were determined and their dimensions calculated: The mean orthogonal distance from the diagonal to the points of the Poincare plot was determined and referred to as short-term variability $\left(\mathrm{STV}=\sum \mathrm{D}_{\mathrm{n}+1}-\mathrm{D}_{13} /[30 * \sqrt{2}]\right.$, where $D$ represents the duration of $R R, Q T$ or MAP). The average distance to the mean of the parameter parallel to the diagonal $\left(\sum\left[\mathrm{D}_{n * 1}+\mathrm{D}_{\mathrm{n}}-2 \mathrm{D}_{\text {mann }} /[30 * \sqrt{2}]\right)\right.$ was regarded as the long-term variability. This nomenclature is adopted from heart-rate variability investigations using Holter monitoring of humans over several hours, in which steady changes over time tend to follow the diagonal and sudden changes (e.g. an extrasystole) result in a deviation from the diagonal. ${ }^{18}$

The QT variability index $\left(\mathrm{QTV}_{30}\right)$ as proposed by Berger et al." and instability ${ }_{30}$ as proposed by Hondeghem at a1..$^{1,2}$ were calculated for QT and for $\mathbb{L V}$ and RV MAPD. 
Because of the fast onset of extrasystolic activity, these were calculated for 30 beats only and not over the proposed 256 seconds and 3 minutes, respectively.

In addition to assessing lability of repolarization at the two time points in the $d-$ sotalol experiments, we assessed STV in data gathered in a study ${ }^{3}$ of 4 weeks of amiodarone treatment ( $40 \mathrm{mg} / \mathrm{kg} /$ day $\mathrm{p}, 0$.).

Transmembrane action potential durations to $95 \%$ repolarization were measured for 30 action potentials from isolated ventricular myocytes to calculate STV at baseline and before early afterdepolarizations (EADs) or at full $I_{\mathrm{kr}}$ block.

\section{Extrasystoles}

d-Sotalol-induced extrasystoles, defined as beats initiating before the end of the preceding $T$ wave, were counted. Discrimination was made between couplets (Figure 2A) and multiples (Figure 2B), because the latter are considered more proarthythmic. $^{15}$

\section{Statistical analysis}

Pooled data are expressed as mean \pm SD unless otherwise stated. Comparisons of EP and lability parameters were performed with a 2-way ANOVA followed by a paired Bonferroni comparison. Countables were tested with a Mann-Whitney rank sum test. Correlations were tested using Pearson product moment correlation. The area under the receiver-operator characteristics was used to assess predictive power of variables. Statistical difference was acknowledged at $P<0.05$. 
A

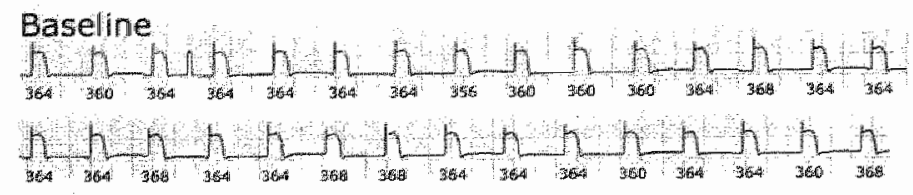

$4 \mathrm{mg} / \mathrm{kg} d-$ sotalol
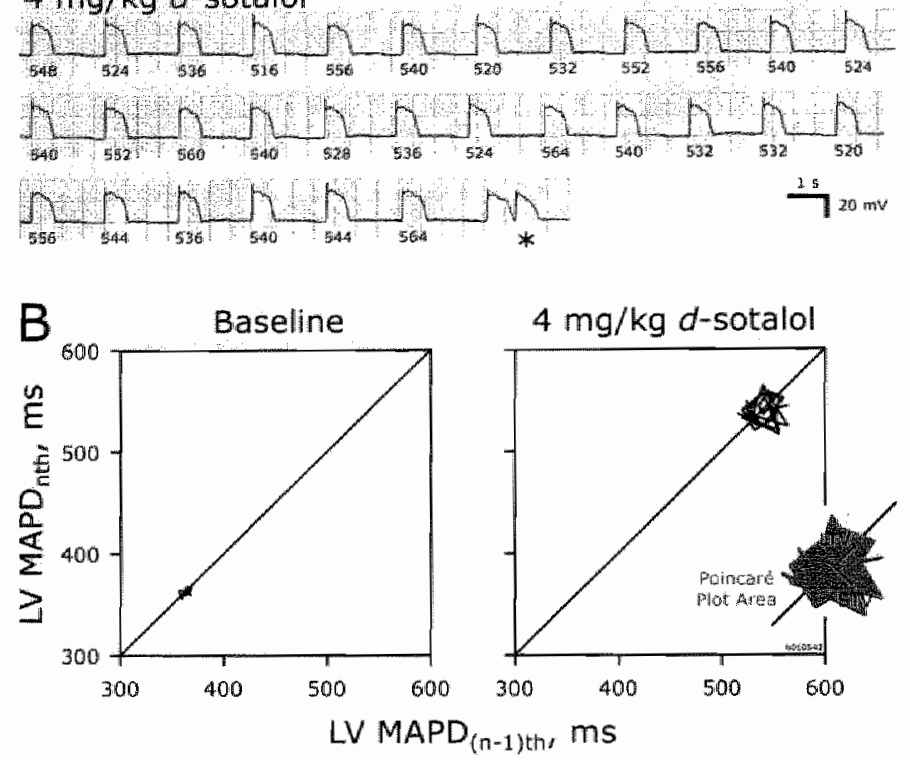

C

Baseline

d-Sotalol
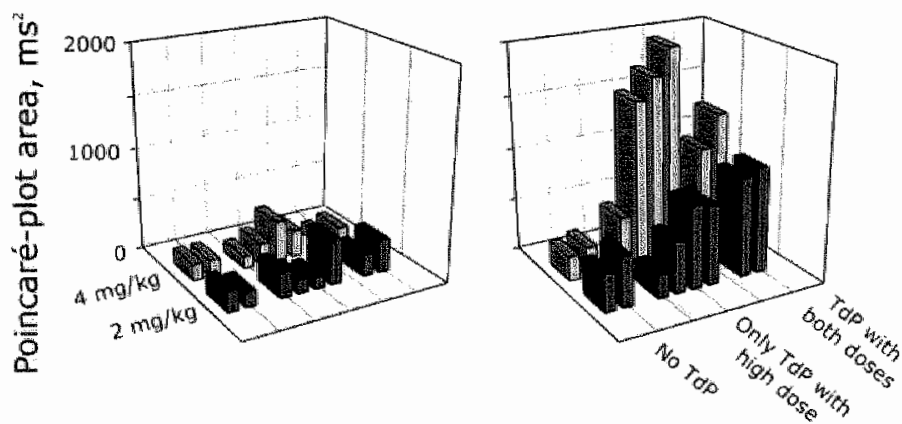

Figure 1

A: LV MAPD determination for 30 beats at baseline and after $4 \mathrm{mg} / \mathrm{kg} d$-sotalol. After administration, LV MAPD is measured just prior to the first extrasystoie (*).

B: Respective Poincare plots are shown. In association with increase in LV MAPD after d-sotalol, there is an expansion of plot area from 198 (left) to 1550 (right) $\mathrm{ms}^{2}$. Inset, schematic representation of Poincaré plot area (gray), STV and long-term variability (LTV).

C: Areas of LV MAPD Poincaré plot at baseline (left) and after $d$-sotalol (right). In each graphi, the long axis represents each of the 8 dogs grouped after their proarrhythmia, with $2 \mathrm{mg} / \mathrm{kg}$ experiments in front. Mean area is significantly larger in dogs showing $T d P$. 


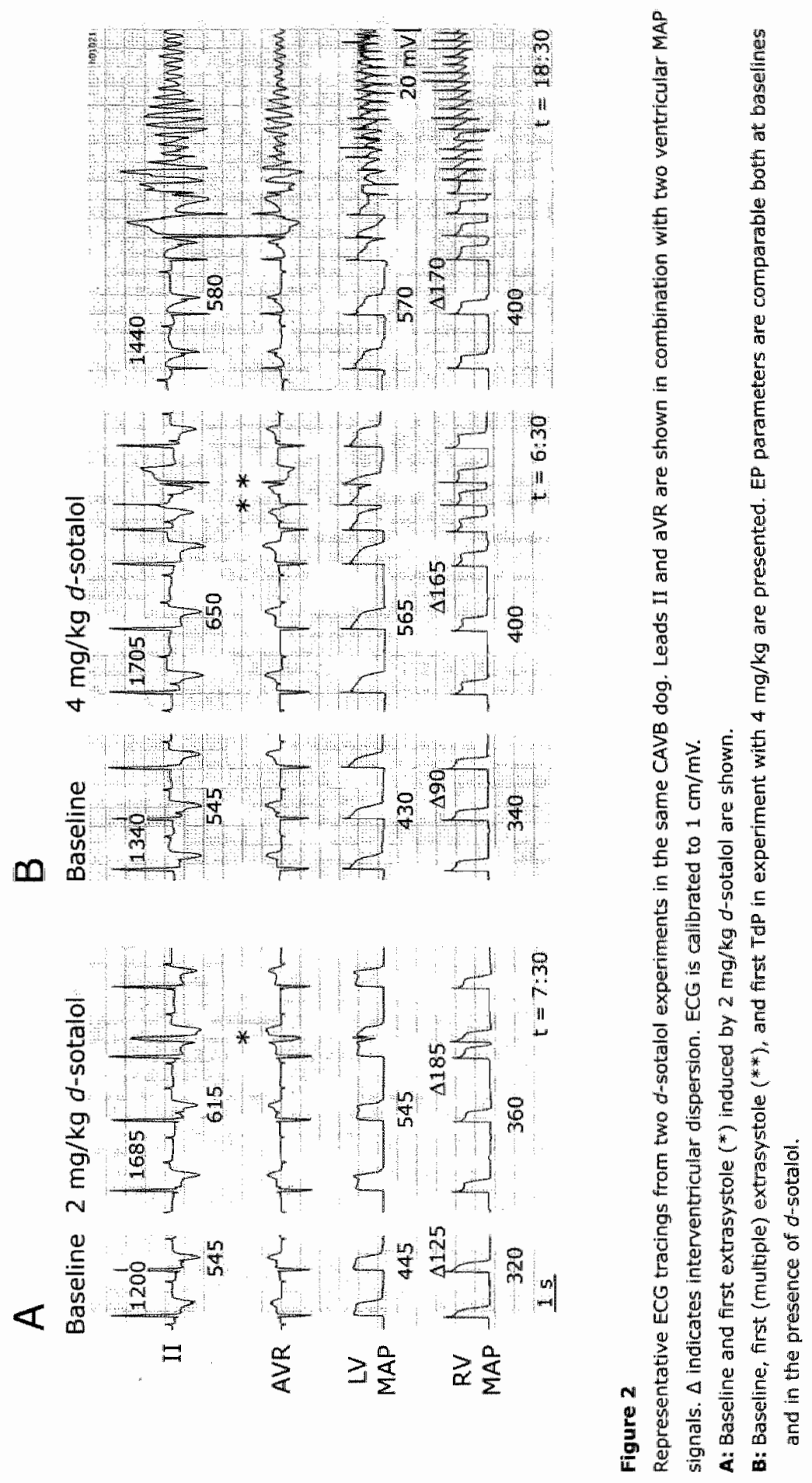




\section{Results}

\section{EP and lability parameters}

Baseline EP and lability parameters were similar at the start of the two experiments (Table 1: Figure 1C). There was a dose-dependent difference in the induction of multiple extrasystoles (Table 1) and TdP after $d$-sotalol (2 of 8 after $2 \mathrm{mg} / \mathrm{kg}$ versus 6 of 8 after $4 \mathrm{mg} / \mathrm{kg}$ ). $d$-Sotalol dose-independently prolonged the QT interval and the LV MAPD, which indicates their inability to provide an explanation for the higher ${ }^{\top} \mathrm{dP}$ incidence at $4 \mathrm{mg} / \mathrm{kg} d$-sotalol (Table 1). RR interval and RV MAPD were only significantly prolonged after $4 \mathrm{mg} / \mathrm{kg} d$-sotalol; however, these values were not different from those seen with $2 \mathrm{mg} / \mathrm{kg} d$-sotalol.

With regard to lability parameters in general, differences between drug treatments were only seen for LV plot area and LV STV (Figure 3; Table 1), while QT plot area and instability ${ }_{30}$ were increased from baseline after the high dose. No changes were seen in the other lability parameters, such as all RR or RV MAPD plot areas or variability indexes (e.g. QTVI, Table 1). No correlations were identified between RR plot areas and QT or LV plot areas $(P=0.7$ and 0.4 , respectively). Table 2 shows that the accuracy of individual predictions in the present study was considerably higher for $L V$ plot area and STV than for temporally averaged QT or LV MAPD. Amiodarone treatment caused prolongation of repolarization (QT; control $340 \pm 40$ ms, amiodarone $\left.470 \pm 75 \mathrm{~ms}, P<0.05,{ }^{3}\right)$ whereas STV did not increase $(2.4 \pm 0.2$ to $2.4 \pm 0.4 \mathrm{~ms}, P=$ NS; Figure 3 ), in agreement with the total absence of TdP.

\section{Paincaréplot area or short-rerm variability}

The advantage of STV over plot area is the feasibility to track its development over time by moving the 30-beats window. In Figure 4, this temporal behavion is shown for a representative dog. On average, half-maximal STV was reached $2.9 \pm 1.3$ minutes earlier than the onset of ectopic beats ( $7 \pm 3$ minutes after start of $d$-sotalol) and $10 \pm 6$ minutes earlier than the first TdP. All changes in LV STV and plot area were reversible upon $l_{\mathrm{K}, \mathrm{ATP}}$ activation with leveromakalim (Figure 3 ). In the cells treated with $I_{\mathrm{Kr}}$ blockers, 5 of 15 showed EADs, which divided the population. STV in baseline was similar in these two groups and increased upon $I_{\mathrm{k},}$ block (Figure 5). In the presence of $I_{\mathrm{Kr}}$ block, STV was significantly larger in the group with EADs, and the increased STV clearly preceded the occurrence of afterdepolarizations. 


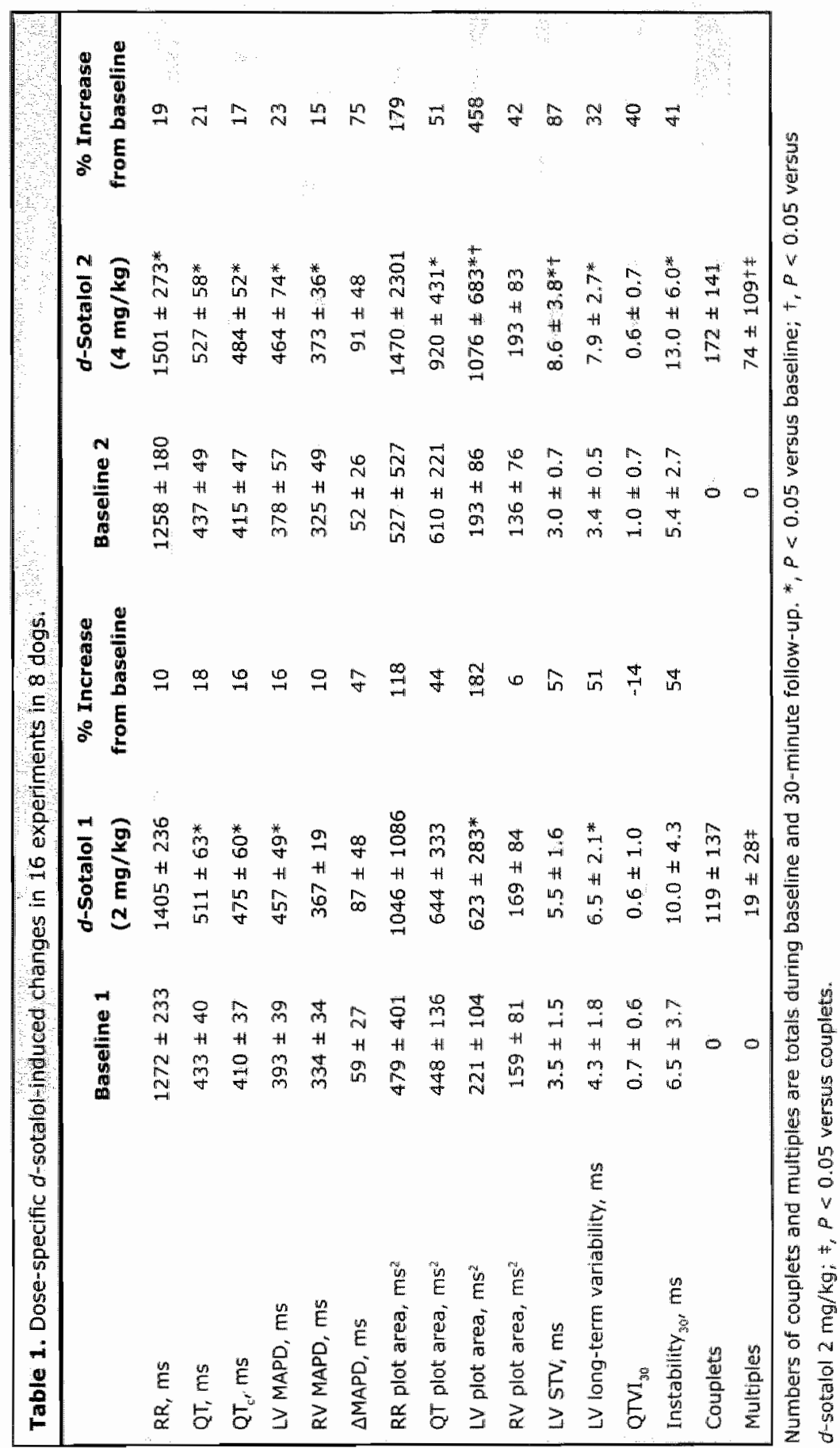




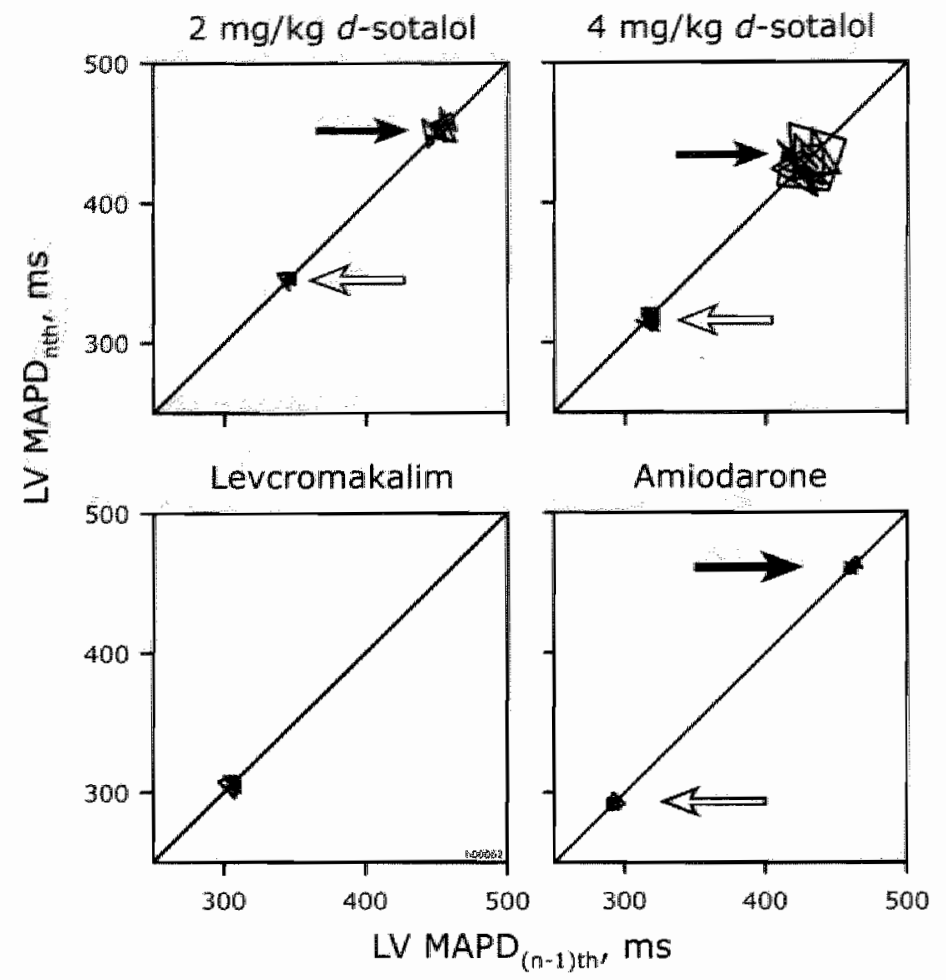

\section{Figure 3}

Poincaré plots obtained from dags under influence of various drugs. At baselines (open arrows), plots cluster around the diagonal where mean LV MAPD, plot area and STV are comparable in all experiments. After administration of drug (closed arrows), comparable prolongations of mean LV MAPD are observed for both doses of $d$-sotaloll (serial experiments) and for amiodarone. Large plot area, STV and TdP are only seen after $4 \mathrm{mg} / \mathrm{kg} d$-satalol. Levcromakalim administered after $4 \mathrm{mg} / \mathrm{kg}$ d-sotalol decreased LV MAPD, plot area and STV to baseline levels, in line with total suppression of TCP: Amlodarone was not associated with TdP.

Table 2. Area under the recelver-operator characteristic plot for some study parameters.

\begin{tabular}{lr}
\hline Mean RR, ms & 0.78 \\
Meart QT, ms & 0.71 \\
Mearn LV MAPD, ms & 0.70 \\
LVPoincare,plot area, ms & 0.97 \\
LV STV, ms & 0.94
\end{tabular}

Plots of receiver-operator characteristics depict sensitivity versus specificity of a variable to predict TdP irrespective of dose over a wide range of cutoff points. Perfect separation of the groups will have a sensitivity of $100 \%$ and specificity of $100 \%$ and hence an area of 1 . The closer the area for a given parameter is to 1 , the better its predictive performance. 
A

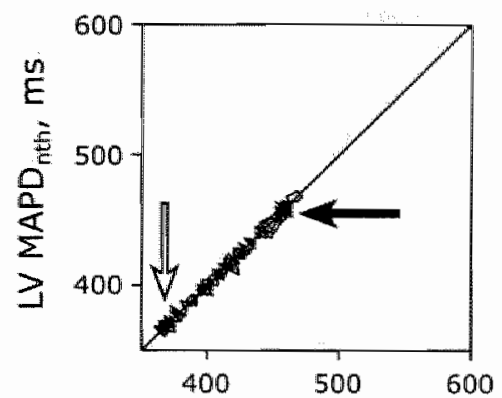

$4 \mathrm{mg} / \mathrm{kg}$

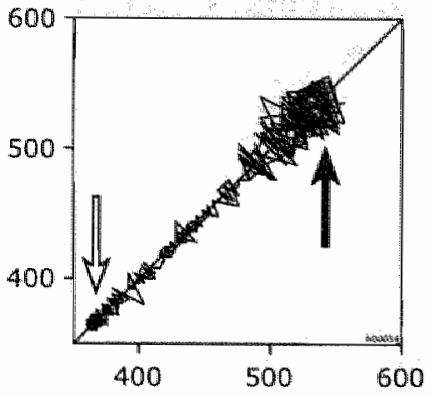

LV MAPD $_{(n-1) \mathrm{th}}$ ms

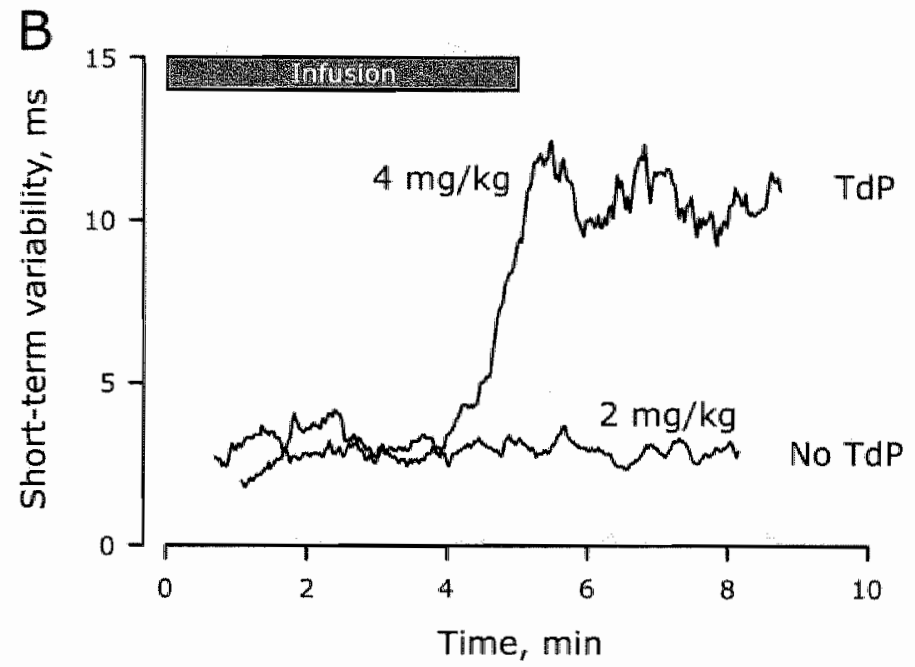

\section{Figure 4}

A: Representative Poincaré plots from the same dog are shown to demonstrate development of BWR in two d-sotalol experiments from baseline (open alrows) to first extrasystole (closed arrow; 9 minutes 51 seconds and 9 minutes 22 secomos for 2 and $4 \mathrm{mg} / \mathrm{kg}$, respectively).

B: Temporal development of STW obtained as 30-beat mowing average of the above Poincaré plots. In the experiment with TdP, there is an instantameous increase of STV 5 minutes after the stant of $d$-sotalol administration. This is 14 minutes before Tdp occurred.

\section{Discussion}

Parameters indicative of proarrhythmia: Lability of repolarization

Over the years, several EP parameters that set the stage for drug-incuced TdP have been suggested. Prolongation of QT interval and increased spatial dispersion of 
repolarization have been associated with TdP in patients" and in experimental models $3,4135,20$ Still, the predictive power of these parameters is rather low (Table 2) and more sensitive methods have been sought.

As proposed by the groups of Berger ${ }^{1,21-23}$ and Hondeghem, ${ }^{1,2}$ lability of repolarization could bear important information to determine susceptibility to proarrhythmia in patients or to assess proarrhythmic potential of drugs. It is hypothesized that repolarization becomes labile when insufficient repolarization strength can be generated (decreased repolarization reserve ${ }^{12}$ ). For us "lability of repolarization" includes all temporal assessments, regardless of whether they are gathered for strict beat-to-beat analyses (Poincaré plots), for subsequent calculations where the order of beats are rearranged (e.g. QTVI'), or for nonconsecutive determinations (e.g. instability ${ }^{1.2}$ ). We consider the term BVR to be restricted to the quantifications derived from Poincaré plots, in which direct beat-to-beat information is taken into account.

\section{Increased beat-lo-beat variability of vepolarization heralds torsades de pointes}

Occurrence of TAP is dependent on the simultaneous presence of a number of different factors. The necessary accumulated magnitude of these factors depends on the underlying substrate. Drugs antagonizing repolarization are examples of such factors. The proarrhythmic substrate consists of various predisposing factors, which may be described as decreases in repolarization reserve.

In the present study, similar values of LV STV and plot area were found at baseline regardless of the proarrhythmic outcome of the drug (Figure 1). Antagonizing repolarization by d-sotalol elevated LV STV and plot area in a pattern that corresponded to TdP "incidence. Prevention of further TdP by the $I_{\mathrm{K}, \mathrm{ATP}}$ opener leveromakalim returned LV STV and area to baseline levels, which indicates that strengthening of repolarization reserve by increasing outward current can decrease STV (Figure 3). The amiodarone data pointed in the same direction, because a prominent and comparable QT prolongation was seen as with other drugs, but LV STV remained low (Figure 3) and TdP was absent. ${ }^{3}$

When the experiments are arbitrarily grouped either by proarrhythmic outcome or by dose (Figure 6), it can be seen that the area of the LV Poincaré plot, which could be substituted with LV STV, is closely associated with TdP incidence. On the other hand, the QT interval was equally increased in all groups and did not correlate with TdP induction. The relationship between sensitivity and specificity of some parameters is illustrated in Table 2, which shows a higher predictive power for LV plot area and LV STV. As mentioned above, we prefer LV STV above plot area, 
because relatively minor computational allocations facilitate online calculation of STV (Figure 4).

In the present study, $\mathrm{QTVI}_{30}$ did mot provide similar information, whereas instability $_{30}$ did, to some extend (Table 1). It must be emphasized that we adapted the two methodologies for our 30-beats comparison for methodological reasons.

Table 2 shows that BVR of the LV is superior to the regular EP parameters in the present study. Although not statistically different, one could read a trend toward a dose-dependent increase in RR plot area after $d$-sotalol (Table 1). There was no correlation between the LV plot areas and RR plot areas or regular RR intervals $(P=$ 0.34). Thus, any possible influence of heart rate is not evident in the phase before the onset of extrasystoles.

Short-term variability is an early indicator of TdP

In addition to EP and lability parameters, extrasystoles that cause shortlong-short morphology of RR intervals has often been proposed as a signal for proarthythmia. ${ }^{13,24}$ Previously, we demonstrated that $\mathrm{TdP}$ can be induced reproducibly by pacing when $d$-sotalol does not provide the trigger. ${ }^{13}$ In the present study, we have shown that the multiple extrasystoles appear dose dependently and at similar QT intervals but presumably at higher plasma or tissue levels of $d$-sotalol. Therefore, there appears to be a safety window (Figure 4) during which maximal. repolarization times are reached before TdP ensues. If BVR increases, TdP is likely to follow. The increase in BVR before the onset of extrasystolic activity suggests a sequence of events that starts with prolongation of repolarization followed by increased BVR, and later, extrasystolic activity and TdP. Because prolongation of repolarization appears to be a dose-independent prerequisite, BVR is the earliest identified determinant of arrhythmias in the present study. Furthermore, it is illustrated (Figure 4) that an abrupt increase in STV occurs approximately at the end of the infusion, which leaves $\sim 10$ minutes response time to prevent TdP.

\section{Repolarization lability is confined to the left ventricle}

In contrast to the LV MAPD, the Poincare plot area of the QT interval was only significantly increased after $4 \mathrm{mg} / \mathrm{kg}$ and was not different from that seen with 2 $\mathrm{mg} / \mathrm{kg} d$-sotalol (Table 1). The global nature of the QT interval versus the localized subendocardial LV MAP signal could illustrate regional lability of the LV, setting the stage for arrhythmias. Like discordant T-wave alternans, ${ }^{25}$ anatomically adjacent regions of the LV with oscillating repolarization durations that are out of phase could 
Chapter 3

confer substantial dispersion, setting the stage for TdP. A MAP catheter registering one of these regions would show large BVR, whereas a global ECG would reveal the average repolarization time of all these regions and thus a relatively lower BVR.

\section{Cellular arigin of $B V R$}

In vivo, we opted to measure BVR before ectopic beats were present. To answer the question of whether BVR has a cellular origin and appears before EADs, we performed single-cell experiments with $I_{K r}$-blocking drugs. We noticed that these drugs increased STV and that STV was increased to higher levels in cells that demonstrated EADs (Figure 5). Hence, we suggest that BVR precedes EADs and that the higher the STV, the greater the likelihood for EADs.

\section{Clinical implications}

This study indicates that increased BVR precedes the induction of TdP arrhythmias in CAVB dogs. Cardiovascular and noncardiovascular drugs that induce TdP in patients with hidden predisposing factors are a major concern because identification of these patients is cumbersome. ${ }^{19}$ Assessment of BVR could identify susceptible patients and provide a parameter together with QT intervals. Patients with congenital long-QT syndrome exhibit higher repolarization variability than unaffected family members, despite comparable heart-rate variabilities. ${ }^{26}$ This suggests that lability of repolarization may be present both in acquired (drug induced) and hereditary repolarization-reserve deficiencies.

\section{Study limitations}

This study limits BVR to invasive, endocardial MAP recordings in anesthetized dogs with a high susceptibility for drug-induced TdP. Whether it can be applied to patients at risk for drug-induced TdP is unknown. It is also unknown whether other noninvasive signals can be used to quantify BVR. Before extrapolations between in vitro and in vivo BVR and proarrhythmia can be made, we must address numerous factors such as adrenergic drive, cellular coupling, electrolyte levels and changes in preload. 
A
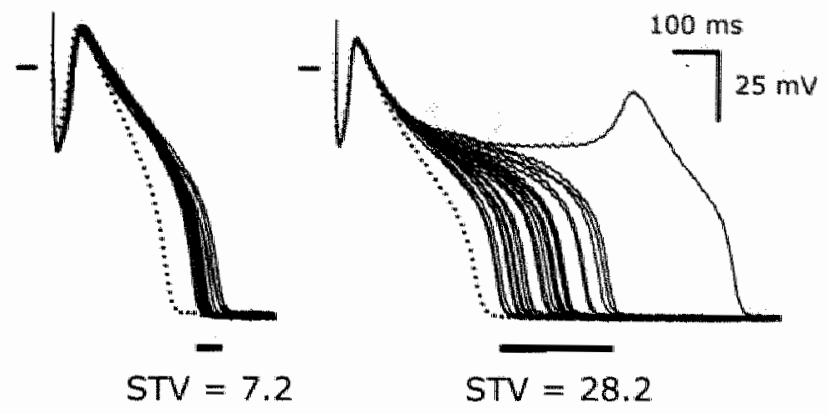

B

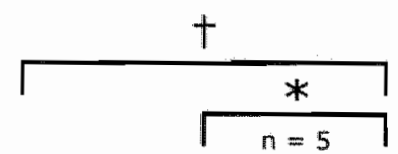

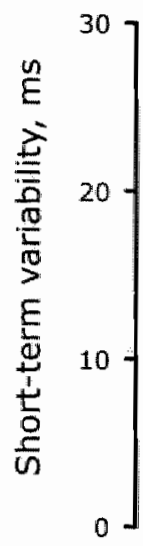

\section{Figure 5}

A: Thirty consecutive transmembrane action potentials recorded from two isolated RV myocytes from the same CAVB dog, one representing cells with (right) and without (left) EADs.

Paced cycle length is $1500 \mathrm{~ms}$ before (datted) and under the influence of $300 \mathrm{mim}$ dofetilide (salid traces).

B: Composite data grouped according to presence of EADS at $I_{k x}$ block. STV was measured at: baseline (open lbars) and during maximal $I_{\text {KKn }}$ block before first EAD (right) or at a comparable point in time (left). ${ }^{*}, P<0.05$ versus baseline; $1, P<0.05$ versus absence of EADs.

Error bars indicate SEM. 


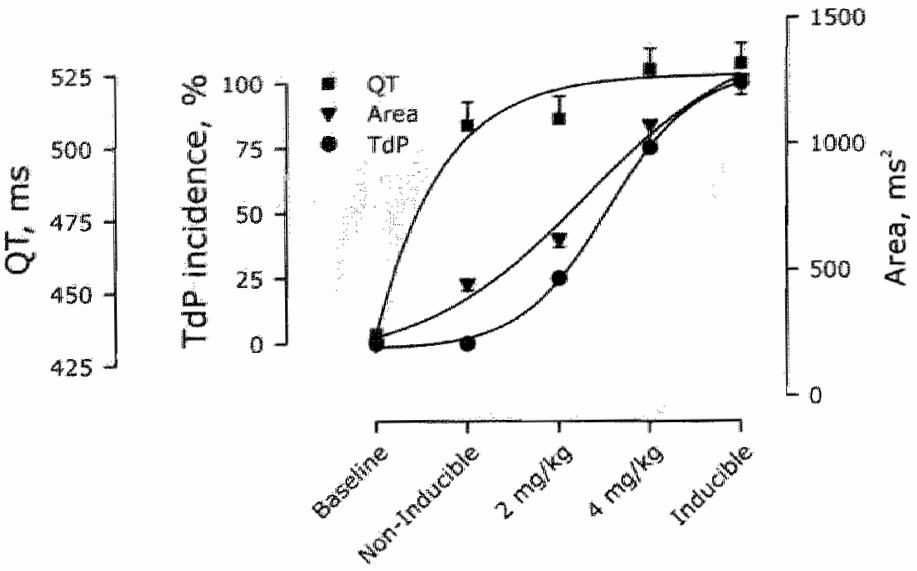

\section{Figure 6}

Graph summarizing the findings of the d-sotalol investigation. Proarrhythmic outcome of the study has been grouped in different arbitrary ways: baseline of 16 experiments, 8 experiments with no TaP Irrespective of dose (noninducible: 6 experiments with $2 \mathrm{mg} / \mathrm{kg}, 2$ experiments with $4 \mathrm{mg} / \mathrm{kg}$ ), 8 dogs receiving $2 \mathrm{mg} / \mathrm{kg} d$-sotalol ( $25 \% \mathrm{TdP}$ ), the same 8 dogs receiving 4 $\mathrm{mg} / \mathrm{kg}(75 \% \mathrm{TdP})$ and 8 experiments with $100 \%$ TdP incidence irrespective of dose (inducible: 2 experiments with $2 \mathrm{mg} / \mathrm{kg}$, 6 experiments with $4 \mathrm{mg} / \mathrm{kg}$ ). TdP incidences (-) are clasely assaciated with BVR ( $\nabla)$, whereas QT intervals ( $(\mathbf{D})$ are not. Sigmoidal fits are for illustration purposes only. Mean \pm SEM.

\section{Conclusions}

The presence or absence of proarrhythmia is not related to differences in prolongation of repolarization parameters but corresponds with BVR, such as STV of LV MAPD. The increase in STV occurred before extrasystoles in viwo and EADS in vitro, which indicates that STV is a candidate parameter to predict drug-induced TdP.

\section{Acknowledgments}

M.B. Thomsen and S.C. Verduyn were financially supported by H. Lundbeck, Denmark and Janssen Research, Belgium, respectively. P.G.A. Volders was supported by The Netherlands Organization for Health and Development (ZonMw 906-02-068). 


\section{References}

1. Hondeghem LM, Dujardin K. De Clerck. F. Phase 2 prolongation, in the absence of instability and triangulation, antagonizes class III proarhythmia. Cardiovasc Res. 2001:50:345-353.

2. Hondeghem LM, Carlsson L, Duker G. Instability and triangulation of the action potential predict serious proarnythmia, but action potential duration prolongation is antiarrhythmic. Cinculation. 2001;103:2004-13.

3. van Opstal JM, Schoenmakers M, Verduyn SC, de Groot SH, Leunissen ID, Der Hulst FF, Molenschot MM, Wellens HJ, Vos MA. Chronic Amiodarone Evokes No Torsade de Pointes Arrhythmias Despite QT Lengthening in an Animal Model of Acquired LongQT Syndrome. Cinculation. 2001;104:2722-2727.

4. Carlsson L, Abrahamsson C, Andersson B, Duker G, Schiller-Linhardt G. Proarthythmic effects of the class III agent almokalant: importance of infusion rate, QT dispersion, and early afterdepolarisations. Cardiovasc Res. 1993;27:2186-93.

5. Thomsen $\mathrm{MB}$, Volders $\mathrm{PG}_{3}$ Stengl M, Spätjens RL, Beekman JD, Bischof U, Kall MA, Frederiksen K, Matz J, Vos MA. Electroplyysiological safety of sertindole in dogs with normal and remodeled hearts. J Pharmacol Exp Ther. 2003;307:776-84.

6. Milberg P, Eckardt L, Bruns HJ, Biertz J, Ramtin S, Reinsch N, Fleischer D, Kinchhof P, Fabritz L, Breithardt G, Haverkamp W. Divergent Proarhythmic Potential of Macrolide Antibiotics Despite Similar QT Prolongation: Fast Plase 3 Repolarization Prevents Early Afterdepolarizations and Torsade de Pointes. J Pharmacol Exp Ther. 2002;303:218-225.

7. Antzelevitch C, Shimizu W. Cellular mechanisms underlying the long QT syndrome. Curr Opin Cardiol. 2002;17:43-51.

8. Rosenbaum DS, Jackson LE, Smith JM, Garan H, Ruskin JN, Cohen RJ. Electrical alternans and vulnerability to ventricular arrhythmias. N Engl $J$ Med. 1994;330:235-41.

9. Zabel M, Malik M. Practical use of T wave morphology assessment. Card Electrophysiol Rev. 2002;6:316-322.

10. van Opstal JM, Verduyn SC, Winckels SK, Leerssen HM, Leunissen JD, Wellens HJ, Vos MA. The JT-Area Indicates Dispersion of Repolarization in Dogs with Atrioventricular Block. J Interv Card Electrophysiol. 2002;6:113-120.

11. Berger RD, Kasper EK, Baughman KL, Marban E, Calkins H, Tomaselli GF. Beat-tobeat QT interval variability: novel evidence for repolarization lability in ischemtc and nonischemic dilated cardiomyopathy. Circulation. 1997;96:1557-1565.

12. Roden DM. Taking the "idio" out of "idiosyncratic": predicting torsades de pointes. Pacing Clin Electrophysiol. 1998;21:1029-1034.

13. Verduyn SC, Vas MA, van der Zande J, Kulcsar A, Wellens HJ. Further observations to elucidate the role of interventricular dispersion of repolarization and early afterdepolarizations in the genesis of acquired torsade de pointes arrhythmias: a comparison between almokalant and d-sotalol using the dog as its own control. $J / \mathrm{Am}$ Coll Cardiol. 1997;30:1575-84

14. Schoenmakers M, Ramakers C, van Opstal JM, Leunissen JD, Londono C, Vos MA. Asynchronous development of electrical remodeling and cardiac hypertrophy in the complete AV block dog. Cardiowasc Res. 2003;59:351-9.

15. Belardinelli L, Antzelevitch C, Vos MA. Assessing predictors of drug-induced torsade de pointes. Trends Pharmacol Sci. 2003;24:619-625.

16. Volders PG, Sipido KR, Vos MA, Kulcsar A, Verduyn SC, Wellens HJ. Cellular basis of biventricular hypertrophy and arrhythmogenesis in dogs with chronic complete atrioventricular block and acquired torsade de pointes. Circulation. 1998;98:1136-47

17. Volders PG, Stengl M, van Opstal IM, Gerlach U, Spatjens RL, Beekman JD, Sipido 
KR: Vos MA. Probing the contribution of IKs to canine ventricular repolarization: key role for beta-adirenergic receptor stimulation. Circulation. 2003;107:2753-60.

18. Brennan $M_{*}$ Pallaniswami $M$, Kamen P. Do existing measures of Poincare plot geonetry refiect nonlinear features of heart rate variability? IEEE Trans Bfomed Eng. $2001 ; 48: 1342-1347$.

19. Kaab 5 , Hinterseer M, Nabauer M, Steinbeck. G. Sottalol testing unmasks altered repolarization in patients with suspected acquired long-QT-syndrome - a case-control pilot study using i, v. sotalol Eur Heart J. 2003;24:649-57.

20. El-Sherif $\mathrm{N}$, Junito $\mathrm{G}$. The long $\mathrm{QT}$ syndrome and torsade de pointes. Pacing Clin Electrophysiol 1999;22:91-110.

21. Murabayashi, Fetics B, Kass D, Nevo E, Gramatikov B, Berger RD. Beat-to-beat QT interval wariability associated with acute myocardial ischemia. $J$ Electrocardiol. $2002 ; 35: 19-25$.

22. Atiga WL, Fananapazir L, McAreavey D, Calkins H, Berger RD. Temporal repolarization :ability in hypertrophic cardiomyopathy caused by beta-myosin heavychain gene mutations. Circulation. 2000;101:1237-1242.

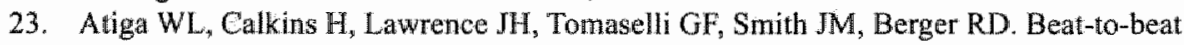
repolarization lability identifies patients at risk for sudden cardiac death. $J$ Cardiovasc Electrophysiol. 1998;9:899-908.

24. El-Sherif N, Caref EB, Chinushi M, Restiwo M. Mechanism of arrhythmogenicity of the short-long cardiac sequence that precedes ventricular tachyarrhythmias in the long QT syndrome. I im Coll Cardiol. 1999;33:1415-23.

25. Walker ML, Rosenbaum DS. Repolarization alternans: implications for the mechanism and prevention of sudden cardiac death. Cardiovase Res. 2003;57:599-614.

26. Perkiomaki JS, Zareba W, Nomura A, Andrews M, Kaufman ES, Moss AJ. Repolarization dynamics in patients with long QT syndrome. $J$ Cardiovasc Electrophysiol. 2002;13:651-656. 


\section{Decreasing the Infusion Rate Reduces the Proarrhythmic Risk of NS-7}

- Confirming the relevance of short-term variability of repolarisation in predicting drug-induced torsades de pointes

Elke Detre', Morten B. Thomsen ${ }^{1,2}$, Jet D.M. Beekman' ${ }^{1,2}$, Karl-Uwe Pefersen ${ }^{3}$ and Marc A. Vos ${ }^{1.2}$

1. Department of Cardiology, Cardiovascular Research Institute Maastricht, Maastricht University, Maastricht, Netherlands.

2. Department of Medical Physiology, University Medical Center Utrecht, Utrecht University, Netherlands.

3. PAION, Aachen, Germany.

Accepted for publication in British Journal of Pharmacology, 2005. 


\section{Abstract}

The rate of infusion has been suggested to be important for drug-induced torsades de pointes arrhythmias (TdP). We investigated the repolarisation-prolonging effects and proarthythmic properties of NS-7, a neuroprotective drug in development, using two different infusion rates. A fast ( 5 mimutes $i$. ) escalating dosing regime $(0.3$ and $3.0 \mathrm{mg} / \mathrm{kg}, \mathrm{n}=4)$ of NS-7 was investigated in anaesthetised control dogs in sinus rhythm (SR). This was compared to a slow infusion ( 60 minutes i.v.) of one dose $(3.0 \mathrm{mg} / \mathrm{kg}, \mathrm{n}=4) \mathrm{NS}-7$. The similar dosing regimes were investigated in anaesthetised dogs with chronic, complete AV block (CAVB), an animal model of $\mathrm{TdP}(\mathrm{n}=6)$. No electrophysiological effects were seen after $0.3 \mathrm{mg} / \mathrm{kg} \mathrm{NS}-7$. Fast infusion of $3.0 \mathrm{mg} / \mathrm{kg}$ caused prolongation of repolarisation, e.g. QT interval: in SR: $6 \pm 1 \%$; in CAVB: $10 \pm 7 \%$, which was accompanied by TdP in 3 of 6 CAVB dogs. No TdP were seen in SR dogs. Slow infusion did not cause TdP in the same CAVB dogs, although NS-7 caused repolarisation to prolong with a similar magnitude $\left(Q_{\dot{c}}: 12 \pm 7 \%\right)$ as in the fast-infusion experiment. Short-term variability (STV) is a novel parameter for the prediction of drug-induced TdP analysing the beat-tobeat variability of repolarisation. STV was only increased after the fast infusion in CAVB dogs $(2.6 \pm 0.3$ versus $6.0 \pm 1.4 \mathrm{~ms}, P<0.05)$, while there was no increase (2. \pm 0.2 versus $2.5 \pm 1.0 \mathrm{~ms}$ ) after the slow infusion of NS-7. Peak plasma concentrations attained were lower in slow $(0.5 \pm 0.1 \mu \mathrm{g} / \mathrm{ml}$ after 50 minutes) than in fast infusion regimen $(2.1 \pm 0.4 \mu \mathrm{g} / \mathrm{ml}$ after 5 mimutes; $P<0.05)$. The results support the conclusion that limiting peak plasma concentration by decreasing the rate of infusion of NS-7 reduces the proarthythmic risk despite comparable prollongation in repolarisation parameters. The relevance of STV in predicting drug-induced TdP was confimed. 


\section{Introduction}

A large number of cardiovascular and non-cardiovascular drugs have been withdrawn from the market in the past decade due to post-marketing reports of clinical drug-induced lethal proarhythmia. ${ }^{1-3}$ Most of these drugs have in common, that they delay the ventricular repolarisation seen as QT prolongation on the ECG. ${ }^{1.2}$ However, numerous studies have shown that there is no straightiorward relation between prolongation of repolarisation and the potentially lethal arrhythmia known as torsades de pointes (TdP). ${ }^{4-11}$ Still, the regulatory authorities require that any new potential drug is investigated to determine both its repolarisation delaying and proarrhythmic properties.

NS-7 (enecadine) is a multichannel blocker $\left(I_{\mathrm{N}: \mathrm{i}}, I_{\mathrm{Ca}}\right.$ and $\left.I_{\mathrm{KI}}\right)$ reported to show promising efficacy in animal models of ischemic stroke. ${ }^{12-17}$ In preclinical electrophysiological studies, $100 \mu \mathrm{M}$ NS-7 prolonged the ventricular action potential in guinea pigs. ${ }^{18}$ In the present study, the electrophysiological and proarthythmic characteristics of the drug were assessed in anaesthetised dogs with normal and electrically remodelled hearts. For the latter purpose, we used the animal model witlt. chronic, complete atrioventricular block (CAVB) that shows a high susceptibility to drug-induced TdP, ${ }^{8,19-23}$

Previously, the rate of drug administration has been shown to be critical for TdP induction at similar prolongation of the QT intervals in rabbits. ${ }^{7}$ Infusion rate has later been included as a risk factor for TdP observed in the clinical setting ${ }^{24}$ Therefore, we employed two different infusion rates of the same total dose in this investigation, along with analysis of beat-to-beat variability of repolarisation (BVR). This methodology was recentlly demonstrated to be a superior predictor for druginduced TdP in the preclinical setting., 4

\section{Methods}

Animal handling was in accordance with the European directive for the protection of vertebrate animals used for experimental and other scientific purposes $(86 / 609 / \mathrm{EU})$. The committee for experiments on animals of Maastricht University approved all experiments. 
A total of 28 experiments were performed on 14 anaesthetized mongrel dogs (body weight $22-33 \mathrm{~kg}$ ) under aseptic conditions. After overnight fasting, anaesthesia was induced by $20 \mathrm{mg} / \mathrm{kg}$ sodium pentobarbital $\mathrm{i}$. and maintained by $0.5 \%$ halothane in a mixture of $\mathrm{O}_{2}$ and $\mathrm{N}_{2} \mathrm{O}(1: 2)$. During artificial ventilation at a frequency of $1.0-12$ per minute, tidal volume $(10-15 \mathrm{ml} / \mathrm{kg})$ was adjusted to maintain end-expired $\mathrm{CO}_{2}$ concentration between 3.5 and $4.0 \%$. A thermal mattress was used to maintain body temperature. To prevent volume depletion, the dog received 0.5 to 1.0 litre $0.9 \%$ saline i.w. Postoperative care included antibiotics ( $1 \mathrm{~g}$ ampicillin $\mathrm{i} . \mathrm{m}$.) and analgesics ( $15 \mu \mathrm{g} / \mathrm{kg}$ buprenorphine i.m.).

Ten ECG leads and 2 monophasic action potentials (MAP) were recorded continuously throughout the experiments. MAP catheters (EP technologies, CA) were placed under fluoroscopic guidance on the endocardium of the left and right ventricle. MAP signals were amplified with a customized isolated DC-coupled differential amplifier at a frequency range of $0-500 \mathrm{~Hz}$ with a $20-\mathrm{mV}$ calibration pulse. The offset of the amplifier was variable and could be adjusted to the recorded signal. Besides minimal amplitude of $15 \mathrm{mV}$ the MAP was required to have a smooth repolarisation and a stable configuration in time.

\section{Experimental design}

Eight dogs were studied during SR to determine 1) the dose-dependent electrophysiological effects of NS-7 in physiologically normal hearts, and 2) the associated plasma concentrations of NS-7. NS-7 was administered at a last infusion ( 5 minutes) scheme of escalating doses $\left(0.3,3.0\right.$ and $10 \mathrm{mg} / \mathrm{kg} \mathrm{i.} \mathrm{v}_{n ;} \mathrm{n}=4$ ) separated by 30 minutes. Furthermore, a slow infusion ( 60 minutes) scheme of $3.0 \mathrm{mg} / \mathrm{kg}$ (i.v.; $\mathrm{n}=4$ ) was performed.

In 9 dogs, complete atrioventricular block was created by radiofrequency ablation. After $4 \pm 1$ weeks of atrioventricular block, the dogs underwent an anaesthetized doletilide-inducibility test $(25 \mu \mathrm{g} / \mathrm{kg}$ i.v.) to determine their sensitivity to drugindweed TdP." Because NS-7 could have a low proarhythmic potential that could escape detection in this model, we opted to exclude dogs that were not susceptible to this positive control. Of 9 dogs with CAVB two failed the dofetilide-inducibility test and one was lost due to drug-induced ventricular fibrillation. Thus, 6 dogs were used for evaluating the electrophysiological and proarrhythmic properties of NS-7 in remodelled hearts.

NS-7 was administered in a fast infusion (5 minutes) scheme of escalating doses 
(0.3 and $3.0 \mathrm{mg} / \mathrm{kg}$ i.v.) separated by 30 minutes or in a slow infusion (60 minutes) scheme of $3.0 \mathrm{mg} / \mathrm{kg}$ (i.v.). This was performed in a serial, random crossover design with 2 weeks between experiments. One dog was lost during a fast-infusion experiment, before the slow-infusion experiment was performed.

In two dogs, the dofetilide challenge was repeated after NS-7 to ascertain preservation of TdP inducibility. NS-7 and dofetilide were provided by PAION. Both drugs were dissolved in equal volumes of $0.9 \%$ saline.

\section{Plasma concentrations}

Blood samples were drawn from a dedicated venous access at various time points throughout the experiments. Samples were collected in citrate tubes, centrifuged for 10 minutes at $4000 \mathrm{rpm}$ at $4^{\circ} \mathrm{C}$ and stored at $-20^{\circ} \mathrm{C}$. NS-7 concentrations were determined by Scope International (Hamburg, Germany).

\section{Data analysis}

Applying a custom-made computer programme ( $\mathrm{ECG}$ view), we measured the following parameters offline at a resolution of $4 \mathrm{~ms}$ : RR and QT intervals from a unipolar lead positioned on the sixth intercostal space near the edge of the sternum. ${ }^{26}$ Also, the left ( $\mathrm{LV}$ ) and right ventricular (RV) monophasic action potential duration (MAPD) to 50 and $100 \%$ repolarisation was determined (MAPD 50 and MAPD respectively). Heart-rate corrected QT intervals were calculated according to van de Water's formula. ${ }^{27}$ Interventricular dispersion of repolarisation ( $\left.\triangle M A P D\right)$ was defined as LV minus RV MAPD.

Beat-to-beat variability of repolarisation was determined according to an earlier publication. "Briefly, Poincaré plots were drawn from 30 consecutive LV MAPD and short-term wariability $\left(S T V=\sum\left|D_{n+1}-D_{n}\right| /\left[30^{*} \sqrt{2}\right]\right.$, where $D_{n}$ represents $L V$ MAPD of beat number $n$ ), representing the mean orthogonal distance to the line-of-identity, was calculated.

All electrophysiological parameters were measured at maximal QT prolongations, which were 10 and 60 minutes after start of the fast and slow infusion, respectively. The frequency of multiple extrasystoles was quantified in 10-minutes intervals after the administration of NS-7 in CAVB dogs. Extrasystoles were defined as premature ventricular complexes occurring at a coupling interval of less than $600 \mathrm{~ms}$.

TdP was defined as polymorphic ventricular tachycardia of at least 5 beats. A dog was defined as inducible when $>3 \mathrm{TdP}$ occurred. If a TdP degenerated into ventricular fibrillation, electrical cardioversion was applied. 


\section{Statistical analysis}

Pooled data are expressed as mean \pm SD unless otherwise stated. Comparisons of electrophysiological data were perforned with repeated-measures ANOVA followed by a Bonferront t-test. Statistical significance was acknowledged at $P<0.05$.

\section{Results}

Fastoinfusion scheme in control SR dogs

Infusing NS-7 over 5 minutes resulted in a dose-dependent increase in RR interval (baseline:" $460 \pm 50 \mathrm{~ms} ; 0.3 \mathrm{mg} / \mathrm{kg}: 475 \pm 35 \mathrm{~ms} ; 3 \mathrm{mg} / \mathrm{kg}: 530 \pm 70 \mathrm{~ms}(P<0.05)$ and $10 \mathrm{mg} / \mathrm{kg}: 540 \pm 25 \mathrm{~ms}(P<0.05)$ ). Prolongation of electrophysiological repolarisation parameters was seen only after the higher doses of 3.0 and $10 \mathrm{mg} / \mathrm{kg}$ (Figure 1 for QT time and Table $\mathbb{1}$ for $3.0 \mathrm{mg} / \mathrm{kg}$ ). Relatively, $3 \mathrm{mg} / \mathrm{kg} \mathrm{NS}-7$ caused a $5.8 \pm 1 \%$ prolongation of the QT interval from basieline, whereas $10 \mathrm{mg} / \mathrm{kg}$ caused a $12.6 \pm 2 \%$ prolongation. The plasma concentrations over the duration of the experiments are depicted in Figure 1, at peak reaching $0.2 \pm 0.02,2.1 \pm 0.4$ and 6.4 $\pm 3.1 \mu \mathrm{g} / \mathrm{ml}$ after $0.3,3.0$ and $10 \mathrm{mg} / \mathrm{kg} \mathrm{NS}-7$, respectively.

\begin{tabular}{|lcc|}
\hline Table 1, Electrophysiolegical data from anaesthetised dogs with normally conducted sinus \\
rhythm $(\mathrm{n}=4)$. & Control & NS-7 \\
\hline & $460 \pm 50$ & $530 \pm 70^{*}$ \\
RR, Ims & $265 \pm 15$ & $290 \pm 20^{*}$ \\
QT, ms & $310 \pm 10$ & $330 \pm 15^{*}$ \\
QT, ms & $215 \pm 5$ & $230 \pm 15^{*}$ \\
LV MAPD, ms & $210 \pm 5$ & $225 \pm 5^{*}$ \\
RV MAPD, ms & $5 \pm 5$ & $5 \pm 5$ \\
AMAPD, ms & $0.8 \pm 0.1$ & $1.0 \pm 0.4$ \\
STV, ms & &
\end{tabular}

Measurements were performed 10 minutes after the start of the 5 -minutes infusion of $3.0 \mathrm{mg} /$ $\mathrm{kg}$ NS- 7 when the QT was meximally prolonged. *, $P<0.05$ versus control.

Administration of $10 \mathrm{mg} / \mathrm{kg}$ NS-7 caused a brief fall in the QT interval (figure 1) attributable to a consistent drug-induced transient shortening of the RR interval from $510 \pm 45$ to $440 \pm 20 \mathrm{~ms}(P<0.05)$. No statistically significant drug-induced increase was seen in the interventricular dispersion ( $\triangle M A P D)$ or beat-to-beat variability of repolarisation (STV, Table 1). 
$0.3 \mathrm{mg} / \mathrm{kg}$ NS-7 caused no proarrhythmia, while $3.0 \mathrm{mg} / \mathrm{kg}$ caused reproducible TdP in 3 of $6 \mathrm{CAVB}$ dogs, associated with a $\mathrm{QT}$ prolongation of $1.8 \pm 1 \%$ and $10.3 \pm 7 \%$, respectively. After the fast infusions, the peak plasma concentrations of NS-7 in CAVB dogs $(0.2 \pm 0.01$ and $1.6 \pm 1.9 \mu \mathrm{g} / \mathrm{m}$ lafter 0.3 and $3.0 \mathrm{mg} / \mathrm{kg} \mathrm{NS}$ 7 , respectively) were similar to those seen in SR dogs. A representative example of TdP caused by $3.0 \mathrm{mg} / \mathrm{kg} \mathrm{NS}-7$ is shown in Figure 2 . Representative Poincaré plots of the LVMAPD 100 at control and under the infuence of $3.0 \mathrm{mg} / \mathrm{kg} \mathrm{NS}-7$, either at fast or slow infusion, are also shown in Figure 2. Table 2 summarizes the electrophysiological changes induced by $3.0 \mathrm{mg} / \mathrm{kg} \mathrm{NS}-7$. During fast infusion of $3.0 \mathrm{mg} / \mathrm{kg} \mathrm{NS}-7$, significant increases in LV MAPD ${ }_{10 \%}$ and STV were observed. On average $9 \pm 20$ multiple extrasystoles were encountered within the first ten minutes after administration. One dog was lost after a drug-induced ventricular fibrillation. where electrical cardioversion was not feasible.

\section{Slow-infusion scheme in control SR dogs}

Administering $3.0 \mathrm{mg} / \mathrm{kg} \mathrm{NS}-7$ over 60 minutes caused an increase in RR ( $550 \pm 55$ versus $625 \pm 40 \mathrm{~ms} ; P<0.05)$. The $Q T$ interval was prolonged to a similar extent as with the fast infusion scheme $(8.1 \pm 2$ versus $5.8 \pm 1 \%$; Figure 3$)$. The maximal values were reached 60 minutes after the start of the slow infusion versus $10-15$ minutes in the fast-infusion experiments. The corresponding plasma concentrations of NS-7 (Figure 3) show significant differences in peak levels $(0.5 \pm 0.1$ versus $2.1 \pm$ $0.4 \mu \mathrm{g} / \mathrm{ml}$ for slow and fast infusion, respectively: $P<0.05$ ). 

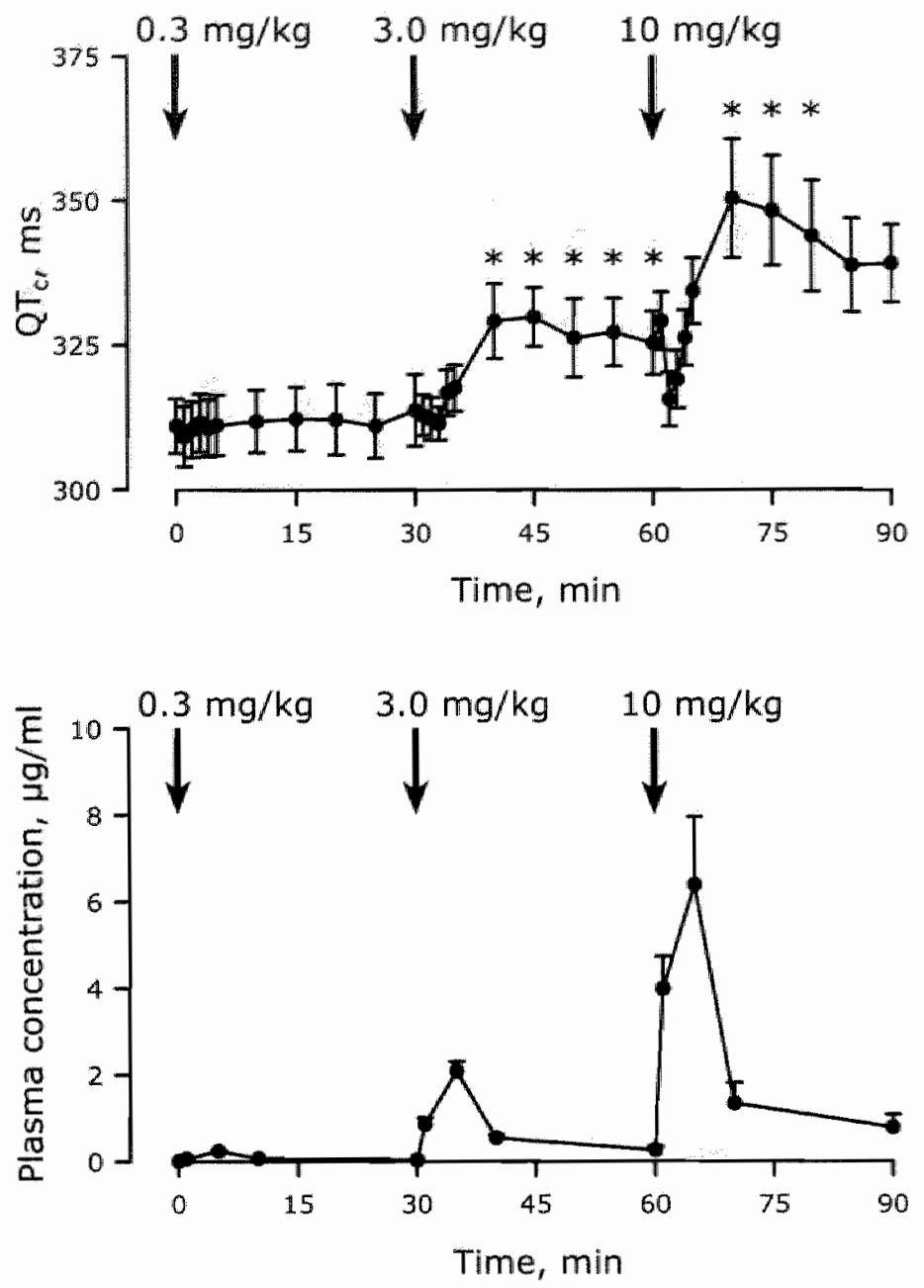

Figure 1

Dose-dependent development in QT interval and plasma concentration after 5-minutes Infusions of N5-7 in anaesthetized dogs in sinus rhythm. Three cumulative doses of NS-7 were administered $I . v_{n}$ as indicated by arrows $(n=4$ dogs $) .{ }^{*}, P^{\prime}<0.05$ versus value before last administration. Mean \pm SEM. 
Table 2. Electrophy siological data from serial investigations in ainaesthetised dogs with CAVB $(\mathrm{n}=5)$.

\begin{tabular}{|c|c|c|c|c|}
\hline & \multicolumn{2}{|c|}{ 5-minutes infusion } & \multicolumn{2}{|c|}{ 60-minutes infusion } \\
\hline & Control & $\mathrm{NS}-7$ & Control & NS- 7 \\
\hline$R R, m s$ & $1240 \pm 155$ & $1300 \pm 115$ & $1255 \pm 215$ & $1370 \pm 275$ \\
\hline$Q T$, ms & $440 \pm 45$ & $4801 \pm 50$ & $450 \pm 30$ & $495 \pm 50$ \\
\hline $\mathrm{QT}_{\mathrm{e}} \mathrm{ms}$ & $420 \pm 40$ & $450 \pm 45$ & $425 \pm 20$ & $460 \perp 30$ \\
\hline LV MAPD & $365 \pm 50$ & $420 \pm 40^{*}$ & $350 \pm 10$ & $410 \pm 55 *$ \\
\hline$L V M A P D_{s o}, \mathrm{~ms}$ & $285 \pm 30$ & $325 \pm 50$ & $275 \pm 15$ & $295+50$ \\
\hline RV MAPD $_{100}$, ms & $300 \pm 35$ & $345 \pm 35$ & $295 \pm 30$ & $340 \pm 55$ \\
\hline RV MAPD $50, \mathrm{~ms}$ & $245 \pm 40$ & $280 \pm 35$ & $240 \pm 35$ & $280+25$ \\
\hline$\triangle M A P D_{200} \mathrm{~ms}$ & $65 \pm 40$ & $75 \pm 45$ & $5.5 \pm 30$ & $70 \pm 10$ \\
\hline$\triangle M A P D_{50}, \mathrm{~ms}$ & $40 \pm 25$ & $45 \pm 45$ & $35 \pm 30$ & $15 \pm 50$ \\
\hline STV LV MAPD ${ }_{100,}$ ms & $2.6 \pm 0.3$ & $6.0 \pm 1.4 *$ & $2.1 \pm 0.2$ & $2.5 \pm 1.0+$ \\
\hline STV LV MAPD $D_{50} \mathrm{~ms}$ & $2.1 \neq 0.7$ & $4.9 \pm 1.6 *$ & $1.9 \pm 0.6$ & $2.1+0.51$ \\
\hline
\end{tabular}

$3.0 \mathrm{mg} / \mathrm{kg}$ NS-7 was administered over 5 minutes or over 60 minutes. Measurements werle performed at 10 and 60 minutes, respectively, when the QT was maximally prolonged.

$*, P<0.05$ versus controli; $+P<0.05$ versus 5 -minutes infusion.

\section{Slow-infusion scheme in proarrhythmic CAVB dogs}

As opposed to the fast-infusion scheme, slow infusion of $3.0 \mathrm{mg} / \mathrm{kg}$ caused no TdP although the LV MAPD and QT time $(11.9 \pm 9 \%$ versus $10.3 \pm 7 \%)$ were prolonged to similar extents (Table 2). The plasma concentration of NS-7 was similar in CAVB and SR dogs after the slow infusions $(0.4 \pm 0.1 \mu \mathrm{g} / \mathrm{ml}$ after $3.0 \mathrm{mg} / \mathrm{kg} \mathrm{NS}-7)$. STV was not altered by the slow infusion of NS-7. Eurthermore, STV was significantly higher after a fast administration of $3.0 \mathrm{mg} / \mathrm{kg}$ NS- 7 than after a slow infusion of the same dose (Table 2). No multiple extrasystoles were observed, however this was not acknowledged as statistically significantly different from the fast infusion, partly due to the very large variation in the frequency in the latter experiments.

Reproducibility of TdP induction with dofetilide in time was confirmed in two experiments. 

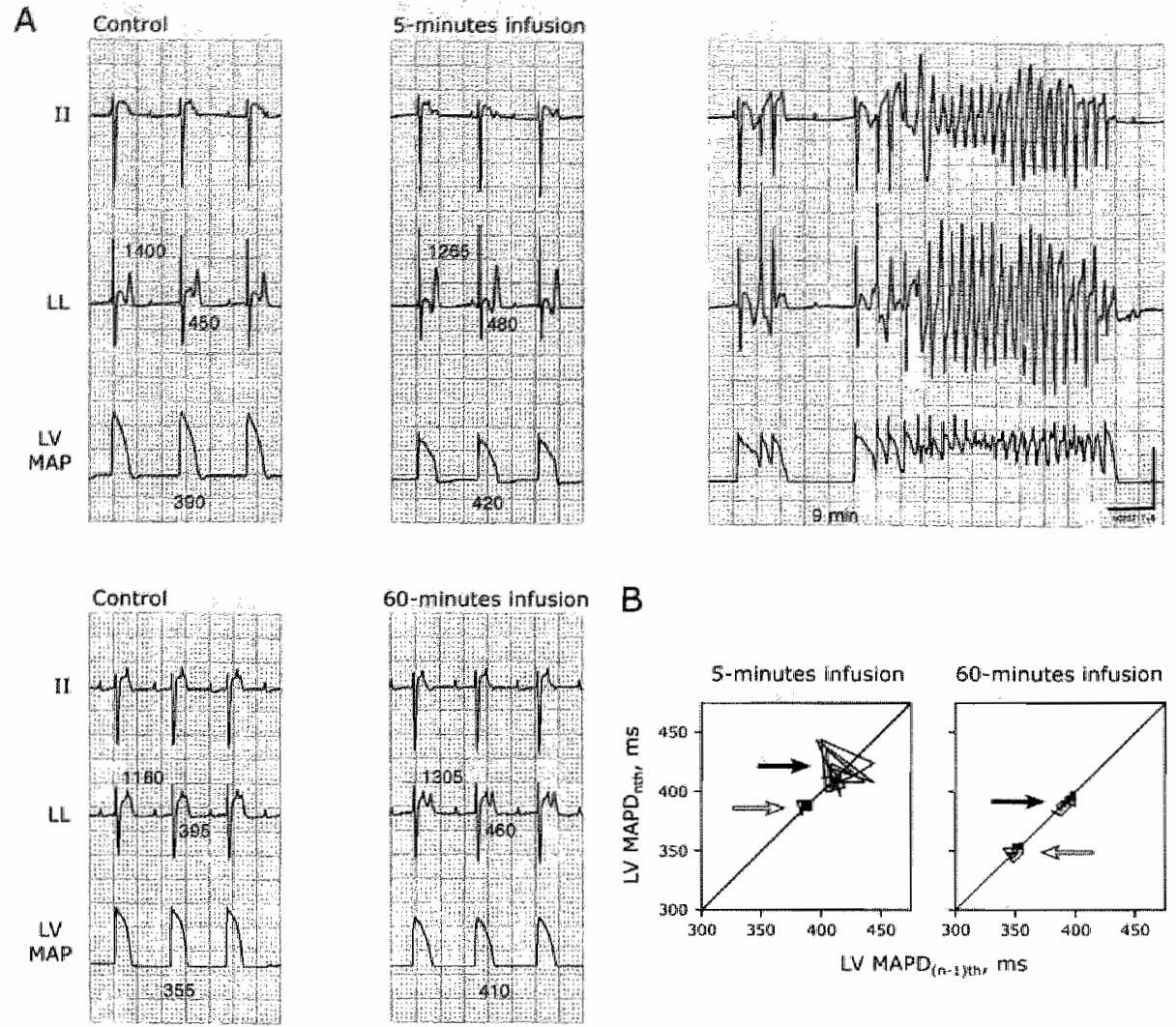

B

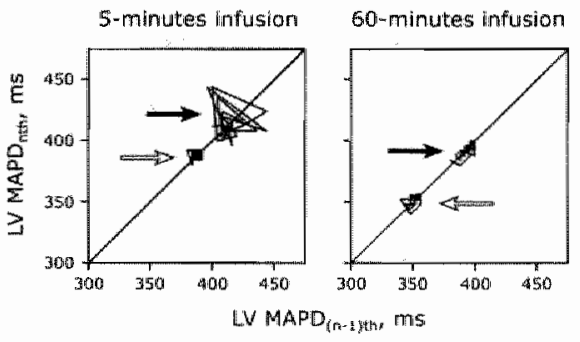

\section{Figure 2}

A: Representative ECG traces before and after administration of $3.0 \mathrm{mg} / \mathrm{kg}$ NS-7 $\mathrm{in}$ an anesthetized dog with CAVB. TdP (right-most panel) only occurred after the fast infusion of NS-7. Two LEG leads (II, lead II; LL, precordial lead placed on the left lateral side of the thorax) and LV MAP recondings are shown in each trace. RR intervals are above and QT time bellow lead LL. MAPD 100 is below the LV MAP trace. ECG calibrated to $1 \mathrm{mV} / \mathrm{cm}$. Vertical scale bar, $20 \mathrm{mV}$ on the MAP signal. Horizontal scale bar, 15.

B: Poincaré plots of the LV MAPD, from the same dog at the two experiments. Open arrow, controll. Closed arrow, $3.0 \mathrm{mg} / \mathrm{kg} \mathrm{NS-7.} \mathrm{A} \mathrm{substantial} \mathrm{increase} \mathrm{in} \mathrm{plot} \mathrm{area} \mathrm{is} \mathrm{appreciable}$ after fast administration, but not after" the slow administration. STV in the fast-infusion experiment increases from $3.0 \mathrm{~ms}$ at control to $8.8 \mathrm{~ms}$ after NS-7, while STV changes from 2.3 $\mathrm{ms}$ to $2.1 \mathrm{~ms}$ in the slow-infusion experiment. 

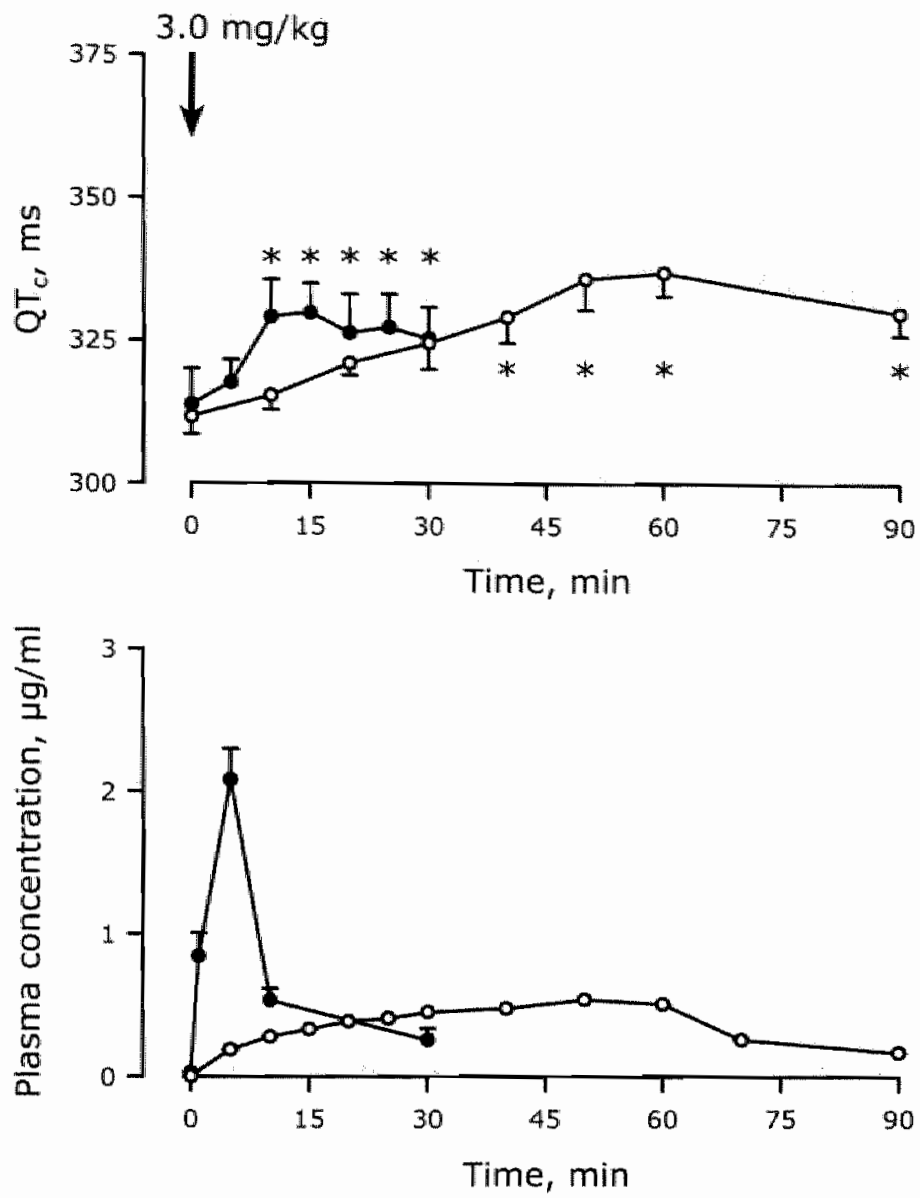

\section{Figure 3}

Comparison of the 5 and 60 -minutes infusion of $3.0 \mathrm{mg} / \mathrm{kg} N S-7$ in anaesthetized dogs $\mathrm{ln}$ sinus rhythm. QT (upper panel) and plasma concentration (lawer panel) are depicted over time for the slow (open circles) and the fast (closed circles) i.v. infusion experiments ( $n=4$ dogs). QT in similariy increased after both infusion schemes, however pealk plasma concentrations are higher after the fast infusion.* $P<0.05$ versus 0 minutes. Mean \pm SEM.

\section{Discussion}

In this study, we show that decreasing the infusion rate of NS-7 limits the peak plasma concentration and decreases or abolishes the risk of TdP. The only electrophysiological parameter that reflected absence of TdP was beat-to-beat variability of repolarisation, quantified as STV. This confirms the inability of the prolonged QT interval to predict TdP. Furthermore, this study stresses the importance of assessing cardiac electrophysiological safety of drugs in animal 
models of reduced repolarisation reserve, because the same dose of NS-7 did not cause proarrhytbmia in ST dogs.

\section{Proarhythmic assessment of NS-7}

NS-7 is under development as a neuroprotective drug after ischemic stroke. The beneficial actions of the drug are thought to be based on block of voltage-activated sodium and calcium channels in neuronal tissue. ${ }^{12,13,28}$ Block of $I_{\mathrm{Kr}}\left(\mathrm{IC}_{50}: 0.4 \mu \mathrm{M}\right.$; PAION; data on file) may underlie the prolongation of action potential duration observed in the present study and in isolated guinea-pig ventricular myocytes. ${ }^{18}$ Specifically, block of $I_{\mathrm{K}}$ has been associated with an increased risk of repolarisationdependent proarrhythmia. ${ }^{3}$

Regulatory authorities like the U.S. Food and Drug Administration or the European Medicines Agency encourage that all potential drugs with suspected QT prolonging properties in humans should be tested pre-clinically for their ability to delay repolarisation and for their proarrhythmic characteristics. Drug testing in normal hearts is essential for the analysis of delayed repolarisation in general, however it is not sufficient for the recognition of potential proarrhythmic effects in the diseased heart of a predisposed, vulnerable individual patient. The canine model with CAVB is known to have acquired QT prolongation and a predisposition to TdP and sudden cardiac death. ${ }^{8,20,22,25,29}$ The CAVB dogs exposed to NS-7 in this investigation were selected on the basis of a positive dofetilide-inducibility test, increasing the sensitivity of the model. ${ }^{8}$ The incidence of dofetilide-induced TdP was 7 of 9 dogs, comparable to earlier investigations, ${ }^{8,25}$ and was reproducible in the two dogs which were retested after the NS-7 experiments had been performed.

To be able to compare NS-7 to other drugs in this animal model, we chose our regular infusion time of 5 minutes as the fast rate ${ }^{8,20.25}$ In an approach to the clinical setting, the slow infusion went over a period of 60 minutes, which is still faster than the anticipated rate in humans.

To the best of our knowledge, this is the first study to report prolonged cardiac repolarisation and proarrhythmia by NS-7 in the intact animal. A dose-dependent prolongation of the QT $\mathrm{T}_{\mathrm{c}}$ interval is appreciable after fast administration of NS-7 in both normal (Figure 1) and CAVB dogs. Peak plasma concentrations clearly exceeded the putative effective therapeutic plasma concentration of 15 to $29 \mathrm{ng} / \mathrm{ml} .^{30}$ TdP was only seen after fast infusion of $3.0 \mathrm{mg} / \mathrm{kg} \mathrm{NS}-7$ in the remodelled hearts of the CAVB dog. The highest dose $(10 \mathrm{mg} / \mathrm{kg})$ was not administered to CAVB dogs, as TdP were already evident at $3.0 \mathrm{mg} / \mathrm{kg}$. 
As expected, peak plasma concentrations were markedly lower during slow than during fast infusion. Even so, prolongation of the infusion time did not reduce the effects seen on $\mathrm{QT}_{c}$ intervals, LV MAPD or interventricular dispersion, neither in control dogs (Figure 3 for QT) nor in CAVB dogs (Table 2). On the other hand, proarrhythmia was completely absent during the slow infusion. Thus, at two different plasma concentrations of NS-7, repolarization was similarly prolonged, suggesting that a certain drug concentration is sufficient to produce the observed prolongation of repolarisation, but a higher concentration is necessary to destabilise repolarisation, trigger ectopic beats and sustain TdP. This vulnerability is likely restricted to areas of lowest repolarisation reserve. ${ }^{31}$ In the CAVB dog, these areas seem to be located in the subendocardial regions of the left ventricle."

Our data confirms the finding of Carlsson et al. ${ }^{7}$ who showed that a fast infusion of the $I_{\mathrm{Kr}}$ blocker almokalant $(25 \mathrm{nmol} / \mathrm{kg} / \mathrm{min})$ produced TdP in 9 of 10 methoxaminetreated anaesthetised rabbits, while a slow infusion $(5 \mathrm{nmol} / \mathrm{kg} / \mathrm{min})$ gave an inducibility of 1 of 8 . This was associated with a $42 \%$ increase in QT after $_{c}$ the slow infusion but only $30 \%$ prolongation after the fast infusion, once more confirming that QT prolongation is not directly convertible into risk of TdP, a conclusion reached by numerous groups. ${ }^{4,69-11}$ We have compared amiodarone and its non-iodinated successor, dronedarone, in chronically dosed CAVB dogs and demonstrated equal. QT prolongations, contrary to a different proarrhythmic outcome. ${ }^{6}$ Similar conclusions were drawn from dose-dependent investigations employing the antipsychotic drug, sertindole or the antiarrhythmic drug, $d$-sotalol. ${ }^{8,9}$ In isolated rabbit hearts, Hondeghem et al. ${ }^{4}$ showed that parameters like instability and triangulation of the action potential were proarrhythmic while action potential prolongation was antiarrhythmic. In a comparison between the macrolide antibiotics erythromycin, clarithromycin, and azithromycin, it was shown that they all caused similar increases in repolarisation duration, however only the latter was devoid of proarrhythmia ${ }^{10}$ Other antibiotics like gatifloxacin and moxifloxacin have developed TdP in conscious $\mathrm{CAVB}$ dogs despite the absence of drug-induced QT prolongation. ${ }^{19}$ Moreover, the experimental calmodulin inhibitor W-7 was able to suppress drug-induced TdP without shortening QT intervals. ${ }^{32.33}$

\section{Beat-to-beat variability of repolarisation}

Repolarisation reserve has been introduced as a concept to explain susceptibility to arrhythmia. ${ }^{31.34}$ A reduction in repolarisation reserve generates an action 
potential that is more vulnerable to additional challenges upon repolarisation, such as drugs with $I_{k,}$ blocking properties. Often $I_{k r}$ blockers are the final challenge on repolarisation, which unmasks an unidentified predisposition precipitating a lethal arrhythmia. in predisposition can be a congenital (long QT syndrome) or an acquired (metabolic or electrolyte disturbances, heart disease etc.) ion channelopathy. Quantification of the repolarisation reserve and identification of the vulnerable patient are therefore important questions for many investigators. Beat-to-beat variability of repolarization is a concept that provides data to identify unsafe drugs. With the use of Poincare plots, STV is one way of quantifying BVR. A dose-dependent TdP occurrence after $d$-sotalol was tightly associated with the elevation of STV, while the absence of TdP after chronic, oral amiodarone was reflected in an unchanged STV." The global nature of the QT interval versus the relatively local recording of an MAP signal possibly explains the low predictive power of beat-to-beat variability of the QT interval. Furthermore, the predominant remodelling of the left ventricle may underlie the absence of drug-induced increases in the BVR of the RV MAPD. ${ }^{9}$ With the assumption that it is a population af cells located in the left ventricular sub-endocardium that has the lowest repolarisation reserve, we would not expect to find physiologically significant drug-induced increases of the STV of the epicardial repolarisation. ${ }^{35}$ This is the first study to show, that within the STV of the LV MAPD, variability is present at both $50 \%$ and $100 \%$ repolarisation levels, supporting the hypothesis that BVR arises at the plateau of the action potential rather than at the fast repolarisation.

In the present study, we have applied STV and confirmed our earlier observation, that an increase in BVR predicts TdP. The only NS-7 induced increase in STV was observed in the fast-infusion experiments in the remodelled CAVB dogs. In nomal hearts as well as with the slow infusion of NS-7 in CAVB dogs, STV was not altered and TdP was absent. Thus, BVR is an attractive addition to assess proarrhythmic actions of drugs. Additionally, STV is present prior to drug-induced early afterdepolarisation and extrasystoles, which allows time for preventive antiarmythmic actions.

\section{Novel parameters in drug screening}

In vivo, repolarisation-dependent arrhythmias have been associated with a QT variabillity index in humans ${ }^{36}$ and with triangulation, spatial dispersion and instability of the MAPD and reverse-use dependency of the drug in isolated rabbit hearts. ${ }^{4}$ Transmural dispersion of repolarisation in arterially perfused canine left ventricular wedge preparations also has predictive value in proarhythmic drug testing. ${ }^{37,3 x}$ 
Short-term variability of repolarisation differs from other measures of temporal lability of repolarisation in its consecutiveness. The former evaluates the direct difference between two consecutive beats while QT variability index and instability rearranges the order of beats.

\section{Conclusions}

Limiting peak plasma concentrations of NS-7 by decreasing the infusion rate reduces the proarrhythmic risk in dogs with remodelled hearts considerably. This occurs despite similar prolongations of the repolarisation parameters, like QT intervals. Conversely, an increase in short-term variability of MAPD predicted the proarthythmic outcome.

\section{Acknowledgments}

This study was in part financed by a grant from. PAION Deutschland GmbH, Aachen, Germany. 


\section{References}

1. Haverkamp W, Breithardi $G$, Camm $A J$, Janse MJ, Rosen MR, Antzelewitch C, Escande D, Franz M, Malik M, Moss A, shah R. The potential for QT prolongation and pro-arrhythmia by non-anti- arrhythmic drugs:

clinical and regulatory implications. Report on a Policy Conference of the European Society of Cardiology. Cardiovasc Res. 2000;47:219-33.

2. Belardinelli L, Antzelevitch C, Vos MA. Assessing predictors of drug-induced torsade de pointes. Thends Pharmacol Sci. 2003;24:619-625.

3. Redfern WS, Carlsson L, Davis AS, Lynch WG, MacKenzie 1, Palethorpe S, SiegI PK, Strang I, Sullivan AT, Wallis R, Camm AJ, Hammond TG. Relationships between preclinical cardiac electrophysiology, clinical QT interval prolongation and torsade de pointes for a broad range of drugs: evidence for a provisional safety margin in drug development. Cardiovasc Res. 2003;58:32-45.

4. Hondeghem LM, Carlsson L, Duker G. Instability and triangulation of the action potential predict serious proarrhythmia, but action potential duration prolongation is antiarrhythmic. Circulation. 2001;103:2004-13.

5. Hondeghem LM, Dujardin K, De Clerck F. Phase 2 prolongation, in the absence of instability and triangulation, antagonizes class III proarrhythmia. Cardiovasc Res. $2001 ; 50 ; 345-353$.

6. van Opstal JM, Schoenmakers M, Verduyn SC, de Groot SH, Leunissen JD, Der Hulst FF, Molenschot MM, Wellens HJ, Vos MA. Chronic Amiodarone Evokes No Torsade de Pointes Arthythmias Despite QT Lengthening in an Animal Model of Acquired LongQT Syndrome. Circulation. 2001;104:2722-2727.

7. Carlsson L, Abrahamsson C, Andersson B, Duker G, Schiller-Linhardt G. Proarthythmic effects of the class III agent almokalant: importance of infusion rate, QT dispersion, and early afterdepolarisations. Cardiovasc Res. 1993;27:2186-93.

8. Thomsen MB, Volders PG, Stengl M, Spätjens RL, Beekman JD, Bischoff U, Kall MA, Frederiksen K, Matz J, Vos MA. Electrophysiological safety of sertindole in dogs with normal and remodeled hearts. J Pharmacol Exp Ther. 2003;307:776-84.

9. Thomsen MB, Verduyn SC, Stengl M, Beekman JD, de Pater G, Van Opstal JM, Volders $P G$, Vos MA. Increased short-term variability of repolarization predicts d-sotalolinduced torsades de pointes in dogs. Circulation. 2004;110:2453-2459.

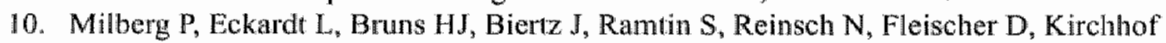
P, Fabritz L., Breithardt G, Haverkamp W. Diwergent Proarrhythmic Potential of Macrolide Antibiotics Despite Similar QT Prolongation: Fast Phase 3 Repolarization Prevents Early Afterdepolarizations and Torsade de Pointes. J Pharmacol Exp Ther. $2002 ; 303: 218-225$.

11. Antzellevitch $\mathrm{C}$, Shimizu W. Cellular mechanisms underlying the long QT syndrome. Curr Opin Cardiol. 2002;17:43-51.

12. Oka M, Hayashi S, Itoh Y. Electrophysiological and neurochemical evidence for voltage-dependent $\mathrm{Ca}(2+)$ channel blockade by a novel neuroprotective agent NS-7. Pharmacol Toxicol. $2001 ; 89: 123-8$.

13. Oka M, Itoh $\mathrm{Y}$, Ukai $\mathrm{Y}$. Preferential inhibition by a novel $\mathrm{Na}(+) / \mathrm{Ca}(2+)$ ehannel blocker NS-7 of severe to mild hypoxic injury in rat cerebrocortical slices: A possible involvement of a highly voltage-dependent blockade of $\mathrm{Ca}(2+)$ channel. $J$ Pharmacol Exp Ther: 2000:293:522-9.

14. Tanaka K, Ito D, Suzuki S, Dembo T, Kosakai A, Fukuuchi Y. A novel voltage-sensitive $\mathrm{Na}(+)$ and $\mathrm{Ca}(2+)$ channel blocker, NS-7, prevents suppression of cyclic AMPdependent protein kinase and reduces infarct area in the acute phase of cerebral ischemia in rat. Brain Res. 2002;924,98-108.

15. Katsumata T, Muramatsu H, Nakamura H, Nishiyama Y, Aoki Y, Katayama $Y$. 
Neuroprotective effect of NS-7, a novel $\mathrm{Na}+$ and $\mathrm{Ca} 2+$ channel blocker, in a focal ischemic model in the rat. Brain Res. 2003;969:168-74.

16. Sopala M, Danysz W, Quack G. Neuroprotective effects of NS-7, woltage-gated $\mathrm{Na}+\mathrm{Ca} 2$ + channel blocker in a rodent model of transient focal ischaemia. Newrotox Res. $2002 ; 4: 655-661$.

17. Suma C, Hayashi S, Ukai Y, Yoshikuni Y, Kimura K. Na+ and high-voltage-activated $\mathrm{Ca} 2+$ channel blocking actions of NS-7, a novel neuroprotective agent, in NG108-15 cells. Eur J Pharmacol. 1997;336:283-90.

18. Satoh $\mathrm{H}$. Cardiac electrophysiological modulation by $\mathrm{NS}-7$, a novel neuroprotective drug, of guimea pig ventricular muscles. Life Sci. 2003; 72:1039-48.

19. Chiba K, Sugiyama A, Hagiwara T, Takahashi S-i, Takasuna $\mathrm{K}$, Hashimoto K. In vivo experimental approach for the risk assessment of tuoroquinolone antibacterial agentsinduced long QT syndrome. European Jounnal of Pharmacology. 2004;486:189-200.

20. Verduyn SC, Vos MA, van der Zande J, Kulcsar A, Wellens HJ. Further observations to elucidate the role of interventricular dispersion of repolarization and early afterdepolarizations in the genesis of acquired torsade de pointes arrhythmias: a comparison between almokalant and $d$-solalol using the dog as its own control. $J \mathrm{Am}$ Coll Cardial 1997;30:1575-84.

21. Verduyn SC, Vos MA, Leunissen HD, van Opstal JM, Wellens HJ. Evaluation of the acute electrophysiologic effects of intravenous dronedarone, an amiodarone-like agent, with special emphasis on ventricular repolarization and acquired torsade de pointes arrhythmias. J Cardiovasc Phormacol. 1999;33:212-22.

22. Vos MA, de Groot $\mathrm{SH}$, Verduyn $\mathrm{SC}$, van der Zande J, Leunissen HD, Cleutjens JP, van Bilsen M, Daemen MJ, Schreuder JJ, Allessie MA, Wellens HJ. Enhanced susceptibility for acquired torsade de pointes arrhythmias in the dog with chronic, compleve AV block is related to cardiac hypertrophy and electrical remodeling. Circulation. 1998;98:112535.

23. Weissenburger $J$, Davy $J \mathrm{M}$, Chezalviel $\mathrm{F}$, Ertzbischoff $\mathrm{O}$, Poirier JM, Engel $\mathrm{F}$, Lainee P, Penin E, Motte G, Cheymol G. Arrhythmogenic activities of antiarthythmic drugs in conscious hypokalemic dogs with atrioventricular block: comparison between quinidine, lidocaine, flecainide, propranolol and sotalol. J Pharmacol Exp Ther. $1991 ; 259: 871-83$.

24. Roden DM. Drug-induced prolongation of the QT interval. $N$ Engl $J$ Med. 2004;350:1013-22.

25. van Opstal JM, Leunissen JD, Wellens HJ, Vos MA. Azimilide and dofetilide produce similar electrophysiological and proarrhythmic effects in a canine model of Torsade de Pointes arrhythmias. Eur J Pharmacol. 2001:412:67-76.

26. Ettinger SJ, Suter PF. Cawine Cardiology. London: W. B. Saunders Company; 1970

27. Van de Water $A$, Verheyen $J$, Xhonneux $R$, Reneman RS. An improved method to correct the QT interval of the electrocardiogram for changes in heart rate. $J$ Pharmacol Methods. 1989;22:207-17.

28. Tanaka K, Nogawa S, Nagata E, Suzuki S, Dembo T, Kosakai A, Fukuuchi Y. Erfects of blockade of voltage-sensitive $\mathrm{Ca}(2+\mathrm{H} / \mathrm{Na}(+)$ channels by a nowel phenylpyrimidine derivative, NS-7, on CREB phosphorylation in Cocal cerebrat ischemia in the rat. Brain Res. 2000;873:83-93.

29. van Opstal JM, Verduyn SC, Leunissen HDM, de Groot SHM, Wellens HJJ, Vos MA. Electrophysiological parameters indicative of sudden cardiac death in the dog with chronic complete AV-block. Candiovascular Reseanch. 2001;50:354-361.

30. Aoki $Y$, Tamura $M$, ltoh Y, Seto T, Nonaka K, Mukai H, Ukai Y. Effective plasma concentration of a novell $\mathrm{Na}+/ \mathrm{Ca} 2+$ channel blocker NS-7 for its cerebroprotective actions in rats with a transient middle cerebral artery occlusion. J Pharmacol Exp Ther. $2001 ; 296: 306-11$. 
31. Roden DM. Taking the "idio" out of "idiosyncratic": predicting torsades de pointes. Pacing Clin Electrophysiol 1998:21:1029-1034.

32. Gbadebo TD, Trimble RW, Khoo MS, Temple $\mathrm{J}_{3}$ Roden DM, Anderson ME. Calmodulin inhibitor W-7 unmasks a novel electrocardiographic parameter that predicts initiation of torsade de pointes. Circulation. 2002;105:770-774.

33. Mazur A, Roden DM, Anderson ME. Systemic administration of calmodulin antagonist W-7 or protein kinase $A$ inhibitor H-8 prevents torsade de pointes in rabbits. Circulation. $1999 ; 100: 2437-42$.

34. Biliczki $\mathrm{P}$, Virag L, Iost $\mathrm{N}$, Papp $\mathrm{JG}_{\mathrm{G}}$, Varro A. Interaction of different potassium channels in cardlac repolarization in dog ventricular preparations: role of repolarization reserve. Brd Pharmacol. 2002;137:361-8.

35. Sicouri $\mathrm{S}$, Antzelevitch $\mathrm{C}$. A subpopulation of cells with unique electrophysiological properties in the deep subepicardium of the camine ventricle. The M cell. Circ Res. $1991 ; 68: 1729-41$.

36. Bilchick K. Viitasalo $M$, Oikarinen $L$, Fetics $B$, Tomaselli $G$, Swan $H$, Laitinen PA,

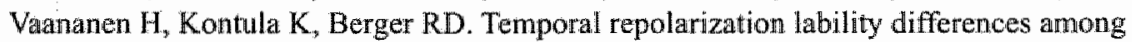
genotyped patients with the long QT syndrome. Am J Cardiol. 2004;94:1312-6.

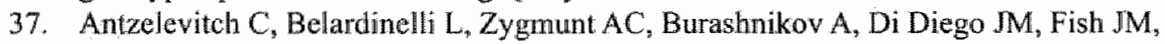
Cordeiro $\mathrm{JM}_{3}$ Thomas $\mathrm{G}$. Electrophysiological effects of ranolazine, a novel antianginal agent with antiarrhythmic properties. Circulation. 2004;110:904-10.

38. Di Diego $\sqrt{\mathrm{M}}$, Belardinelli $\mathrm{L}$, Antzelevitch C. Cisapride-induced transmural dispersion of repolarization and torsade de pointes in the canine left ventricular wedge preparation during epicardial stimulation. Circulation. 2003;108:1027-33. 


\section{Sudden Cardiac Death in Dogs with Remodeled Hearts is Associated with Larger Beat-To-Beat Variability of Repolarization}

Morten B. Thomsen ${ }^{1.2}$, Michiel Truin', Jurren van Opstal ${ }^{1}$, Jet D.M. Beekman ${ }^{1.2}$, Paul G.A. Volders', Milan Stengl!,2 and Marc A. Vos ${ }^{1,2}$

1. Department of Cardiology, Cardiovascular Research Institute Marastricht, Maastricht University, Maastricht, Netherlands.

2. Department of Medical Physiology, University Medical Center Utrecht, Utrecht University, Netherlands. 


\section{Abstract}

Increased proarrhythmia in dogs with chronic AV block (AVB) has been explained by ventricular remodeling causing a decrease in repolarization reserve. Beat-tobeat variability of repolarization (BVR) has been suggested to reflect repolarization reserve, in which high variability represents diminished reserve and larger propensity for repolarization-dependent ventricular arrhythmia. A subset of chronic AVB dogs (10\%) suffers sudden cardiac death (SCD). With the assumption that repolarization defects constitute a potentially lethal proarrhythmic substrate, we hypothesized that BVR in SCD dogs are larger than in matched control chronic AVB dogs.

From a population of 200 chronic AVB dogs, initially two groups were chosen retrospectively: 8 dogs that died suddenly (SCD) and 8 control dogs. Control dogs had a longer lifespan after AVB (10 to 18 weeks) than SCD dogs (5 to 10 weeks). All dogs had undergone electrophysiological testing under anesthesia where $\mathrm{ECG}_{\text {* }}$ left and right ventricular endocardial monophasic action potentials (MAP) were recorded. BVR was assessed from 30 consecutive beats, illustrated by Poincaré plots and was the only parameter discriminating between SCD and control group. All other electrophysiological parameters (RR, QT and MAP durations) were comparable for the two groups. Extending the number of animals and groups confirmed a larger BVR in the SCD group (SCD: $5.1 \pm 2.7 ; \mathrm{n}=11$ versus control: $2.5 \pm 0.4 \mathrm{~ms} ; \mathrm{n}=61 ; P<0.05)$ and showed reverse-use dependence of $\mathrm{BVR}$. In comparison $_{n}$ dogs with acute AVB had low variability $(1.3 \pm 0.3 \mathrm{~ms} ; \mathrm{n}=9 ; P<0.05$ versus chronic AVB).

Cardiac electrical remodeling after AVB is associated with an increase in beat-10beat variability of repolarization. Chronic AVB dogs displaying further elevated variability of repolarization are prone to arrhythmia-related SCD. 


\section{Introduction}

Lability of repolarization has previously been reported to be increased in patients with ventricular heart disease experiencing sudden cardiac death (SCD)." However, more than half of all SCD occurs in people without any history of known cardiac disease, while heart failure is present in only $26 \%$ of all SCD cases. ${ }^{2}$ Hence, the so-called high-risk patients constitute only a fraction of the total population suffering SCD. ${ }^{3}$ This stresses the importance of developing better markers to predict individual arrhythmogenic risk among the general population.

The dog model with chronic complete atrioventricular block (AVB) has been used extensively to investigate mechanisms of ventricular arrhythmia. A high susceptibility for repolarization-dependent proarmythmia has been established: $10 \%$ of the dogs die suddenly under conscious circumstances, while class-III drugs induce arrhythmia in $56-67 \%$ of the remaining animals under anesthesia. ${ }^{4-7}$ This enhanced susceptibility for repolarization-dependent arrhythmias can be attributed to electrical ventricular remodeling. ${ }^{8}$ Previously, beat-to-beat variability of repolarization (BVR) was used to quantify variations in action potential duration from Poincare plots. ${ }^{9}$ A drug-induced increase in BVR from the left ventricular monophasic action potential duration (LV MAPD) was strongly associated with subsequent druginduced torsades de pointes arrhythmia (TdP). Vice versa, no change in BVR was linked to the absence of ventricular arrhythmia, establishing a high power of BVR in predicting drug-induced TdP.

If SCD is associated with repolarization-dependent arrhythmia, we hypothesize that BVR in SCD dogs is larger than in control dogs with chronic AVB. Furthermore, we hypothesize that $B V R$ is increased alongside ventricular remodeling from acute to chronic AVB. The objective of the present study was to establish the applicability of BVR in the prediction of lethal ventricular remodeling under drug* free circumstances.

\section{Methods}

Over the last ten years, AVB has been performed in a population of more than 200 dogs. In this period 22 dogs, with chronic AVB have died suddenly unrelated to the studies performed. Any non-cardiac cause of death was excluded by autopsy. 
Animal experiments took place in accordance with the European Directive for the Protection of Vertebrate Animals Used for Experimental and Other Scientific Purposes (86/609/EU) and with the approval of the Committee for Experiments on Animals of Meastricht and Utrecht University, The Netherlands. All experiments were performed under aseptic conditions in anesthetized mongrel dogs of either sex. Full anesthesia was induced by sodium pentobarbital $(20 \mathrm{mg} / \mathrm{kg} \mathrm{i.v}$ ) and maintained by halothane inhalation $\left(0.5 \%\right.$ in $\left.\mathrm{O}_{2} / \mathrm{N}_{2} \mathrm{O}(\mathrm{l}: 2)\right)$. Methodological descriptions of the creation of AVB and electrophysiological studies at chronic AVB have been published earlier ${ }^{6,8,10}$

Six surface ECG leads and monophasic action potentials from the left and right endocardium were recorded simultaneously during experiments at acute and chronic AVB and stored on hard disc. MAP catheters (MAP, EP Technologies, CA) were placed under fluotoscopic guidance on the free wall or in the apices of the ventricles. MAP signals were amplified with a customized isolated DC-coupled differential amplifier at a frequency range of $0-500 \mathrm{~Hz}$ with a $20-\mathrm{mV}$ calibration pulse. The offset of the amplifier was variable and could be adjusted to the recorded signal. The position of the MAP catheter was accepted when the following criteria were met: 1 , minimal amplitude from plateau to baseline of $15 \mathrm{mV} ; 2$, smoothness of repolarization and; 3 , stability in time.

Tellemetry recordings were successfully obtained in 10 dogs with chronic AVB, of which 2 died suddenly. For a description of the telemetric device, implantation and recording procedures, we refer to a previous publication. ${ }^{5}$

\section{Group composition}

Retrospectively, 8 dogs experiencing SCD during follow-up were selected on the basis of the availability of baseline recordings of $>30$ minutes. These electrophysiological studies took place at $5 \pm 2$ weeks after AVB, at which electrical remodeling is complete ${ }^{10,11}$ while sudden cardiac death occurred at $7 \pm$ 2 weeks after AVB (range 5 to 10 ). The control population consisted of 8 matched dogs from the chronic AVB group selected on the basis of similar time points of electrophysiological testing, $>30$ minutes baseline recording and a follow-up that significantly exceeded that of the SCD dogs ( $13 \pm 3$ weeks, range 10 to 18 weeks; from $A V$-node ablation to experimental sacrifice).

In a larger comparison, 30-minutes baseline recording were no longer an inclusion. criteria (see further). Three groups of AVB dogs were selected: 1, acute AVB with 
recordings 10 to 30 minutes after $\mathrm{AV}$-node ablation $(\mathrm{n}=9) ; 2$, chronio $\mathrm{AVB}$ with additionally 53 dogs $(n=61) ; 3$, all $\mathrm{SCD}$ dogs in which an electrophysiological follow-up study with MAP recordings were perfomed $(\mathrm{n}=11)$.

Additionally, 8 dogs were prospectively included in a serial study analyzing the influence of heart rate on BVR. At acute and chronic AVB, steady state pacing (cycle length (CL) 600 and $1400 \mathrm{~ms}$ ) was performed from the right ventricular MAP catheter.

\section{Data analysis}

Upon application of a custom-made computer program with an adjustable gain and time scale, the following electrophysiological parameters were measured off line at a resolution of $4 \mathrm{~ms}$ : CL of the idioventricular rhythm (RR) and QT interval from lead II and the duration to $100 \%$ repolarization of the left and right ventricular MAP (LV and RV MAPD, respectively). The interventricular dispersion of repolarization ( $\triangle M A P D=$ LV MAPD minus RV MAPD) was calculated. Heart-rate corrected QT interval (QT, was determined according to Van de Water's formula, ${ }^{12}$ which is superior to other rate-correction formulas used in anesthetized bradycardic dogs. In dogs with 30 -minutes recordings, the electrophysiological parameters were measured every 5 minutes and averaged.

Beat-to-beat variability was assessed for each electrophysiological parameter over 30 consecutive beats with a constant ventricular focus. The time periods were randomly chosen and their origins were blinded for the analyzer. The 30 beats were plotted in Poincaré plots, 9,13,14 and short-term variability (STV), defined as the average distance of the points to the diagonal in the Poincaré plot (STV $=\sum \mid D_{n+1}-$ $D_{13} \mid /\left[30^{*} \sqrt{2}\right]$, where $D$ represents the duration of the electrophysiological parameter) was calculated."

Heart-to-body weight ratios were established upon sacrifice (control chronic AVB group) or autopsy (SCD group) and served as an indicator for hypertrophy and structural remodeling. Of the 61 control dogs, 47 heart-to-body weight ratios were available, while all $11 \mathrm{SCD}$ ratios were obtained. Heart-to-body weight ratios from previous sacrifices of dogs in normally conducted sinus thythm $(\mathrm{n}=79$ ) served as representative for the acute $\mathrm{AVB}$ group. 


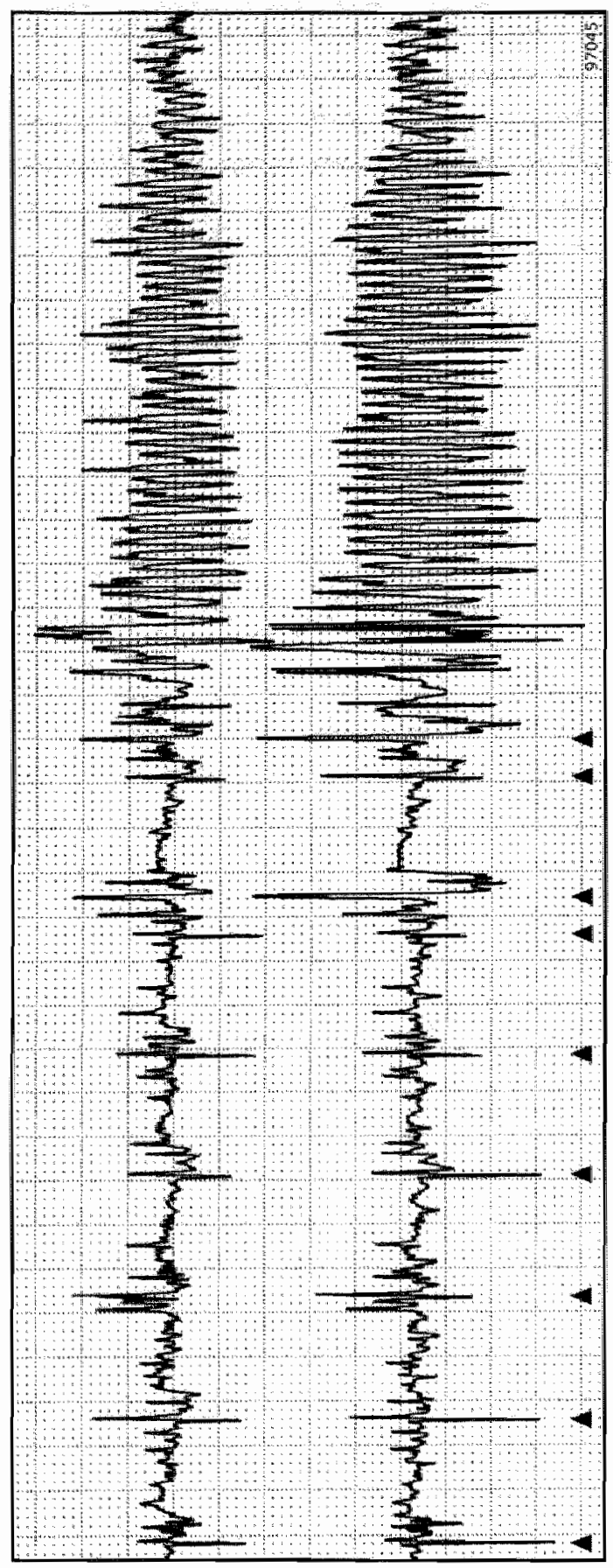

蒙量

등

范

号

덴

목 을

जा

尔 $\geq \frac{0}{2}$

㝵焉

to $\frac{9}{5}$

E

E

5

원원

둥

ठ E E

Q

可

的至 8

प्र

告

론

占

in

은 管

品 $\frac{\omega}{5}$

8 인

눌

5 눙

官

$\pi$ ए

$5 \frac{10}{8}$

5 ए

空点

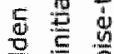

궁을

on 8

동

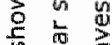

o 3

든

品䓃

崖 3

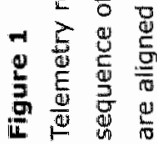


Stanistical anabsts

Pooled data are expressed as mean 1 SD. Comparisons were made using ANOVA followed by a Bonferroni t-test. The area under the curve of receiver-operator characteristics was used to assess the predictive power of variables: $P<0.05$ were considered significant.

\section{Results}

Figure 1 shows a telemetric recording of the arhythmia causing death in a dog with chronic AVB. A short-long-short sequence of the RR intervals precedes a polymorphic ventricular tachycardia deteriorating into lethal ventricular fibrillation.

\section{Beat-to-beat variability of repolarization}

The example in Figure $2 A$ illustrates the oscillatory behavior of the LV MAPD in an anesthetized chronic AVB dog that later died suddenly and unexpectedly under conscious circumstances. At a rather stable idioventricular escape rhythm recorded for 50 minutes (1750 - $1850 \mathrm{~ms}$ ), the LV MAPD changed considerably between 375 and $490 \mathrm{~ms}$. The RV MAPD show lesser degree of fluctuation giving rise to periods with interventricular dispersion exceeding $100 \mathrm{~ms}$. At three time points, the surface ECG and MAP are depicted in Figure $2 \mathrm{~B}$. While the ventricular origin of activation remains constant, large changes in the QT interval and LV MAPD are appreciable, associated with slight alterations in T-wave morphology. In Figure 3,15 minutes of beat-to-beat analysis of the LV MAPD is illustrated from the dog of Figure 2 and compared to a representative control dog with chronic AVB. Large oscillations of LV MAPD seem to be present throughout the whole period in the SCD dog, whereas the LV MAPD of the control dog in a sinilar time frame showed minimal oscillations.

When the 30-minutes temporally averaged electrophysiological parameters (RR, QT, $\mathrm{QT}_{c}$ and $\mathrm{LV}$ - RV- or $\triangle \mathrm{MAPD}$ ) were compared between $\mathrm{SCD}$ dogs and the matched dogs with chronic AVB, no differences were observed (Table 1). Also, when the electrophysiological parameters were compared as the mean from 5 consecutive beats at a single time point, being either the start or the end of the observation period, no differences between the two groups were seen (not shown). Only when the maximal electrophysiological values during the observational period were compared, interventricular dispersion was significantly larger in the SCD dogs: $11 \| \pm 48$ versus control: $66 \pm 23 \mathrm{~ms}, P<0.05$. 


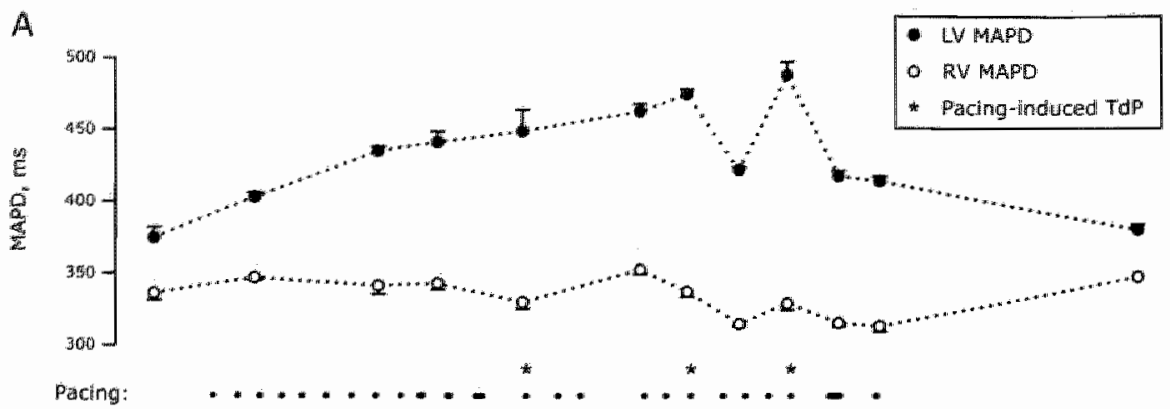

Figure 3:

B

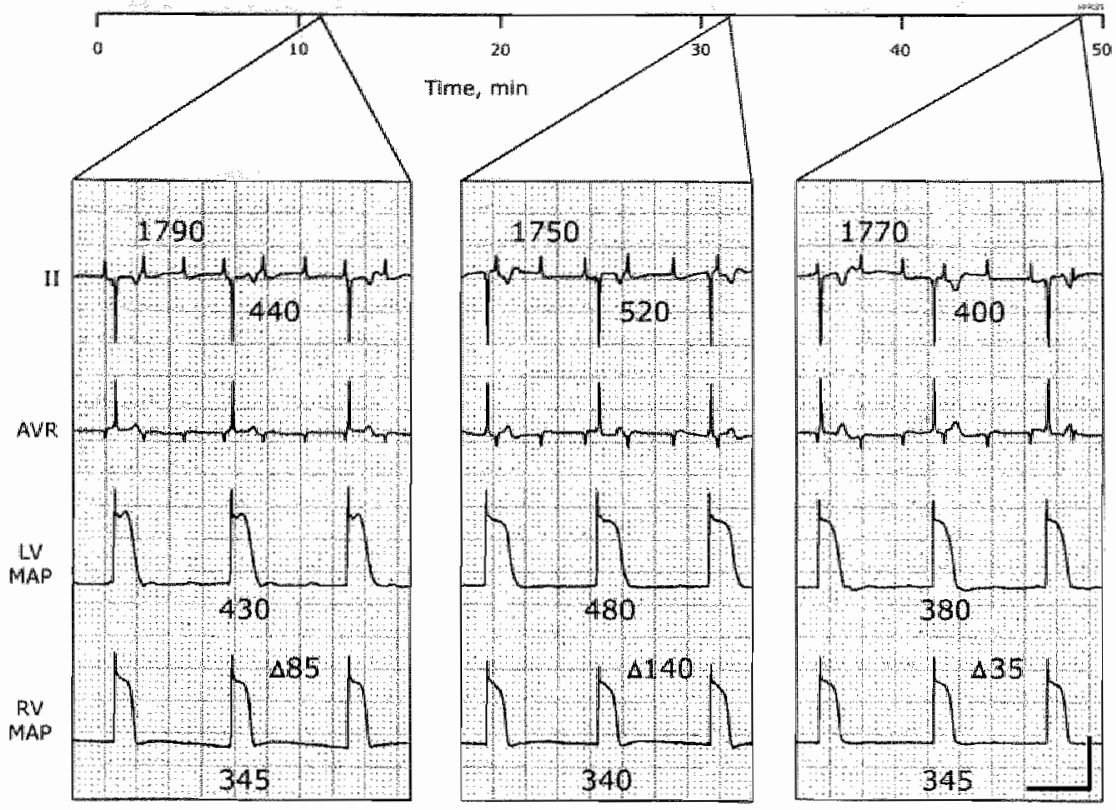

\section{Figure 2.}

A: Left- and right ventricular MAPD displayed at random time points during 50 minutes in an anesthetized dog with chronic AVB, which died 24 days later. Large temporal oscillations of the LV MAPD induce periods of accentuated interventricular dispersion of repolarization.

Maximal differences over the 50-minutes observation period were 115, 40 and $125 \mathrm{~ms}$ for $L V_{\text {, }}$ RV and $\triangle M A P D$, respectively, Pacing from the RV MAP catheter to address proarthythmia and contractile potentiation is indicated along the time axis. Asterisks indicate pacinguinduced TdP.

B: Three representative tracings of ECG and MAP during the time course in A. In periods between pacing, activation of the ventricles had the same focus, while the repolarization had minor shifts based on changing T-wave morphology. RR and QT intervals are noted above and below lead II, respectivelly, while MAPD is visualized under each signal. $\Delta$ : interventricular dispersion. ECG calibrated to $1 \mathrm{mV} / \mathrm{cm}$. Scale bar: 1 second, horizontally versus $20 \mathrm{mV}$ on the $M \mathrm{AP}_{\text {, }}$ vertically. 


\begin{tabular}{|c|c|c|c|c|}
\hline & \multicolumn{2}{|c|}{ Electrophysiological parameters } & \multicolumn{2}{|c|}{ Shortaterm variability } \\
\hline & $S C D$ & Control & $\mathrm{sco}$ & Control \\
\hline $\mathrm{RR}$ & $1599+293$ & $1534+426$ & $18.0 \pm 29.0$ & $11.8 \pm 12, ?$ \\
\hline$Q T$ & $438 \pm 77$ & $403 \pm 32$ & $6.3 \pm 3.2$ & $4.6 \neq 1.7$ \\
\hline $\mathrm{QT}_{\mathrm{C}}$ & $403 \pm 85$ & $356 \pm 39$ & $69 \pm 3$. & $50 \pm 2$, \\
\hline LVMAPD & $407 \pm 71$ & $373 \pm 18$ & $5.1 \pm 2.7$ & $2.5 \pm 0.4 *$ \\
\hline RV MAPD & $339 \pm 46$ & $325 \pm 29$ & $3.0 \pm 1.7$ & $2.9 \pm 0.8$ \\
\hline$\triangle M A P D$ & $69 \pm 36$ & $49 \pm 17$ & $5.8 \pm 2.6$ & $4.1 \pm 0.8$ \\
\hline
\end{tabular}

All measurements in ms. ${ }^{*} P<0.05$ versus $S C D$.

Recently we have introduced methods to quantify beat-to-beat variability of repolarization. ${ }^{9}$ In Figure 4 A, LV MAPD from 30 beats are compared for SCD dogs and control dogs. Although there are large interindividual differences in the mean LV MAPD, the beat-to-beat variability seems to be augmented in the SCD group. By plotting Poincare plots of the 30 beats (Figure $4 \mathrm{~B}$ ), STV as a measure of the width of the plot quantifies the variability. The STV of all electroplysiological parameters are summarized in Table 1 where only STV of the LV MAPD is significantly higher in the SCD group.

\section{Time frame.}

Beat-to-beat variability of LV MAPD in the SCD dog in Figure 3 seems to be present over the whole period independent of whether pacing protocols are performed. To further validate STV measurements of 30 beats, we continuously calculated STV over 15 minutes revealing a minimum STV of $5.9 \mathrm{~ms}$ (at 5 minutes) in the SCD dog compared with a maximum STV of $4.4 \mathrm{~ms}$ (at 6 minutes) in the control dog. Shortening the period over which STV is calculated from 30 to 10 beats results in an STV in the SCD dog that is lower than the maximal STV of the control $\operatorname{dog} 27 \%$ of the time. From 24-beat analysis and longer, STV of the SCD dog is higher than the maximal STV of the control dog constantly during the 15 minutes, supporting our choice of 30 beats. 


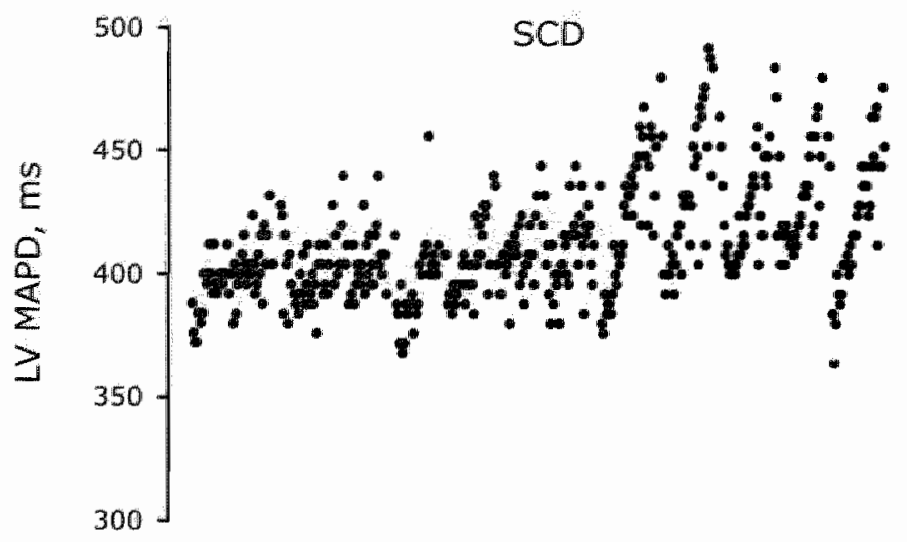

Pacing:
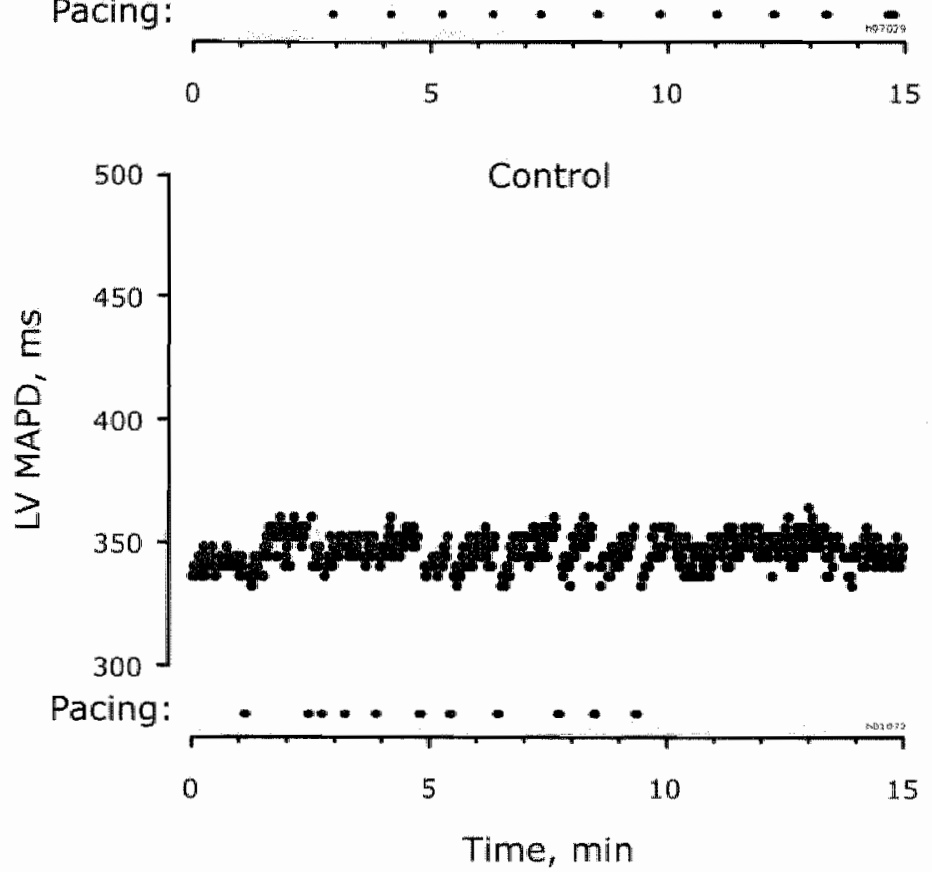

Fitigure 3

LV MAPD of every spontanieous beat during 115 minutes in the SCD dog of Figure 2 (upper panel) and a control dog (lower panel). Again, paicing trains are indicated allong the time axes. Beat-to-beat variability of repolarization seems to be larger in the SCD diog. 
Since availability of 30 minutes is not a prerequisite for analysis of variability we included additional dogs to quantify STV between groups of larger sizes. In Figure 5 it is shown that STV of the LV MAPD increases from $1.3 \pm 0.3 \mathrm{~ms}$ at acute AVB to $2.7 \pm 0.9$ at chronic AVB $(P<0.001)$, while the SCD group still has the highest STV $(5.4 \pm 1.4 \mathrm{~ms} ; P<0.001$ versus chronic AVB). LV MAPD in these larger groups is not significantly different from the smaller groups in Table 1 (chronic AVB: $359 \pm$ $54, \mathrm{n}=61 ; \mathrm{SCD}: 412 \pm 70 \mathrm{~ms}, \mathrm{n}=11 ; P=\mathrm{NS}$ for both).

The heart-to-body weight ratio was significantly higher in remodeled hearts (chronic AVB: $11.1 \pm 1.8$ versus acute AVB: $8.5 \pm 1.1 \mathrm{~g} / \mathrm{kg} ; P<0.01$ ). The heart-to-body weight ratios of the SCD group were comparable to the other chronic AVB dogs $(12.1 \pm 2.1 \mathrm{~g} / \mathrm{kg} ; P=\mathrm{NS})$.

Receiver-operator characteristics were used to compare how strongly the parameters would predict SCD among dogs with chronic AVB. With an area under the curve of 0.97 , STV was superior to the heart-to-body weight ratio (0.72), LV MAPD (0.71) and RR (0.69) in predicting SCD.

\section{Frequency dependency of short-term variability}

We performed a prospective serial investigation to evaluate the association between STV at acute and chronic AVB at two different paced CL (Figure 6). There is no rate dependency of STV in the non-remodeled acute AVB dogs. In the remodeled chronic AVB dogs, STV is only elevated at CL approaching the idioventricular rhythm ( $1400 \mathrm{~ms}$ ), while there is no difference in STV between acute and cluronic AVB at CL comparable to sinus rhythm $(600 \mathrm{~ms})$. Changing from an idioventricular rhythm with inherent heart-rate variability to a paced rhythm of fixed CL does not change STV (Figure 6). 
A

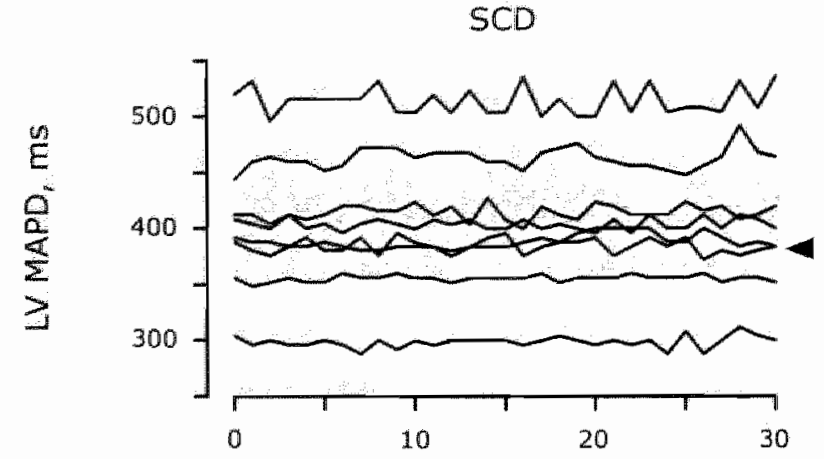

Control

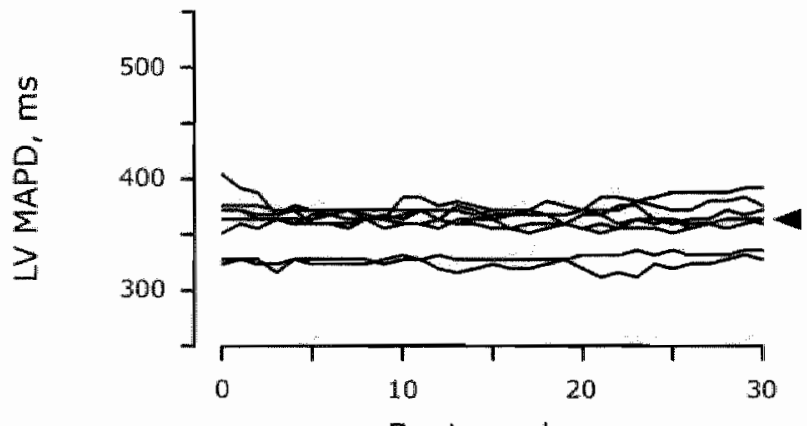

Beat number

B

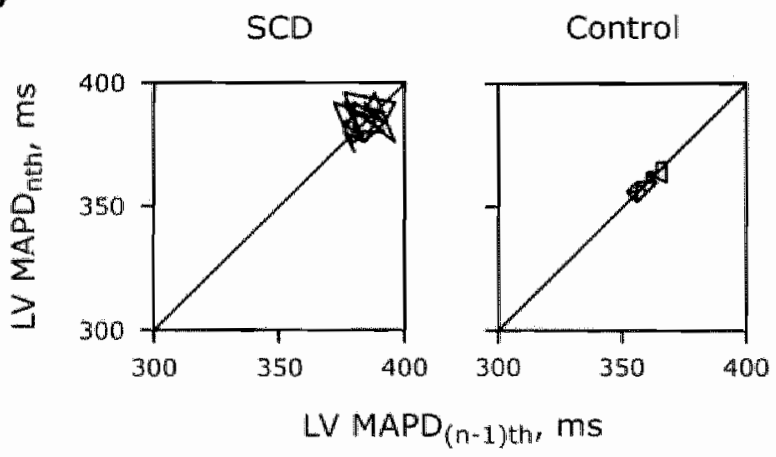

\section{Figure 4}

A: Individual LV MAPD of 30 consecutive spontaneous beats in the 8 SCD dogs (above) and the 8 controll dogs (below).

B: The LV MAPD of every beat is plotted aganinst the LV MAPD of the former beat in one Poincare plot per dog (tracings indicated by arrowheads in A). A larger width of the Poincare plot can be appreciated in the SCD do9, whereas the mean LV MAPD for the two groups was not different (Table 1). 


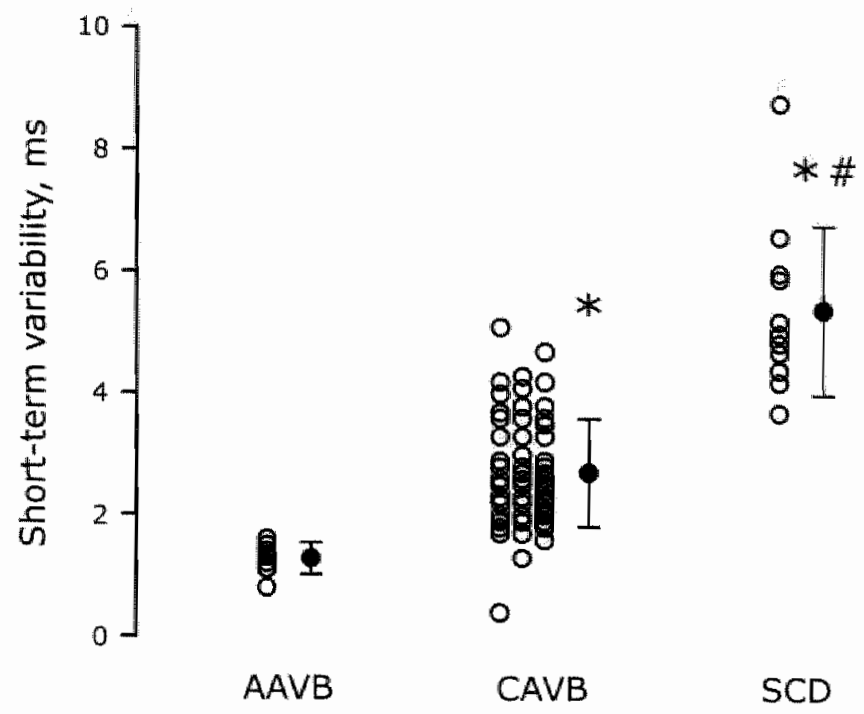

\section{Figure $\mathbf{5}$}

Short-term variability in three phenotypes of dogs at acute AV block (AAVB, $n=9$ ), at chronic AVB (CAVB, $n=61)$ and in the SCD group $(n=11)$. ${ }^{*}, P<0.0001$ versus acute AVB; \#, $P<$ $10^{-11}$ versus chronic AVB.

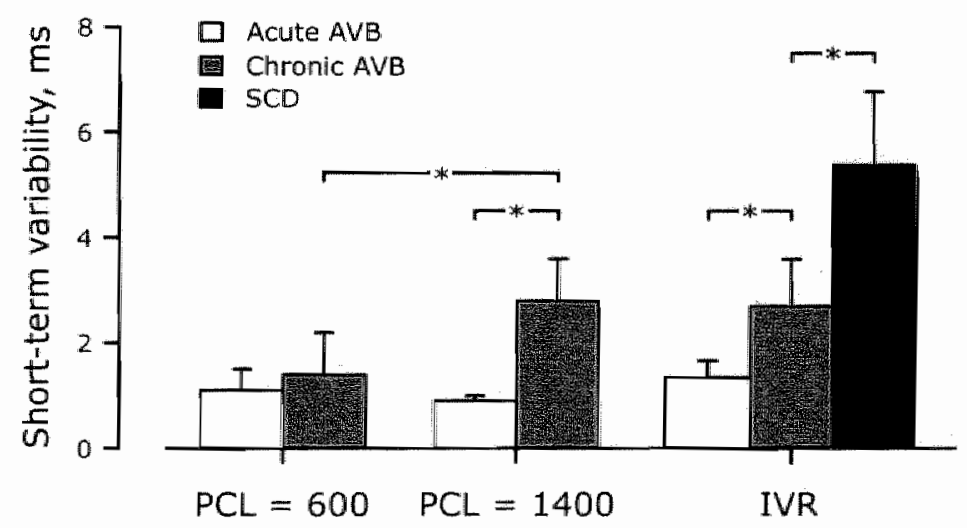

\section{Figure 6}

STV of the LV MAPD at paced CL of 600 and $1400 \mathrm{~ms}$ in dogs with acute and chronic AVB. For comparison, STV measured under idioventricular rate is provided for acute and chronic AVB dogs and for the SCD group (individual data in Figure 5). $*, P<0,05$. 


\section{Discussion}

In the present study, we show that dogs with remodeled hearts due to chronic AVB have larger BVR than control dogs with normal hearts. Furthermore, BVR is reverse-use dependent in chronic AVB dogs. Finally, dogs with remodeled hearts that die suddenly have larger BVR than surviving chronic AVB dogs.

\section{Candiac remadeling and reduced repolarization reserve}

After AVB, several ventricular remodeling processes accur. Using our historical database, we confirm cardiac hypertrophy at the organ level based on an increased heart-to-body weight ratio ${ }^{8: 10}$ On the surface $\mathrm{ECG}$, the QT interval is prolonged and the T-wave morphology changed. ${ }^{15}$ Locally, the endocardially-recorded ventricular MAPs are inhomogenously prolonged, augmenting interventricular dispersion of repolarization. Cellular action-potential prolongation can partly be explained by the downregulation of the delayed rectifier potassium currents and by upregulation of the sodium-calcium exchange current. ${ }^{15-17}$ The compensated hemodynamic state is achieved by contractile adaptations in both ventricles. ${ }^{8}$ Enhanced sarcoplasmic reticulum calcium release improves contraction, especially at slow rates. ${ }^{17}$ These ventricular adaptation processes contribute to an enhanced susceptibility to repolarization-dependent arthythmia, seen as afterdepolarizations in vitro ${ }^{18}$ and afterdepolarization-dependent triggering of arrhythmia in vivo ${ }^{17,19}$ In response to infusion of drugs with $I_{\mathrm{Kr}}$-blocking characteristics, there is a higher propensity of $T d P$ in the dogs with chronic AVB. ${ }^{6,7}$ Whereas no drug-induced TdP is seen in dogs with acute AVB, the chronic AVB dogs has a 56-67\% risk of TdP after the same drugs, ${ }^{4,6,720}$ Based on these findings, we believe that compared with acute AVB, at chronic AVB the dogs have a diminished repolarization reserve, ${ }^{21}$ by which they are unable to withstand a challenge on repolarization and thereby more vulnerable to TidP.

The 22 dogs that died suddenly constitute a population of the chronic AVB dogs that experience arrhythmias under anesthesia as well as under conscious circumstances (Figures 1, 2 and reference ${ }^{5}$ ). This is a unique characteristic, since induction of arrhythmia in the majority of the chronic AVB population requires additional hits, e.g. by administration of $I_{k,}$ blockers, anesthesia and/or pacing. ${ }^{4}$ Earlier studies by our group showed that maximal LV MAPD and interventricular dispersion of repolarization during baselines of variable lengths were significantly larger in SCD dogs than in 78 control dogs with chronic AVB. A number of the SCD dogs were observed to experience syncope followed by death in association with a suspected 
increase in adrenergic tone: ${ }^{5}$ One possible explanation for the vulnerable substrate is that the reported downregulation of $\int_{\mathrm{K} \text {. }}$ induces a loss of repollarisation shortening after $\beta$-adrenergic stimulation, which would be most dangerous at fast heart rates or during sudden rate changes. 14,15

\section{Beat-io-beat variability of repolarization}

From Figure 3 it is appreciable that the variability of repolarization in SCD dogs is not a slow undulating phenomenon, but that it configures as a scatter of large instantaneous changes. Hence, extensive baseline recordings may not be nequired for an assessment of variability. Earlier quantification of beat-to-beat vartability of repolarization was restricted to 30 consecutive beats, which showed to be valuable in predicting the occurrence of drug-induced $T d P$ in anesthetized dogs with chronic AVB. ${ }^{9}$ Our preferred quantification of beat-to-beat variability of repolarization is short-term variability (STV). In this analysis, the direct differences in duration of two consecutive beats are averaged over a 30 -beat period. In the example of Figure 3 , we measured every beat in a 15-minute time frame. It is shown that the STV of an SCD dog is at all times were higher than the maximal STV of a control dog. Thus, in this setting, the analysis of a single epoch of 30 beats gathers enough information to identify the vulnerable animal.

Only the STV of the LV MAPD showed significant differences between SCD dogs and control dogs, whereas the electrophysiological parameters, including RR and QT intervals from the surface FCG, the right ventricular MAPD and the interventricular difference in MAPD did not differ (Table 1). Furthermore, in the statistical analysis of predictive power, STV of the LV MAPD was superior to both temporally averaged LV MAPD and RR intervals. Table 1 also shows, that only the STV of LV MAPD is increased in the SCD population while the STV of other repolarization parameters does not contain similar information. The global nature of the QT interval versus the local recoding of an MAP signal suggests that BVR is a regional phenomenon, giving rise to the hypothesis that local discordant differences in repolarization duration render the tissue susceptible to arthythmias by the infringement of focally triggered extrasystoles. ${ }^{20.22}$ The RV MAPD did not show an increased STV in the SCD population, suggesting a stronger repolarization reserve in the right ventricle, which indeed fits with previous cellular findings of larger repolarizing currents in the right than in the left ventricle. ${ }^{2 \pi-2.5}$

It is tempting to speculate that the genetic nature of individual animals determines whether a dog develops the lethal SCD phenotype or a stable one upon induction of AVB. In the SCD population, instances of increased adrenergic drive during specific 
Chapter

conditions (e.g. feeding or excitement) may profoundly exaggerate BVR leading to arrhythmic death.

\section{Influence of heart rate on beat-to-beat variability of repolarization}

In the non-remodeled heart, STV appears to be heart-rate independent (Figure 6). A long CL facilitates STV in dogs with chronic AVB, whereas faster pacing decreases STV. The STV at $1400 \mathrm{~ms}$ paced CL is comparable to the STV during idioventricular rate, suggesting that the limited heart-rate variability at spontaneous ventricular rhythm does not infuence STV. A decrease in STV as heart rate increases argues against proarrhythmia at increased adrenergic drive as the cause of SCD. However, it is possible that the relationship between STV and CL is altered by anesthesia. Furthermore, there is likely to be direct influences of increased adrenergic drive on STV that are not mimicked by ventricular pacing.

\section{Novel parameters associated with sudden cardiac death}

In the clinic, T-wave alternans and heart-rate variability are promising parameters for identifying the indivicual at risk. ${ }^{26-30}$ A potential new proarrhythmic marker is the QT variability index (QTVI), a non-invasive parameter that normalizes the QT variance for the heart-rate variance over a 5 -minute period. ${ }^{31}$ Specifically, patients with a history of SCD have a significantly higher QTVI than patients with heart disease without SCD.'

Drug-induced repolarization-dependent arrhythmias have previously been associated with early markers like prolongation and instability of the MAPD in the isolated rabbit heart. ${ }^{13}$ Recently, other parameters like transmural dispersion of repolarization in ventricular wedge preparations have been very useful for understanding the role of repolarization gradients in proarrhythmia. ${ }^{32}$

In the Western population, reported overall incidences lie between 0.1 and $0.2 \%$. Still, too often SCD is the first manifestation of cardiovascular disease. ${ }^{33}$ These aspects strongly support further investigations of these predictive techniques. The present study shows that BVR is increased in dogs that experience $\mathrm{SCD}$, which calls for clinical studies to determine whether elevated BVR could herald SCD in humans too. 


\section{Study limitations}

In this study, variability of repolarization was limited to invasive, endocardial recordings in anesthetized dogs with remodeled hearts. All experiments were performed under anesthesia, which has profound effects on electrophysiological parameters, ${ }^{34,35}$ however the anesthetic treatment was identical in all experiments. Not all sudden deaths were witnessed or recorded through telemetric devices, so we are not able to generalize upon the mode of death. Still, we consider repolarizationdependent arrhythmias as the most probable cause of death. This study established an association between increased $\mathrm{BVR}$ and $\mathrm{SCD}$, whereas a prospective design is needed to elucidate possible common denominators.

\section{Conclusions}

Electrical ventricular remodeling after AVB is associated with an increase in shortterm variability of repolarization, which is reverse-use dependent at chronic AVB. Chronic AVB dogs that suffer SCD have an even higher STV, suggesting that BVR could be a potential additional parameter in the identification of the patient at risk for sudden cardiac death.

\section{Acknowledgments}

H. Lundbeck, Denmark, financially supported M. B. Thomsen. The Netherlands Organization for Health and Development supported P.G.A. Volders (ZonMw 90602-068). 


\section{References}

1. Atiga WL, Calkins H, Lawrence JH, Tomaselli GF, Smith JM, Berger RD. Beat-tobeat repolarization lability idemifies patients at risk for sudden cardiac death. $J$ Cardiovase Electrophysiol. 1998;9:899-908.

2. Gorgels AP, Gijsbers $\mathrm{C}$, de Vreede-Swagemakers J, Lousberg A, Wellens HJ. Outof-hospital cardiac arrest--the relevance of heart failure. The Maastricht Circulatory Arrest Registry. Eur Heart J. 2003;24:1204-9.

3. Myerburg RJ, Interian A, Jr., Mitrani RM, Kessler KM, Castellanos A. Frequency of sudden cardiac death and profiles of risk. Am J Cardiol. 1997;80:10F-19F.

4. Verduyn $\mathrm{SC}$, Vos MA, van der Zande J, Kulcsar A, Wellens H.J. Further obserwations to elucidate the role of interventricular dispersion of repolarization and early afterdepolarizations in the genesis of acquired torsade de pointes arrhythmias: a comparison between almokalant and d-sotalol using the dog as its own control. $J$ Am Coll Cardiol. 1997;30:1575-84.

5. wan Opstal JM, Verduyn SC, Leunissen HDM, de Groot SHM, Wellens HJ, Vos MA. Electrophysiological parameters indicative of sudden cardiac death in the dog with chronic complete AV-block. Cardiovascular Research. 2001;50:354-361.

6. wan Opstal JM, Leunissen $\mathrm{JD}_{t}$ Wellens HJ, Vos MA. Azimilide and dofetilide produce similar ellectroplysiological and proarrhythmic effects in a canine model of Torsade de Pointes arrhythmias. Eur I Pharmaciol. 2001;412:67-76.

7. Thomsen MB, Volders PG, Stengl M, Spätjens RL, Beekman JD, Bischoff U, Kall MA, Frederiksen K, Matz J, Vos MA. Electrophysiological safety of sertindole in dogs with normal and remodeled hearts. I Pharmacol Exp Ther. 2003;307:776-84.

8. Vos MA, de Groot SH, Verduyn SC, van der Zande I, Leunissen HD, Cleutjens IP, van Bilsen M, Daemen MJ, Schreuder JJ, Allessie MA, Wellens HJ. Enhanced susceptibility for acquired torsade de pointes arrhythmias in the dog with chronic, complete AV block is related to cardiac hypertrophy and electrical remodeling. Circulation. 1998;98:112535.

9. Thomsen MB, Verduyn SC, StengI M, Beekman JD, de Pater G, Van Opstal JM, Volders PG, Vos MA. Increased short-term variability of repolarization predicts d-sotalolinduced torsades de pointes in dogs. Circulation. 2004;110:2453-2459.

10. Schoenmakers M, Ramakers C, wan Opstal JM. Leunissen JD, Londono C, Vos MA. Asynchronous development of electrical remodeling and cardiac hypertrophy in the complete AV block dog. Cardiovase Res. 2003;59:351-9.

11. Verduyn SC, Rannakers C. Snoep G, Leunissen JD, Wellens HJ, Vos MA. Time course of structural adaptations in chronic AV block dogs: evidence for differential wentricular remodeling. Am J Physiol Hear Circ Physiol, 2001;280;H2882-H2890.

12. Van de Water A, Verheyen $J$, Xhomeux R, Reneman RS. An improved method to correct the QT interval of the electrocardiogram for changes in heart rate. J Pharmacal Methods. 1989;22:207-17.

13. Hondeghen LM, Carlsson L, Duker G. Instability and triangulation of the action potential predict serious proarrhythmia, but action potential duration prolongation is antiarthythmic. Circulation. 2001;103:2004-13.

14. Volders PG, Stengl M, van Opstal JM, Gerlach U, Spatjens RL, Beekman ID, Sipido KR, Vos MA. Probing the contribution of IKs to canime ventricular repolarization: key role for beta-adrenergic receptor stimulation. Circulation, 2003;107:2753-60.

15. Volders PG, Sipido KR, vos MA, Spatjens RL, Leunissen JD, Carmeliet E, Wellens HJ. Dowmegulation of delayed rectifier $K(+)$ currents in dogs with chronic complete zatrioventricular block and acquired torsades de pointes. Circulation. 1999;100:2455-61.

16. Thomas GP, Vos MA, Antzelevitch $C$. The effect of volume overload hypertrophy on transmural distribution of the delayed rectifier (IKr and IKs) and transient outward (Ito) 
currents in the canime heart (Abstract). Pacing Clin Elechophysiol. 2001,24:234.

17. Sipido KR, Volders $\mathrm{PG}$, de Groot $\mathrm{SH}$, Verdonck $\mathrm{F}_{\text {, Van de Werf }} \mathrm{F}_{\mathrm{s}}$ Wellens $\mathrm{HJ}$, Vos MA. Enhanced $\mathrm{Ca}(2+)$ release and $\mathrm{Na} / \mathrm{Ca}$ exchange activity in hypertrophied canine. ventricular myocytes: potential link between contractile adaptation and arrhythmogenesis. Circulation. 2000;102:2 1137.44 .

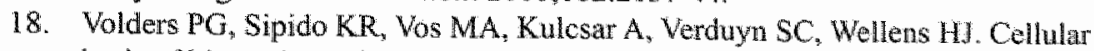
basis of biventricular hypertrophy and arthythmogenesis in dogs with chronic complete atrioventricular block and acquired torsade de pointes. Circulation. 1998;98:1136-47.

19. de Groot SH, Schoenmakers M, Molenschot MM, Leunissen. JD, Wellens HJ, Vos MA. Contractile adaptations preserving cardiac output predispose the hypertrophied canine heart to delayed afterdepolarization-dependent ventricular arthythmias. Circulation. 2000; 102:2145-2151.

20. Schreiner KD, Voss F, Senges JC, Becker $R$, Kuft P, Bauer A, Kelemen K, Kuebler W, Vos MA, Schoels $W$. Tridimensional activation patterns of acquired torsade-depointes-tachycardias in dogs with chronic AV-block Basic Res Cartiol. 2004;99:288-98.

21. Roden DM. Taking the "idio" out of "idiosyncratic": predicting torsades de pointes. Pacing Clin Electrophysial. 1998;21:1029-1034.

22. Senges JC, Sterns LD, Freigang KD, Bauer A, Becker R, Kubler W, Schoels W. Cesium chloride induced ventricular arhythmias in dogs: three-dimensional activation patterns and their relation to the cesium dose applied. Basic Res Cardiol. 2000;95:152-62.

23. Ramakers C, Vos MA, Doevendans PA, Schoenmakers M, Wu YS, Scicchitano S, lodice A, Thomas GP, Antzelevitch C, Dumaine R. Coordinated down-regulation of $\mathrm{KCNQ1}$ and $\mathrm{KCNEI}$ expression contributes to reduction of $\mathrm{I}(\mathrm{Ks})$ in canine hypertrophied hearts. Cardiovase Res. 2003;57:486-496.

24. Di Diego JM, Sun ZQ, Antzelevitch C. I(to) and action potential notch are smaller in left vs. right camine ventricular epicardium. Am $J$ Physiol. 1996;271:H548-61.

25. Volders PG, Sipido KR, Carmeliet E, Spatjens RL, Wellens HJ, Vos MA. Repolarizing $\mathrm{K}+$ currents ITOI and IKs are larger in right than left canine ventricular midmyocardum. Circulation. 1999;99:206-10.

26. Hohnloser SH, Klingenheben T, Li YG, Zabel M, Peetermans J, Cohen RJ. T wave alternans as a predictor of recurrent ventricular tachyarrhythmias in ICD recipients: prospective comparison with conventional risk markers. I Cardiovase Electrophysiol. 1998;9:1258-68.

27. Kozhevnikov DO, Yamamoto K, Robotis D, Restivo M, El Sherif N. Electrophysiological mechanism of enhanced susceptibility of hypertrophied heart to acquired torsade de pointes arrhythmias: tridimensional mapping of activation and recovery patterns. Circulation, 2002;105:1128-1134.

28. Rosenbaum DS, Jackson LE, Smith JM, Garan H, Ruskin JN, Cohen RJ. Electrical alternans and wulnerability to ventricular arrhythmias. N Engl J Med. 1994;330:235-41.

29. Huikuri HV, Makikallio TH, Raatikainen MJ, Perkiomaki J, Castellanos A, Myerburg RJ. Prediction of sudden cardiac death: appraisal of the studies and methods assessing the risk of sudden arritythmic death. Circularion. 2003;108:110.5.

30. Josephson M, Wellens H.I. Implantable defibrillators and sudden cardiac death. Circulation. 2004;109:2685-91.

31. Berger RD, Kasper EK, Baughman KL Marban E, Callkins H, Tomaselli GF, Beatto-beat QT interval variability: novel evidence for repolarization lability in ischemic and nonischemic dilated cardiomyopathy. Circulation. 1997:96:1557-1565.

32. Antzelevitch C, Shimizu W. Cellular mechanisms underlying the long QT syndrome. Curr Opin Cardiol. 2002;17:43-51.

33. Zipes DP, Wellens. HJ. Sudden cardiac death. Circulation. 1998;98:2334-2351.

34. Shimizu W, McMahon B, Antzelevitch C. Sodiun pentobarbital reduces transmural dispersion of repolarization and prewents torsades de Pointes in models of acquired and 
Chaperats

congenital long QT syndrome. I Cardiovasc Electrophysiol. 1999;10:154-64.

35. Yamamoto $K$. Tamura $T$, Imai R, Yamamoto M. Acute canine model for drug-induced Torsades de Pointes in drug safety evaluation-infuences of anesthesia and validation with quinidine and astemizole. Toxicol Sci. 2001;60:165-76. 


\section{Beat-to-Beat Variability of Repolarization Determines Proarrhythmic Outcome in Dogs Susceptible to Drug-Induced Torsades de Pointes}

Morten B. Thomsen 1.2, Paul G.A. Volders', Jet D.M. Beekman', Jorgen Matz and $\operatorname{Marc}$ A. $\operatorname{Vos}^{2}$

1. Department of Medical Physiology, Heart Lung Center Utreclyt, University Medical Center Utrecht, Utrecht, Netherlands.

2. Department of Cardiology, Cardiovascular Research Institute Maastricht, Maastricht University, Maastricht, Netherlands.

3. Center of Exceltence, Cardiovascular Research, H. Lundbeck, Copenhagen, Denmark. 


\section{Abstract}

Recent results in dogs show that increased beat-to-beat variability of repolarization (BVR) predicts drug-induced torsades de pointes (TdP) more accurately than conventional measures of repolarization prolongation. We investigated whether increasing or decreasing BVR would change proarrhythmic outcome accordingly. The non-cardiovascular $I_{\mathrm{k}:}$-blocking drug sertindole $(1.0 \mathrm{mg} / \mathrm{kg}$ i.v.) induced $\mathrm{TdP}$ in 10 of 13 anesthetized dogs with chronic AV block. At a lower dose $(0.2 \mathrm{mg} / \mathrm{kg}$ i.v. no TdP was induced, despite similar increases in QT intervals $(1.0 \mathrm{mg} / \mathrm{kg}: 400$ \pm 60 to $495 \pm 65 \mathrm{~ms}, P<0.05$ (*); $0.2 \mathrm{mg} / \mathrm{kg}: 400 \pm 60$ to $475 \pm 85 \mathrm{~ms} *$ ). BVR, quantified as short-term variability (STV) from Poincaré plots (STV $=\sum \mathrm{D}_{\mathrm{n}+1}$ $\mathrm{D}_{n} \mid /\left[30^{*} \sqrt{2}\right], \mathrm{D}=$ left ventricular monophasic action potential duration (LV MAPD)), was the only parameter that was associated with TdP outcome $(1.0 \mathrm{mg} / \mathrm{kg}: 2.3 \pm 1$ to $5.1 \pm 2 * ; 0.2 \mathrm{mg} / \mathrm{kg}: 2.3 \pm 1$ to $3.2 \pm 1, P=\mathrm{NS}$ ). Three interventions were used to prevent sertindole-induced TdP. None of these altered the sertindole-induced prolonged QT interval, LV MAPD or interventricular dispersion of MAPD. (1) KCl infused i.v. elevated plasma potassium from $2.8 \pm 0.3$ to $4.6 \pm 0.9 \mathrm{mM}$ and reduced the incidence of sertindole-induced TdP from 6 of 7 to 1 of 7 dogs*. During $\mathrm{KCl}$ treatment sertindole-related increase of STV was much lower: $3.0 \pm 1$ versus $4.5 \pm$ $1 \mathrm{~ms}^{*}$. (2) Levcromakalim ( $I_{\mathrm{K}, \mathrm{ATP}}$ activator, $3 \mu \mathrm{g} / \mathrm{kg} \mathrm{i} . \mathrm{v}$.) reduced sertindole-induced TdP and decreased STV from $4.9 \pm 2$ to $2.6 \pm 1 \mathrm{~ms}^{*}$. (3) Steady-state ventricular pacing $(60 \mathrm{bpm})$ momentarily abolished sertindole-induced TdP and decreased STV from $4.9 \pm 2$ to $3.2 \pm 1^{*}$. TdP reappeared upon return to ventricular rhythm.

Manipulation of BVR is feasible in the intact dog heart. The magnitude of BVR determines proarrhythmic outcome. BVR proves to be a superior marker for the prediction and prevention of drug-induced TdP. 


\section{Introduction}

Drug-induced torsades de pointes arrhythmia (TdP) is an unwanted adverse effect, which by definition is associated with prolonged ventricular repolarization. However, it has been demonstrated that QT prolongation does not have to be proarrhythmic. ${ }^{1-6} \mathrm{TdP}$ incidences by non-cardiovascular QT-prolonging drugs is very llow relative to the number of treated patients. In these few affected patients, it is hypothesized that the drug is the final hit in an already vulnerable heart. This predisposition is thought to be the result of an insufficient repolarization reserve, which can be inherited, acquired or both. 8.9 Identifying the patient at risk and preventing arrhythmia by enhancing his or her repolarization reserve are long-sought medical aspirations. Classical electrophysiological parameters, such as the duration of the QT interval, seem to be of limited value in quantifying repolarization reserve. Recently, beat-to-beat variability of repolarization (BVR) has been introduced as an alternative. $^{2}$

In anesthetized dogs with chronic AV block (CAVB) predisposed for drug-induced $T d P,{ }^{1,10-12}$ baseline BVR is increased during electrical remodeling. ${ }^{13}$ The highest BVR values were obtained in CAVB dogs that later suffered sudden cardiac death. ${ }^{13}$ Furthermore, we showed that a dose-dependent increase in BVR was predicting proarrhythmic outcome after $d$-sotalol administration. ${ }^{2}$ Chronic amiodarone administration, a drug considered free of proarrhythmia in patients, did not increase BVR or induce TdP in CAVB dogs. ${ }^{2,6,14}$ Similarly, we observed an unchanged BVR and concurrent absence of TdP after increasing the infusion time of NS-7, a drug in development for anti-stroke therapy. ${ }^{15}$

Thus, we believe that BVR, quantified as short-term variability (STV), could be an alternative parameter to detect decreased repolarization reserve. In the present study, we investigated whether increasing or decreasing BVR would change proarrhythmic outcome accordingly. For this purpose, we examined the dose-dependent induction of TdP after administration of the antipsychotic drug sertindole linking this to differential changes of STV. We employed three interventions with the aim of enhancing repolarization reserve to control BVR and prevent or suppress sertindoleinduced TdP. During all of these interventions, we examined the value of STV versus other repolarization-prolongation parameters. 


\section{Methods}

\section{General}

Animal handling was in accordance with the European Directive for the Protection of Vertebrate Anmals Used for Experimental and Other Scientific Purposes (86/609/EU). The Committee for Experiments on Animals of Utrecht University approved all experiments. In a preliminary experiment, AV block was induced in 11 dogs (Marsitiall, $\mathrm{NY}$ ) by radiofrequency ablation according to methods previously described. "Experiments reported here were performed $>4$ weeks after ablation allowing cardiac remodeling to complete." Three animals died unexpectedly before experiments could be performed. Complete anesthesia was induced by sodium pentobarbital ( $20 \mathrm{mg} / \mathrm{kg} \mathrm{i.v}$ ) and maintained by halothane $\left(0.5 \%\right.$ in $\mathrm{O}_{2}$

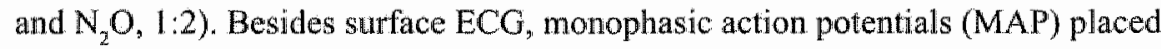
endocardially on the free walls of the left (LV) and right ventricle (RV), were recorded. Perioperative care, signal processing and data recording have been described in detail previously. ${ }^{12}$ All drugs were administered intravenously. Plasmapotassium levels were measured from samples taken from a contra-lateral vein (ABL, Radiometer, Denmark).

\section{Dose-dependent induction of TdP}

Five dogs received serially 0.2 and $1.0 \mathrm{mg} / \mathrm{kg}$ sertindole in a random-crossover design with two weeks between experiments. Additional 3 dogs received only 1.0 $\mathrm{mg} / \mathrm{kg}$. The data set was extended by adding experiments from 9 additional dogs $\left(\mathrm{n}_{0.2}=4 ; \mathrm{n}_{1,0}=5\right)$ participating in a previously reported sertindole study.' Sertindole (purchased from H. Lundbeek, Denmark) was administered over 5 minutes i.v.

\section{Prevention of TdP by elevating plasma-potassium concentrations}

Seven dogs received $1.0 \mathrm{mg} / \mathrm{kg}$ sertindole with and without potassium-pretreatment in a random-crossover design. 30 to $60 \mathrm{mmol} \mathrm{KCl}$ was infused over 2 hours, where after $1.0 \mathrm{mg} / \mathrm{kg}$ sertindole was administered as the proarrhythmic challenge. Potassium levels and ECG were monitored every 10 minutes. 
Suppression of drug-induced TdP by levcromakalin-induced activation of $\|_{K A T P}$

In 7 experiments after sertindole-induced TdP, the $I_{\mathrm{K}, \mathrm{ARP}}$ opener levcromakalim ( 3 and $10 \mu \mathrm{g} / \mathrm{kg} / 3$-minutes, i.v.) was administered with a 10 -minute interval. Measurements were done 5 to 10 minutes after the start of levcromakalim administration. Because the higher dose of leveromakalim is antiarrhythmic and shortens repolarization parameters, we also selected the lower dose to possibly dissociate the effects on increased BVR and prolonged repolarization.

\section{Preventing reappearance of $T d P$ by right ventricular pacing}

Six dogs were paced from the RV MAP catheter $(60 \mathrm{bpm})$ directly after the reproducible occurrence of sertindole-induced TdP was noted. In this way, the antiarrhythmic effects of controlled heart rate on BVR were evaluated. Pacing intervention was considered successful when no extrasystoles or TdP had occurred for 2 minutes.

\section{Analysis}

Mean RR and QT intervals from lead III were measured manually (ECGview, Maastricht University). Durations of the MAP to $90 \%$ repolarization (MAPD) were determined semi-automatically (ECG-Auto, EMKA Technologies, France). Interventricular dispersion ( $\triangle M A P D$ ) was defined as LV minus RV MAPD. Measurements were performed during periods without extrasystolic activity as previously described. ${ }^{2}$ BVR was assessed from 30 consecutive beats and quantified as short-term variability (STV) describing the mean orthogonal distance to the lineof-identity on a Poincaré plot, as described earlier ${ }^{2}$ (Figure 1, STV $=\sum\left|D_{n+1}-D_{n}\right|$ $/\left[30^{*} \sqrt{2}\right]$, where D represents LV MAPD). Dogs were considered inducible when 3 or more TdP consisting of $>5$ beats were observed.

\section{Statistical analysis}

Pooled data are expressed as mean $\pm \mathrm{SD}$. Comparisons were performed with 2 way ANOVA or I-way repeated measures ANOVA followed by paired Bonferroni comparisons. TdP incidences were compared with a Chi-square test. Statistical difference was acknowledged at $P<0.05$. 


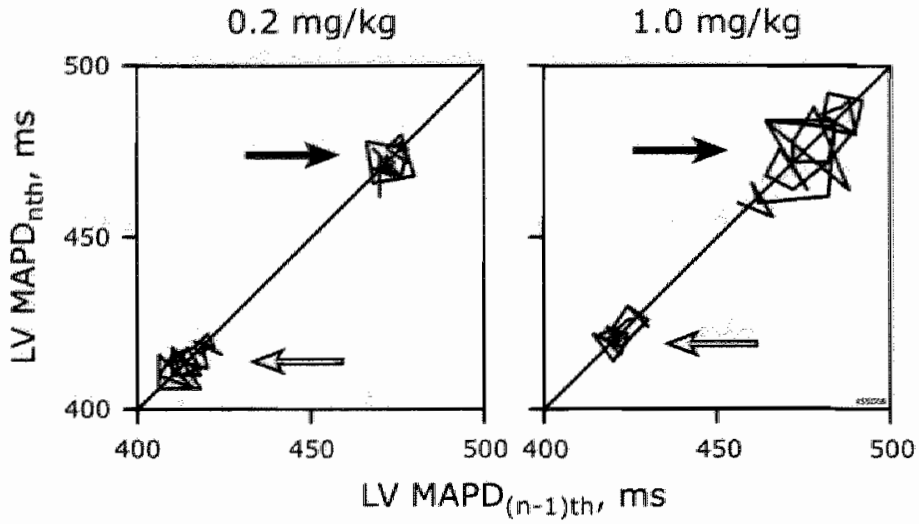

Flgure 1

Poincare plots obtained from a dog under the influence of $\|$ ow $(0.2 \mathrm{mg} / \mathrm{kg}$, left) or high dose (1.0 mg/kg, right) sertinciole. At control (open arrows), comparable low BVR ( 2.3 and $2.5 \mathrm{~ms}$, respectively) and LV MAPD are present. After administration of sertindole (closed arrows), the mean LV MAPD prolongs to similar levels, while STV is only increased after the proarrhythmic high dase ( 2.6 and $5.2 \mathrm{~ms}$, respectively).

Table 1, sertindole-induced changes in electrophysiological parameters and TdP.

\begin{tabular}{|c|c|c|c|c|}
\hline & Control 1 & $0.2 \mathrm{mg} / \mathrm{kg}$ & Control 2 & $1.0 \mathrm{mg} / \mathrm{kg}$ \\
\hline $\mathrm{RR}, \mathrm{ms}$ & $1384 \pm 349$ & $1407 \pm 318$ & $1427 \pm 228$ & $1503 \pm 268$ \\
\hline $\mathrm{QT}, \mathrm{ms}$ & $400 \pm 60$ & $474 \pm 85^{*}$ & $398 \pm 60$ & $496 \pm 65^{*}$ \\
\hline $\mathrm{QT}_{\mathrm{c}^{\prime}} \mathrm{ms}$ & $367 \pm 54$ & $439 \pm 78 *$ & $361 \pm 54$ & $45.2 \pm 63^{*}$ \\
\hline LV MAPD, ms & $353 \pm 51$ & $416 \pm 66^{*}$ & $336 \pm 48$ & $427 \pm 66^{*}$ \\
\hline RV MAPD, ms & $307 \pm 37$ & $354 \pm 48 *$ & $3018 \pm 43$ & $370 \pm 61^{*}$ \\
\hline$\triangle M A P D, m s$ & $46 \pm 36$ & $62 \pm 27$ & $27 \pm 20$ & $57 \pm 45$ \\
\hline STV $\mathrm{ms}$ & $2.3 \pm 0.8$ & $3.2 \pm 1.1$ & $2.3 \pm 0.7$ & $5.1 \pm 2.1 * \dagger$ \\
\hline TdP & - & 0 of 9 & . & 10 of $13 *$ \\
\hline
\end{tabular}

There are no differences in values before the two experiments. TdP quantified as the number of Inducible dogs relative to group size. $*, P<0.05$ versus baseline; $t, P<0.05$ versus $0.2 \mathrm{mg} / \mathrm{kg}$ sertindole.

\section{Results}

\section{Dose-dependent induction of TdP}

All electrophysiological parameters were similar at the start of the dose-dependent sertindole experiments. No difference was seen between the serial $(n=5)$ and the group comparison (Table 1). No dogs were inducible after the low dose while 10 
of 13 dogs showed TdP after $1.0 \mathrm{mg} / \mathrm{kg}$ sertindole $(P<0.05$; Table 1$)$. QT interval, LV and RV MAPD were all significantly increased to comparable levels atter the two doses of sertindole (Table 1). There was an increase in STV after $1.0 \mathrm{mg} / \mathrm{kg}$ sertindole $(2.3 \pm 0.7$ to $5.1 \pm 2.1 \mathrm{~ms}, P<0.001)$, while $0.2 \mathrm{mg} / \mathrm{kg}$ sertindole did not change STV $(2.3 \pm 0.8$ to $3.2 \pm 1.1, P=$ NS; Table 1, Figure 1). Furthermore, the STV reached after $1.0 \mathrm{mg} / \mathrm{kg}$ sertindole was significantly higher than the STV induced by $0.2 \mathrm{mg} / \mathrm{kg}$ sertindole $(P<0.05)$.

\section{Prevention of TdP by elevating plasma-potassim concentration}

Infusion of $\mathrm{KCl}$ increased plasma potassium from $2.8 \pm 0.3 \mathrm{mmol} / \mathrm{L}$ to $4.6 \pm 0.9$ mmol $/ L(P<0.05 ;$ Figure 2$)$. This did not lead to any changes in the ventricular electrophysiological parameters (Figure 2; QRS width changed from $81 \pm 16$ to $88 \pm 15 \mathrm{~ms}, P=\mathrm{NS}$ ). In the serial comparison, baseline STV was not altered by elevated potassium levels (Figure 3). Potassium pretreatment, however, reduced the sertindole-induced TdP incidence from 6 of 7 to 1 of $7(P<0.05$; Figure 3$)$, which was not associated by differential changes in RR (1557 \pm 37 versus $1816 \pm 615 \mathrm{~ms}$; no potassium versus potassium pretreatment, respectively), QT (488 \pm 64 versus 528 $\pm 79 \mathrm{~ms}), \mathrm{LV}$ MAPD ( $408 \pm 65$ versus $432 \pm 72 \mathrm{~ms}), \mathrm{RV}$ MAPD (372 \pm 71 versus $367 \pm 51 \mathrm{~ms})$ or $\triangle \mathrm{MAPD}(37 \pm 43$ versus $65 \pm 44 \mathrm{~ms}, P=\mathrm{NS}$ for all). Sertindole increased STV in control experiments $(2.0 \pm 0.7$ to $4.5 \pm 1.2 \mathrm{~ms}, P<0.001)$ but not in potassium experiments $(2.2 \pm 0.7$ to $3.0 \pm 1.1 \mathrm{~ms}, P=\mathrm{NS}$; Figure 3 ). Furthermore, the sertindole-induced STV was significantly higher in control experiments when compared to potassium experiments $(P<0.05$; Figure 3 ). 

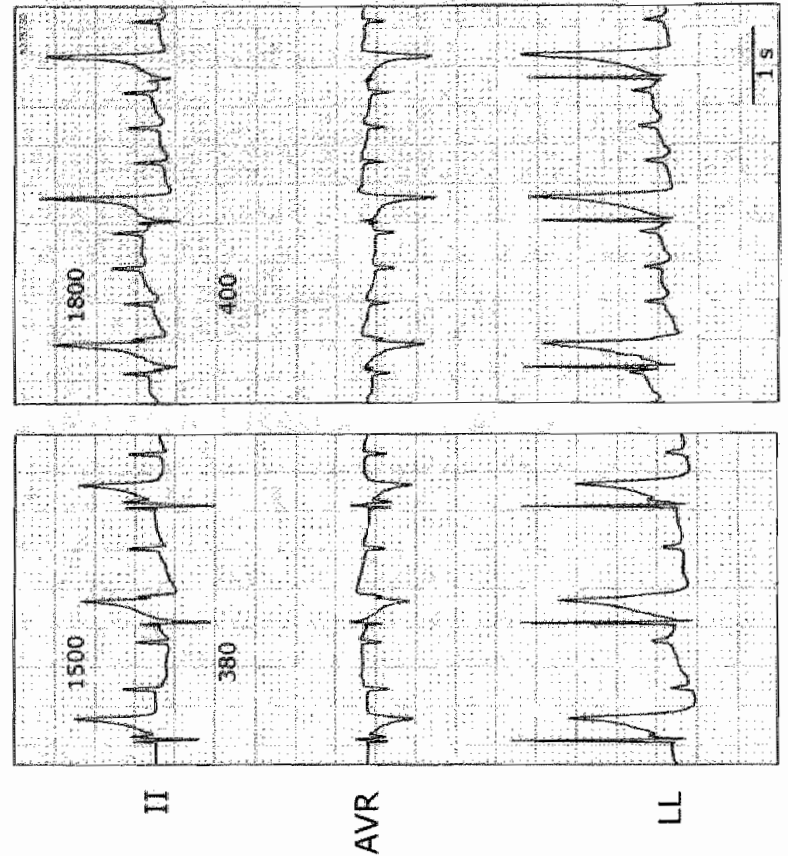

$\infty$

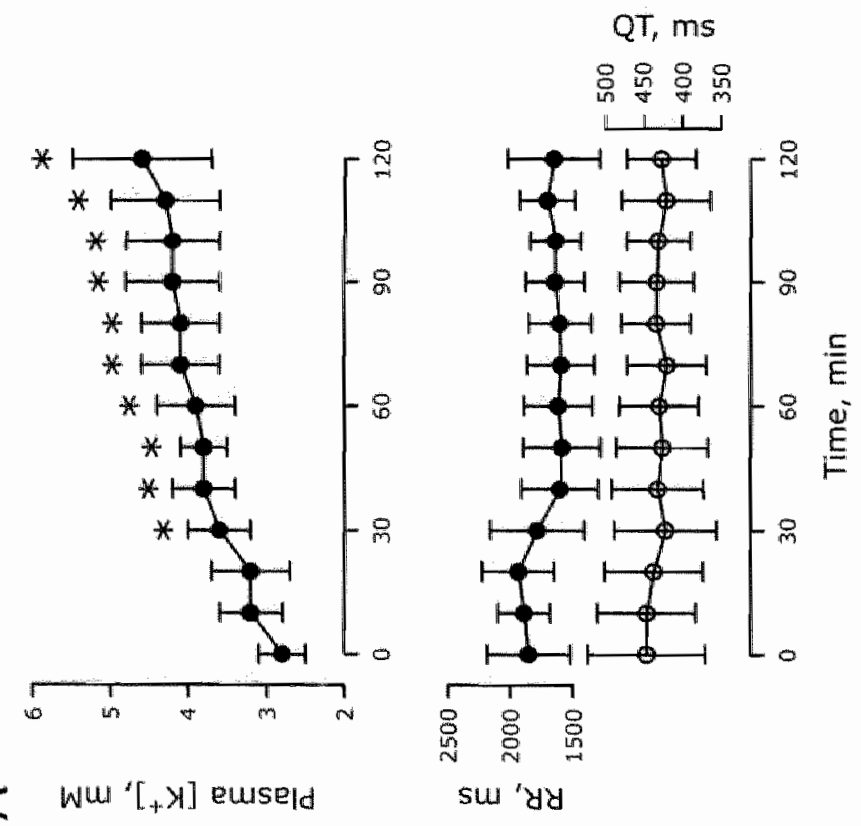

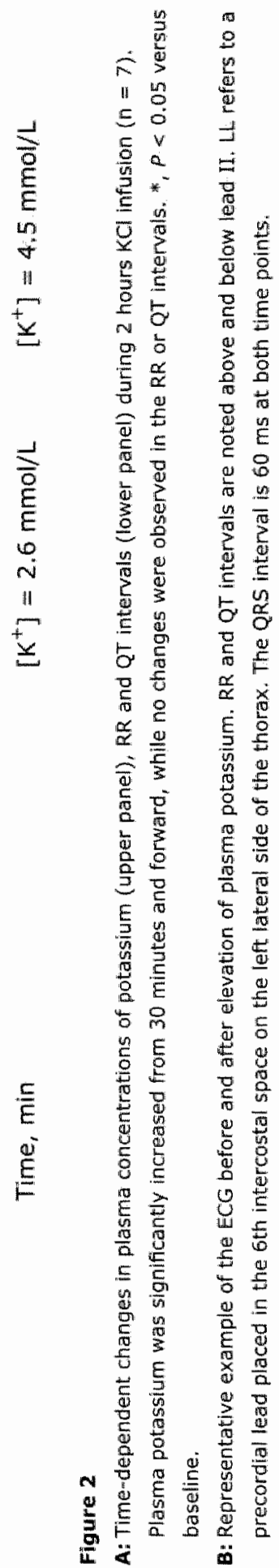




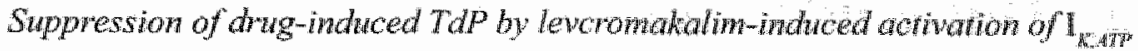

Both $3 \mu \mathrm{g} / \mathrm{kg}$ and additionally $10 \mu \mathrm{g} / \mathrm{kg}$ leveromakalin were effective in preventhg further arthythmia, reducing the sertindole-induced TdP frequency from $2,1 \pm 1,3$ TdP per minute to $0.5 \pm 0.6(P<0.05$; Figure 4$)$ and to $0.1 \pm 0.4$ TdP per minute $(P<0.001$; Figure 4$)$, consecutively. While leaving the heart rate unonanged $(R R$ : $1487 \pm 333$ to $1277 \pm 190 \mathrm{~ms}, P=N S$ ), the high dose abbreviated the sertindoleprolonged QT interval $(502 \pm 74$ to $404 \pm 55 \mathrm{~ms}, P<0.05)$, LV MAPD (Figure 4), RV MAPD $(373 \pm 54$ to $305 \pm 46 \mathrm{~ms}, P<0.05)$ and decreased STV (Figure 4 ). The lower dose had no statistical significant effect on heart rate (RR, $1399 \pm 362 \mathrm{~ms}$ ), QT interval (496 $74 \mathrm{~ms}$ ), LV MAPD (Figure 4) or RV MAPD $(359 \pm 50 \mathrm{~ms}, P=$ NS for all). $\triangle M A P D$ was not significantly changed by either dose of levcromakalim. Only STV was decreased by the lower dose $(4.9 \pm 2.1$ to $2.6 \pm 0.9 \mathrm{~ms}, P<0.05$; Figure 4 ) along with the reduction in proarthythmia.
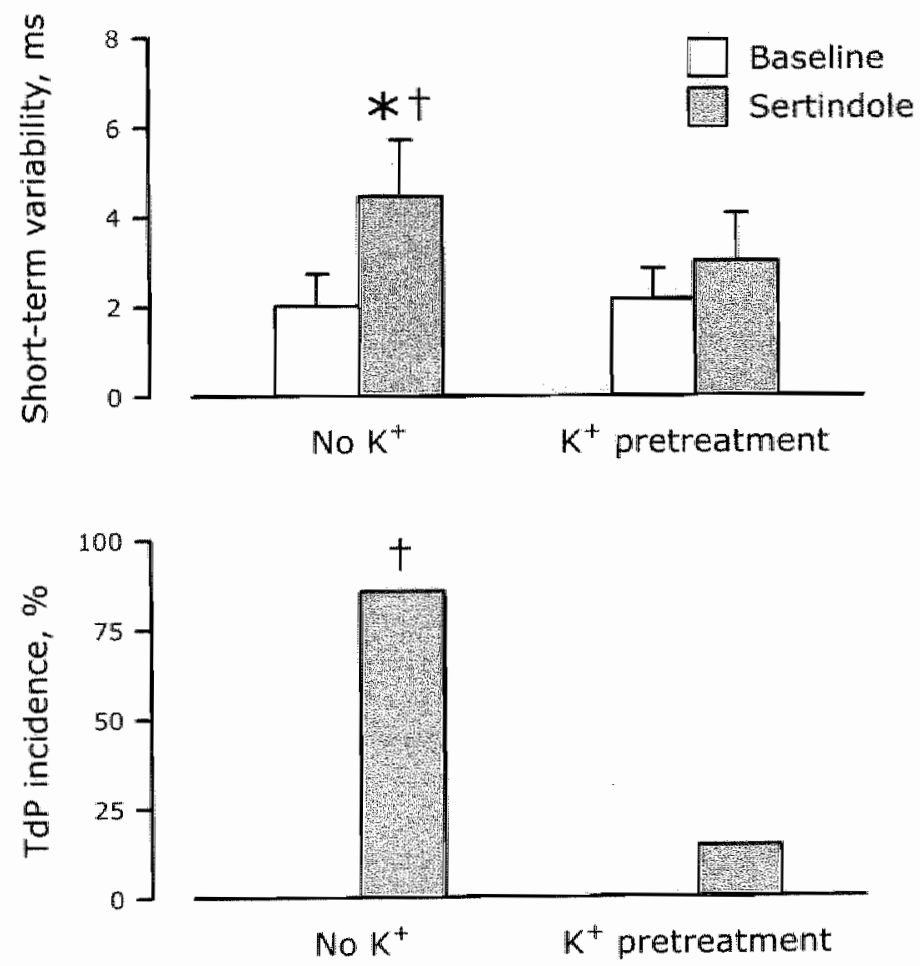

\section{Figure 3}

Short-term variabllity (upper panel) and TdP incidence (llower panel) in sertindalie experiments $(1.0 \mathrm{mg} / \mathrm{kg})$ with and without potassium pretreatment $(n=7)$. An elevated plasma-potassium concentration has no effect on baseline STV, however it prevents sertindale-induced elevation of STV and the occurrence of TdP. *, $P<0.001$ versus baseline; $t, P<0.05$ versus potassium pretreatment. 


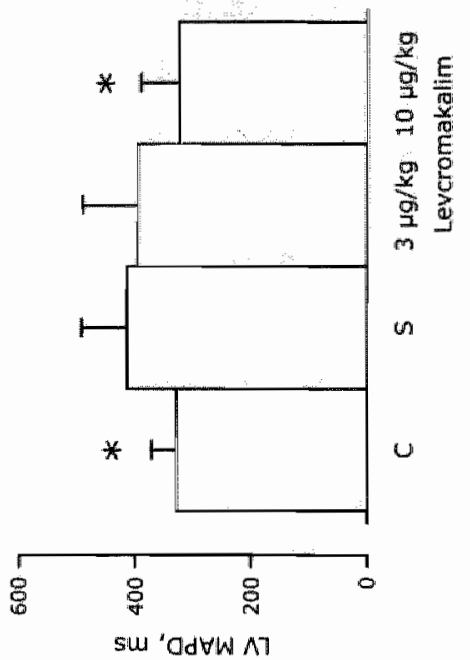

$\infty$

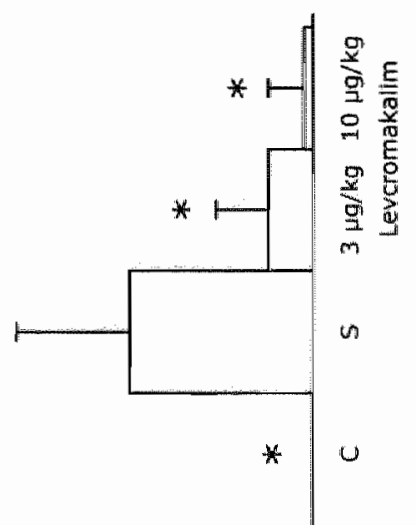

$\varangle$

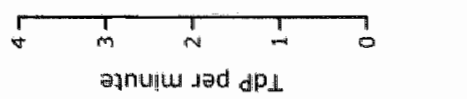

吕

要

至

包

告

语

음

范

in

要

$\frac{5}{2}$

之

in on

岁

응

(4)

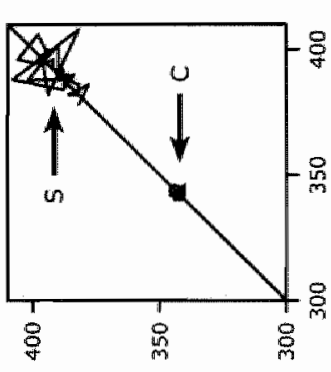

응

窇言

i 운

$\therefore$

in 4

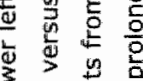

亭 年

F $v$ o

Q $E \geq$

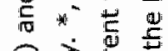
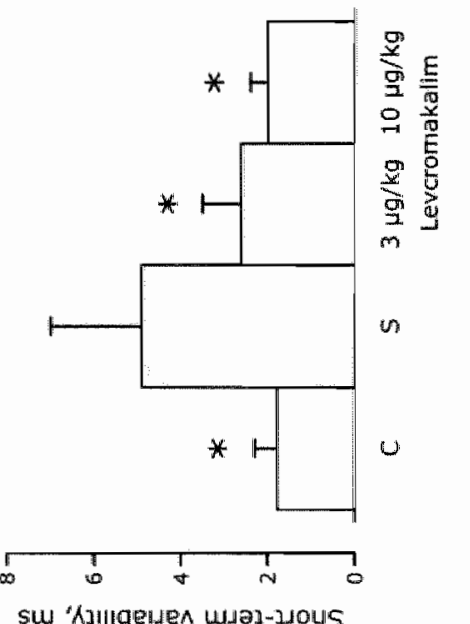

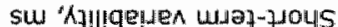

焉交

몬 总害

过

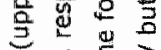

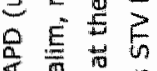

造要罯点

350

言离总连

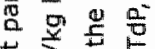

步 호

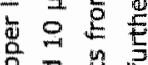

을 흠흠

t $m$ c

एั

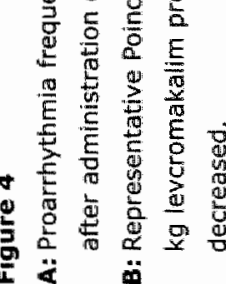



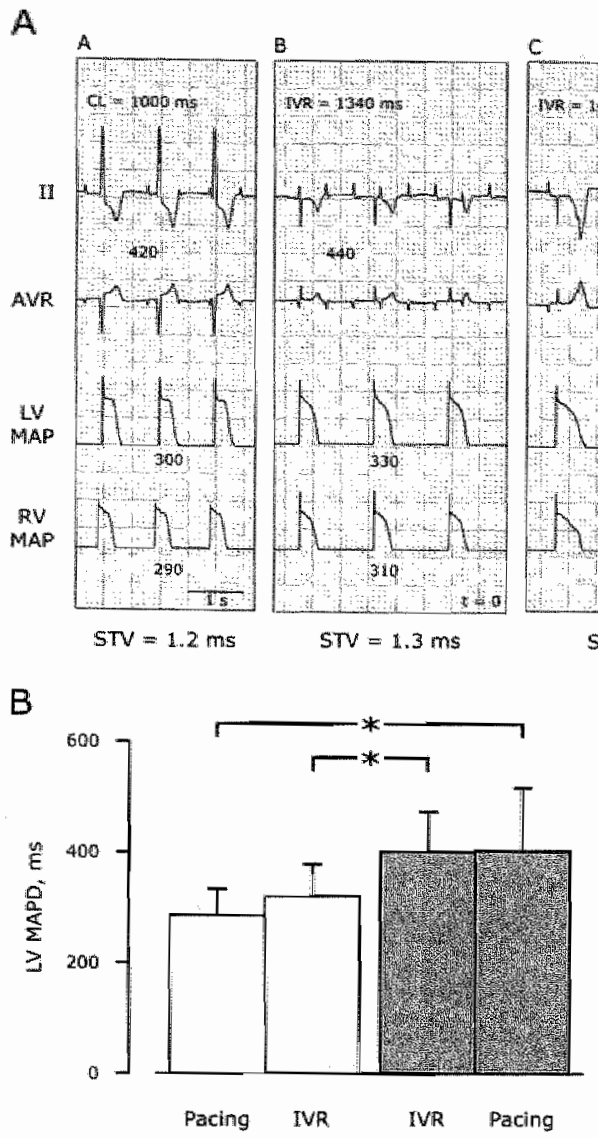

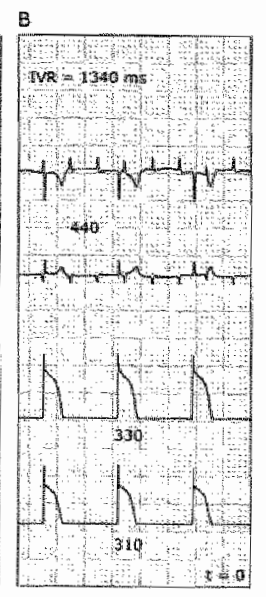

$S T V=1.3 \mathrm{~ms}$

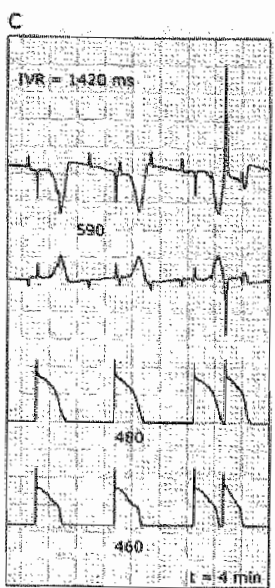

$S T V=4.9 \mathrm{~ms}$
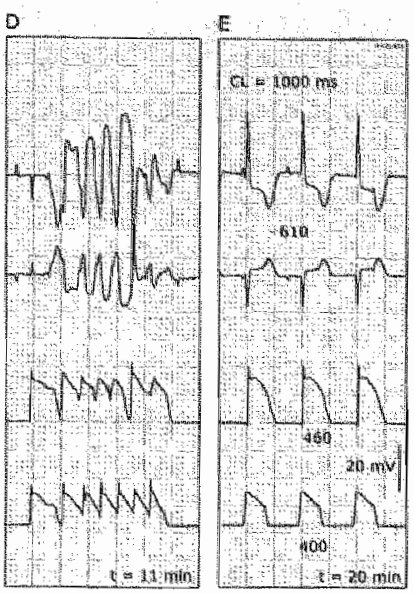

STV $=2.5 \mathrm{~ms}$

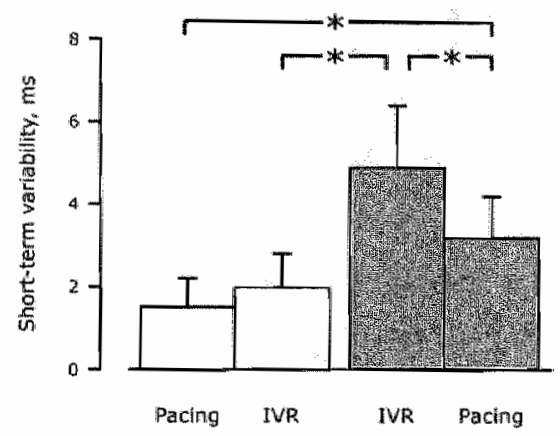

Control

Sertindole

\section{Figure 5}

A: Electrophysiological changes during a represientative experiment employlng sertindole 11.0 $\mathrm{mg} / \mathrm{kg}$ ) to induce $T \mathrm{dP}$ and pacing to prevent further arrhythmia. Two ECG leads ( $1 \mathrm{mV} / \mathrm{cm}$ ), LV and RV MAP recordings are shown in each panel at a paper speed of $1 \mathrm{~cm} / \mathrm{s}$. Paced cycle length (CL) or idioventricular rhythm (IVR) is shown at the top. QT interval and MAPD are below each signal. Time $(\mathrm{t})$ is relative to start af sertindole administration. STV is noted under each panel. In the control situation (panel B) with an RR interval of $1340 \mathrm{~ms}$ and during pacing with a CL of $1000 \mathrm{~ms}$ (panel A), STV were low and comparable. Sertindole administration prolonged repolarization, increased STV, induced extrasystoles (panel C), consequently precipitating TdP (panel D). When CL was decreased to 1000 ms, TdP was temporarily prevented and STV decreased along with minor changes in the duration of repolarization (panel E).

B: Composite data from 6 experiments where $\mathrm{CL}$ was shortened by pacing to suppress TdP. Pacing-induced prevention of TdP' was associated with a decrease in the STV, however the $L V$ MAPD remained as long as before extrasystolic activity. $P<0.05$. 
At baseline, QT intervals, LV MAPD and STV decreased non-significantly by shortening the ventricular cycle length from $1398 \pm 207$ to $1000 \mathrm{~ms}$ (Figure 5 ). Sertindole prolonged repolarization both at idioventricular rhythm and at 1000 ms paced cycle length. Without pacing, sertindole-induced TdP in 5 of 6 dogs, which was momentarily abolished by pacing. When pacing was discontinued, TdP reappeared in all experiments. A representative example of such an experiment is illustrated in Figure $5 \mathrm{~A}$. When the effect of pacing was compared to the non-paced. period preceding the first drug-induced extrasystole, the QT (489 \pm 72 versus 486 $\pm 89 \mathrm{~ms}$ ), LV MAPD (Figure 5B), RV MAPD ( $370 \pm 76$ versus $351 \pm 77 \mathrm{~ms}$ ) and $\triangle M A P D(45 \pm 36$ versus $52 \pm 45 \mathrm{~ms}, P=$ NS for all) were all similar. Only the STV was reduced $(4.9 \pm 1.5$ to $3.2 \pm 1.0 \mathrm{~ms}, P<0.05$; Figure $5 \mathrm{~B})$ as a consequence pacing.

\section{Discussion}

In this study, we demonstrated by using various interventions that increasing or decreasing BVR determined the proarrhythmic outcome. BVR proved superior to other repolarization-prolongation parameters in predicting TdP inducibility well before the proarrhythmia precipitated, making prevention feasible.

\section{Proarkhythmic increase in $B V R$}

The risk of TdP in humans and animal models is inversely correlated to the ventricular repolarization reserve. As such, the concept of repolarization reserve has been used to describe the inability of the heart to withstand additional challenges on repolarization. ${ }^{2 \pi}$ Based on novel insights, classical electrophysiological parameters such as QT-interval or MAPD prolongation are not capable of detecting repolarization reserve. ${ }^{1-6}$ Recently, we have suggested BVR as a concept closely associated with repolarization reserve. This parameter is superior to other repolarization-lability parameters and to the static repolarization parameters in predicting drug-induced TdP in anesthetized dogs with CAVB. ${ }^{2}$ So far, beat-tobeat variability of repolarization induced by two class-III drugs ( $d$-sotalol and amiodarone) and an anti-stroke compound (NS-7) have been reported. ${ }^{2.15}$ In anesthetized CAVB dogs $(n=20)$, baseline STV was $2.6 \pm 1.1 \mathrm{~ms}$ in the first experiments and $2.7 \pm 0.8$ in their second experiment $(P=0.8)$, illustrating the 
stability of the parameter over time in the CAVB dog. In the present study, baseline STV was at this level (Table 1, Figures 3-5).

The dose-dependent proarhythmic properties of the antipsychotic drug sertindole were compared to verify that $B V R$ is capable of predicting differences in the induction of TdP by non-cardiovascular drugs. We have shown that sertindole is a selective blocker of $I_{\mathrm{FERG}}$ and native canine $I_{\mathrm{K}_{5}}$ which translates into prolongation of repolarization in vitro and in vivo. Although 0.2 and $1.0 \mathrm{mg} / \mathrm{kg}$ sertindole gave rise to comparable prolongation of repolarization in sinus-rhythm dogs as well as CAVB dogs, only the high dose induced TdP in the remodeled hearts of the CAVB dogs. This study confirms the presence of elevated STV before the onset of ventricular extrasystoles and minutes before arrhythmia (Fignre 5).

The only QT-prolonging drug devoid of BVR increase known to us is amiodarone. At doses below proarrhythmic threshold, $d$-sotalol, NS-7 and sertindole all show non-significant trends towards increasing BVR. Although the results of lower plasma concentrations of the drugs do not show a significant increase in STV, a small elevation could bear mportant information when drugs are ewaluated for latent proarrhythmic potentials.

\section{Potassium levels and repolarization reserve}

Baseline levels of plasma potassium were unexpectedly low in these CAVB dogs $(2.8 \pm 0.2 \mathrm{mmol} / \mathrm{L}){ }^{16}$ It appear to be a characteristic of these dogs rather than of the AV block, since control dogs in sinus rhythm have similar low levels of potassium $(2.4 \pm 0.5 \mathrm{mmol} / \mathrm{L} ; \mathrm{n}=6 ; P=\mathrm{NS}$ versus $\mathrm{CAVB})$. In earlier studies with anesthetized CAVB dogs, we have observed higher levels $(4.2 \pm 0.5 \mathrm{mmol} / \mathrm{L} ; \mathrm{n}=8)$, excluding the possibility of anesthesia-induced low potassium. ${ }^{17}$

Raising the potassium levels by $\mathrm{KCl}$ infusion did not change the ventricular electrophysiological parameters, including RR, QT, QRS or STV (Figures 2 and 3), although T-wave morphology did show slight changes, suggesting an effect of potassium on repolarization (Figure 2B). Overall, we do not consider the pretreatment associated with (toxic) hyperkalemia.

Increasing extracellular potassium concentrations in vitro results in a slower inactivation of $I_{k}$, thereby enhancing repolarization strength. ${ }^{18}$ Humans with adequate cardiac repolarization reserve show no change in QT intervals upon a modest increase in plasma potassium. Only patients with acquired or congenital long-QT syndromes who experience elevation of potassium concentrations, respond by shortening their QT intervals. ${ }^{19.21}$ The absence of QT shortening in CAVB dogs, would suggest a physiologically normal repolarization reserve, which is contradicted 
by the pathological susceptibility to proarthythmic drugs and an STV of $2.6 \pm 1.1$ ms, which is significantly higher than dogs without cardiac electrical remodeling $(1.3 \pm 0.3 \mathrm{~ms}) .{ }^{3}$ The behavior of repolarization lability in long-QT patients and controls receiving potassium is unknown. Nevertheless, increasing repolarization reserve by $\mathrm{KCl}$ in this study was not recognized in the sertindole-induced prolongation of repolarization parameters, but by controlled STV and reduced proarthythmia.

It has been shown that drug affinity to the $I_{\mathrm{K}, \mathrm{r}}$ channel is altered when potassium concentrations are changed. ${ }^{1822}$ We have no data suggesting if this is also the case in sertindole-treated CAVB dogs, however, since QT prolongation was similar after 1.0 $\mathrm{mg} / \mathrm{kg}$ sertindole with and without potassium pretreatment, we assume that altered binding kinetics play a minor role in our findings.

\section{Decreasing BVR and proarmythmia}

Earlier we have described that: levcromakalim possesses electrophysiological and antiarrhythmic properties presumably by $I_{\mathrm{K}, \mathrm{ATP}}$ activation, leading to QT shortening, a decrease in $B V R$ and effective prevention of $T d P, 2,23,24$ The experiments reported here employed a titration of levcromakalim in order to potentially separate QT abbreviation and $\mathrm{BVR}$ reduction and to elucidate which of the two had the closest association to TdP induction. In Figure 4, data is presented that clearly shows a significant decrease in proarrhythmia accompanied by a decrease in STV following $3 \mu \mathrm{g} / \mathrm{kg}$ levcromakalim. This was neither accompanied by shortened repolarization (QT interval or LV MAPD) nor by decreased interventricular dispersion of repolarization.

Figure $5 \mathrm{~B}$ shows a small but non-significant decrease of STV at baseline as a consequence of steady-state pacing at an increased rate. However, when the same pacing üs performed under circumstances of sertindole-induced prolonged repolarization, elevated BVR and proarrhythmia, a significant decrease in BVR is noted. Again this was accompanied by a reduction in TdP incidence, but not by an abbreviation of the prolonged repolarization. The latter, which is not the anticipated frequency-dependent response of repolarization, could be due to the relatively slow heart rates at wich the repolarization times are determined in this study. In this frequency range, the repolarization has a rather horizontal relationship with heart rate.

Although not statistically significant, administration of sertindole tend to increase $R R$ intervals while levcromakalim tend to decrease the $R R$ interval, raising the question of the influence of heart rate on STV. The longest RR intervals were 


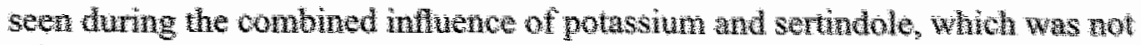

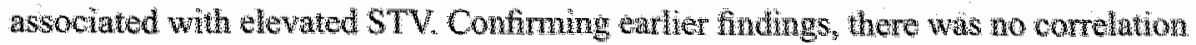
between the RR intervals and STV $(P=0.36$ in these experiments. Reatimg hred cycle-1engh pacing at control and under the infuence of sertindol, also inustrates the rate-independence of STV whin the physiological range of hear rates in the CAVB dog. Hence, when controming for the bradycardic effect mherent to ${ }_{\mathrm{X} .}$ bockers, BVR is stin increased by proarhythmic drugs. Futhermore, decreasing the ventricular frequency by pacing woder drug-free circumstances did not wead to a significant decrease in STV (Figure 5B). Futher experiments wil be designed to scrutuize the effects of faster pacing on STV.

\section{Clinical implications}

This study shows that manipulation of BVR was the only deteminant for the induction of TdP arhythmia in anesthetized CAVB dogs. This opens the possibithy in cinical studies to assess whether BVR can be advantageous ${ }^{n}$ identifying the patient at risk of developing dug-induced TdP. Limiting the inctease in BVR may be an effective therapy against increased proarhythmic risk.

\section{Study limitations}

This study limits BVR to invasive, endocardial MAP recordings in anestherized dogs with high susceptibility for drug-induced TdP. In the present state of our knowledge no adequate explanation can be given for the mechanisms responsible for BVR.

\section{Conclusions}

Influencing BVR is feasible in vivo. Interventions that decrease BVR do also suppress proarrhythmia. Conversely, when BVR is critically increased, TdP is likely to ensue. This study confirms once more, that prolongation of repolarization is not proarrhythmic per se. BVR proves as a superior marker for the prediction and prevention of drug-induced TdP.

\section{Acknowledgments}

The technical assistance of N. Atteveld is appreciated. P.G.A. Volders was supported by The Netherlands Organization for Health and Development (ZonMw 906-02068). 


\section{Referenices}

1. Thomgen MB, Volders $P G_{i}$ Stengl $M$, Spätjens RL, Beekman ID, Bischoff U, Kall MA. Frederiksen K, Matz J, Vos MA. Electrophysiological safety of sertindole in dogs with normal and remodeled hearts. $J$ Pharmacol Exp Ther, 2003;307:776-84.

2. Thomsen MB, Verduyn SC, Stengl M, Beekman JD, de Pater $G$, Van Opstal JM, Volders $\mathrm{PG}_{3}$ Vos MA. Increased short-term variability of repolarization predicts d-sotalolinduced torsades de pointes in dogs. Circulation. 2004;110:2453-2459.

3. Belardinelli $L$, Antzelevitch C, Vos MA. Assessing predictors of drug-induced torsade de pointes. Trends Pharmacol Sci. 2003;24:619-625.

4. Hondeghem LM, Carlsson L, Duker G. Instability and triangulation of the action potential predict serious proarrhythmia, but action potential duration prolongation is antiarrhythmic. Cinculation. 2001;103:2004-13.

5. Milberg $P$, Eckardt L, Brums HJ, Biertz J, Ramtin $S$, Reinsch $\mathbb{N}$, Fleischer D, Kirchhof P, Fabritz L, Breithardt G, Haverkamp W. Divergent Proarrhythmic Potential of Macrolide Antibiotics Despite Similar QT Prolongation: Fast Phase 3 Repolarization Prevents Early Afterdepolarizations and Torsade de Pointes. J Pharmacol Exp Ther. 2002;303:218-225.

6. van Opstal JM, Schoenmakers M, Verduyn SC, de Groot SH, Leunissen JD, Der Hulst FF, Molenschot MM, Wellens HJ, Vos MA. Chronic Amiodarone Evokes No Torsnde de Pointes Arrhythmias Despite QT Lengthening in an Animal Model of Acquired LongQT Syndrome. Circulation. 2001;104:2722-2727.

7. Fenichell RR, Malik M, Antzelevitch $C_{y}$ Sanguinetti MC, Roden DM, Priori SG, Ruskin IN, Lipichy RJ, Cantilena LR. Drug-induced torsades de pointes and implications for drug development. $J$ Cardiovasc Electrophysiol. 2004;15:475-495.

8. Roden DM. Taking the "idio" out of "idiosyncratic": predicting torsades de pointes. Pacing Clin Electrophysiol. 1998;21:1029-1034.

9. Roden DM. Drug-induced prolongation of the QT interval. $N$ Engl J Med. 2004;350:1013-22.

10. Vos MA, de Groot SH, Verduyn SC, van der Zande J, Leunissen HD, Cleutjens JP, van Bilsen M, Daemen MJ, Schreuder JJ, Allessie MA, Wellens HJ. Enhanced susceptibility for acquired torsade de pointes arrhythmias in the dog with chronic, complete AV block is related to cardiac hypertrophy and electrical remodeling. Circulation. 1998;98:112535.

11. Schoenmakers M, Ramakers C, van Opstal JM, Leunissen JD, Londono C, Vos MA. Asynchronous development of electrical remodeling and cardiac hypertrophy in the complete AV block dog. Cardiovasc Res. 2003;59:351-9.

12. van Opstal JM, Leunissen ID, Wellens HJ, Vos MA. Azimilide and dofetilide produce similar electrophysiological and proarrhythmic effects in a canine model of Torsade de Pointes arthythmias. Eur J Phormacol. 2001;412:67-76.

13. Thomsen MB, Truin M, Van Opstal JM, Beekman JD, Volders PG, StengI M, Vos MA. Sudden cardiac death in dogs with remodeled hearts is associated with larger beat-tobeat variability of repolarization. Accepted for publication in Basic Res Cardiol. 2005.

14. Julian DG, Camm A.J, Frangin G, Janse MJ, Munoz A, Schwartz PJ, Simon P. Randomised trial of effech of amiodarone on mortality in patients with left-ventricular dysfunction after recent myocardial infarction: EMIAT. European Myocardial Infarct Amiodarone Trial Investigators. Lancet. 1997;349:667-74.

15. Detre E, Thomsen MB, Beekman JD, Petersen K-U, Vos MA. Decreasing the infusion rate reduces the proarhythmic risk of NS-7: Confirming the relevance of short-term variability of repolarization in predicting drug-induced torsades de pointes. Accepred for publication in BrJ Pharmacol. 2005.

16. Weissenburger J, Davy JM, Chezalviel F, Ertzbischoff O, Poirier JM, Engel F, Lainee 
P, Penin E, Motte G, Cheymol G. Amhythnogenic activities of antarmythmic dnges in conscious bypokalemic dogs with atrioventricular block: comparison between. guinidine, lidocaine, flecainide, propranolol and sotalol. I Pharmacol Exp Ther. 1991;259:871-83.

17. Verduyn $\mathrm{SC}$, Vos MA, Gorgels AP, van der Zande J, Leunissen JD, Wellens HJ. The effect of funarizine and ryanodine on acquired torsades de pointes arriythmias in the intact canine heart. I Cardiovasc Electrophysiol 1995;6:189-200.

18. Yang T, Snyders DJ, Roden DM. Rapid inactivation determines the rectification and $[\mathrm{K} *$ ] dependence of the rapid component of the delayed rectifer $\mathrm{K}+$ current in cardiac cells. Circ Res. 1997;80:782-789.

19. Compton SJ, Lux RL, Ramsey MR, Strelich KR, Sunguinetti MC, Green LS, Keating MT, Mason JW. Genetically Defined Therapy of Inherited Long-QT Syndrome:

Correction of Abnormal Repolarization by Potassium. Circulation. 1996;94:1018-1022.

20. Etheridge SR, Compton SI, Tristani-Firouzi M, Mason JW. A new oral therapy for long QT syndrome: long-term oral potassium improves repolarization in patients with HLRG mutations. IAm Coll Cardiol. 2003;42:1777-82.

21. Choy AM, Lang CC, Chomsky DM, Rayos GH, Wilson JR, Roden DM. Nomalization of acquired QT prolongation in humans by intravenous potassium. Circulation. $1997 ; 96: 2149-54$.

22. Diaz GJ, Daniell K, Leitza ST, Martin RL, Su Z, McDermott JS, Cox BF, Gintant GA. The [(3)H]dofetilide binding assay is a predictive screening tool for hERG blockade and proarthythmia: Comparison of intact cell and membrane preparations and effects of altering $[\mathrm{K}(+)](0)$. J Pharmacol Toxicol Methods. 2004;50:1.87-99.

23. van Opstal JM, Verduyn SC, Winckels SK, Leerssen HM, Leunissen ID, Wellens H.I, Vos MA. The JT-Area Indicates Dispersion of Repolarization in Dogs with Atrioventricular Block. J Inrerv Card Electrophysiol. 2002;6:113-120.

24. Vos MA, Gorgels AP, Lipcsei GC, de Groot SH, Leunissen JD, Wellens HJ. Mechanismspecific antiarrhythmic effects of the potassium channel activator levcromakalim against repolarization-dependent tachycardias. I Cardiovasc Electrophysiol. 1994;5:731-42. 


\section{General Discussion}

Content:

Introduction

Multiple challenges on the repolarisation reserve

Electrophysiological parameters

Why yeu another measure for variability?

Possible mechanisms of beat-to-beat variability of repolarisation duration

Challenges ahead 
Chapuer 


\section{Introduction}

In 1966, Dessertenne first used the name torsades de pointes to describe a polymorphic ventricular tachycardia in a woman with attioventricular block. Despite major scientific efforts, the mechanisms underlying this potentially lethal cardiac arthythmia are still not fully understood. Drug-induced torsades de pointes were later identified as a serious side-effect of medical treatment. Large efforts from the pharmaceutical industry, academic scientists and regulatory authorities are aimed at identifying precarious drugs before they are introduced to the market. Nevertheless, the methodology behind the testing is meither standardised nor perfect. Abundant results have advocated the need to assess drugs on multiple levels of complexities before a risk/benefit analysis of the potential drug can be made. In chapter 2, we assessed the electrophysiological and proarrhythmic properties of a drug on multiple levels of complexity, from cloned ion-channel to proarrhythmic animal model. Presently, the developing international guidelines on the testing of drugs are concerned with the aspect of delayed repolarisation, which per se is not dangerous. Only when multiple predisposing factors are present simultaneously, torsades de pointes can precipitate. In chapter 2, we also showed that torsades de pointes were only initiated under the concurrent existence of electrical remodelling and high drug dosing. These aspects reflect on a hypothesis that has become known as the hypothesis of the multiple hits on repolarisation reserve. Indeed, this deserves to be incorporated in the developing guidelines.

Identification of early parameters predicting proarrhythmic events has long been a medical aspiration. In addition, these parameters can be beneficial in the proarthythmic assessment of drugs. The availability of new additional surrogate markers for torsades de pointes is essential. 


\section{Multiple challenges on the repolarisation reserve}

The low incidence of torsades de pointes in healthy humans is likely linked to a strong repolarisation. In chapter 3 , we suggest a description of the concept of repolarisation reserve $\mathrm{e}^{2}$ in which we regard it as the abllity of a heart to withstand a challenge on repolarisation. Thus, the healthy individual can withstand serious challenges on repolarisation. Metabolic or electrolyte disturbances, heart disease and other underlying pathologies can induce acquired QT prolongation, whereas the inherited forms of channelopathies are grouped under the congenital long-QT syndromes. However, a patient with a long-QT syndrome does not necessarily have a prolonged QT on the ECG. ${ }^{3-6}$ Both patients with congenital long-QT syndromes and those with acquired QT prolongation are expected to have a lower repolarisation reserve and thus will be more vullnerable to additional repolarisation challenges. ${ }^{7,8}$ In this assumption, the different repolarising potassium channels have an overlapping or compensating relationship, in order to safeguard repolarisation. A phamaceutical agent blocking such a repolarising current can result in drug-induced QT prolongation, regarded as an additional challenge on repolarisation, increasing the risk of torsades de pointes.

Various laboratories have investigated this assumption and attenuated repolarisation by introducing multiple consecutive pharmacological agents. ${ }^{9-13}$ Table 1 summarizes several studies in which two potassium currents $\left(I_{\mathrm{Kr},} I_{\mathrm{Ks}}\right.$ or $\left.I_{\mathrm{K} 1}\right)$ were blocked individually and simultaneously. The investigations were performed in tissues from healthy dogs, so it is assumed that repolarisation at baseline was plnysiological strong. A single challenge prolonged the action potential considerably in all incidences, however interestingly, the combined challenge increased action potential duration far more than would be expected from simple summation of the two individual effects.

The synergistic relationship of multiple hits is applicable to the clinical situation, where the patient with an already acquired or congenital decreased repolarisation reserve encounters an additional challenge and eventually passes the threshold to potentially develop torsades de pointes. In the person with a sufficient repolarisation reserve this additional challenge would hardly be noticed.

This clinical scenario underscores the importance of including models of reduced repolarisation reserve in the assessment of proarrhythmic potentials of novel treatments. As stated in chapter 1, some models are already available. The studies that served as the basis for thesis employed the use of the dog with chronic complete atrioventricular block, in which the individual components of a decreased repolarisation reserve are well documented. ${ }^{4-24}$ 


\section{Electrophysiological and proarrhythmic parameters}

A serial, dose-dependent assessment of electrophysiological and proarthythmic properties of drugs provides several advantages. When the animal serves as its own control, biological variation is decreased. Reproducibility of baseline values can be evaluated and the predictive values of parameters can be assessed with greater certainty. Dose- or concentration-dependent drug effects are basic characteristics of the majority of chemicals affecting a receptor or an ion channel. For example, a pure $I_{\mathrm{Kr}}$ blocker will prolong the cardiac action potential in a concentration dependent manner until $I_{\mathrm{Kr}}$ is fully blocked and no further effect is seen. The effect of dofetilide on action potential duration in isolated canine ventricular myocytes in chapter 2 is an example of such a characteristic. Well-known exceptions from this concentration dependency are found in drugs with multiple actions underlying the measured effect. When the drug has effects on more than one ion channel, all of these effects. will be incorporated into the response of the action potential. This can result in amplification, an early plateau effect or even a bell-shaped concentration-response curve of the action potential prolongation. ${ }^{25}$ Examples of bell-shaped response curves are reported for multifaced drugs like ranolazine, quinidine, terfenadine and cisapride. $^{26-31}$

Table 1. Multiole pharmacological hits on repolarisation reserve.

\begin{tabular}{|c|c|c|c|c|}
\hline Preparation & $I_{K, r}$ block & $I_{\mathrm{Ks}}$ or $I_{\mathrm{ks}}$ block & $\begin{array}{c}\text { Combined } \\
\text { block }\end{array}$ & Reference \\
\hline Tissue slices & $100 \%$ & $10 \%\left(I_{\mathrm{Kg}}\right)$ & $160 \%$ & 9 \\
\hline Transmural wedges & $10 \%$ & $20 \%\left(I_{\mathrm{K}_{\mathrm{S} S}}\right)$ & $110 \% *$ & 9 \\
\hline Papillary muscles & $25 \%$ & $5 \%\left(I_{\mathrm{K}: \mathrm{s}}\right)$ & $47 \%$ & 10 \\
\hline Papillary muscles & $50 \%$ & $10 \%\left(I_{\mathrm{ks}}\right)$ & $90 \%$ & 11 \\
\hline Paplllary muscles & $30 \%$ & $20 \%\left(I_{k_{2}}\right)$ & $100 \% *$ & in \\
\hline Papillary muscles & $9 \%$ & $14 \%\left(I_{\kappa 1}\right)$ & $35 \%$ & 1.? \\
\hline Isolated myocytes & $130 \%$ & $\mathrm{OOH}\left(\mathrm{I}_{\mathrm{Ke}}\right)$ & $2170 \%$ & is \\
\hline
\end{tabular}

Two different repolarising currents were blocked elther individually or simultaneously. All studies were performed in canine ventricular tissue. Relatiwe prolongation in action potentiall duration from baseline is noted. Asterisks indicate the presence of early afterdepolarisations.

Throughout the experimental planning for the previous chapters, the importance of serial, dose-dependent investigations was taken into account. Dose-dependent investigations were performed with sertindole (chapters 2 and 6 ), $d$-sotalol (chapter 3) and NS-7 (chapter 4). In addition to altering the dose, we also decreased the infusion rate by increasing the infusion time of a fixed dose of NS-7 (chapter 4). 
The electrophysiological and proarrhythmic characteristics of these drugs in anaesthetised dogs with chronic atrioventricular block are summarised in Table 2. In this table, the electrophysiological and proarrhythmic effects of the three drugs are stummarised and compared to a single dose of dofetilide. At baseline, a high reproducibility of all electrophysiological parameters is present. The drugs are all able to induce torsades de pointes in this model when administered at high dose or fast delivery. The classical electrophysiological parameters (upper part of Table 2) include QT intervals, and lefit and right ventricular monophasic action potential duration (MAPD). Listed are the averaged absolute values attained at baseline and with the drug administered. With only one exception, are none of these parameters able to differentiate between the proarrhythmic outcomes of the studies. Only with $d$-sotalol are the right ventricular MAPD increased with the high proarrhythmic dose while it was not increased after the low and less proarhythmic dose. In no instance is there a significant difference between drug-induced effects of the two doses/rates. Also, when the absolute drug-induced increases are compared, none of the effects are significantly different from the other administration protocols (not shown). Hence, in these studies, the serial comparisons are not able to discriminate the hazardous dose based on the repolarisation parameters QT interval, left or right ventricular $\mathrm{MAPD}$.

The lower half of Table 2 covers some of the novel proarhythmic predictors employed in this thesis. The triggers inducing torsades de pointes have been attributed to early-afterdepolarisation dependent triggered activity observable on the ECG as extrasystoles. ${ }^{32}$ In the analysis of the events leading to drug-induced torsades de pointes, regional dispersion of repolarisation, and single and multiple (see chapter 2) extrasystoles are often important players. ${ }^{15,19}$ In no instance was the interventricular dispersion of repolarisation, calculated as the absolute difference between left and right ventricular MAPD, able to predict the proarthythmic outcome. We measured the time duration from the start of drug administration to the occurrence of the first single and multiple extrasystoles to evaluate the aggressiveness of the treatment. Furthermore, we established the frequency of multiple extrasystoles. If prolongation of repolarisation is recognised as the substrate, these extrasystoles can be regarded as triggers, cumulatively increasing the likelihood of initiating torsades de pointes. ${ }^{32,33}$ When the substrate is comparable in all incidences (upper part of Table 2), the occurrence and frequency of triggers may be a reasonable indicator for the likelihood of torsades de pointes to ensue. No differences between the time points of occurrence of extrasystolic activity (singles or multiples) are observable, partly due to a large variation between the experiments. 


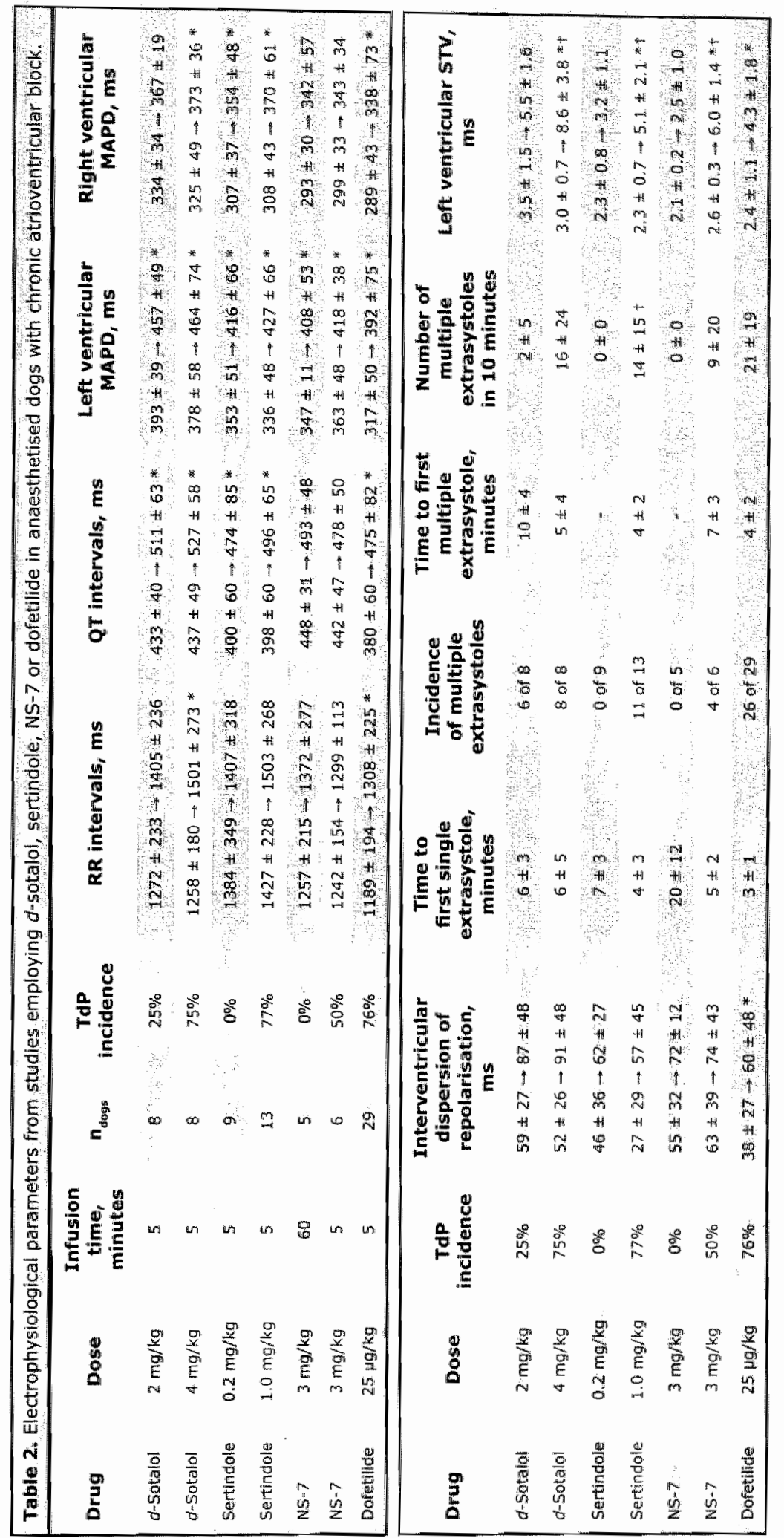

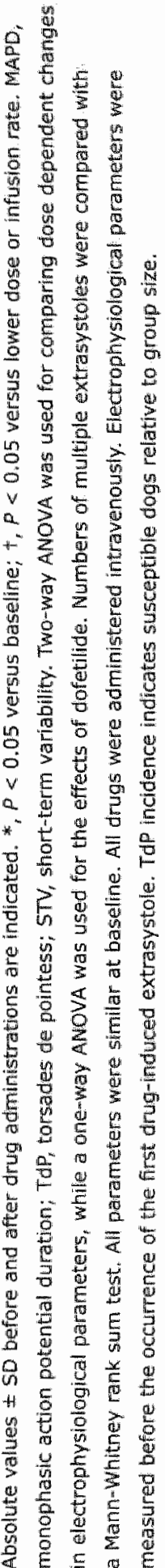


Nevertheless, the absence of multiple extrasystoles after administrations devoid of arrhythmia indicates some predictive value.

The last column of Table 2 summarises the importance of short-term variability of repolarisation observed with the different administration regimens. Contrary to the other repolarisation parameters listed in the table, there are significant differences. in short-term variability between proarrhythmic and non-proarthythmic challenges. This is also the case, when the absojute drug-induced increases are compared (not shown). Thus, it seems to be possible to predict proarrhythmic consequences based on this parameter. Figure 1 graphically compares the short-term variability from Table 2 and chapter 5 .

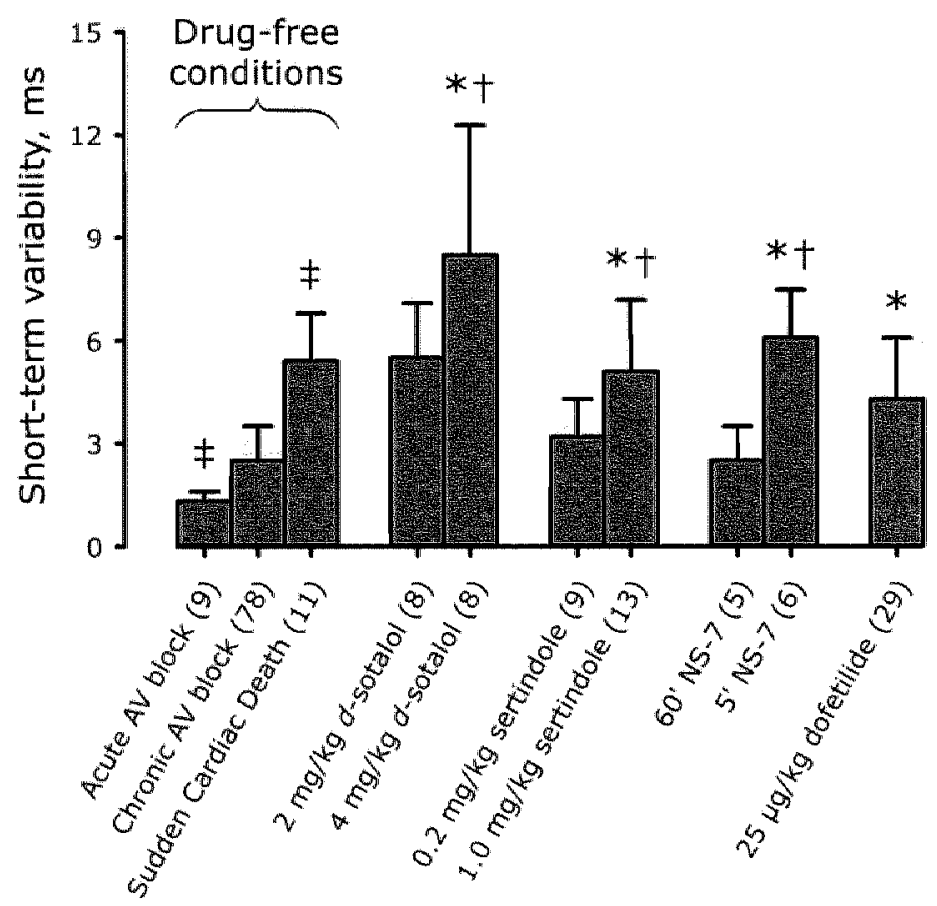

\section{Figure 1}

Short-term variability (STV) in anaesthetised dogs with chronic atrioventricular block at baseline and under the influence of various cardiovascular and non-cardiovascular drugs. Group sizes are indicated in brackets. Sudden cardiac death refers to a subpopulation of dogs with chronic atrioventricular block that dies suddenly (chapter 5). Both $d$-sotalol and sertindole were analysed in two different doses (5-minutes infusion, chapters 2,3 and 6$)$, while NS-7 (3 $\mathrm{mg} / \mathrm{kg}$ ) were administered over 60 or 5 minutes (chapters 4). Dofetilide was only tested in one dose. *, $P<0.05$ versus chronic atrioventricular block (serial comparison); $\uparrow, P<0.05$ versus ather dose or rate; $\neq, P<0.05$ versus chronic atrioventricular block (group comparison). 
To further analyse the proarryythmic-predictive values of the nine electrophysiological parameters in Table 2, receiwer-operator characteristics were plotted and the area under the curve quantified (Table 3). The different electrophysiological parameters at baseline or after arug administration were analysed for their ability to discriminate between experiments with torsades de pointes and those without. Collectively, this analysis includes 43 experiments with reproducible drug-induced torsades de pointes and 35 experiments without. The classical electrophysiological parameters like the QT interval along with left and right ventricular MAPD and interventricular dispersion of repolarisation are not satisfactory in predicting torsades de pointes. A crucial message protruding from the data is that inducing the arrhythmia itself should be a main objective of the assessment of proarrhythmic properties of drugs. The predictive value of multiple extrasystoles seems advantageous, especially the frequency within the first ten minutes. This is compatible with the theory of a comparable substrate in all experiments, while proarrhythmia is related to the frequency of triggers increasing the chance of precipitating runs of torsades de pointes. At baseline, short-term. variability does not seem to be superior to the established electrophysiological parameters in predicting a proarrhythmic experiment irrespective of drug or infusion time. However, after the drug is administered, short-term variability is a useful indicator of arrhythmia to develop later on.

As part of the methodology, short-term variability is measured before the first druginduced extrasystole, which is well in advance of the onset of the triggers (multiple extrasystoles) and torsades de pointes. Hence, in these studies, the earliest known parameter with superior predictive value is short-term variability.

Table 3. Proar hythmic predictive values of the parameters analysed in Table 2.

\begin{tabular}{lcc|}
\hline & Baseline & Drug \\
RR intervals & 0.61 & 0.61 \\
QT intervals & 0.53 & 0.63 \\
Left ventricular MAPD & 0.56 & 0.58 \\
Right ventricular MAPD & 0.46 & 0.46 \\
Interveritriculail dispersion & 0.49 & 0.56 \\
Time to 1st single extrasystole & - & 0.55 \\
Time to 1st multiple extrasystole & - & 0.80 \\
Number of multiples in 1.0 minutes & - & 0.93 \\
Short-term variability & 0.58 & 0.79 \\
\hline
\end{tabular}

Calculated are the areas under the curves of the receiver-operator characteristics for 78 experiments of which 43 showed torsades de pointes. 


\section{Why yet another measure for variability?}

Various formulas, algorithms and methods for quantifying wariability within a series of measurements are available in the scientific literature. Best known is probably the standard deviation. Specifically for the measure of temporal lability of repolarisation duration, a few other measures have been proposed. In 1997, Berger reported on the QT-variability inde ${ }^{34}$ while Hondeghem described instabillity of the action potential in 2001. ${ }^{35}$ There are speeific discrepancies between the methods. Advantages and limitations should be considered, when the decision is made of which formula to employ. Table 4 summarises the differences between the QT-variability index, instability and short-term variability as presented in this thesis.

There are important differences between these measures of lability and alternans of repolarisation. Alternans is typically occurring at fast ventricular frequencies, has a repetitive $T$ wave or action potential morphology and is mechanistically coupled to intra- and intercellular calcium cycling. ${ }^{36-39}$ Lability of repolarisation including beatto-beat variability is present at slower heart rates and seems chaotic in appearance. Moreover, the underlying mechanism is far less elucidated.

\begin{tabular}{|lccc|}
\hline Table 4. Comparison of three selected methods for quantifying lability of repolarization. \\
\hline & QTVI & Instability & STV \\
Signal & ECG & MAP & MAP \\
Time duration & $5 \mathrm{~min}$ & $3 \mathrm{~min}$ & $<1$ min \\
Application & Clinlcal & Non-clinical & Non-clinical \\
Consecutiveness in methodology & - & - & + \\
Invasive & - & + & + \\
References & $34,40.43$ & $35,43-46$ & Chapters 3 to 6 \\
\hline
\end{tabular}

* Beat-to-beat variability of repolarisation analyses the direct difference between two consecutive beats, whereas non-consecutive algorithms disregards ar reorder the sequence of beats. QTVI, QT varlabillity index; STV, short-term variability; MAP, monophasic action potentials.".

QT-variability index represents the logarithmic ratio between the QT-interval and. heart-rate variances, each normalised by their squared means. About 5 mimutes ECG is recorded, in which ventricular premature complexes are deleted. Patients with dilated cardiomyopathy, ${ }^{3,461}$ ischemia, ${ }^{41,42}$ or survivors of sudden cardiac arrest ${ }^{4 / 1}$ have increased QT variability index.

Instability of the action potential duration to $60 \%$ repolarisation ( $A P D_{60}$ ) is calculated using the last 20 action potentials each minute for 3 minutes during 
steady-state pacing at a cycle length of $1000 \mathrm{~ms}$. The APD, sare then sorted after duration and fitted by linear regression. The instability is time difference between the upper and lower quartile estmates from the regression. The measure is traditionally used on isolated Langendorff-perfused rabbit hearts to predict proarthythmic potentials of perfused drugs. ${ }^{35,43-46}$

Short-term variability derives from Poincare plots, which is a simple way to look for deterministic relationships in complex time series. In these plots, the present state (e.g. an APD) is plotted against the previous state (i.e. the former APD). Slow uniform changes tend to follow the line-of-unity, while abrupt changes, e.g. an extrasystole with a short APD, deviates from the diagonal and produces a triangle. More serious multiple extrasystoles and arrhythmias cause polygons on the Poincaré plot. Short-term variability has been defined as the dispersion of points perpendicular to the line-of-identity or simply as the average distance of the points to the diagonal. This measure is used on anaesthetised dogs with chronic atrioventricular block to predict proarrhythmic potentials of administered drugs (chapters 3,4 and 6) and to assess antiarthythmic interventions or preventions (chapter 6). Furthermore, it is increased in electrically remodelled canine hearts (chapter 5). In these studies, the Poincare plots were drawn and the short-term variability were calculated before the onset of extrasystolic activity to dissociate drug-induced beat-to-beat variability of repolarisation from extrasystole-induced changes in repolarisation.

To compare the importance of consecutiveness in the methods a theoretical example is presented. Thirty random numbers, artificially representing repolarisation duration of 30 consecutive ventricular complexes, were generated.. In the example, aspects of heart-rate changes are not included. Two scenarios were made in which the first characterizes high lability with the random order of points conserved. In the second scenario, consecutiveness is disregarded and the random numbers were ordered from low to high. Figure 2 shows a graphical representation of the two series of identical numbers. Table 5 compares data calculated using the 30 numbers. Obviously, the mean is identical, however also the standard deviation is the same, since it is based on the calculation of variance, which ignores consecutiveness. QT variability is based on variance, so like the standard deviation, it is identical in the two series. The example serves to illustrate the importance of consecutiveness, and since heart rate is defined to be constant, the aspect of heart-rate variability in the QT variability index is disregarded in the present example. Thus, this example should not be extrapolated to situations of physiologically significant heart-rate variability. The method of action-potential instability ${ }^{35}$ orders the action potentials after their 
duration, so the two series in this example become identical. The only measure that discriminates between the lability of the two series is the short-term variability. As illustrated in the left Poincare plots of Figure 2, the random numbers make a large plot and the dispersion of points from the line-of-identity is considerable compared to the right Poincare plot of the ordered points.

As this example is derived from artificially generated numbers, there is no connection to arrhythmia of any kind. Intuitively, the chaotic series is likelly to be more proarrlythmic than the gradual "prolongation", however this remains to be proven in an experimental set-up.
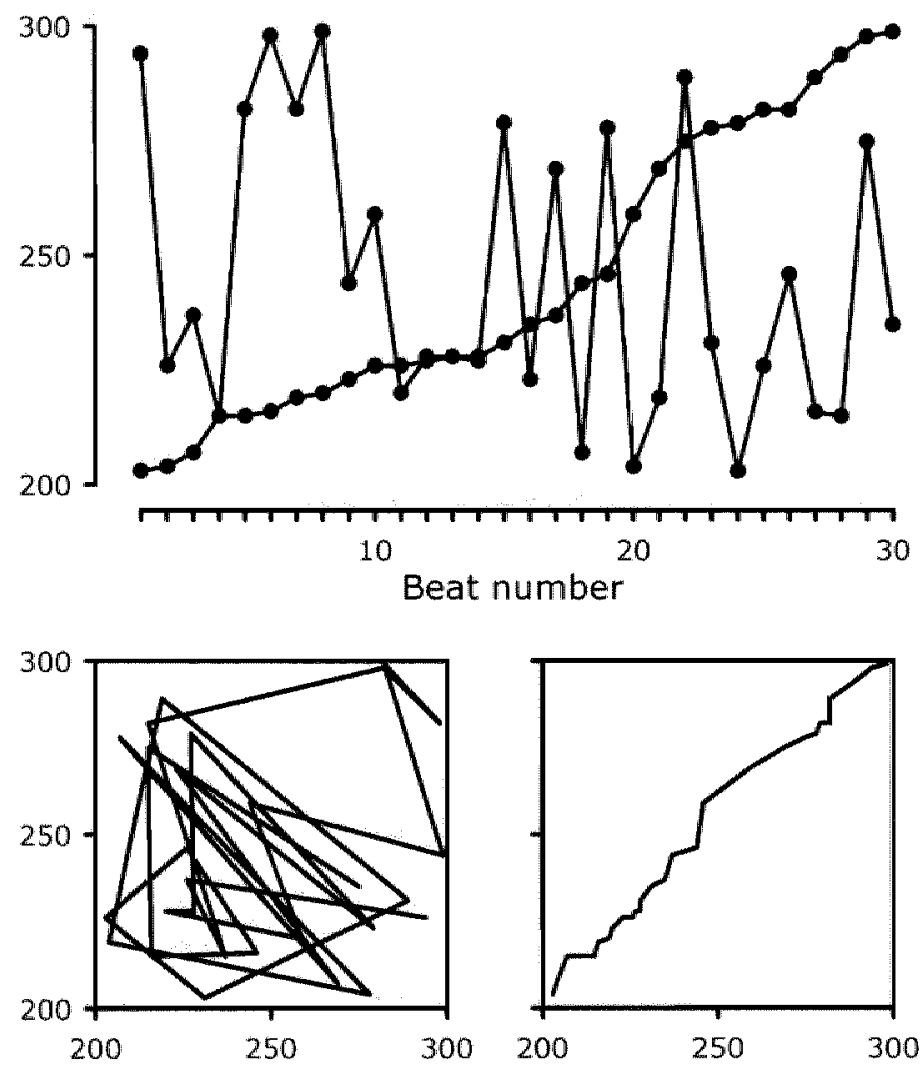

\section{Filgure 2}

Artificially generated example to illustrate the importance of consecutiveness. Thirty numbers between 200 and 300 were created. Either the order was preserved or the series was ordered from lowest to highest. The upper graph illlustrates the two series in time. The Poincare plots below shows one number as a function of the former number for all 30 numbers. The plot to the left, which has the largest area, is derived from the series with conserved order, while the right graph illustrates the ordered numbers. 
As discussed in the introduction, QT interval measurentents are not very reproducible, since the return of the $T$ wave to the isoelectric line is gradual In that sense, transmembrane action potentials and to a certain limit also the monophasio action potentials are more reproducibly measured, when the duration to 90 or $95 \%$ repolarisation is determined. However in principle, the calculations of lability could be applied to all measures of repolarisation. The weakness of short-term variability at this point is that it is dependent on the availability of monophasic action potentials. Besides the invasive nature of monophasic action potential catheters, the recordings are not always as stable in time as one would wish. Throughout the preceding chapters, the minimally accepted amplitude of the monophasic action potentials was $15 \mathrm{mV}$. Below this amplitude, the signal was not accepted as a measure of the ventricular action potential duration. If the acceptance threshold is set too high, repetitive mechanical manupulation of the catheters is likely to be necessary, which often can induce extrasystoles, possibly influencing the variability measures.

\begin{tabular}{|c|c|c|}
\hline & Random series & Ordered series \\
\hline 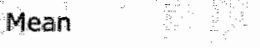 & 245 & 245 \\
\hline Standard deviation & 31 & 31 \\
\hline QTV & -1.8 & $-1,8$ \\
\hline Instabillity & 51.5 & 51.5 \\
\hline STV & 25.4 & 2.3 \\
\hline
\end{tabular}

QTV: $\log \left(\mathrm{QT}_{\text {wrsianced }} / \mathrm{QT}_{\text {rretan }}{ }^{2}\right)$. The linear regression used for instability analysis had an $\mathrm{R}$-squared valutie of 0.95 .

The formula for short-term variability does not include a normalisation for heart rate, which could be an influencing factor. Figure 3 summarises experiments at fixed heart rates in non-remodelled and remodelled anaesthetised dogs with atrioventricular block. The experiments confirm that the left ventricular monophasic action potential duration is rate dependent in both control dogs and in dogs with electrical remodelling. Due to the remodelling processes, the heart-rate dependence of the action potential duration is steeper at chronic atrioventricular block. In the dogs with acute atrioventricular block, short-term variability seems to be independent of heart rate. This reflects the non-remodelled state of the heart, although cardiac stretch and neurohumoral factors may be altered compared to the sinus-rhythm situation, possibly influencing short-term variability. In the remodelled situation at chronic atrioventricular block, the short-term variability is increased at 

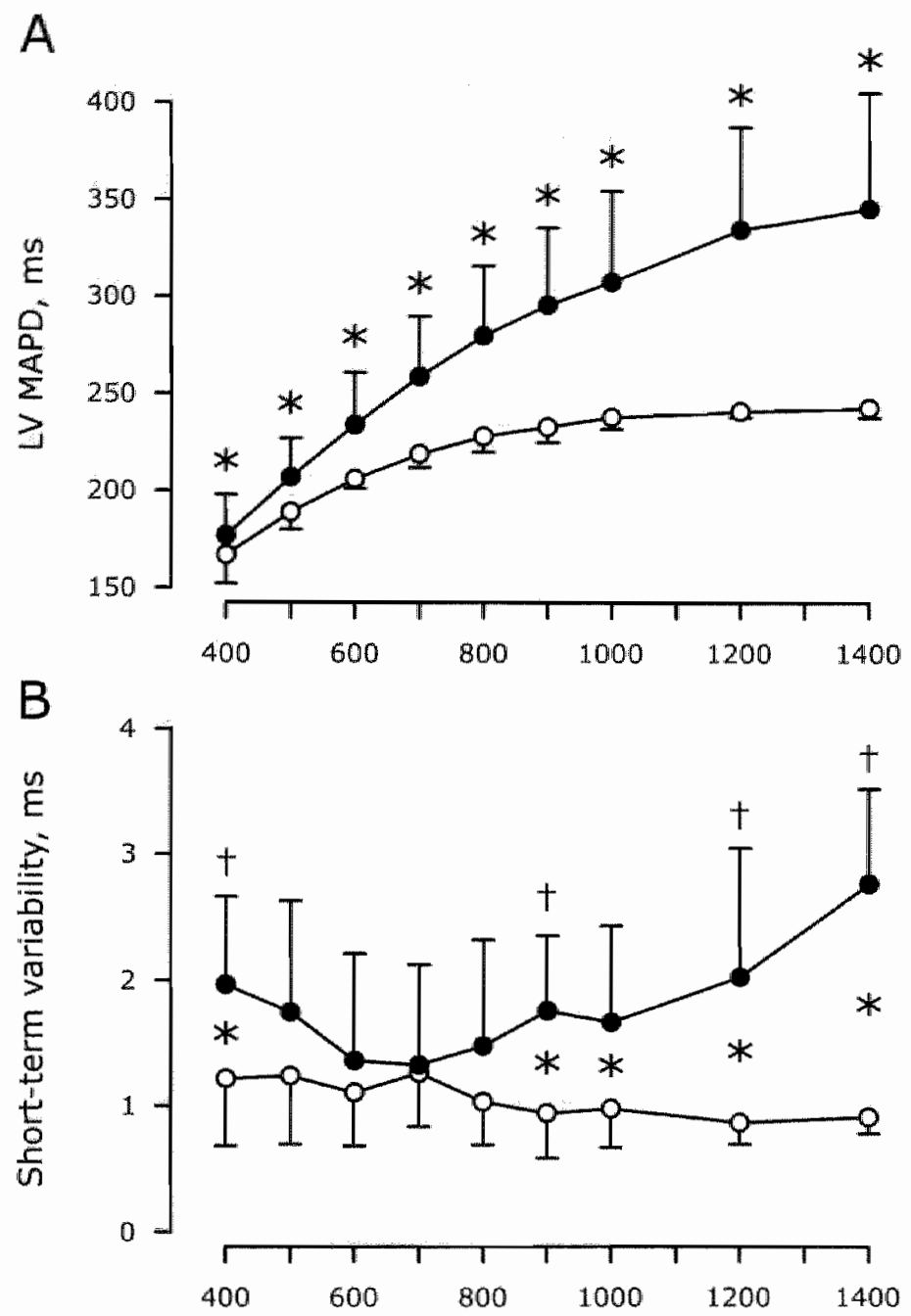

\section{Figure 3}

A: Left ventricular monophasic action potential duration as a function of paced cycle length at acute (open symbals) and chronic (closed symbols) atrioventricular block. Eight dogs under anaesthesia were paced ( $>2$ minutes) from the right ventricle at acute and chronic atrioventricullar block in a serial design.

B: Short-term variability of the same action potentials as in $A . *, P<0.05$ acute versus chronic atrioventricular block; $\uparrow, P<0.05$ versus $700 \mathrm{~ms}$ paced cycle length in chronic AV block dogs. 
short and long cycle lengths producing a "U" shaped curve. Interestingly, minimal short-term variability short and long cyele is present at paced cycle lengths representative of sinus rate (500 to $800 \mathrm{~ms})$. The increase in short-term variability at 400-ms cycle length suggests a transition towards altemans. At slow cycle lengths, representative of the idioventricular rhythm of the chronic atrioventriculat block dogs, there is an increased short-term variability due to remodelling. Thus, within a range of specific heart rates, short-term variability is dependent on ventricular frequency in the remodelled heart. This was used in chapter 6 to intervene with the proarrhythmic outcome of drug-induced torsades de pointes. Finally, the two graphs in Figure 3 propose that short-term variability is independent of the duration of the left ventricular monophasic action potential.

\section{Possible mechanisms of beat-to-beat variability of repolarisation duration}

While it is reasonably well documented that repolarisation altemans is closely coupled to inefficient calcium cycling, the mechanism underlying beat-to-beat variability of repolarisation is far less investigated. ${ }^{37,38,48}$ We know that beat-to-beat variability of repolarisation is inherent to both the single cardiomyocyte and in the intact heart (chapter 3). Short-term variability generally reaches larger values in the isolated myocytes compared to measures from the whole heart, compatible with a reduction in variability upon intercellular coupling. ${ }^{49}$

Variability of the action potential is likely to derive from an intrinsic stochastic behaviour of one or more ion conductances. Both in in-vivo and in-vitro experiments, beat-to-beat variability is available from the action potential already from $50 \%$ repolarisation (chapter 4 ) indicating that the determinant for the variability should be sought early in the action potential before the onset of fast repolarisation. This would be compatible with the theory that an early ionic current during the plateau (e.g. $I_{N,}, I_{b}, I_{0}$ or $I_{C a L}$ ) is mechanistically important. The variability induced by this early current would under normal circumstances be counteracted by currents aiding repolarisation reserve later in the action potential (e.g. $I_{\mathrm{K},}, I_{\mathrm{Ks}}$ or $I_{\mathrm{K}}$ ). Hence, by blocking repolarising potassium channels, the observed increase in beat-to-beat variability would be unmasked (chapter 3 and references $\left.{ }^{13,49}\right)$. On the other hand, $I_{\mathrm{Kr}}$ or $I_{\mathrm{ks}}$ block itself could also be the primary cause of beat-to-beat variability of repolarisation.

Using action-potential clamp techniques, we have suggested that variability in calcium-induced calcium release is not the primary cause of action potential variability. ${ }^{56}$ However, chelating intracellular calcium reduce repolarisation variability, ${ }^{49}$ suggesting that variability in calcium concentrations can induce action- 
potential variability possibly through calcium-dependent currents.

Beat-to-beat variability is also decreased by blocking sodium channels. ${ }^{53}$ Intracellular sodium and calcium are tightly regulated by the sodium-calcium exchanger and the sodium-potassium pump, among others. The increased subsarcolemmal sodium concentrations observed in dogs with chronic atrioventricular block ${ }^{23}$ along with an increased sodium-calcium exchange current $t^{20}$ could then possibly explain the larger variability of repolarisation in these dogs (chapter 5 ).

Thus, it is conceivable that the source of beat-to-beat variability of repolarisation duration lies already in the beginning of the action potential. Additional research is essential before mechanisms can be advocated.

\section{Challenges ahead}

Action potential prolongation is probably a prerequisite, but not a sufficient change of cardiac electrophysiology to render the heart susceptible to lethal arrhythmias. Conceivably, prolongation of the action potential is an adaptive safety factor that may even be antiarrhythmic. The levels of accompanying lability and possibly (micro-)spatial dispersion are vital in assessing the vulnerability of the heart. A central question in this thesis has been the evaluation of individual drugs. To which extent is the action potential prolonged, repolarisation reserve decreased and lability enhanced? The underlying basis for action potential prolongation has been elucidlated to some extent, however large areas are still unknown. The fundamental in situ, ionic, molecular and genetic source of beat-to-beat variability of repolarisation is even more unexplored. Exciting challenges lie ahead for basic research.

Given the increased beat-to-beat variability of repolarisation in sudden-death prone dogs (chapter 5) together with the possibility to prevent approaching arrhythmia by limiting short-term variability of repolarisation (chapter 6) may create clinical beneficial options. For example, if beat-to-beat variability is detectable in the ventricles of proarthythmic patients with pacemakers and if pacemakers could detect this variability, the pacemaker could engage antiarrhythmic modes (e.g. by increasing heart rate) once a certain variability threshold is reached. Another likely application is the monitoring of patients receiving infusions of a class-III antiarrhythmic drug to convert atrial fibrillation. Online beat-to-beat variability can be monitored (chapter 3 ) and precautions against developing torsades de pointes could be taken or assessment of interventional strategies could be performed (chapter 6). Although these examples approach clinical applicability, several 
steps are still to be taken. For broad-based clinical utilitization, the method would preferably employ a non-invasive signal, like the ECG. Thus, exciting chailenges lie ahead for the clinical approach.

The present draft of the regulatory guideline on the safety assessment of new potential drugs encourages interested parties to develop and test proarrhythmic models and novel indices associated with torsades de pointes. ${ }^{52}$ Certainly, there already exist well-described animal models with decreased repolarisation reserve that have an increased susceptibility to torsades de pointes. The pharmaceutical industry could benefit importantly from adopting these models and the proarrhythmic predictors that are available. The challenge for doctors, scientists, regulatory experts and industry is to revise current concepts and to surpass guidelines. 


\section{References}

1. Dessertenne F. La tachycardie ventriculaire a deux foyers opposés variables. Arch des Mal du Cour. 1966;59:263-272.

2. Roden DM. Taking the "idio" out of "idiosyncratic": predicting torsades de pointes. Pacing Clin Electrophysiol. 1998;21:1029-1034.

3. Lande G, Kyndt F, Baro I, Chabannes D, Boisseau P, Pony JC, Escande D, Le Marec H. Dynamic analysis of the QT interval in long QT1 syndrome patients with a normal phenotype. Eur Hear J. 2001;22:410-422.

4. Kaufman ES, Priori SG, Napolitano C, Schwartz PJ, Jyengar S, Elston RC, Schnell AH, Gorodeski EZ, Rammohan G, Bahhur NO, Connuck D, Verrilli L, Rosenbaum DS, Brown AM. Electrocardiographic prediction of abnormal genotype in congenital long QT syndrome: experience in 101 related family members. $J$ Cardiovasc Electrophysiol. $2001 ; 12: 455-61$.

5. Priori SG, Barhanin J, Hauer RN, Haverkamp W, Jongsma HJ, Kleber AG, McKenna WJ, Roden DM, Rudy Y, Schwartz K, Schwartz PJ, Towbin JA, Wilde AM. Genetic and molecular basis of cardiac arrhythmias: impact on clinical management parts I and II. Circularion. 1999;99:518-28.

6. Schwartz PJ, Priori SG, Spazzolini C, Moss AJ, Vincent GM, Napolitano C, Denjoy I, Guicheney P, Breithardt G, Keating MT, Towbin JA, Beggs AH, Brink P, Wilde A.A, Toivonen L, Zareba W, Robinson JL, Timothy KW, Corfield V, Wattanasirichaigoon D, Corbett C, Haverkamp W, Schulze-Bahr E, Lehmann MH, Schwartz K, Coumel P, Bloise R. Genotype-phenotype correlation in the long-QT syndrome: gene-specific triggers for life-threatening arrhythmias. Circulation 2001;103:89-95.

7. Roden DM. Drug-induced prolongation of the QT interval. $N$ Engl J Med. 2004;350:1013-22.

8. Tomaselli GF, Zipes DP. What causes sudden death in heart failure? Circ Res. 2004;95:754-63.

9. Burashnikow A, Antzelevitch C. Prominent $I\left(K_{s}\right)$ in epicardium and endocardium contributes to development of transmural dispersion of repolarization but protects against development of early afterdepolarizations. J Cardiovasc Electrophysiol. 2002;13:172-7.

10. Varro A, Balati B, lost N, Takacs J, virag L, Lathrop DA, Csaba L, Talosi L, Papp JG. The role of the delayed rectifier component IKs in dog ventricular muscle and Purkinje fibre repolarization. J Physiol. 2000;523:67-81.

11. Biliczki P, Virag L, Jost N, Papp JG, Varro A. Interaction of different potassium channels in cardiac repolarization in dog ventinicular preparations: role of repolarization reserve. Br.J Pharmacol. 2002;137;36I-8.

12. Lengyell $C$, Dezsi $\mathbb{L}$, Biliczki P, Horvath C, Virag L, lost $\mathbb{N}$, Nemeth M, Talosi L, Papp JG, Varro A. Effect of a neuroprotective drug, eliprodil on cardiac repolarisation: importance of the decreased repolarisation reserve in the development of proarthythmic risk. Br.J Pharmacol. 2004.

13. Volders PG, Stengl M, van Opstal JM, Gerlach U, Spatjens RL, Beekman JD, Sipido KR, Vos MA. Probing the contribution of IKs to canine ventricular repolarization: key role for beta-adrenergic receptor stimulation. Circulation. 2003; 107:2753-60.

14. Vos MA, Verduyn SC, Gorgels AP, Lipcsei GC, Wellens HJ. Reproducible induction of early afterdepolarizations and torsade de pointes arrhythmias by $d$-sotalol and pacing in dogs with chronic atrioventricular block. Circulation. 1995;91:864-72.

15. Verduyn SC, Vos MA, van der Zande J, Kulcsar A, Wellens HJ. Further observations to elucidate the role of interventricular dispersion of repolarization and early afterdepolarizations in the genesis of acquired torsade de pointes arrhythmias: a comparison between almokalant and d-sotalol using the dog as its own control. $J \mathrm{Am}$ 
Coll Cardiol. 1997;30:1575-84

16. Volders PG, Sipido KR, Vos MA, Kulcsar A, Verduyn SC, Wellens HJ. Cellular basis of biventricular hypertrophy and arrbythmogenesis in dogs with chronic complete atriowentricular block and acquired torsade de pointes. Cirowlation, $1998 ; 98: 1136-47$.

17. Vos MA, de Groot SH, Verduyn SC, van der Zande J, Leunissen HD, Cleutjens IP, wan Bilsen M, Daemen MJ, Schreuder JJ, Allessie MA, Wellens HJ. Enhanced susceptibility for acquired torsade de pointes arthythmias in the dog with chronic, complete AV block is related to cardiac hypertrophy and electrical remodeling. Circulation. 1998,98:112535.

18. Volders PG, Sipido KR, Vos MA, Spatiens RL, Leunissen ID, Carmeliet E, Wellens HJ. Downregulation of delayed rectifier $\mathrm{K}(+)$ currents in dogs with chronic complete atrioventricular block and acquired torsades de pointes. Circtlation. 1999;100:2455-61.

19. Vos MA, Gorenek B, Verduyn SC, van der Hulst FF, Leunissen JD, Dohmen L, Wellens HJ. Observations on the onset of torsade de pointes arrhythmias in the acquired long QT syndrome. Cardiovasc Res. 2000;48:421-9.

20. Sipido KR, Volders $\mathrm{PG}$, de Groot $\mathrm{SH}$, Verdonck $\mathrm{E}$, Van de Werf $\mathrm{F}$, Wellens HJ, Vos MA. Enhanced $\mathrm{Ca}(2+)$ release and $\mathrm{Na} / \mathrm{Ca}$ exchange activity in hypertrophied canine ventricular myocytes: potential link between oontractile adaptation and arrhythmogenesis. Circulation. 2000;102:2137-44.

21. de Groot SH, Schoenmakers M, Molenschot MM, Leunissen JD, Wellens HJ, Vos MA. Contractile adaptations preserving cardiac output predispose the hypertrophied canine heart to delayed afterdepolarization-dependent ventricular arrhythmias. Circulation. 2000;102:2145-2151.

22. Ramakers C, Vos MA, Doevendans PA, Schoenmakers M, Wu YS, Scicchitano S, Iodice A. Thomas GP, Antzelevitch C, Dumaine R. Coordinated down-regulation of KCNQI and KCNE1 expression contributes to reduction of $1(\mathrm{Ks})$ in canine hypertrophied hearts. Cardiovasc Res.. 2003;57:486-496.

23. Verdonck $F$, Volders $P G$, Vos MA, Sipido KR. Increased $\mathrm{Na}(+)$ concentration and altered $\mathrm{Na} / \mathrm{K}$ pump activity in hypertrophied canine ventricular cells. Cardiovasc Res. $2003 ; 57: 1035-43$

24. Schoenmakers M, Ramakers C, van Opstal JM, Leunissen JD, Londono C, Vos MA Asymchronous development of electrical remodeling and cardiac hypertrophy in the complete AV block dog. Cardiowasc Res; 2003;59:351-9.

25. Martin RL, McDermott JS, Salmen HJ, Palmatier J, Cox BF, Gintant GA. The Utility of hERG and Repolarization Assays in Evaluating Delayed Cardiac Repolarization: Infuence of Multi-Channel Block. J Cardiovase Pharnacol. 2004;43:369-379.

26. Di Diego JM, Belardinelli L, Antzelevitch C. Cisapride-induced transmural dispersion of repolarization and torsade de pointes in the canine left ventricular wedge preparation during epicardial stimulation. Circulation. 2003; 108:1027-33.

27. Gintant GA, Limberis JT, McDermott JS, Wegner CD, Cox BF. The canine Purkinje fiber: an in vitro model system for acquired long QT syndrome and drug-induced arrhythmogenesis. J Cardiovasc Pharmocol. 2001;37:607-18.

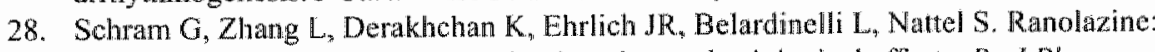
lon-channel-blocking actions and in vivo eleetrophysiological effects. Br.J Phamacol. 2004.

29. Antzelevitch C, Belardinelli L, Zygmuni AC, Burashnikov A, Di Diego JM, Fish JM, Cordeiro JM, Thomas $G$. Electrophysiological effects of tanolazine, a novel antianginal agent with antiarthythmic properties. Circulation. 2004;110:904-10.

30. Davie C, Pierre-Valentin J, Pollard C, Standen N, Mitcheson J, Alexander P, Thong B. Comparative pharmacology of Guinea pig cardiac myocyte and cloned HERG (0) channel. I Cardiovasc Electrophysiol. 2004;15:1302-9.

31. Wyse KR, Ye V, Campbell TI. Action potential prolongation exhibits simple dose- 
dependence for sotalol, but reverse dosemdependence for quinidine and disopyramide: implications for proanhythmia due to triggered activity. $J$ Cardiovasc Pharmacol. $1993 ; 21: 31.622$.

32. Volders $\mathrm{PG}$, Vos MA, Szabo B, Sipido KR, de Groot SH, Gorgels AP, Wellens HJ, Lazzara R. Progress in the understanding of cardiac early afterdepolarizations and torsades de pointes: time to revise current concepts. Cardrovasc Res. 2000;46:376-92.

33. Volders $P G$, Kulcsar A, Vos MA, Sipido KR, Wellens $H J$, Lazzara R, Szabo B. Similarities between early and delayed afterdepolarizations induced by isoproterenol in canine ventricular myocytes. Cardiovasc Res. 1997;34:348-59.

34. Berger RD, Kasper EK, Batighman KL, Marban E, Calkins H, Tomaselli GF. Beatto-beat QT interval variability: novel evidence for repolarization lability in ischemic and nonischemic dilated cardiomyopathy. Crrculation. 1997;96:1557-1565.

35. Hondeghem LM, Carlsson L, Duker G. Instability and triangulation of the action potential predict serious proarrhythmia, but action potential duration prolongation is antiarrhythmic. Circulation. 2001;103:2004-13.

36. Chudin E, Goldhaber J, Garfinkel A, Weiss J, Kogan B. Intracellular Ca(2 2 ) dynamics and the stability of ventricular tachycardia. Biophys $J$. 1999;77:2930-41.

37. Rosenbraum DS, Jackson LE, Smith JM, Garan H, Ruskin JN, Cohen RJ, Electrical alternaris and vulnerabillity to ventricular arrhythmias. $N$ Engl I Med. 1994;330:235-41.

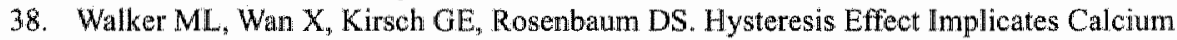
Cycling as a Mechanism of Repolarization Altemans. Circulation. 2003.

39. Walker ML, Rosenbaum DS. Repolarization alternans: implications for the mechanism and prevention of sudden cardiac death. Cardiovasc Res. 2003;57:599-614.

40. Atiga WL, Fananapazir L, McAreavey D, Calkins H, Berger RD. Temporal repolarization lability in hypertrophic cardiomyopathy caused by beta-myosin heavychain gene mutations. Circulation. 2000;101:1237-1242.

41. Atiga WL, Calkins H, Lawrence JH, Tomaselli GF, Smith JM, Berger RD. Beat-tobeat repolarization lability identifies patients at risk for sudden cardiac death. $J$ Cardiovasc Electrophysiol. 1998;9;899-908.

42. Murabayashi T, Fetics B, Kass D, Nevo E, Gramatikov B, Berger RD. Beat-to-beat QT interval variability associated with acute myocardial ischemia. J Electrocardiol. $2002 ; 35: 19-25$.

43. Hondeghem LM, Dujardin K, De Clerck F. Phase 2 prolongation, in the absence

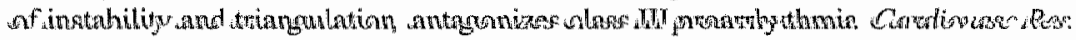
2001;50:345-353.

44. Hondeghem LM, Hoffmann P. Blinded test in isolated female rabbit heart reliably identifies action potential duration prolongation and proarrhythmic drugs: importance of triangulation, reverse use dependence, and instability. J Cardiovasc Pharmacol. $2003 ; 41: 14-24$.

45. Hondeghem LM, Lu HR, van Rossem K, De Clerck F. Detection of proarrhythmia in the female rabbit heart: blinded validation. I Cardiovasc Electrophysiol, 2003;14:287-94.

46. Valentin IP, Hoffmann P, De Clerck F, Hammond TG, Hondeghem L. Review of the predictive value of the Langendorff heart model (Screenit system) in assessing the proarthythmic potential of drugs. J Pharmacol Toxicol Methods. 2004;49:171-81.

47. Brennan M, Palaniswami M, Kamen P. Do existing measures of Poincare plot geometry reflect nonlinear features of heart rate variability? IEEE Trans Biomed Eng. $2001 ; 48: 1342-1347$

48. Pruvot EJ, Katra RP, Rosenbaum DS, Laurita KR. Role of Calcium Cycling Versus Restitution in the Mechanism of Repolarization Alternans. Circ Res. 2004.

49. Zaniboni M, Pollard AE, Yang L, Spitzer KW. Beat-to-beat repolarization variability in ventricular myocytes and its suppression by electrical coupling. Am J Physiol Heart Cine Physiol. 2000;278:H677-H687. 
50. Antoons G, StengI M, Thonsen MB, Beekman JD, Vos MA, Sipido KR. Sarcoplinsmic reticulum $\mathrm{Ca} 2$ + release and repolarization lability in myocytes from the dog with cthronic atrioventricular block (c.AVB). Biophys J. 2005.

51. Undrowinas Al, Maltsev VA, Sabbah HN. Repolarization abnormalities in cardionyocytes of dogs with chronic heart failure: role of sustamed inward current. $\mathrm{Cel}$ Mol Life Sci. $1999 ; 55 ; 494-505$.

52. International conference on hamonisation of technical requirements for registration of pharmaceuticals for human use: The nonclinical ewaluation of the potential for delayed ventricular repolarization (QT interval prolongation) by human pharmacenticals. S7B. http:/wwwich.org. 2004 . 
English Summary 
The function of the ventricles of the heart is to mechanically drive blood through the vessels. The ventricles consist mainly of muscular tissue that contracts when activated. For contraction to act synchronised, electrical impulses control the rate and the sequential order of regional activation.

The muscle fibres of the ventricles consist primarily of cardiomyocytes, which are the heart-specific muscle cells. In every single myocyte electrical stimulation initiates an action potential. Charged ions flow through channels in the outer membrane of the cell, causing changes in the voltage difference over the membrane. Upon electrical stimulation of the cardiomyocyte, depolarisation followed by repolarisation shapes the action potential. The combination of all action potentials instigated throughout the heart is the basis of the electrocardiogram.

Changes in the force of depolarisation and/or repolarisation will change the shape of the action potential and when this occurs in a significant fraction of cardiac myocytes, the morphology of the electrocardiogram will change. The present thesis addresses changes in repolarisation, i.e. the electrical "relaxation" of the heart, as a cause of ventricular arrhythmia. If the ionic currents responsible for the repolarisation decrease, repolarisation is delayed, the action potential prolongs and so does the QT interval on the electrocardiogram. Repolarisation is an important cardiac event that enables the heart to be ready for the next cycle. Considerable reserve of the repolarising ion currents is normally present to secure that a fast electrical recovery is maintained. Inhibitions of these currents may deplete repolarisation reserve in such a way that the myocyte will be unable to remain electrical active and contribute to ventricular contraction. Furthermore, since the individual myocytes are intricately connected to each other, the failure of repolarisation in at cell will inffluence a neighbouring cell and can lead to the initiation of a premature action potential. The fast and timely generation of abnormal impulses may cause depolarising wave fronts that can initiate ventricular tachyarrhythmia. If the ventricles are susceptible to the initiated arrhythmia, it may be sustained. When the ventricular arrhythmia occurs in a setting of reduced repolarisation reserve it usually has a polymorphic appearance on the electrocardiogram with typical twisting around the baseline. If the preceding repolarisation is overtly prolonged this arrhythmia is called torsades de pointes. This term is pleasant for ear and describes a beautiful electrocardiographic feature. Unfortunately, torsades de pointes can be fatal when it deteriorates into ventricular fibrillation.

Decreases in repolarisation reserve can occur as acquired (heart disease, metabolic or electrolyte disturbances), congenital (inherited) or dnug-induced syndromes. Pharmaceutical companies, regulatory authorities and scientific communities 
are concerned with the latter one, because a number of drags have been directy connected to a decrease in repolarisation reserve and a risk of lethal torsades de pointes to a level where the drugs are withdrawn from the market

Chapter 1 of the present thesis is the general introduction, which describes the current efforts to assess the proarnythmic potential of drugs before they are tested in humans. Different levels of investigation are described, emphasizing the importance of evaluating potential repolarisation-dependent adverse effects on the lavel of individual ion currents, integrated action potentials and electrocardiograms. The deficiency of reliable electrophysiological parameters to predict proarrhythmia is discussed and the aims of the thesis are put forward.

In Chapter 2 the cardiac electrophysiological properties of the antipsychotic agent. sertindole are described. By decreasing the repolarisation reserve, sertindole is able to prolong the action potential and QT interval in normal dogs and in dogs with an acquired reduction in their repolarisation reserve. In the latter dogs, torsades de pointes are induced by high doses of sertindole. Thus, an important finding in this study is that ventricular electrical remodelling of the ventricles is a prerequisite for the induction of torsades de pointes. The dose-dependent difference in the induction of torsades de pointes is not reflected in a dose-dependent prolongation of repolarisation, confirming that QT prolongation per se is a poor predictor of torsades de pointes.

In Chapter 3 a novel electrophysiological measure is proposed that is based on temporal differences rather than averaged values of repolarisation duration. The parameter beat-to-beat variability of repolarisation provides information whether the dose of the proarthythmic agent $d$-sotalol will ultimately induce torsades de pointes in an experiment. Importantly, this information is available early in the experiment, well before the initiation of ventricular extrasystoles, thus enabling the prediction of torsades de pointes with stronger confidence.

In addition to investigating the dose of a proarrhythmic drug, we have also examined the rate of intravenous administration in the studies for Chapter 4 . Decreasing the rate of infusion of the drug NS-7 creates lower peak blood concentrations of the agent and lesser proarrhythmia. At the same time, the QT interval is equally prolonged while beat-to-beat variability of repolarisation is able to predict differences in the proarrhythmic outcome.

Our historical registry of sudden cardiac death in dogs with ventricular electrical remodelling is analysed in Chapter 5 . Dogs with a severely reduced repollarisation reserve are so vulnerable to proarrhythmic stimuli that they die suddenly in their cage. These dogs have a very high beat-to-beat variability of repolarisation, which corresponds to a higher incidence of torsades de pointes and sudden death. 


\section{English Sumary}

Furthermore, alongside cardiac remodelling after atrioventricular block, the beat-tobeat variability of repolarisation increases.

In Chapter 6 it is described how beat-to-beat variability of repolarisation can be manipulated. When a drug increases beat-to-beat variability, torsades de pointes are expected. Vice versa, when the variability is decreased from an already proarrhythmic level, torsades de pointes can be prevented or stopped.

Finally, in Chapter 7 the results of all previous chapters are discussed in a wider perspective. The concept of repolarisation reserve is described and beat-tobeat variability of repolarisation is compared to traditional electropllysiological parameters and to other measures of repolarisation variability. Hypothetical mechanistic explanations based on the current knowledge are considered, conchuding that additional research is necessary for the full understanding of this phenomenon at the cellular and ionic level. An important conclusion of this thesis is that pathological animal models of proarrhythmia are required for the assessment of proarrhythmict next to existing assays of drug-induced changes in ventricular repolarisation. Furthermore, it is plausible that the magnitude of beat-to-beat variability of repolarisation is closely associated with the amount of remaining repolarisation reserve. 
Nederlandse Samenvatting 
De functie van het hart is ervoor te zorgen dat het bloed door de bloedvaten wordt gepompt. De ventrikels bestaan voomamelijk uit spierweefsel dat samentrekt als het geactiveerd wordt. On de samentrekking georganiseerd te laten gebeuren, bepalen elektrische prikkels het hartritme en de volgorde van activering van bepaalde delen van het hart.

De spierbundels van de ventrikels bestaan voomamelijk uit hartspiercellen. In elke hartspiercel leidt een elektrische prikkel tot een actiepotential. Geladen ionen gaan door kanalen in de buitenste membraan van de cel. Dit leidt tot een voltage verschil over het membraan. Na elektrische stimulatie van de hartspiercel ontstaat depolarisatie gevolgd door repolarisatie, er ontstaat een actiepotentiaal. Alle actiepotentialen van het hart samen vormen de basis voor het elektrocardiogram. Veranderingen in de sterkte van de depolarisatie en/of repolarisatie zullen de actiepotentiaal veranderen. Wanneer dit in een significant deel van de hartspiercellen gebeurt, zal de vorm van het elektrocardiogram veranderen. In dit proefschrift worden veranderingen in de repolarisatie (de elektrische relaxatie van het hart) aangewezen als een oorzaak van ventriculaire ritmestoornissen. Als de ion-stromen die verantwoordelijk zijn woor de repolarisatie afnemen, dan wordt de repolarisatie vertraagd. Hierdoor verlengen zowel de actiepotentiaal als het QT interval op het elektrocardiogram. Repolarisatie zorgt ervoor dat het hart weer tijdig "klaar" is voor de volgende samentrekking. Onder normale omstandigheden is voldoende repolarisatie-reserve stroom aanwezig, wat ervoor zorgt dat een snel elektrisch herstel gehandhaafd blijft. Afname van deze stromen kunnen de repolarisatiereserve zodanig verstoren dat een hartspiercel niet in staat zal zijn elektrisch actief te blijven en bij te dragen aan ventriculaire contractie. Aangezien de hartspiercellen op een complexe manier aan elkaar gekoppeld zijn, zal de repolarisatiestoornis van één cel de onliggende cellen beinnwoeden en kan dit leiden tot het ontstaan van een vroegtijdige actiepotentiaal. Het snelle en vroegtijdige ontstaan van abnormale impulsen kan depolariserende golven veroorzaken die snelle ventriculaire ritmestoornissen tot gevolg kunnen hebben. Als de wentrikels gevoelig zijn voor de beginnende ritmestoornissen, dan zijn deze ritmestoornissen aanhoudend. Als deze ventriculaire ritmestoomis plaats vindt op basis van verminderd repolarisatievermogen, dan uit zich dit in het elektrocardiogram meestal "polymorf", met een kenmerkende draaiing rond de basislijn van het elektrocardiogram.

Als de voorafgaande repolarisatie duidelijk verlengd is, dan noemt tmen deze ritmestoomis torsades de pointes. Deze mooi klinkende naam beschrijft een mooi elektrocardiografisch kenmerk van het hart. Helaas kan torsades de pointes echter dodelijk zijn als het eindigt in kamerfibrilleren.

Verminderde repolarisatie-reserve kan verschillende achtergronden hebben: het kan 
verkregen zijn (hartziekte, metabole of elektrolytische veranderingen), aangeboren zijn (geërfd), of door medicijnen worden geïnduceerd. De genesmiddelenindustrie, de overheid en wetenschappelijke instanties zijn bezorgd on de latstgenoende, aangezien van een aantal geneesmiddelen is aangetoond dat ze rechtstreeks de repolarisatie-reserve verminderen en op die manier het risico op torsades de pointes ritmestoornissen zodanig vergroten dat de geneesmiddelen van de markt moesten worden gehaald.

Hoofdstuk $I$ van dit proefschrift is de algemene introductie. Hierin worden de huidige pogingen beschreven die gedaan worden om het vermogen van medicamenten om ritmestoomissen te veroorzaken in kaart te brengen voordat deze op mensen worden getest. Er zijn al diverse onderzoeken beschreven die de nadruk leggen op het belang van het testen van mogelijke repolarisatie-afhankelijke nadelige effecten op ionkanaal-, actiepotentiaal- en elektrocardiogramniveau. Het ontbreken van betrouwbare elektrofysiologische parameters die gevoeligheid voor ritmestoornissen kumnen voorspellen wordt in dit hoofdstuk bediscussieerd. Tevens wordt hier het doel van dit proefschrift beschreven.

In Hoofdstuk 2 worden de elektrofysiologische eigenschappen van het antipsychotische medicament sertindole beschreven. In zowel normale honden als honden met een verkregen vermindering van de repolarisatie kan sertindole de actiepotentiaalduur en de QT tijd verlengen. In die laatste groep honden kan een hoge dosis sertindole torsades de pointes ritmestoomissen opwekken. Een belangrijke bevinding in deze studie is dan ook dat ventriculaire remodelering van de ventrikels vereist is voor het opwekken van torsades de pointes ritmestoornissen. Het dosis-afhankelijke verschil in het voorkomen van torsades de pointes ritmestoornissen is niet terug te vinden als een dosis-afhankelijke verlenging van de repolarisatie. Dit bevestigt dat QT-tijd verlenging alléén voor torsades de pointes ritmestoornissen een slechte voorspeller is.

In Hoofdstuk 3 wordt een nieuwe elektrofysiologische maat voorgesteld die is gebaseerd op temporele verschillen in plaats van op gemiddelde waarden van repolarisatieduur. De parameter slag-op-slag variabiliteit van repolarisatie (beat-10beat variability of repolarisation) geeft informatie over het feit of een dosis van het pro-aritmogene medicament $d$-sotalol uiteindelijk tot torsades de pointes zal leiden in een experiment. Het is van belang dat deze informatie op een vroeg punt in een experiment beschikbaar is, en wel vók het ontstaan van extra ventriculaire slagen, om op deze manier met grote zekerheid torsades de pointes ritmestoomissen te kunnen voorspellen.

In Hoofdstak 4 wordt vervolgens de snelheid van intravenenze toediening van pro-aritmische medicamenten onderzocht. Tragere infusie van het medicament 
NS-7 levent lagere maximale bloedconcentraties wan dit medicament op en minder ritmestoomissen. De QT tijd is hierbij gelijkmatig verlengd terwijl slag-op-slag variabiliteit wan repolarisatio de verschillen in gevoeligheid voor ritmestoomissen kan voorspellen.

Onze historische registratie van plotse hartdood in honden met ventriculaire elektrische remodelering wordt geanalyseerd in Hoofdstuk 5. Honden met een erristig verminderde repolarisatie-reserve zijn zo vatbaar voor pro-aritmogene stimuli, dat ze plotseling kumnen overlijden in hun hok. Deze honden hebben een zeer hoge slag-op-slag variabiliteit van repolarisatie, wat overeenkomt met een hogere incidentie van torsades de pointes ritmestoornissen en plotse hartdood. Verder groeit de slag-op-slag variabiliteit van repolarisatie naast de remodelering van het hart na compleet hartblok.

In Hoofdstuk 6 wordt beschreven hoe slag-op-slag variabiliteit van repolarisatie kan worden gemanipuleerd. Als een medicament de variabiliteit van repolarisatie verhoogt, kumnen torsades de pointes ritmestoornissen worden verwacht. Door slagop-slag variabiliteit van repolarisatie te verlagen van een pro-aritmogeen niveau tot een non-aritmogeen niveau, kunnen torsades de pointes ritmestoomissen worden voorkomen of gestopt.

Uiteindelijk zullen in Hoofdstuk 7 de resultaten van alle voorafgaande hoofdstukken in een breder perspectief worden neergezet. Het concept van repolarisatie-reserve wordt beschreven en slag-op-slag variabiliteit van repolarisatie wordt vergeleken met traditionele elektrofysiologische parameters en met andere maten voor variabiliteit van de repolarisatie. Hypothetische mechanistische verklaringen, gebaseerd op de huidige kennis, zijn in overweging genomen, watrbij geconcludeerd wordt dat verder onderzoek noodzakelijk is om dit fenomeen volledig op cellulair en jonkanaalniveau te kunnen verklaren. Een belangrijke conclusie in dit proefschrift is dat pathologische pro-aritmogene diermodellen nodig zijn om aanvullende informatie te krijgen over pro-aritmogene eigenschappen van medicamenten, naast de reeds bestaande testen voor medicament-gerelateerde veranderingen in de ventriculaire repolarisatie. Verder is het zeer waarschijnlijk dat de grootte van de stag-op-slag variabiliteit van repolarisatie nauw gerelateerd is aan de aanwezige repolarisatie-reserve. 
Dansk Resumé 
Hjertekamrenes funktion er at pumpe kroppens blod gennem blodarerne ud til kroppen. Hjertekamrene består af muskulatur, der kontraherer năr det aktiveres. For at kontraheringen er synkroniseret, kontrollerer elektriske impulser rytmen og den regionale rakkefolge af aktiveringen.

Muskelfibrene i hjertekamrene bestar af kardiomyocytter, der er specialiserede hjerte-muskelceller. En elektrisk impuls starter et aktionspotentiale i hver kardiomyocyt. Elektrisk Jadede ioner stremmer gennem den ydre cellemembran, hvilket forărsager en zendring af spæendingspotentialet over membranen.

Depolarisering efterfugt af repolarisering former aktionspotentialet efter kardiomyocytten er blevet aktiveret. Alle aktionspotentialer initieret i hjertet er ophav til elektrokardiogrammet.

Endringer i styrken af depolarisering og/eller repolarisering vil æandre formen af aktionspotentialet og năr dette sker i tilstrækkeligt mange kardiomyocytter vil elektrokardiogrammet ogsa andres. Denne afhandling beskæftiger sig med andringer i repolariseringen, med andre ord den elektriske "afslappelse" af hjertet, som baggrund for rytmeforstyrrelser i hijertekamrene. Hvis ion-strømmene, der er ărsag til repolariseringen forringes, forlænges repolariseringen, hvilket bevirker at aktionspotentialet og QT intervallet på elektrokardiogrammet forlænges.

Repolariseringen er en vigtig del af hjertets rytme, fordi det medvirker til], at hjertet er klar til at pumpe den neste portion blod ud i kroppen. Betragtelig reserve af ion-stromme er normalt til stede, hvilket sikrer en hurtig repolarisering. Hvis ionstrømmene er nedsat kan reserven blive opbrugt således at kardiomyocytten bliver elektrisk inaktiv og dermed ikke er i stand til at bidrage til sammentrakningen af hjertemuskulaturen. Da alle kardiomyocytteme er tat koblet til hinanden vil en celle, der ikke formår at repolarisere påvirke nabocellerne, hvilket kan give anledning til et for tidligt og usynkroniseret aktionspotentiale. Tidlige aktionspotentialer, der opstar pî̉ sărbare tidspunkter kan vare ophav til depolariserende bolger, der kan starte en rytmeforstyrrelse. Hvis hjertekamrene er modtagelige for denne rytmeforstyrrelse, kan denne blive opretholdt. Hvis rytmeforstyrrelsen opstår i en situation, hvor repolariseringsreserven er nedsat har den typisk et polymorft udseende pả elektrokardiogrammet med typiske drejninger omkring sin egen akse. Hvis den forudgande repolarisering er åbenlyst forlanget, kalder man rytmeforstyrrelsen torsacles de pointes. Dette navn lyder godt og beskriver et flot elektrokardiografisk fanomen. Desvarre kan torsades de pointes være dedbringende, hvis den forvarres till fibrillering i lyjertekamrene,

Nedsat repolariseringsreserve kan vare erhvervet (hjerte sygdomme, metabolit eller elektrolyt forstyrrelser), medfodt (genetisk disponering) eller medicin-induceret. Medicin industrien, sundhedsstyrelsen og videnskabelige grupper er interesserede 
i de medicin-inducere de tilfalde af nedsat repolariseringsreserve, fordi en rekke produkter er blevet direkte forbundet med nedsat repolariseringsireserve og risiko for dødelig torsades de pointes til en sådan grad, at de er blevet taget af markedet.

Kapitel 1 af denne afhandling er en general introduktion, der beskriver de undersøgelser, der bliver gjort for ny medicin bliver afprevet i mennesker. Forskellige undersøgelser bliver beskrevet med vagt lagt på at evaluere den ny medicins bivirkninger på repolariseringen på ion-strem niveau, pă aktionspotentiale niveau og på elektrokardiogram niveau. Mangelen pă pălidelige elektrofysiologiske parametre, som kan forudsige rytmeforstyrrelser er diskuteret og målsæatningen med denne afhandling er formuleret.

I. Kapitel 2 er de elektrofysiologiske bivirkninger af det antipsykotiske medicin sertindole beskrevet. Ved at nedsætte repolariseringsreserven kan sertindole forlange aktionspotentialet og QT intervallet på elektrokardiogrammet i normale hunde og $\mathrm{i}$ hunde med erhvervet nedsat repolariseringsreserve. I de sidste hunde kan hoje doser af sertindole starte torsades de pointes rytmeforstyrrelser. En vigtig konklusion i denne afhandling er, at et disponeret hjerte med nedsat repolariseringsreserve er nødvendigt for at inducere rytmeforstyrrelsen. Den dosis-afhangige torsades de pointes induktion er ikke reflekteret i den dosis-afhengige forlangelse af repolariseringen, bvilket bekræfter at QT forlængelse på elektrokardiogrammet er en upålicelig parameter når torsades de pointes skal forudsiges.

Kapitel 3 beskriver en ny elektrofysiologisk parameter, som er baseret på tidsafhængige forskelle i stedet for gennemsnitlige værdier for repolarisering. Den nye parameter kaldes slag-til-slag variabilitet af repolarisering (beat-1obeat variability of repolarisation) $\mathrm{og}$ informerer om, hvorvidt en dosis af det rytmeforstyrrende medicin $d$-sotalol giver rytmeforstyrrelser senere i undersøgelsen. Denne information er tilstede tidligt $i$ undersøgelsen, for de tidlige aktionspotentialer opstår, og man er således i stand til at forudsige torsades de pointes med storre sikkerhed.

Foruden at undersøge dosis-afhængigheden af et rytmeforstyrrende medicin, undersøgte vi også effekten af at ændre hastigheden af intravenøs administration i studieme bag Kapitel 4. Ved at nedsætte infusionshastigheden af medicinen NS-7 fik vi lavere blodkoncentrationer af dette stof og farre rytmeforstyrrelser. Samtidigt var forlængelsen af repolarisering ens, mens slag-til-slag variabiliteten af repolariseringen kunne forudsige, hvorvid rytmeforstyrrelser ville blive induceret. Vores historiske arkiv af pludseligt hjertestop hos hunde, der er disponeret for hjerterytmeforstyrrelser, er analyseret i Kapitel 5 . Hunde med stor nedsattelse af repolariseringsreserven er să sårbare overfor rytmeforstyrrende stimuli, at de făr hjertestop i deres bure. Disse hunde har en meget høj slag-til-slag variabilitet 


\section{Dans Resume}

af repolariseringen, hvilket er i overensstemmelse med hojere risiko for torsades de pointes og pludseligt hjertestop. Endvidere ages slag-til-slag variabiliteten af repolarisenngen samtidigt med, at hundene bliver disponeret for rytmeforstyrrelser efter atrio-ventrikular blokade.

I Kapitel 6 beskrives, hvorledes slag-til-slag variabiliteten af repolariseringen kan andres. Torsades de pointes er forventet, hvis en medicin øger slag-til-slag variabiliteten af repolariseringen. $P$ is den anden side, hvis slag-til-slag variabiliteten af repolariseringen bliver nedsat fra et højt rytmeforstyrrende niveau, kan torsades de pointes forebygges eller stoppes.

Til sidst, i Kapitel 7 er resultaterne fra de forgående kapitler diskuteret i et bredere perspektiv. Repolariseringsreserven som koncept er beskrevet og slagtil-slag variabiliteten af repolariseringen er sammenlignet med traditionelle elektrofysiologiske parametre og andre metoder til at måle variabilitet af repolarisering. Hypotetiske mekanistiske forklaringer baseret på den tilstedeværende viden er droftet, konkluderende at yderligere forskning er nødvendig for slag-tilslag variabilitet af repolarisering kan forstås pä cellulæert og ion-strøm niveau. En vigtig konkJusion af denne afhandling er, at patologiske dyremodeller for rytmeforstyrrelser er et nødvendigt supplement til eksisterende undersøgelser af medicin-forarsaget andringer af hjertets repolarisering. Endvidere er det sandsynligt at graden af: slag-til-slag variabilitet af repolarisering er tat forbundet med mangden af tilbagevarende repolariseringsreserve. 
Acknowledgments 
Producing a thesis with all that it takes is not done without the support of others. Numerous interactions witli students, colleagues, senior scientists, top-notch professors, and everybody in between, pave the road and facilitate the process. The people providing the greatest support, help and encouragement eventually become dear friends. This part of the thesis is devoted to some of these people.

Prof. Dr. Vos, dear Marc, from the very start in 2001 in Maastricht you have provided inspiration for the work. You continued to do so when you were appointed professor in Utrecht. Your students and employees know your style of management and many groups throughout the academic society could benefit from this approach. In the research field, you know the important balance between ambitious scientific excellence and realistically attainable goals for the student. I appreciate your support the day l' came into your office and told you about this beat-to-beat thing - soon I felt I had the help of two post docs and three students. We have consumed a few beers the last four years - both in Maastricht, Utrecht and at various meetings all over the world. I hope we will continue to discuss science and drink beers, whenever we meet in the future.

Dr. Volders, dear Paul, I greatly admire your scientific standard. You wrote a very ambitious $\mathrm{PhD}$ proposal for me, and the continuous high level of ambition you had on my behalf has astonished me from time to time. You had always time for a short discussion - which in the end lasted several hours over the phone. I am glad that I am the first PhD you have guided through the process and I wish to thank you for being an active co-promotor. Good luck with building a great group in Maastricht. I hope, I will be able to continue to benefit from your scientific opinions in the future. A word here should also go to Ilja: I am sorry for the evenings where Paul came home late because of me.

Dr. Matz, dear Jørgen, thank you for believing and investing in me. Already in 1999 when we met the first time, you have impressed me with your pace. Decision making newer took more than a few seconds, no matter what I asked for. I appreciate your support when Uncle L. had a stroke. I look back on our many Duvels - we were almost Swedish at some points. I hope you will continue to have a great career, with the appropriate blend of academic teaching and drug development.

My paranim/s, Roel Spãtjens and Christian Ramakers, have been very active in helping me with the organisation of this thesis defence. Roel, no need to say what everybody knows: Your presence in the cell lab makes everything possible. Thank you for all the solutions, the talks, the coffee breaks, the help and the quick phone calls to the bakery, when there was something to celebrate. We had some very nice evenings in Roermond making pasta. I wish all the best for you, Anouk and Fleur. Chris, my mate. I appreciate the long evenings and nights we had in various cities 
throughout the Netherlands. When discussing science four 0 "clock in the morning, we knew all the mechanisms and the perfect protocols. Where did they go? I hope you will have a fruitful time in Rome. When you have located the best espresso, give me a call.

Jet Beekman, my "third co-promotor", you have taught me all my practical skills. The mere fact that you are on all my publications (only matched by Marc) reflects the many hours in the operations room. Thank you for the enthusiasm, friendship and your contaminating good mood.

I am gratefull to the members of the thesis-assessment committee professors Struijker Boudier, Allessie, Crijns, Roden and Torp-Pedersen for critically reading this thesis. Dan and Christian, I appreciate that you took the long trip to Maastricht to attend the defence.

Colleagues from both Maastricht and Utrecht have made imperative contributions to this work - from producing a pleasant working environment to rewarding collaborations in studies. From Maastricht: Marieke, Jurren, Jérồme, Dirk, Milan, Maaike, Chiel, Geert, Elke, Ashish, Cora, Monique and Theo. From Utrecht: Gudrun, Anita, Bart, Bürgit, Avram, Stefan, Mohamed, Teun, Marcus, Mera, Peter, Nico, Marti, Antoinette, Martin, Marcel, Harold, Toon, Karin, Tobias and Jacques. Furthermore, I am indebted to the always-helpful secretaries, especially Vivian, Miriam and Tonny.

Dear Nancy, your support was fantastic. I am grateful for your encouragement, understanding and patience. Sorry for the late evenings and the working weekends. Kære mor, tak for støtten og forstăelsen, da jeg besluttede mig til at rejse fra Aalborg, Jylland og senere Danmark. Måske bliver det også Europa, men jeg rejser aldrig for langt vak. 


\section{Curriculum vitae}

June 25th, 1975

$1994-1997$

$1997-2000$

$2001-2005$

$2003-2005$
Born in Aarhus, Denmark

Bachelor of Science (Biology), University of Aarhus, Denmark

Master of Science (Human Biology), University of Copenhagen, Denmark $\mathrm{PhD}$, Department of Cardiology, Cardiovascular Research Institute Maastricht, Maastricht University, Netherlands PhD, Department of Medical Physiology, Heart Lung Centre Utrecht, Utrecht, Netherlands 


\section{Publications}

\section{Abstracts}

- van Opstal JM, Truin M, Schoenmakers M, Thomsen MB, Leunissen J and Vos MA. Sudden cardiac death and torsade de pointes arthythmias in the chronic AV-block dog are associated with large temporal- and temporospatial repolarization variance. Pacing Clin Elecirophysiol 2002;25:576

- Thomsen MB, Verduyn SC, Stengl M, van Opstal JM, Leunissen J, de Pater G, Volders PGA and Vos MA. Beat-to-beat variability is an independent and early indicator for $d$-sotalol-induced arrhythmias in vivo. $J$ Am Coll Cardiol. 2003;41 (Suppl A):91A

- Thomsen MB, Volders PGA, Spätjens RLHMG, Leunissen JDM, Stengl M, Matz $I$ and Vos MA. Electrophysiological safety of sertindole in dogs with normal and remodeled hearts. Pacing Clin Electrophysiol. 2003;26:1089

- Truin M, Thomsen M., Stengl M, van Opstal J, Beekman JDM and Vos MA. Chronic AV block dogs that die suddenly show increased lability of: repolarization. Neth Heart $J .2003 ; 11: 14$

- Thomsen MB, Verduyn SC, Stengl M, van Opstal JM, Leunissen J, de Pater G, Volders PGA and Vos MA. Beat-to-beat variability is an independent and early indicator for $d$-sotalol-induced arrhythmias in vivo. Molecular Pathology of Cardiac Arrhythmias (Keystone Symposia), 50, 2003

- Stengl M, Volders PGA, Thomsen MB, Spätjens RLHMG, Sipido K and Vos MA. Accumulation of $I_{K S}$ in canine ventricular myocytes assessed by action potential clamp. Biophys J. 2003;84:408A

- Thomsen MB, Truin M, Beekman JDM, Stengl M and Vos MA. Beat-to-beat variability of repolarization is increased before sudden arthythmogenic death in dogs with remodelled hearts. Eur Heart J. 2004;25:29

- Antoons G, Stengl M, Thomsen MB, Beekman JDM, Vos MA and Sipido K. Sarcoplasmic reticulum $\mathrm{Ca}^{2 *}$ release and repolarization lability in myocytes from the dog with chronic atrioventricular block. Biophys 2.2005 ;

- Thomsen MB, Volders PGA, Beekman JDM, Matz J and Vos MA. Beat-tobeat variability of repolarization determines proarrhythmic outcome in dogs susceptible to drug-induced torsades de pointes. Pacing Chin Electrophysiol. 2005 ; 


\section{Journall Articles}

- Thomsen MB, Volders PGA, Stengi M, Spätjens RLHMG, Beekman JDM, Bischoff U, Kall MA, Frederiksen K, Matz I and Vos MA. Electrophysiological safety of sertindole in dogs with normal and remodeled hearts. J Pharmacol Exp Ther: $2003 ; 307: 776-784$

- Stengl M, Volders PGA, Thomsen MB, Spätjens RLHMG, Sipido KR and Vos MA. Accumulation of slowly activating delayed rectifier potassium current (IKs) in canine ventricular myocytes. $J$ Physiol. 2003;551:777-786

- Thomsen MB, Verduyn SC, Stengl M, Beekman JDM, de Pater G, van Opstal I, Volders PGA and Vos MA. Increased short-term variability of repolarization predicts d-sotalol-induced torsades de pointes in dogs. Circulation. $2004 ; 110: 2460-2466$

- Detre E, Thomsen MB, Beekman JD, Petersen KU and Vos MA. Decreasing the infusion rate reduces the proarrhythmic risk of NS-7: Confirming the relevance of short-term variability of repolarisation in predicting drug-induced torsades de pointes. Accepted for publication in Br.l Pharmacol 2005

- Thomsen MB, Truin M, van Opstal JM, Beekman JDM, Volders PGA, Stengl M and Vos MA. Sudden cardiac death in dogs with remodeled hearts is associated with larger beat-to-beat variability of repolarization. Accepted for publication in Basic Res Cardiol, 2005 